\title{
Development of Carbonaceous Chemistry for Computational Modeling (C3M) with Application of Uncertainty Quantification (UQ) Analysis for Coal Gasification Kinetics in Computational Fluid Dynamics (CFD) Modeling
}

Kiran P Chaudhari

West Virginia University

Follow this and additional works at: https://researchrepository.wvu.edu/etd

\footnotetext{
Recommended Citation

Chaudhari, Kiran P, "Development of Carbonaceous Chemistry for Computational Modeling (C3M) with Application of Uncertainty Quantification (UQ) Analysis for Coal Gasification Kinetics in Computational Fluid Dynamics (CFD) Modeling" (2013). Graduate Theses, Dissertations, and Problem Reports. 3650. https://researchrepository.wvu.edu/etd/3650
}

This Dissertation is protected by copyright and/or related rights. It has been brought to you by the The Research Repository @ WVU with permission from the rights-holder(s). You are free to use this Dissertation in any way that is permitted by the copyright and related rights legislation that applies to your use. For other uses you must obtain permission from the rights-holder(s) directly, unless additional rights are indicated by a Creative Commons license in the record and/ or on the work itself. This Dissertation has been accepted for inclusion in WVU Graduate Theses, Dissertations, and Problem Reports collection by an authorized administrator of The Research Repository @ WVU. For more information, please contact researchrepository@mail.wvu.edu. 


\title{
Development of Carbonaceous Chemistry for Computational Modeling (C3M) with Application of Uncertainty Quantification (UQ) Analysis for Coal Gasification Kinetics in Computational Fluid Dynamics (CFD) Modeling
}

\author{
By \\ Kiran P Chaudhari \\ Dissertation submitted to the \\ Benjamin M. Statler College of Engineering and Mineral Resources \\ at West Virginia University \\ in partial fulfillment of the requirements for the degree of \\ Doctor of philosophy \\ Chemical Engineering
}

\author{
Approved by \\ Dr. Richard Turton \\ Dr. John Zondlo \\ Dr. Charter Stinespring \\ Dr. Chris Guenther \\ Dr. Mehrdad Shahnam \\ Dr. Richard Bajura \\ Chemical Engineering \\ Morgantown, West Virginia \\ 2013
}

Keywords: Coal gasification, Uncertainty Quantification, C3M, CFD, Sensitivity Analysis Copyright (2013) Kiran Chaudhari 


\begin{abstract}
Development of Carbonaceous Chemistry for Computational Modeling (C3M) with Application of Uncertainty Quantification (UQ) Analysis for Coal Gasification Kinetics in Computational Fluid Dynamics (CFD) Modeling
\end{abstract}

\title{
Kiran P Chaudhari
}

In association with Department of Energy's National Energy Technology Laboratory (NETL), a software platform entitled Carbonaceous Chemistry for Computational Modeling (C3M) that can access a variety of kinetic processes and reaction mechanisms typically found in coal gasification, gas clean-up, and carbon capture processes, has been developed to overcome the limitations in terms of applicable operating conditions and fuel types. It interfaces with CFD software such as Multiphase Flow with Interphase Exchanges (MFIX) developed at NETL, ANSYS-FLUENT by ANSYS Inc., and BARRACUDA by CPFD Software and provides relevant parameters to simulate chemical kinetics and/or to replicate laboratory data. The reaction kinetics data in $\mathrm{C} 3 \mathrm{M}$ are provided by one or more detailed reaction models such as PC Coal Lab (PCCL), Chemical Percolation Model for Coal Devolatilization (CPD), Solomon's Functional-Group, Depolymerization, Vaporization, Cross-linking (FGDVC) model, or through experimental data generated at NETL.

Algorithms were written to create this interface and to extract the kinetic information from all models. This functionality provides the CFD user with a framework to conduct virtual kinetic experiments to evaluate kinetic predictions as a function of fuel and sorbent type and/or operating conditions. The effort on the user's part to search, analyze and to check the accuracy of the kinetics of interest is drastically reduced. Validity and compatibility of C3M kinetics were tested by implementing them in a (2-D) transport gasifier and in an industrial GE Texaco gasifier model (1-D). The predicted exit gas composition and trends of gas species matched very closely with the experimental and industrial data. To improve the kinetic database, a detailed coal/biomass derived soot literature review was completed. It was found that there is a gap in coal derived soot formation and gasification kinetics for high temperature and pressure operating conditions.

In addition to the kinetic studies, uncertainty quantification (UQ) techniques were employed in the CFD models to study the variations of chemical reaction kinetics in a coal gasifier. The uncertainty in exit gas composition based on the variations in input parameters such as temperature, pressure, heating rate and coal feed composition were implemented. Changes in devolatilization product yields (such as mass fractions of $\mathrm{CO}, \mathrm{CO}_{2}, \mathrm{H}_{2}$, tar, $\mathrm{H}_{2} \mathrm{O}$, and $\mathrm{CH}_{4}$ along with total volatile yield) were used as response variables and were recorded and correlated based on distributions of input parameters such as temperature, pressure and heating rates. The correlations among the response variables and input parameters were investigated by computing a correlation matrix. The uncertainties in output responses were in close agreement with data reported in literature. This study strongly suggested the importance of considering uncertainties in chemical reaction kinetics in CFD modeling. 
For the first time, the response of exit gas composition on coal feed variations were tested in a (2-D) transport and (1-D) entrained flow gasifier model. Various coal samples of Pittsburgh No.8, Illinois No.6, Lignite and Powder River Basin (PRB) were obtained from the open literature. Findings from this UQ study provided a way to predict the bound on exit gas composition of synthesis gas based on variations in coal feed for everyday operation in a coal gasifier plant.

Keywords: Coal Gasification Kinetics, C3M, Uncertainty Quantification, CFD, Sensitivity Analysis 


\section{Acknowledgments}

"Learn from yesterday, live for today, hope for tomorrow. The important thing to do is not to stop questioning"

- Albert Einstein

I dedicate this 'Doctorate degree' to my parents (Aai and Nana) - the real 'Heroes' as I see them, who sacrificed a lot to see me at this position. Their never ending love and affection provide me strength and keep me strong to surpass all the hurdles in my way. I am grateful to my elder sisters (Tai and Didi) and my elder brother (Chetan) for all the flowery moments of childhood we shared and whom I always looked up to throughout my childhood. They are always among the strongest pillars of my support system. I specially want to mention my brother in law Pramod Sonawane, who always backed me throughout my student life.

With all my heart I would like to thank "Dr. T" (Dr. Richard Turton), who guided me with fatherly affection throughout my $\mathrm{PhD}$. With his charm, difficulties and tensions would melt down in minutes before I realize. His kind and encouraging words, always kept my spirits high, no matter if the results were good or bad. Along with technical and mathematical skills, he taught the tricks of life, which made the way easier and helped me to improve my personality. The quality of this work is a reflection of expert advice that has been received from him.

Appreciation is also extended to Dr. Guenther, Dr. Shahnam, Dr. Zondlo, Dr. Stinespring, and Dr. Bajura for their useful comments, advice and direction in this research work. There have been many people whose cooperation and assistance have been vital during this research. I am grateful to our C3M group members Philip Nicoletti, Dr. Li, Dr. VanEssendelft, Dr. Wang who was always there for me and answered all my queries. Special thanks to Greg, for helping me out with cluster and scilan access in my modeling work. 
I wish to express my thanks to my group members Dr. Bhattacharyya, Dr. Kasule, Dr. Modekurti, Dustin, Paul, Pratik and Qiang. The time spent with them while working in the lab, in the conferences, in trips and during lunches was just amazing. I am thankful to them for every small and 'interesting' discussion we had in the lab which has a special place in my memory book.

I would also like to thank my dearest friends Soumya, Kedar, Sonu, Mayuri, Rutooj, Pranit, Alok, and Veeru who always pushed me to strive for success. I would also like to thank Tanya, Somu, Deepa, Meena, Srinath, Ashish, Madhur, Akshaya, Saurabh, Rutika, Sonali, Sanket, Rini, Amruta, and Mayank for making my stay in Morgantown a memorable one. I am never going to forget this amazing journey.

Financial support provided through National Energy Technology Laboratory (NETL), Morgantown is gratefully acknowledged. 


\section{Table of Content}

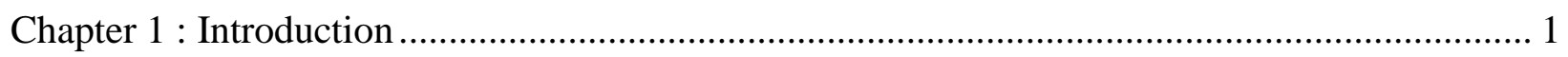

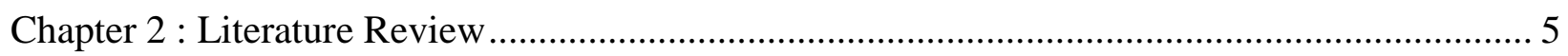

2.1. Carbonaceous Chemistry for Computational Modeling (C3M) ………………........ 5

2.1.1 METC Gasifier Advanced Simulation (MGAS) ................................................ 6

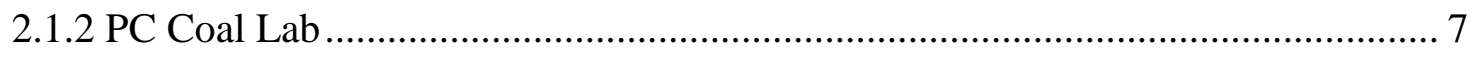

2.1.3 Chemical Percolation Model for Coal Devolatilization (CPD) ........................... 10

2.1.4 Functional-Group, Depolymerization, Vaporization, Cross-linking (FG-DVC). 11

2.1.5 Experimental Data ……………………………...................................... 12

2.1.6 Combustion Kinetics from Literature ............................................................... 13

2.2 Effect of Operating Conditions on Coal Gasification ................................................. 15

2.2.1 Effect of Heating Rate on Coal Devolatilization ............................................... 16

2.2.2 Effect of Temperature on Coal Devolatilization.................................................. 18

2.2.3 Effect of Pressure on Coal Devolatilization........................................................ 20

$2.3 \mathrm{Coal} / \mathrm{biomass}$ Derived Soot Formation ................................................................ 22

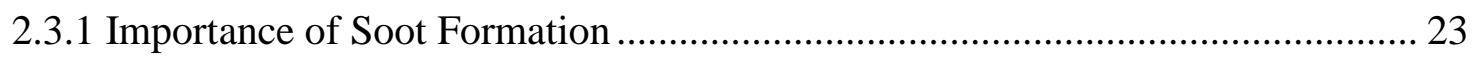

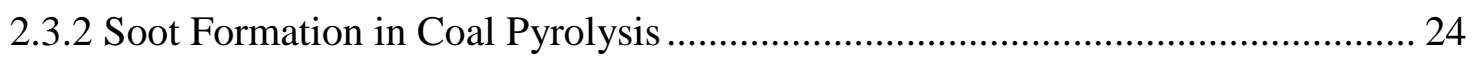

2.3.4 Soot Formation in Biomass Pyrolysis .................................................................. 27

2.3.5 Effect of Temperature on Soot Production .......................................................... 30

2.3.6 Effect of Residence Time on Soot Production..................................................... 31

2.3.7 Effect of Pressure on Soot Production ................................................................. 31

2.3.8 Effect of Coal/Biomass Type on Soot Production .............................................. 32

2.3.9 Effect of O/ C Ratio on Soot Production ............................................................. 33

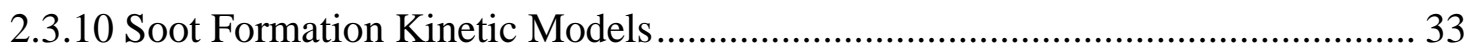




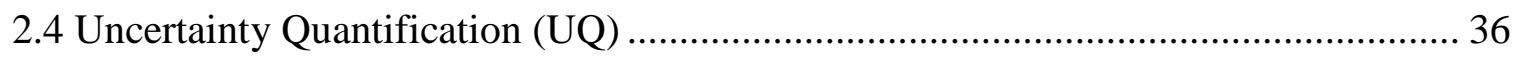

Chapter 3 Reactive Flow Modeling with C3M ........................................................................... 40

3.1 Transport Flow Gasifier........................................................................................ 40

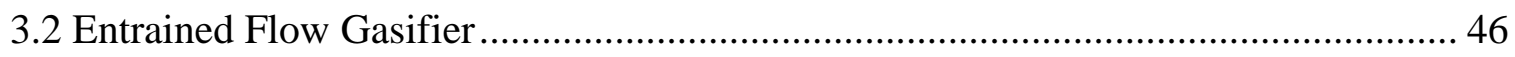

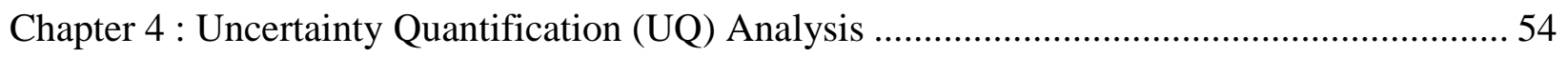

4.1 Effect of Operating Conditions on Devolatilization Kinetics...................................... 56

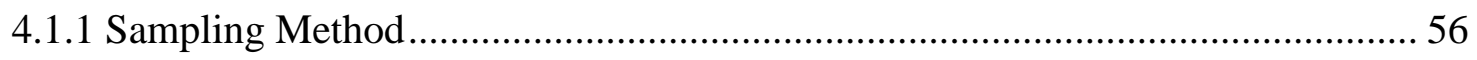

4.1.2 Propagation of Input Uncertainties with Direct Monte Carlo Simulation ............ 60

4.1.3 Correlation Matrix for Response Variables …………………………………... 70

4.2 Implementing a Sub-Model for Coal Devolatilization Kinetics .................................. 75

4.3 Uncertainties Related to Coal Feed Variation ......................................................... 81

4.3.1 Coal Feed Variation in Transport Flow Gasifier ................................................ 84

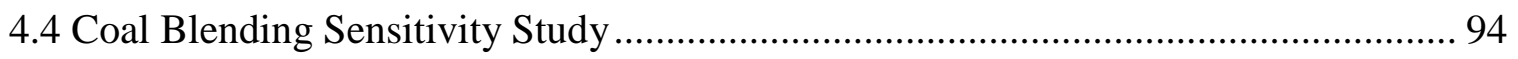

4.4.1 Coal Blending in a Transport Flow Gasifier...................................................... 94

4.4.2 Effect of Coal Blending in Entrained Flow Gasifier ........................................... 99

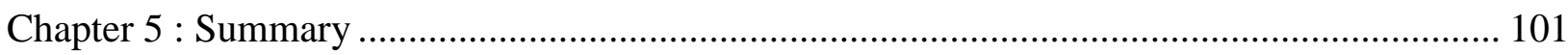

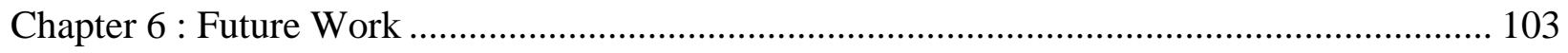

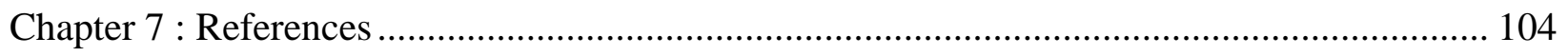

Appendix I: Soot Formation Experimental Matrix …………................................................. 2

Appendix II: Co-pyrolysis kinetics for low heating rates ......................................................... 5 


\section{List of Figures}

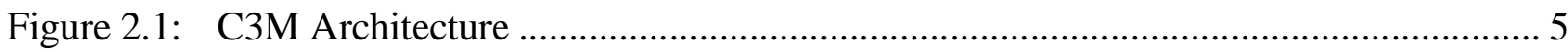

Figure 2.2: Effect of heating rates $(1,10,100$, and $1000 \mathrm{~K} / \mathrm{s})$ on total volatile yield at $700{ }^{\circ} \mathrm{C}$, 1.2 bar pressure for $(\square)$ Wyoming coal, $(\Delta)$ Pocahontas No.3 coal, $(\Theta)$ Illinois No.6 coal

Figure 2.3: Tar and total volatile yield as a function of heating rates at $1073 \mathrm{~K}$ for Pittsburgh No.8 18

Figure 2.4: Effect of temperature on volatile products yield of Taiheiyo coal 19

Figure 2.5: Volatile yield as a function of pressure reported . 21

Figure 2.6: SEM Micrograph showing soot/coal mixture collected in the cyclone at a residence time of $34 \mathrm{~ms}$ and temperature of $1900 \mathrm{~K}$. 22

Figure 2.7: Coal devolatilization and soot formation pathways ............................................ 26

Figure 2.8: Illustration of the development of a soot aggregate structure ................................. 28

Figure 2.9: Schematic Illustration of PAC and soot formation during biomass combustion .... 29

Figure 2.10: Important reaction pathways for soot formation in biomass volatile combustion... 30

Figure 2.11: Rank dependence of primary and secondary tar yields . ........................................ 32

Figure 2.12: The major reactions taking place in soot formation ( $\mathrm{PAH}^{*}$ : PAH radical) ............ 33

Figure 2.13: Recommended designs according to the number of factors and system complexity

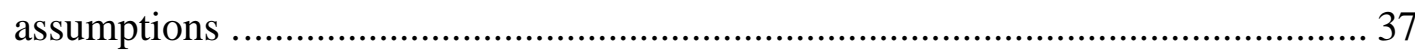

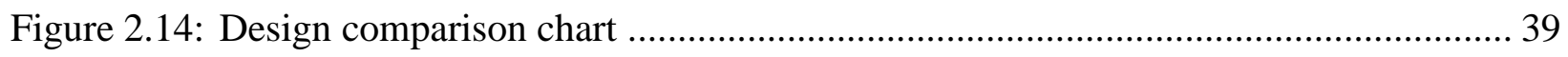

Figure 3.1: 2-D Transport Flow Gasifier.............................................................................. 42

Figure 3.2: Mass fraction of gas species $\left(\mathrm{CO}\right.$, soot, $\mathrm{H}_{2} \mathrm{O}$ and $\left.\mathrm{H}_{2}\right)$ along the reactor length....... 43

Figure 3.3: Mass fraction of soot along the reactor length........................................................ 45

Figure 3.4: Mass fraction of $\mathrm{O}_{2}$ along the reactor length. ..................................................... 45

Figure 3.5: Schematic of the GEE-Texaco gasifier with RSC …………………….................. 46

Figure 3.6: Exit gas composition of TECO gasifier CH4 free and dry basis .............................. 47 
Figure 3.7: Exit gas composition with modified devoltilization, $\mathrm{CH}_{4}$ free, $\mathrm{H}_{2} \mathrm{~S}$ free, and dry basis

Figure 3.8: Exit gas composition with modified devoltilization, $\mathrm{CH}_{4}$ free, and dry basis ........ 50

Figure 3.9: Exit gas composition with modified devoltilization and $\mathrm{CO}_{2} / \mathrm{H}_{2} \mathrm{O}$ char gasification kinetics, $\mathrm{CH}_{4}$ free, $\mathrm{H}_{2} \mathrm{~S}$ free and dry basis

Figure 3.10: Exit gas composition with modified devoltilization and $\mathrm{CO}_{2} / \mathrm{H}_{2} \mathrm{O}$ char gasification kinetics, $\mathrm{CH}_{4}$ free, and dry basis 53

Figure 4.1: $\quad$ Scatter plot matrix using CCD 57

Figure 4.2: $\quad$ Scatter plot matrix using $2 \times 2 \times 2$ Full Factorial Design...................................... 58

Figure 4.3: Scatter plot matrix using Latin Hypercube method for 250 runs........................... 59

Figure 4.4: Scatter plot matrix of Monte Carlo simulation sampling for 10,000 samples ......... 60

Figure 4.5 : Distribution of 10,000 samples of heating rate, temperature and pressure............ 61

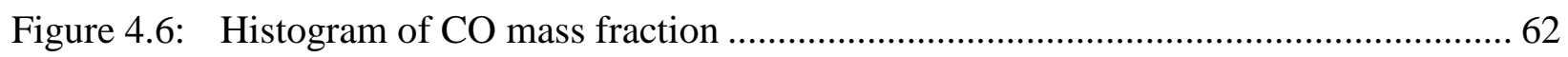

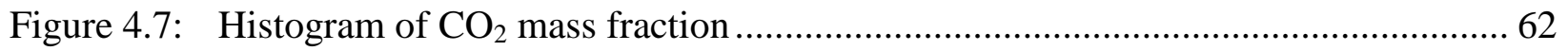

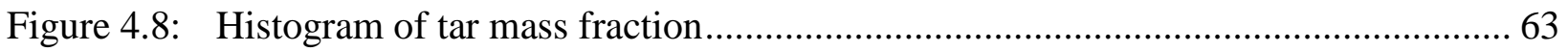

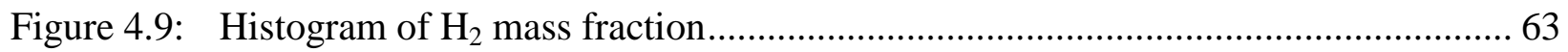

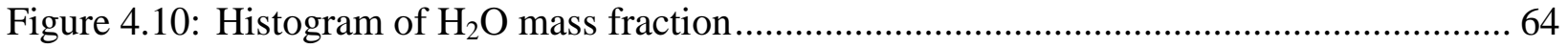

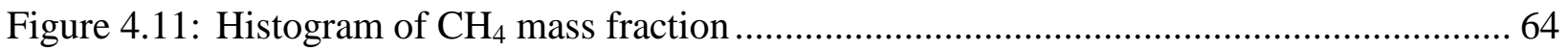

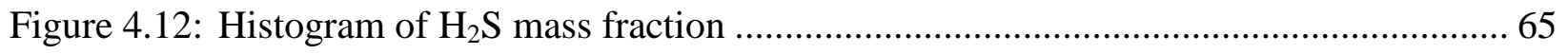

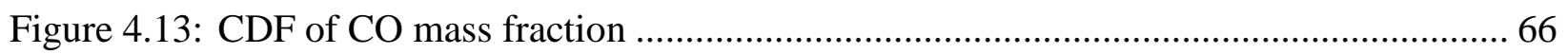

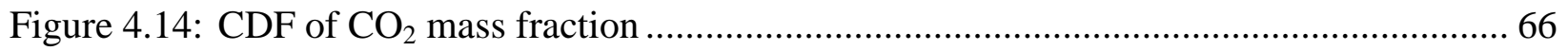

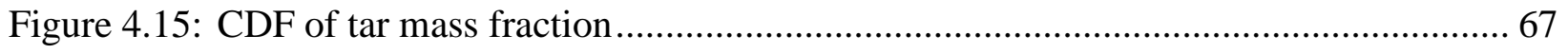

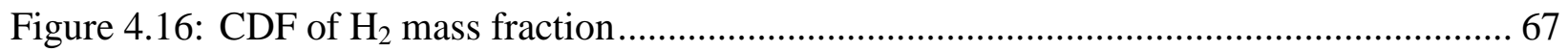

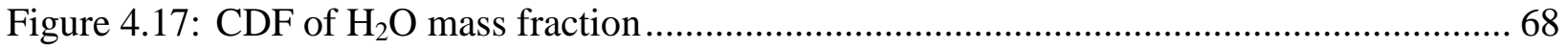

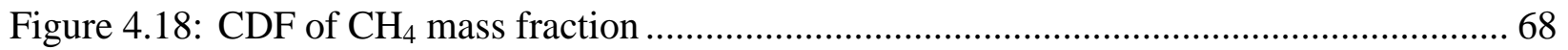

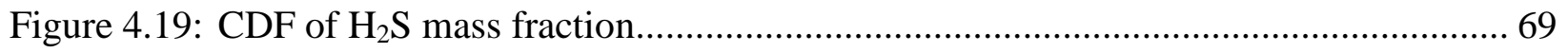


Figure 4.20: Devolatilization gaseous product yield obtained for PRB coal at 600, 800 and $975{ }^{\circ} \mathrm{C}$

Figure 4.21: Devolatilizaiton yield of $\mathrm{CO}_{2}$ and $\mathrm{H}_{2} \mathrm{O}$ for Pittsburgh No.8 .............................. 72

Figure 4.22: Multivariate plot of response variables...................................................... 73

Figure 4.23: Plot showing linear fit predictions for tar yield in given input uncertainties.......... 74

Figure 4.24 : Devolatilization reaction rate response over different temperature ranges ............ 76

Figure 4.25: Effect of temperature on Arrhenius constant ................................................. 78

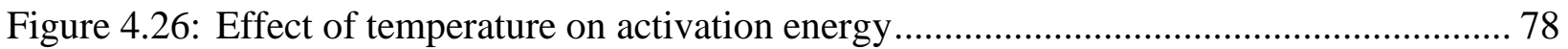

Figure 4.27: Comparison of predicted devolatilization rate with respect to PCCL devolatilization rate 80

Figure 4.28: Exit syngas composition CH4 free and dry basis with modified PCCL devolatilization rate.

Figure 4. 29: Mass fraction of CO along the reactor height for grid resolutions of $10 \times 1200,20$ $\times 2400,40 \times 4800$ and $60 \times 7200$ PRB coal.

Figure 4.30: Mass fraction of $\mathrm{CO}_{2}$ along the reactor height for grid resolutions of $10 \times 1200,20$ $\times 2400,40 \times 4800$ and $60 \times 7200$ PRB coal.

Figure 4.31: Mass fraction of $\mathrm{H}_{2}$ along the reactor height for grid resolutions of $10 \times 1200,20$ $\times 2400,40 \times 4800$ and $60 \times 7200$ PRB coal.

Figure 4.32: Mass fraction of $\mathrm{CO}$ along the reactor height for 10 coal samples of Pittsburgh No.8

Figure 4.33: Mass fraction of $\mathrm{H}_{2}$ along the reactor height for 10 coal samples of Pittsburgh No.8

Figure 4.34: Exit molar gas composition of $\mathrm{CO}, \mathrm{CO}_{2}, \mathrm{H}_{2}, \mathrm{CH}_{4}$ for 10 samples of Pittsburgh No.8

Figure 4.35: Exit molar gas composition of $\mathrm{CO}, \mathrm{CO}_{2}, \mathrm{H}_{2}, \mathrm{CH}_{4}$ for 10 samples of Illinois No.6. 90

Figure 4.36: Exit molar gas composition of $\mathrm{CO}, \mathrm{CO}_{2}, \mathrm{H}_{2}, \mathrm{CH}_{4}$ for 7 samples of PRB Coal ...... 91

Figure 4.37: Exit molar gas composition of $\mathrm{CO}, \mathrm{CO}_{2}, \mathrm{H}_{2}, \mathrm{CH}_{4}$ for 6 samples of Lignite Coal ... 91

Figure 4.38: Graph showing variation in $\mathrm{CO} \mathrm{CO}_{2}, \mathrm{CH}_{4}$ and $\mathrm{H}_{2}$ mol fractions at exit for Illinois No.6 coal in transport flow gasifier.. 
Figure 4.39: Transient exit gas composition of CO for Pittsburgh No.8 coal blending. 95

Figure 4.40: Transient exit gas composition of $\mathrm{CO}_{2}$ for Pittsburgh No.8 coal blending ............ 96

Figure 4.41: Transient exit gas composition of $\mathrm{H}_{2}$ for Pittsburgh No.8 coal blending ............... 96

Figure 4.42: Transient exit gas composition of CO for Illinois No.6 coal blending.................. 97

Figure 4.43: Transient exit gas composition of $\mathrm{CO}_{2}$ for Illinois No.6 coal blending................. 97

Figure 4.44: Transient exit gas composition of $\mathrm{H}_{2}$ for Illinois No.6 coal blending ................... 98

Figure 4.45: Exit syngas composition, $\mathrm{CH} 4$ free and dry basis. ........................................ 100

\section{List of Tables}

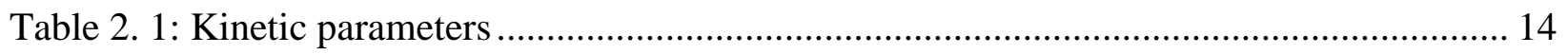

Table 2.2: Kinetic parameters for the twenty one-step PAH/soot reduction formation mechanism

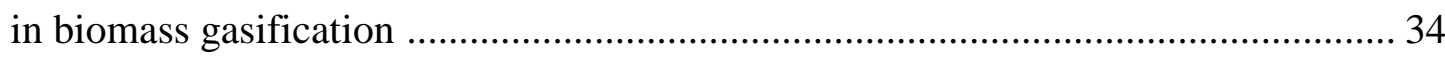

Table 3.1: Details of the 2-D transport flow gasifier simulation ......................................... 41

Table 3.2: Reaction kinetics obtained from C3M. ........................................................ 42

Table 3.3: Details of the 2-D transport flow gasifier simulation ............................................ 44

Table 3.4: Proximate and Ultimate Analysis of Illinois \# 6 coal .......................................... 48

Table 3.5: Devolatilization reaction kinetics parameters................................................. 49

Table 3.6: Gasification reaction parameters from PCCL.................................................. 52

Table 4.1: Factors values for the UQ analysis used in the current work ................................5 57

Table 4.2: $\quad$ Response variables from PCCL ........................................................................ 61

Table 4.3: Ranges of input and output parameters for PRB coal ....................................... 70

Table 4.4: Correlation matrix for response variables ................................................... 71

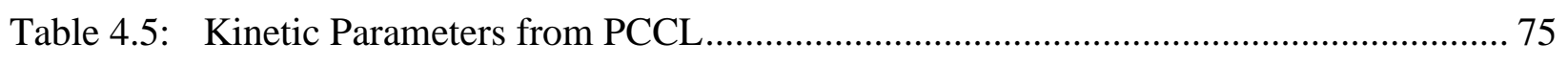

Table 4.6: Devolatilization reaction rate parameters ........................................................ 77 
Table 4.7: Analyses of Pittsburgh No. 8 ....................................................................... 82

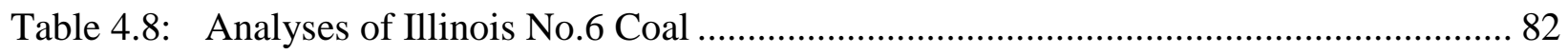

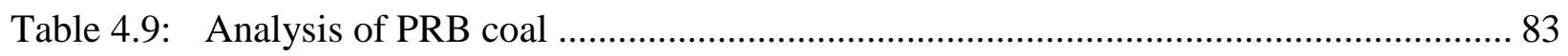

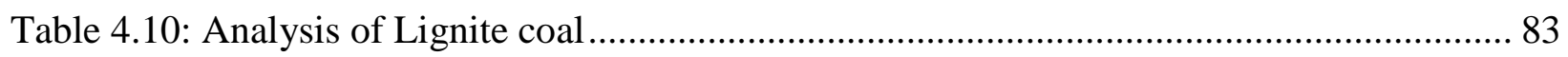

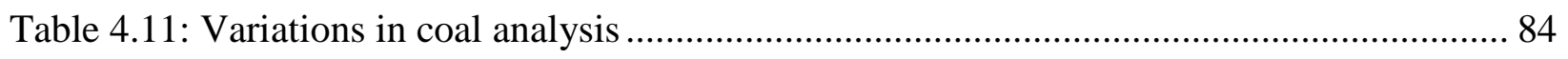

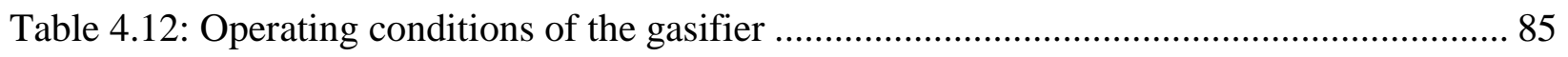

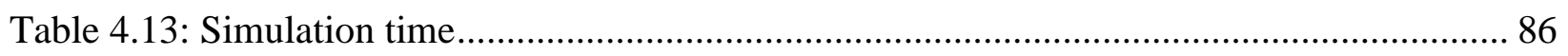

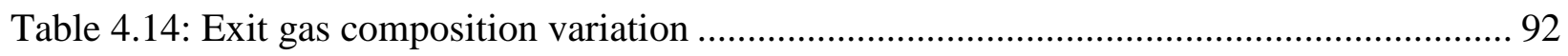

Table 4.15: Coal Blends used for the Transport Flow Gasifier Study.................................... 94

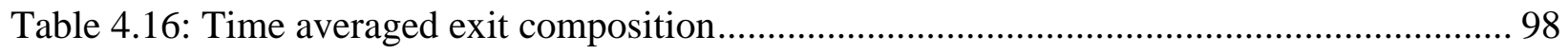

Table 4.17: Coal Analyses of Illinois No.6 as received...................................................... 99 


\section{Chapter 1 : Introduction}

Gasification is a process that converts carbonaceous fuels into a usable mixture of gases known as synthesis gas or simply syngas. Gasifiers around the world are being fueled by coal, petcoke, biomass, and municipal wastes to produce electricity, fuels, and other chemical products. To meet the energy demands of the $21^{\text {st }}$ century, any new coal-fed gasifiers coming online will need to be designed for greater fuel flexibility, reliability, availability, maintainability, and higher throughput and conversion. With this in mind, a detailed study to understand the complex interactions between the gasification reactions and the hydrodynamics of the gasifier should be undertaken. Different mathematical/computational models are useful tools to understand these processes and also serve as cost and time effective techniques compared to traditional experiments. Specifically, computational fluid dynamics (CFD) modeling is a viable option to understand the gasification process (of coal/biomass/petcoke) from both a hydrodynamic and a chemical point of view.

The gasification of coal at moderate temperatures goes through 4 stages: (1) primary devolatilization; (2) pyrolysis of secondary volatiles; (3) homogeneous reforming of noncondensables; and (4) char conversion via oxidation and gasification (Naik et al., 2006). Moisture release occurs at the initial stage of reaction. Volatile matter in the coal is released as several gas phase species through devolatilization. Fixed carbon participates in combustion and gasification reactions. Ash may act as a catalyst for some gas phase reactions but it is not consumed. Review articles by Mohammad et al. (2011), Taba et al., (2012), and Bell et al. (2011) discuss the kinetics for coal gasification in detail.

Detailed scientific knowledge is still lacking about the complex interactions between the gasification reactions and the hydrodynamics that take place in a coal gasifier. Computational fluid dynamics (CFD) modeling is an important tool to learn and predict the coal / biomass/ petcoke gasification process from both hydrodynamic and chemical reaction basis (Syamlal et al., 2011; Singh 2013 et al.). Hence, there has been growing interest in mathematical modeling of coal processing techniques to simulate and predict the variations in the output of these processes. 
Modeling is fast and inexpensive compared to the traditional approach of building and testing at multiple scales prior to commercialization. These models allow the possibility of even skipping steps (scales) to accelerate technology from bench to commercial scale offering insight into the commercial performance (Guenther et al., 2012). CFD codes such as Multiphase Flow with Interphase Exchanges (MFIX) developed at National Energy Technology Laboratory (NETL), ANSYS-Fluent by ANSYS Inc., and Barracuda by CPFD Software do a decent job in simulating coal gasification processes. The accuracy and validity of CFD models depends on the kinetic models used to describe the homogeneous and the heterogeneous reactions that take place in the gasifier. The homogeneous gas-phase reactions, taking place between pure components, are well known (with the exception of the water-gas shift reaction occurring at high pressure) but the initial devolatilization and subsequent tar cracking reactions are not well documented especially when the effects of temperature, heating rate, pressure and coal type are included (Chaudhari, 2010). Hence, a good prediction of kinetics for these reactions is needed. One way to accomplish this is to perform experiments that can be expensive and time consuming. The other way is to use kinetic packages that predict reaction kinetics over a wide range of operating conditions and fuel types. Transferring this kinetic information in the accurate format of the CFD code is very time consuming and an error-prone step. Currently there is no software platform available through which a user has access to the information from the kinetic packages and that easily converts the predictions of the models into usable, correctly formatted, reaction expressions that can be subsequently used directly to run the CFD codes.

Different approaches (described in detailed in Chapter 2) have been presented to describe the gasification of coal and its behavioral changes due to varying operating conditions and process dependence on the coal's individual properties. The heterogeneous reactions (e.g., the initial devolatilization, subsequent tar cracking and char gasification/oxidation reactions) are far more difficult to model when the effects of temperature, heating rate, pressure, and coal structure are included.

The current research focused on relating such approaches used in the detailed models such as METC Gasifier Advanced Simulation (MGAS), PC Coal Lab (PCCL), Chemical Percolation Model for Coal Devolatilization (CPD), Solomon's Functional-Group, Depolymerization, Vaporization, Cross-linking model with existing CFD codes (mentioned 
above), process models and reduced-order reaction models. This is achieved through a graphical user interface (GUI) known as Carbonaceous Chemistry for Computational Modeling (C3M) marketed by NETL. C3M. The capabilities of C3M will be discussed in more detail in the upcoming chapters. The algorithm to create a seamless connection between PCCL (devolatilziation and secondary pyrolysis) kinetics and MFIX was completed previously (Chaudhari, 2010).

Very little information regarding coal derived soot is available in the literature compared to soot formed by combustion of other fuels like acetylene, $\mathrm{CH}_{4}$, and diesel fuels (Ma, 1996). No exact soot formation mechanisms are available for coal tar, which is probably due the complexity of the species involved (Fletcher and Brown, 1998). One of the goals of this research was to develop soot formation kinetics based on the experimental data. Hence a literature review was performed for coal derived soot formation, and an experimental matrix with operating conditions was proposed to carry out the experiments. The experimental soot reaction kinetics study will be done experimentally by Dr. Ping Wang of NETL.

Uncertainty Quantification (UQ) is a statistical technique used to develop a numerical or mathematical model predicting the uncertainty in the output based on the variations in input parameters. Some prediction uncertainties can be reduced by additional research, data collection and analysis. However gathering and analyzing additional data may be expensive in terms of time and money, hence it is reasonable to do a UQ analysis on a model prediction to determine the parameters that affect the model predictions. UQ for coal gasification processes in CFD modeling had not been studied in the past. The current study addressed the input parameter uncertainties affecting the chemical reactions taking place during coal conversion by employing non-intrusive input parameter uncertainty propagation techniques. In this research UQ study was performed using $\mathrm{C} 3 \mathrm{M}$ and toolboxes (e.g., PSUADE). With this approach a user is able to observe and predict the uncertainties/variations in product yields and reaction rates with the prescribed variability in the operating conditions and fuel properties using UQ in C3M. 
The main objectives of this research were as follows:

1) Develop the software package Carbonaceous Chemistry for Computational Modeling $(\mathrm{C} 3 \mathrm{M})$.

2) Construct a connecting bridge between kinetic packages such as PCCL (char oxidation and gasification), CPD (devolatilization), FGDVC (devolatilziation and tar cracking) along with experimental data obtained at NETL sites with the CFD code of interest and/or process models for C3M.

3) Write algorithms for the interface and derivation of reaction kinetic models for CFD codes.

4) Perform a literature review for coal derived soot formation and prepare an experimental matrix.

5) Perform Uncertainty Quantification (UQ) analyses for coal gasification processes to study effects of variations in temperature, pressure, heating rate and coal feed on exit gas composition.

6) Carry out 2-D and 3-D simulations for transport and entrained flow gasifiers based on the kinetics obtained for coal gasification from $\mathrm{C} 3 \mathrm{M}$ and compare simulation results to available experimental and industrial data. 


\section{Chapter 2 : Literature Review}

\subsection{Carbonaceous Chemistry for Computational Modeling (C3M)}

The Department of Energy's National Energy Technology Laboratory (NETL) has developed a software platform entitled Carbonaceous Chemistry for Computational Modeling $(\mathrm{C} 3 \mathrm{M})$ that is used to access a variety of kinetic processes and reaction mechanisms typically found in coal gasification, gas clean-up, and carbon capture processes. Figure 2.1 below illustrates schematically how C3M works to provide a user-friendly graphical user interface (GUI) linking coal or other fuel chemistry and/or kinetics codes to higher level computational fluid dynamics simulations.

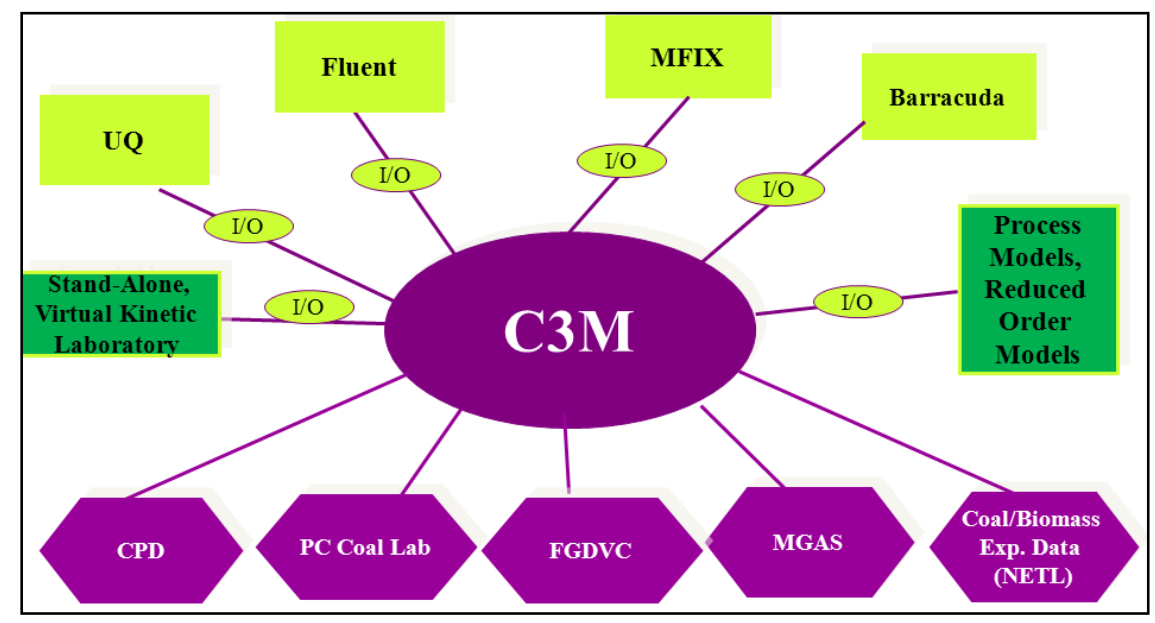

Figure 2.1: C3M Architecture

The C3M GUI allows users to enter easily the fuel properties and operating conditions, select one or more kinetic packages from the C3M GUI menu, and compare graphically their output to show the sensitivity of fuel properties and/or operating conditions on predicted rates and yields. C3M allows modelers to extract kinetic rates and yields for coal/biomass/petcoke pyrolysis and gasification steps from leading kinetic databases and models. The desired kinetic output is automatically updated into a specified computational model. By doing this, C3M effectively opens up a virtual window into the actual operation of a gasifier giving engineers, designers, and plant managers access to information inside a gasification-based energy system that previously has been unavailable. This unique software serves as a virtual kinetic laboratory. The following section describes the building blocks of C3M. 


\subsubsection{METC Gasifier Advanced Simulation (MGAS)}

The METC Gasifier Advanced Simulation (MGAS) by Syamlal and Bissett (1992) describes the transient operations of co-flow, counter-flow, or fixed-bed gasifiers and is based on the gasification kinetic equations proposed by Wen et al. (1982). The kinetics for coal gasification reactions in the MGAS subroutine is limited to only five types of coal (Pittsburgh No.8 (Bituminous), Arkwright Pittsburgh (Bituminous), Illinois No. 6 (Bituminous), Rosebud (Subbituminous), and North Dakota (Lignite)). The kinetic parameters for coal gasification are fixed for these five types of coal. Hence, a coal type other than one of these five has to be treated as one of them in order to predict the gasification process and is not accurate in many cases.

In addition, the devolatilizaiton kinetics in MGAS do not predict the effect of heating rate or pressure on devolatilization yield. Moreover there are no soot formation reactions or polyaromatic hydrocarbon (PAH) formation mechanisms/kinetics in MGAS. These additional reactions may have a significant impact on calculations of radiation heat transfer. Despite these limitations, successful modeling activities have been conducted in the past using MFIX and MGAS (Guenther et al., 2002 and Guenther et al., 2003) however, some adjustment to the rates was necessary in order to match experimental data.

More recently, NETL won an Innovative and Novel Computational Impact on Theory and Experiment (INCITE) award to conduct high resolution simulations of a transport gasifier (Syamlal et al., 2009 and Gel et al., 2009). These first-of- a-kind simulations focused on porting MFIX to a high performance computing system and optimizing its performance. In addition, this work concentrated on the coupling between the hydrodynamics and kinetics inside the gasifier in the coal jet region to gain insight into how coal enters and reacts as it is fed to a transport gasifier.

The limitations of MGAS and the need to modify rates given previously motivated this research to expand MGAS allowing MFIX or other multiphase CFD models to be capable of handling the chemistry of any type of coal fuel other than the basic five in MGAS along with biomass and petcoke.

The other advantage of MGAS is it has been implemented in MFIX, ANSYS FLUENT and BARRACUDA in the past. Hence MGAS serves as a starting point for C3M development. 
Efforts were made to incorporate the new reaction kinetics predicted by the kinetic packages in MGAS. Once MGAS is updated with these kinetics, the link up to CFD codes of interest is relatively easy.

\subsubsection{PC Coal Lab}

PCCL was developed by NIKSA ENERGY ASSOCIATES LLC, and is a set of mathematical models to predict a fuel's (mainly coal, petroleum coke and biomass) devolatilization and gasification behavior by simulating processes as they would occur in simple laboratory test facilities (Niksa, 2008). Input data is based on proximate and ultimate analysis of the coal. PCCL predicts the devolatilization, combustion, and gasification behavior of a wide variety of coals (more than 2000 types worldwide). The software can simulate two types of tests, namely, an electrically heated wire grid experiment and a laminar flow drop tube furnace experiment. The predictions give the yields of all major primary devolatilization products $-\mathrm{CO}_{2}$, $\mathrm{H}_{2} \mathrm{O}, \mathrm{CO}, \mathrm{CH}_{4}, \mathrm{C}_{2} \mathrm{H}_{4}, \mathrm{C}_{2} \mathrm{H}_{6}, \mathrm{C}_{3} \mathrm{H}_{6}, \mathrm{C}_{3} \mathrm{H}_{8}, \mathrm{H}_{2}, \mathrm{H}_{2} \mathrm{~S}, \mathrm{HCN}$, tar, and char - as well as the elemental compositions of tar and char and the tar molecular weight distribution. It also predicts the subsequent secondary pyrolysis of primary volatiles into $\mathrm{CO}_{2}, \mathrm{H}_{2} \mathrm{O}, \mathrm{CO}, \mathrm{H}_{2}, \mathrm{CH}_{4}, \mathrm{C}_{2} \mathrm{H}_{2}$, and soot. PCCL v4.1 predicts char combustion from ignition throughout the later stages of burnout based on the expanded version of Hurt's Carbon Burnout Kinetics (CBK) Model (Hurt, 2002). It also describes char gasification by $\mathrm{H}_{2} \mathrm{O}, \mathrm{CO}_{2}, \mathrm{H}_{2}$, and $\mathrm{CO}$ with a newly expanded version of CBK called CBK/G. PCCL can predict the effects of temperature, pressure and heating rate on pyrolysis of coal.

In PCCL, when the temperature in secondary pyrolysis is above $1000^{\circ} \mathrm{C}$ it is advisable to consider the conversion of tar into soot and for temperatures below $1000^{\circ} \mathrm{C}$ polyaromatic hydrocarbons $(\mathrm{PAH})$ are the main products of tar decomposition. Depending on the availability of hydrogen, PAH may get converted further into gases such as higher hydrocarbons and methane. PCCL has three different mechanisms to predict devolatilization: single first-order reaction (SFOR), the competing two-step reactions model (C2SM) and the distributed activation energy model (DAEM). PCCL predicts the simple $n^{\text {th }}$ order reaction (SNOR) kinetics for char/soot oxidation and gasification reactions. It also provides a coefficient called an annealing factor to incorporate an annealing mechanism for both oxidation and gasification reaction. It is 
predicted by a fifth-order polynomial correlation that gives the decay in the reaction rate with conversion. The polynomial coefficients are evaluated by fitting the product of the annealing factor, surface area factor (from the random pore model), and char density factor evaluated directly from the baseline CBK/G simulations. (Niksa, 2008). Thermal annealing significantly reduces the char oxidation reactivity, and annealing in entrained flow systems is primarily a function of the highest exposure temperature. The annealing factor is assumed to be the same for all the heterogeneous reactions.

Some reasonable assumptions were made to export PCCL outputs in acceptable CFD input formats (Chaudhari, 2010), and are given as follows:

1) The hydrocarbons $\left(\mathrm{C}_{2} \mathrm{H}_{4}, \mathrm{C}_{2} \mathrm{H}_{6}, \mathrm{C}_{3} \mathrm{H}_{6}\right.$, and $\left.\mathrm{C}_{3} \mathrm{H}_{8}\right)$ higher than $\mathrm{CH}_{4}$ will be treated as $\mathrm{CH}_{4}$.

2) Molecular weight of soot is assumed to be $300 \mathrm{~g} / \mathrm{mol}$.

3) PAH and soot have approximately $95 \%$ of carbon content. Therefore the specific heat of PAH and soot are assumed to be the same as fixed carbon.

4) Oil is a mixture of benzene, toluene, xylene (BTX) with an average molecular weight of oil is $92 \mathrm{~g} / \mathrm{mol}$.

5) Version 4.1 of PCCL is not programmed to give kinetics for soot generation in secondary pyrolysis. In this research, it is assumed that when the temperature is above $1000^{\circ} \mathrm{C}$, soot and $\mathrm{C}_{2} \mathrm{H}_{2}$ will be products in the devolatilization step.

The reaction schemes used from PCCL are described below:-

Devolatilization :-

$$
\mathrm{VM} \rightarrow \alpha_{d} \text { tar }+\beta_{\mathrm{CO}}^{d} \mathrm{CO}+\beta_{\mathrm{CO}_{2}}^{d} \mathrm{CO}_{2}+\beta_{\mathrm{CH}_{4}}^{d} \mathrm{CH}_{4}+\beta_{\mathrm{H}_{2}}^{d} \mathrm{H}_{2}+\beta_{\mathrm{H}_{2} \mathrm{O}_{2}}^{d} \mathrm{H}_{2} \mathrm{O}
$$

Tar cracking:-

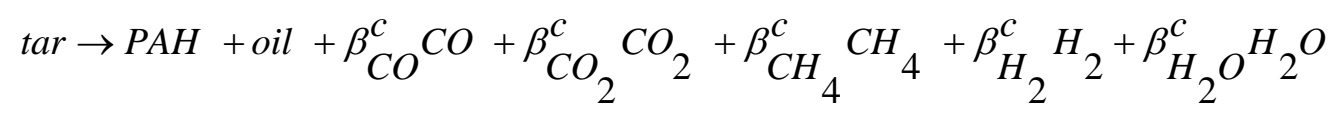

Devolatilization with soot formation:- 


$$
\mathrm{VM} \rightarrow \mathrm{soot}+\mathrm{C}_{2} \mathrm{H}_{2}+\beta_{\mathrm{CO}}^{d} \mathrm{CO}+\beta_{\mathrm{CO}_{2}}^{d} \mathrm{CO}_{2}+\beta_{\mathrm{CH}_{4}}^{d} \mathrm{CH}_{4}+\beta_{\mathrm{H}_{2}}^{d} \mathrm{H}_{2}+\beta_{\mathrm{H}_{2} \mathrm{O}}^{d} \mathrm{H}_{2} \mathrm{O}
$$

Char Oxidation:-

$$
2 \mathrm{C}+\mathrm{O}_{2} \rightarrow \mathrm{CO}
$$

Char Gasification:-

$$
\begin{gathered}
\mathrm{C}+\mathrm{H}_{2} \mathrm{O} \rightarrow \mathrm{CO}+\mathrm{H}_{2} \\
\mathrm{C}+\mathrm{CO}_{2} \rightarrow 2 \mathrm{CO} \\
\frac{1}{2} \mathrm{C}+\mathrm{H}_{2} \rightarrow \frac{1}{2} \mathrm{CH}_{4}
\end{gathered}
$$

Soot oxidation:-

$$
\text { soot }+25.4906 \mathrm{O}_{2} \rightarrow 24.75 \mathrm{CO}_{2}+1.4833 \mathrm{H}_{2} \mathrm{O}
$$

Soot gasification:-

$$
\begin{aligned}
& \text { soot }+25 \mathrm{H}_{2} \mathrm{O} \rightarrow 25 \mathrm{CO}+25 \mathrm{H}_{2} \\
& \text { soot }+25 \mathrm{CO}_{2} \rightarrow 50 \mathrm{CO} \\
& \text { soot }+50 \mathrm{H}_{2} \rightarrow 25 \mathrm{CH}_{4}
\end{aligned}
$$

Biomass devolatilization:-

$$
\begin{aligned}
\mathrm{VM} \rightarrow & \mathrm{CO}+\mathrm{CO}_{2}+\mathrm{H}_{2} \mathrm{O}+\mathrm{H}_{2}+\mathrm{CH}_{4}+\mathrm{C}_{2} \mathrm{H}_{2}+\mathrm{C}_{2} \mathrm{H}_{4}+\mathrm{C}_{2} \mathrm{H}_{6}+\mathrm{C}_{3} \mathrm{H}_{8}+\text { tar } \\
& +\mathrm{CH}_{3} \mathrm{OH}+\mathrm{CH}_{3} \mathrm{CO}+\text { Acetaldehyde }+\mathrm{CH}_{2} \mathrm{O}+\mathrm{C}_{2} \mathrm{H}_{5} \mathrm{O}+\mathrm{NH}_{3}+\mathrm{H}_{2} \mathrm{~S}
\end{aligned}
$$




\subsubsection{Chemical Percolation Model for Coal Devolatilization (CPD)}

The CPD model is another well-known model for predicting coal devolatilization. It was developed by Sandia National Laboratories, and the University of Utah (Fletcher et al., 1992). The model describes the devolatilization behavior of rapidly heated coal based on the chemical structure of the parent coal. The CPD model successfully predicts the effects of pressure on tar and total volatiles yields observed in rapid heating grid experiments for various coals. Predictions of the amount and characteristics of gas and tar from many different coals compare well with available data (Fletcher et al., 1992). CPD predicts the devoltilization mainly via a bridge reacting mechanism, percolation lattice statistics, a vapor-liquid mechanism, and a cross linking mechanism. The CPD model was developed in FORTRAN on a VAX system. There are several versions of the CPD model. For example, one version requires particle temperature as a function of residence time as an input and a second requires gas temperature with residence time as an input. In $\mathrm{C} 3 \mathrm{M}$ the later model is used to predict the effect of heating rate. However, both require the proximate and ultimate analysis of the coal. In addition to the previous set of input parameters, the CPD model enables a user to specify the chemical structure of the coal as measured directly by ${ }^{13} \mathrm{C}$ NMR analyses. Initially NMR data were available for only 15 coal types that placed some restrictions on the industrial usefulness of CPD. However, this restriction has been substantially removed by developing a regression-model-based-correlation for the coals that do not have NMR data. After running CPD for the operating conditions of interest, the output generated contains the yield of devolatilization product gases $\left(\mathrm{CO}, \mathrm{CO}_{2}, \mathrm{CH}_{4}, \mathrm{H}_{2} \mathrm{O}\right.$ and tar) and char along with the particle temperature-time history.

The current CPD model predicts coal devolatilization only. Like SFOR in PCCL, the CPD devolatilization reaction mechanism can be better explained assuming a two-step reaction scheme as shown below,

$$
\begin{aligned}
& \alpha_{1 d}{ }^{t a r}+\beta_{C O}^{1 d} \mathrm{CO}+\beta_{C O_{2}}^{1 d} \mathrm{CO}_{2}+\beta_{\mathrm{CH}_{4}}^{1 d} \mathrm{CH}_{4}+\beta_{\mathrm{H}_{2} \mathrm{O}_{2}}^{1 d} \mathrm{O} \\
& V M \nearrow \\
& \searrow \alpha_{2 d} \text { tar }+\beta_{C O}^{2 d} \mathrm{CO}+\beta_{\mathrm{CO}_{2}}^{2 d} \mathrm{CO}_{2}+\beta_{\mathrm{CH}_{4}}^{2 d} \mathrm{CH}_{4}+\beta_{\mathrm{H}_{2} \mathrm{O}_{2} \mathrm{O}}^{2 d}
\end{aligned}
$$


An algorithm was developed to extract the two-step devolatilization kinetics parameter from CPD output files. CPD does not report the hydrogen formation and the yield of higher hydrocarbons are lumped into $\mathrm{CH}_{4}$, similar to PCCL.

Although CPD does not have a soot formation mechanism in the code itself, Fletcher and co-workers have reported SFOR kinetics for soot formation (Fletcher and Brown, 1998). According to the mechanism, all the tar goes to soot and it agglomerates to bigger soot particles. This has been incorporated into the soot formation kinetics in $\mathrm{C} 3 \mathrm{M}$ without the agglomeration step.

\subsubsection{Functional-Group, Depolymerization, Vaporization, Cross-linking (FG-DVC)}

The FG-DVC model is a comprehensive code for predicting yields and compositions of coal pyrolysis products (gas, tar, and char). The code is particularly useful in modeling high heating rate processes, where experimental data are difficult to collect along with the pressure effect. In addition to coal FGDVC can handle fuels like biomass and waste materials such as rubber tires (Wojtowicz, 2005). It can operate over a wide range of coals (lignite to bituminous coals) and heating rates (from 0.05 to $20,000 \mathrm{~K} / \mathrm{s}$ ). FG-DVC can be used with only the coal ultimate analysis as an input but better results are obtained if a TG-FTIR (thermogravimetric analyzer combined with Fourier transform infrared analysis of evolving products) experimental data for the coal are used.

The FG-DVC model combines two previously developed models by Solomon and coworkers (Solomon et. al, 1984-87), a Functional Group (FG) model and a Depolymerization, Vaporization, and Cross-linking (DVC) model. The FG subroutine is used to describe gas evolution and the elemental and functional group compositions while the DVC subroutine is employed to determine the amount and molecular weight of macromolecular fragments. FGDVC coal kinetics are rank dependent. Although tar cracking along with devolatilization reactions are reported, the tar cracking predictions are not recommended.

Coal devolatilization:- 


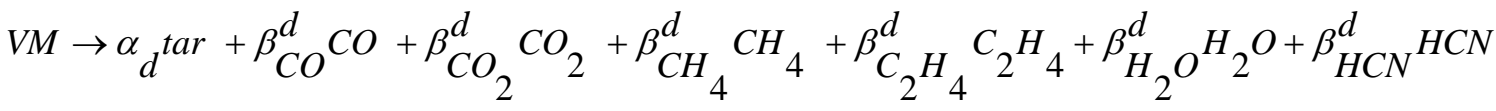

$$
\begin{aligned}
& +\beta_{\mathrm{NH}_{3}}^{d} \mathrm{NH}_{3}+\beta_{\mathrm{SO}_{2}}^{d} \mathrm{SO}_{2}+\beta_{\mathrm{COS}}^{d} \mathrm{COS}+\beta_{\mathrm{CS}_{2}}^{d} \mathrm{CS}_{2}+\beta_{\mathrm{H}_{2} \mathrm{~S}_{2}}^{d} \mathrm{~S}+\text { olefins }+ \text { parafins }
\end{aligned}
$$

The FG-DVC program needs three input files for a given coal (Pollack, 2012):

- The composition file defines the sizes of "pools" of precursor material for each pyrolysis product.

- The kinetic file contains the values of the mean activation energy and the distribution factor $s$ for the coal.

- The polymer file contains information about the macromolecular structure of the coal and the behavior of this structure during pyrolysis.

The model had been integrated with the CFD codes such as FLUENT, PCGC-2 (pulverized coal combustion/gasification - Brigham Young University), AIOLOS (University of Stuttgart), MBED-1 (fixed beds - Brigham Young University), FBED-1 (fixed beds - Brigham Young University), and MFIX (fluidized beds - U.S. Department of Energy).

\subsubsection{Experimental Data}

$\mathrm{C} 3 \mathrm{M}$ also provides easy access and implementation of the experimental and TGA data obtained from experiments performed at NETL sites. The experiments performed include copyrolysis and gasification of coal and biomass at transport flow gasifier conditions (performed by Dr. Nathan Weiland, NETL); a detail study of coal derived soot (to be performed by Dr. Ping Wang, NETL); and entrained flow reactor coal gasification study (to be performed by Dr. S. Pisupati, PSU).

Weiland et al. (2011) completed experimental studies on isothermal co-pyrolysis of Illinois No. 6 coal and switchgrass in a drop reactor at $900^{\circ} \mathrm{C}$. The purpose of this work was to investigate the effects of co-feeding on pyrolysis product distributions under conditions relevant to transport gasifiers. Coal/biomass mixtures were fed to the reactor in feed ratios of 100/0, $85 / 15,70 / 30,50 / 50$, and 0/100, while primary gaseous products $\left(\mathrm{CO}, \mathrm{CO}_{2}, \mathrm{CH}_{4}, \mathrm{H}_{2}\right.$ and $\left.\mathrm{H}_{2} \mathrm{O}\right)$ 
were monitored and analyzed online. Details of the reactor set up and experimental procedure are described in Weiland et al. (2011).

Wang et al. (2012) investigated thermal behavior of coal and biomass blends in inert gas environment at low heating rates and experimental data was obtained using TGA. As a part of this research, simplified kinetic models were developed using model fitting techniques based on the experimental data shown in Appendix II.

\subsubsection{Combustion Kinetics from Literature}

PCCL and FGDVC predict the product yield of higher hydrocarbons $\left(\mathrm{C}_{2} \mathrm{H}_{2}, \mathrm{C}_{2} \mathrm{H}_{4}, \mathrm{C}_{2} \mathrm{H}_{6}\right.$, $\mathrm{C}_{3} \mathrm{H}_{6}$ ) along with $\mathrm{H}_{2} \mathrm{~S}$ and $\mathrm{NH}_{3}$. Initially for simplicity higher hydrocarbons were lumped into $\mathrm{CH}_{4}$, and $\mathrm{H}_{2} \mathrm{~S}$ along with $\mathrm{NH}_{3}$ in to tar (Chaudhari, 2010). When formations of these gas species are considered via pyrolysis, they remain unreacted in the system because there are no reactive reactions involving them. In real gasifier systems these gas species will take part in oxidation reactions (Westbrooke and Dryer, 1981). Hence literature was reviewed to extract the oxidation reaction kinetics for these gas species.

Westbrooke and Dryer (1981) reported the simplified reaction mechanism for higher hydrocarbons combustion. Equation 2.15 to 2.18 give the reaction scheme for $\mathrm{C}_{2} \mathrm{H}_{4}, \mathrm{C}_{2} \mathrm{H}_{6}, \mathrm{C}_{3} \mathrm{H}_{6}$ and $\mathrm{C}_{3} \mathrm{H}_{8}$ combustion respectively. The kinetics for single step reaction have been shown in equation 2.19. Where fuel is reacting hydrocarbon species and oxidizer is molecular oxygen.

$$
\begin{gathered}
\mathrm{C}_{2} \mathrm{H}_{4}+3 \mathrm{O}_{2} \rightarrow 2 \mathrm{CO}_{2}+2 \mathrm{H}_{2} \mathrm{O} \\
2 \mathrm{C}_{2} \mathrm{H}_{6}+7 \mathrm{O}_{2} \rightarrow 4 \mathrm{CO}_{2}+6 \mathrm{H}_{2} \mathrm{O} \\
2 \mathrm{C}_{3} \mathrm{H}_{6}+9 \mathrm{O}_{2} \rightarrow 6 \mathrm{CO}_{2}+6 \mathrm{H}_{2} \mathrm{O} \\
\mathrm{C}_{3} \mathrm{H}_{8}+5 \mathrm{O}_{2} \rightarrow 3 \mathrm{CO}_{2}+4 \mathrm{H}_{2} \mathrm{O} \\
\text { rate }=\text { AT } \exp (-\mathrm{E} / \mathrm{RT})(\text { Fuel })^{a}(\text { Oxidizer })^{b}
\end{gathered}
$$


Table 2.1 reports the kinetic parameter obtained for all the hydrocarbons. These parameters predicted the conversion closely to experimental data when tested.

Table 2.1: Kinetic parameters (Westbrooke and Dryer, 1981)

\begin{tabular}{|c|c|c|c|c|}
\hline Fuel & $\mathbf{A}(\mathbf{1} / \mathbf{s . K})$ & $\mathbf{E}(\mathbf{k c a l} / \mathbf{m o l})$ & $\mathbf{a}$ & $\mathbf{b}$ \\
\hline $\mathbf{C}_{\mathbf{2}} \mathbf{H}_{\mathbf{4}}$ & $2 \times 10^{12}$ & 30 & 0.1 & 1.65 \\
\hline $\mathbf{C}_{\mathbf{2}} \mathbf{H}_{\mathbf{6}}$ & $1.1 \times 10^{12}$ & 30 & 0.1 & 1.65 \\
\hline $\mathbf{C}_{\mathbf{3}} \mathbf{H}_{\mathbf{6}}$ & $4.2 \times 10^{12}$ & 30 & 0.1 & 1.85 \\
\hline $\mathbf{C}_{\mathbf{3}} \mathbf{H}_{\mathbf{8}}$ & $8.6 \times 10^{11}$ & 30 & -0.1 & 1.65 \\
\hline
\end{tabular}

Yu et al. (2007) reported the reaction mechanism and kinetics as per equation 2.20 and 2.21 for $\mathrm{NH}_{3}$ combustion while investing behavior of bubbling fluidized bed reactor. In modeling oxy fuel combustion boiler, Haryanto and Hong (2011) reported the oxidation reaction mechanism and kinetics for $\mathrm{H}_{2} \mathrm{~S}$ as shown in equation 2.22 and 2.23. All these reaction kinetics have been used in modeling coal combustion or gasifier systems, hence these kinetics implementation were chosen.

$$
\begin{gathered}
4 \mathrm{NH}_{3}+5 \mathrm{O}_{2} \rightarrow 4 \mathrm{NO}+6 \mathrm{H}_{2} \mathrm{O} \\
\text { rate }=9.78 \times 10^{11} \mathrm{EXP}\left(-19,655 / \mathrm{T}_{g}\right)\left[\mathrm{NH}_{3}\right]^{0.86}\left[\mathrm{O}_{2}\right]^{1.04} \rho_{g}^{1.9} \\
2 \mathrm{H}_{2} \mathrm{~S}+3 \mathrm{O}_{2} \rightarrow 2 \mathrm{H}_{2} \mathrm{O}+\mathrm{SO}_{2} \\
\text { rate }=6.3 \times 10^{12} \mathrm{EXP}(-300 / \mathrm{T})\left[\mathrm{SO}_{2}\right]\left[\mathrm{H}_{2} \mathrm{O}\right]
\end{gathered}
$$


According to Niksa (2008), the tar cracking reaction produces oil as a product from the reaction. Currently in $\mathrm{C} 3 \mathrm{M}$ there is no reaction scheme involving consumption of oil. It's a mixture of BTX, and based on average molecular weight close to 92, it was assumed to be toluene for simplification (Chaudhari, 2010). Toluene steam reforming reaction mechanism and kinetics were investigated by Joshi (1998). Equation 2.24 and 2.25 shows the reaction scheme and kinetics reported for this study.

$$
\begin{aligned}
& \mathrm{C}_{6} \mathrm{H}_{5} \mathrm{CH}_{3}+7 \mathrm{H}_{2} \mathrm{O} \rightarrow 7 \mathrm{CO}+11 \mathrm{H}_{2} \\
& \text { rate }=A \exp (-\mathrm{E} / \mathrm{RT}) C_{A}^{m} C_{B}^{n}
\end{aligned}
$$

Where, $A=6.07 \times 10^{13} \mathrm{~cm}^{3} / \mathrm{mol} . \mathrm{s}, E=45,386 \mathrm{cal} / \mathrm{mol}, R=1.987 \mathrm{cal} / \mathrm{K} . \mathrm{mol}, n=m=1.02$ and $C_{A}$ and $C_{B}$ are concentration of toluene and water in $\mathrm{mol} / \mathrm{cm}^{3}$ respectively.

An algorithm was prepared to implement the reaction kinetics and mechanism described with equations 2.15 to 2.25 into $\mathrm{C} 3 \mathrm{M}$.

\subsection{Effect of Operating Conditions on Coal Gasification}

Coal gasification reactions depend on the organic properties of the coal. The quantity of volatiles released during pyrolysis impacts the char's heterogenous and gas phase homogeneous reaction chemistry. Various studies (Chaudhari, 2010; Khan, 1984; Manton et al., 2004; Fermosa et al., 2011) have reported that operating conditions such as temperature, pressure, heating rate, particle diameter, residence time, and coal rank can affect the coal devolatilization reaction kinetics. Hence, it is crucial to obtain kinetics and product yields for devolatilization by considering the effects of these parameters. 


\subsubsection{Effect of Heating Rate on Coal Devolatilization}

Heating rate has a significant effect on coal pyrolysis such that primary devolatilization reaction rate and yield increase with an increasing heating rate (Guo et al., 2012; Fletcher and Shartz, 2010). Various experimental and analytical studies have reported that an increase in heating rate during coal devolatilization can lead to a decrease in coal particle swelling ratio, an increase in the amount of tar produced, an increase in total volatile yield released causing a decrease in char yield, along with an increase in devolatilization rate (Wang, 2011; Wiktorsson and Wanzl, 2000; Chen et al., 2010; Chaudhari, 2010). In the literature, different coal types have been tested showing the effects of heating rate on coal devolatilization. Work performed by Gibbins and Kandiyoti (1989) on coal samples of Pittsburgh No.8, Illinois No. 6, Wyoming Wyodak- Anderson, and Pocahontas No.3 used heating heating rates from 1 to $1000^{\circ} \mathrm{C} / \mathrm{s}$. Figure 2.2 shows effect of heating rate on total volatile yield reported by them for Wyoming, Pocahontas No.3 and Illinois No.6 coals. It can be seen that total volatile yield increases with an increase in heating rate. 


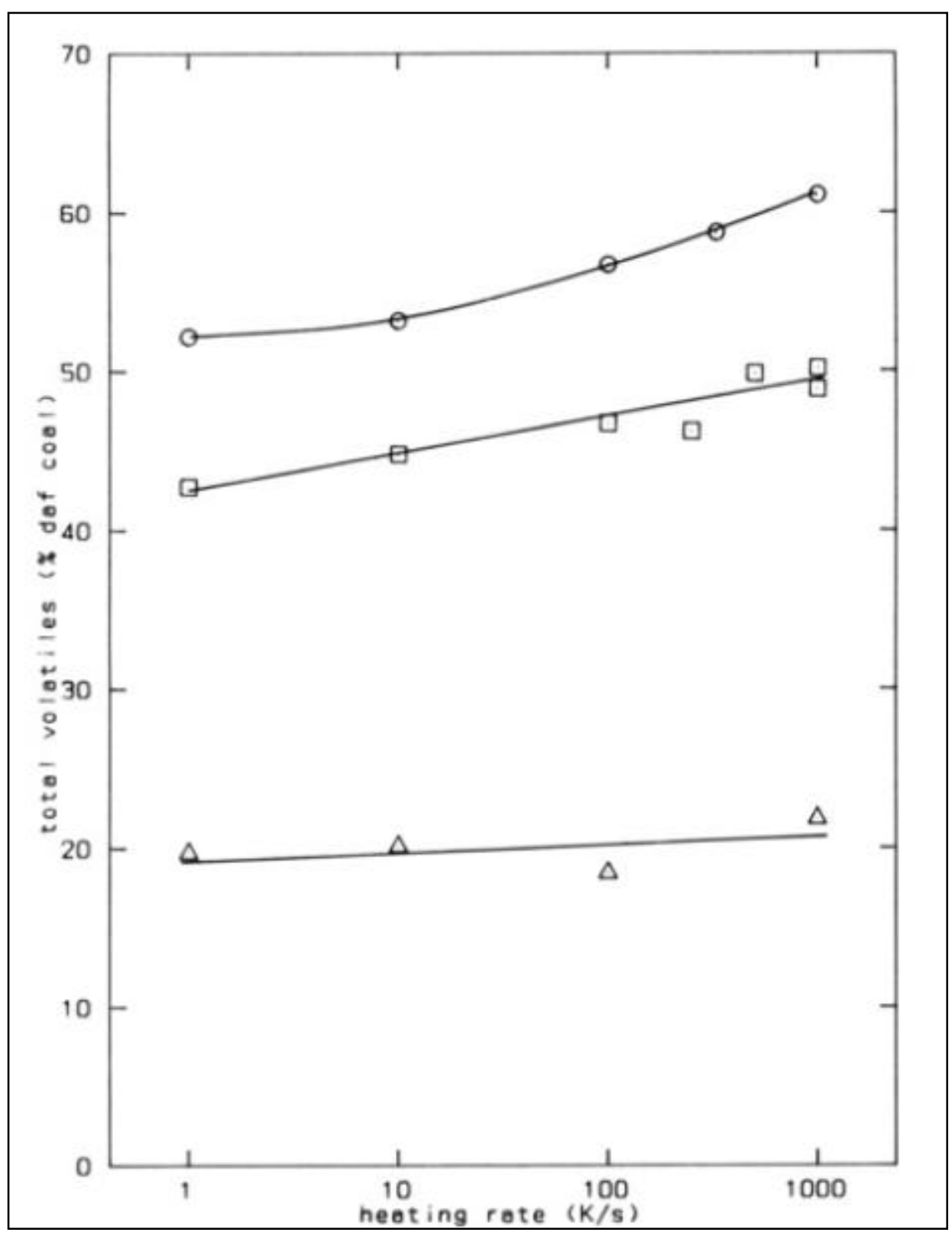

Figure 2.2: Effect of heating rates $(1,10,100$, and $1000 \mathrm{~K} / \mathrm{s})$ on total volatile yield at $700{ }^{\circ} \mathrm{C}$, 1.2 bar pressure for $(\square)$ Wyoming coal, $(\Delta)$ Pocahontas No.3 coal, $(\Theta)$ Illinois No.6 coal (Gibbins and Kandiyoti, 1989).

Experiments performed by Griffin et al. (1994) on samples of Pittsburgh No.8 at heating rates between 10 to 20,000 K/s and data reported by Freihaut and Seery (1985) on Ben and Utah bituminous coal samples at heating rates ranging from 1.0 to $10^{5} \mathrm{~K} / \mathrm{s}$, provide evidence for an 
increase in the tar and total volatile yield at higher heating rates for coal devolatilization. Figure 2.3 shows findings of study done by Griffin et al. (1994) for Pittsburgh No.8 at 1073 K.

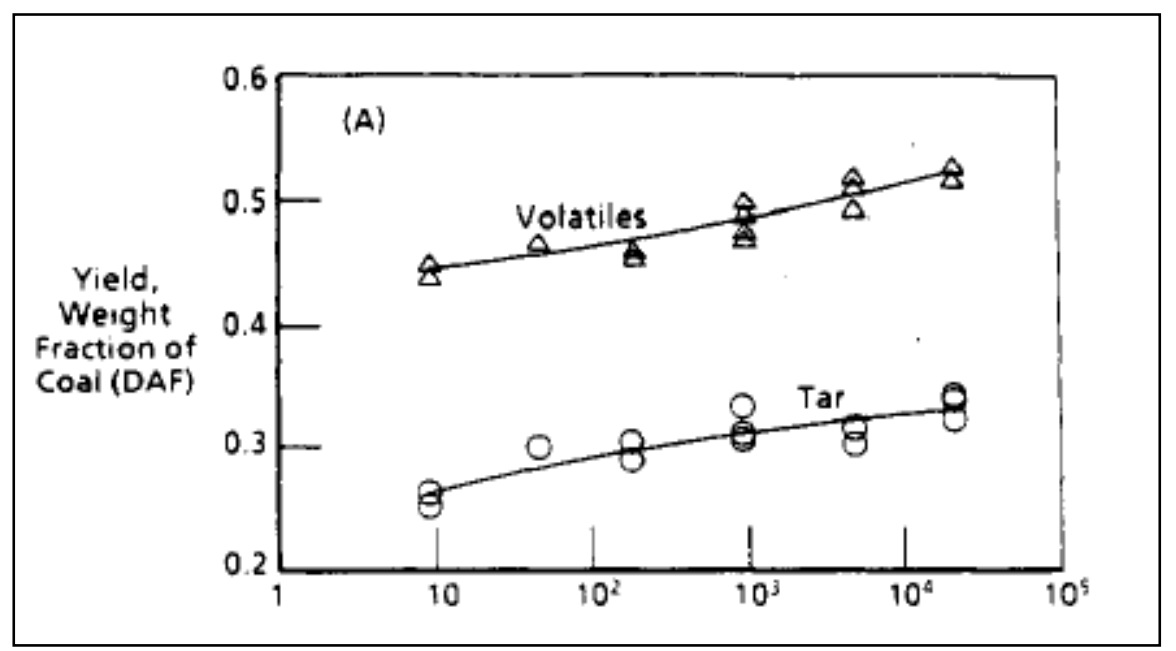

Figure 2.3: Tar and total volatile yield as a function of heating rates at $1073 \mathrm{~K}$ for Pittsburgh No.8 (Griffin et al., 1994).

Hayashi et al. (2000) reported that when brown coal was pyrolyzed at slow and high heating rates, it affected the selectivity to tar, $\mathrm{CO}, \mathrm{CO}_{2}$, and gaseous hydrocarbons (GHC) on a carbon basis.

Fletcher and Shurtz (2010) observed an increase in swelling ratio when Pittsburgh No. 8 and Illinois No.6 coal were pyrolyzed at heating rates between 1 to $10^{6} \mathrm{~K} / \mathrm{s}$. Findings of studies carried out by Roberts et al. (2003) on Australian coal and by Serio et al. (1987) on North Dakota (Zap) lignite, Gillette and Montana Rosebud subbituminous coals, and Pittsburgh No. 8, Kentucky No. 9, and Illinois No. 6 bituminous coals, report an increase in devolatilization rate with respect to heating rates. These findings confirm the importance of heating rate as an input parameter in this study.

\subsubsection{Effect of Temperature on Coal Devolatilization}

Temperature has a similar effect as heating rate on coal devolatilization. Reaction rate of primary pyrolysis/devolatilzation along with total volatile yield increases with an increase in temperatures (Tamhankar et al., 1984; Serio et al. 1987). Total tar yield depletes when temperature is increased beyond $650^{\circ} \mathrm{C}$ because of the on-set of secondary tar cracking reactions (Freihaut and Seery,1985; Zhong et al., 2012; Nelson et al., 1988). Ismail (1993) reported that 
the particle swelling ratio increases with temperature during coal devolatilization for plastic coals such as bituminous and sub-bituminous coals but does not change significantly for non-plastic coals such as lignite and anthracite. In a similar way, the study performed by Zhong et al. (2012) on bituminous coal showed the effect of changing temperature $\left(700-950^{\circ} \mathrm{C}\right)$ on devoalitlizaiton yield and rate, along with experiments done by Matsuoka et al. (2003) on Taiheiyo coal at operating temperatures $600-850^{\circ} \mathrm{C}$. The latter reported an increase in $\mathrm{H}_{2}, \mathrm{CH}_{4}, \mathrm{CO}$ and $\mathrm{CO}_{2}$ yields, while the yields of $\mathrm{H}_{2} \mathrm{O}$ and tar decreased with respect to increasing temperature. Figure 2.4 reports one of the findings of Matsuoka et al. (2003) showing effect of temperature on volatile product distribution for Taiheiyo coal.

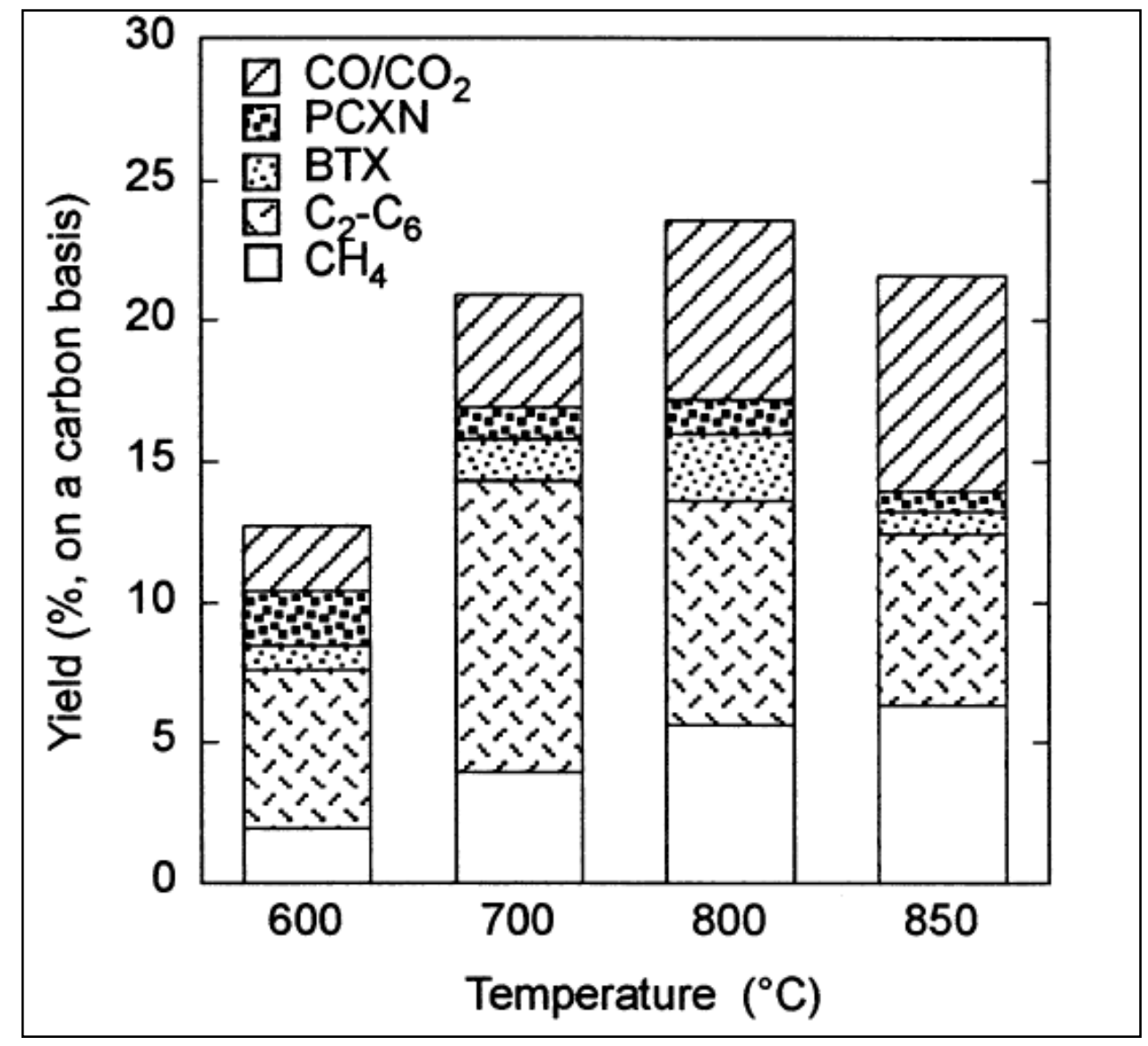

Figure 2.4: Effect of temperature on volatile products yield of Taiheiyo coal (Matusaka, et al. 2003) 
The results of these studies confirm the significant effect that temperature has on volatile yields and reaction rates for devolatilization and that temperature can introduce uncertainty in coal gasifier model predictions.

\subsubsection{Effect of Pressure on Coal Devolatilization}

The effects of pressure on coal devolatilization have been observed for different coal ranks over a wide range of operating conditions. Multiple studies have reported that the devolatilization rate decreases as pressure increases (Oh et al, 1989; Niksa et al 2003; Lee et al 1991; Van Heek 1990, Yun and Lee, 1999). Increasing pressure inhibits tar release that ultimately reduces the total volatile gas yield and promotes secondary tar reactions (Fletcher and Shartz, 2010; Matsuoka et al., 2003; Lee et al., 1991). Serio et al. (1987) observed the reduction

in tar yield with increase in pressure and the reduction in char reactivity when pyrolysis experiments were carried out on three subbituminous and one lignite coal at pressures between 3 and 13 atm in argon gas. The reduction in tar and total volatile yields appear to be most significant for bituminous coals and less pronounced for lignite. However, according to Zheng (2005), the effect of pressure on the tar and total volatile yields appears to be less pronounced at high pressure.

Sun et al. (1997) examined the pyrolysis of two Chinese coals (0.4-4 mm) as a function of pressure (1 to $13 \mathrm{~atm}$ ), their results showed that the yield of total volatiles decreased with increasing pressure when temperature was above a certain value $\left(560^{\circ} \mathrm{C}\right.$ for a Chinese bituminous coal and $680^{\circ} \mathrm{C}$ for a Chinese anthracite coal). Arendt and van Heek (1981), Griffin et al. (1994), Anthony and Howard (1976), and Bautista (1986) confirmed this trend while studying a variety of coals. Shan (2000) summarized the effect of pressure on total volatile yield from literature, as shown in Figure 2.5. 


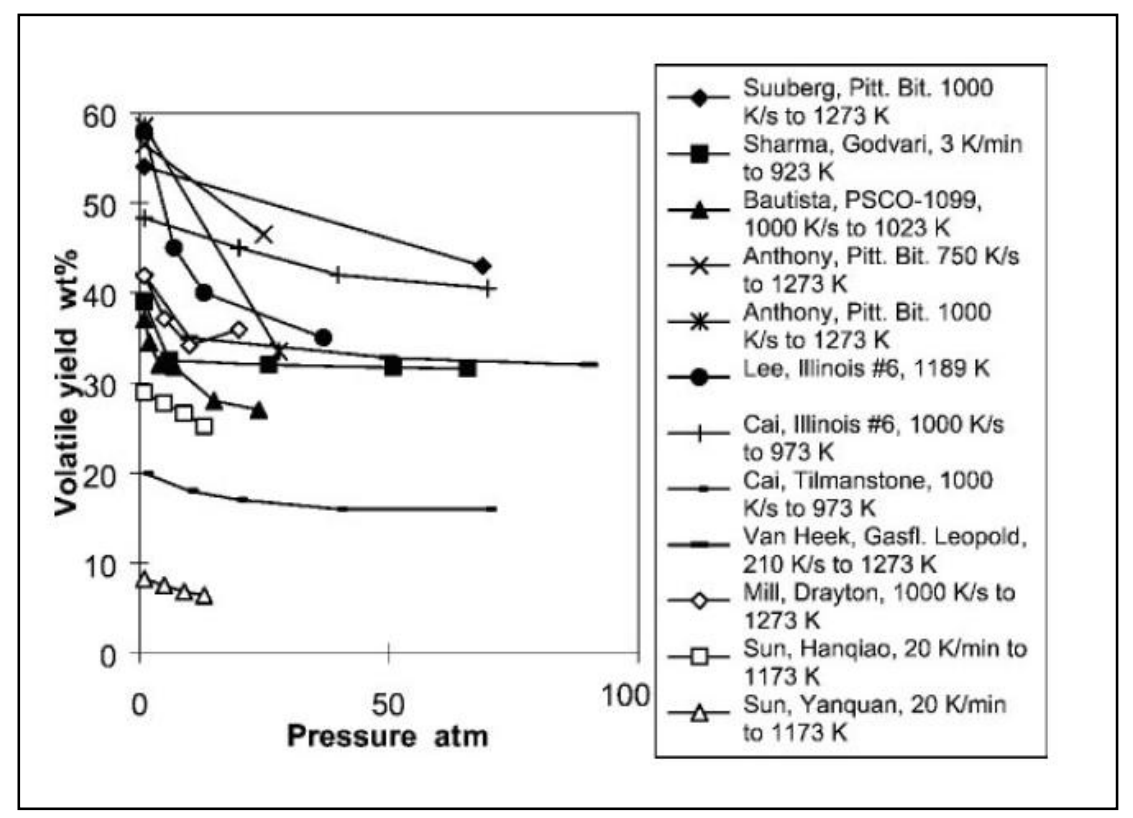

Figure 2.5: Volatile yield as a function of pressure reported by Shan (2000).

The Matsuoka et al. (2003) study, mentioned earlier, reported increases in yields of $\mathrm{CH}_{4}$ and $\mathrm{CO}_{2}$ with increasing pressure, whereas $\mathrm{C}_{2}-\mathrm{C}_{6}$ product yields monotonically decreased with increasing pressure. Fletcher and Shurtz (2010) reported a decrease in particle swelling ratio with an increase in pressure. The sensitivity of pressure on coal devolatilization makes it a suitable choice for an input parameter for this study.

The UQ for coal gasification processes can be used to predict the uncertainties/variations in product yields and reaction rates given the variations in operating conditions and fuel properties. 


\subsection{Coal/biomass Derived Soot Formation}

Small submicron carbonaceous particles generated in the combustion and pyrolysis of hydrocarbons are known as soot. Soot is formed in many practical combustion systems ranging from a burning candle to sophisticated combustors such as gas turbines and internal combustion engines. Based on experimental observations, it is found that soot is usually formed when conditions are sufficiently fuel rich to allow condensation or polymerization reactions of the fuel to compete with oxidation (Haynes and Prado, 1980). Tar is believed to be the precursor of coalderived soot, as suggested by many researchers (McLean, et al., 1981; Nenniger, 1986; Wornat, et al., 1987; Chen, 1991). Soot can be present in the form of individual particles along with agglomerates (Ma, 1997). Figure 2.6 shows the SEM micrograph of soot/coal mixture. Soot is an undesirable combustion product, and its formation represents one of the most complex chemical systems in combustion. This research will address soot formation in coal and biomass pyrolysis.

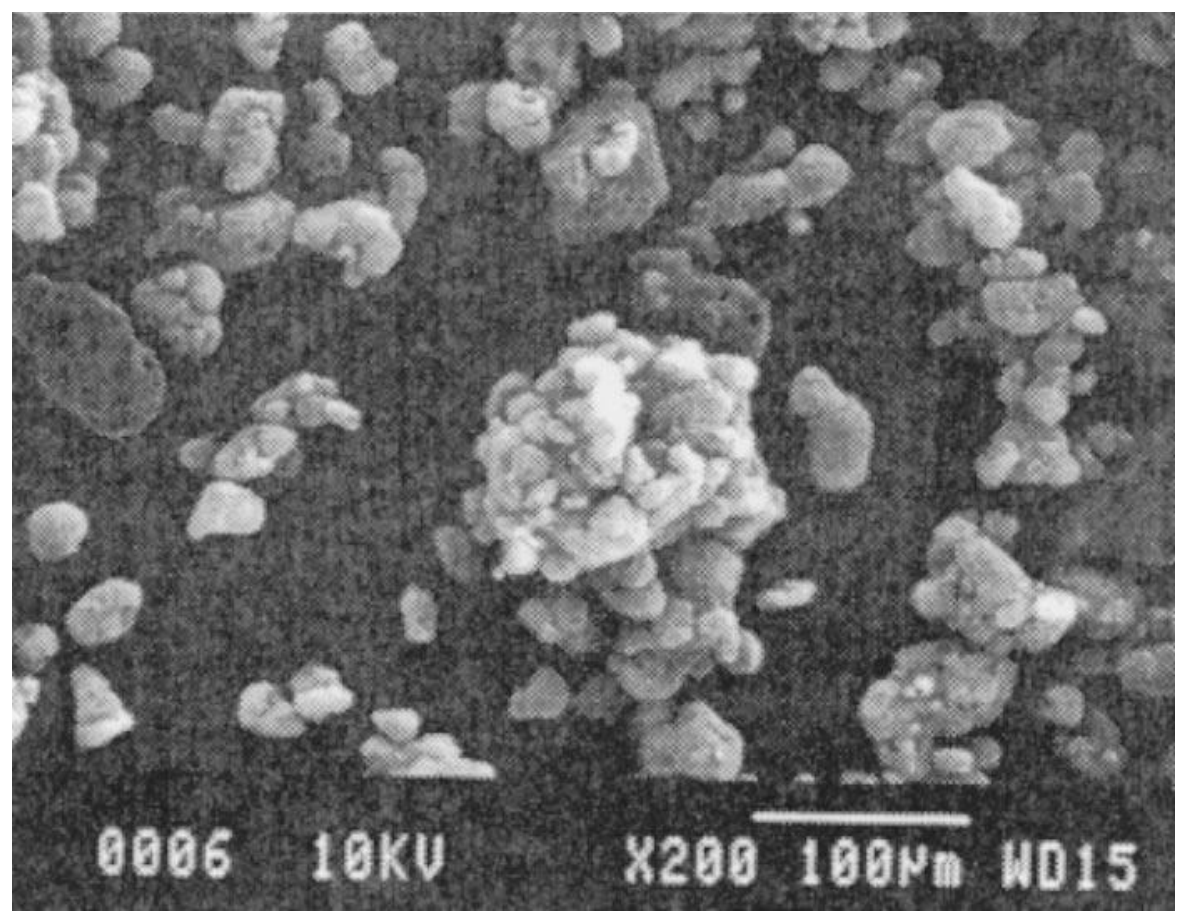

Figure 2.6: SEM Micrograph showing soot/coal mixture collected in the cyclone at a residence time of $34 \mathrm{~ms}$ and temperature of $1900 \mathrm{~K}$ (Ma and Fletcher, 1996). 


\subsubsection{Importance of Soot Formation}

Very little information regarding coal derived soot is available in the literature compared to soot formed by combustion of other fuels such as acetylene, $\mathrm{CH}_{4}$, and diesel fuels. Most of the published work describes soot generated in inert atmospheres, which is not the case for commercial gasifiers and burners. No exact soot formation mechanisms are available for coal tar, due the complexity of the species involved (Brown and Fletcher, 1998).

Soot is formed naturally in hydrocarbon flames and is important to combustion systems because of radiative heat-transfer effects. Soot radiation can lower the gas temperature in the flame zone by hundreds of Kelvin (Fletcher 1996). Soot is also important in coal flames mainly for the following reasons: (1) soot particle radiation is an important heat-transfer mechanism near the burner because the small sizes of the soot particles provide a large surface area; (2) coalderived soot contains nitrogen and can lead to $\mathrm{NO}_{\mathrm{x}}$ formation at high temperatures.

Emission of soot leads to fuel loss and it acts as a hazard to the environment. A large variety of heavy hydrocarbon molecules are adsorbed on the surfaces of soot particles. Soot can be a carrier of pollutants like polynuclear aromatic compounds (PAC) (Kozinski and Saade, 1998). PACs are a health concern because of their potential carcinogenic, mutagenic, and toxic characteristics. In addition, the presence of soot in the air reduces visibility.

The purpose of the current work is to understand the soot formation mechanism and its kinetics. This, in turn, will lead to the development of an experimental program for determining the key parameters in the soot formation mechanism. 


\subsubsection{Soot Formation in Coal Pyrolysis}

Soot formation in coal flames is thought to occur when tars or the higher molecular weight hydrocarbons, given off during devolatilization, combine and condense to form soot particles. This is a different mechanism to that of soot formation from gaseous fuels. Primary pyrolysis of coal (devolatilization) products include light gases, char, and tar, which is a gas mixture of heavy-molecular-weight hydrocarbons at high temperatures and which are condensable at room temperature. Simultaneously, the volatile matter released in the gas phase may also undergo secondary reactions. Soot is believed to be one of the products of these secondary reactions. Primary devolatilization products are transformed into secondary pyrolysis products at high temperatures such as soot, $\mathrm{CO}, \mathrm{H}_{2}$, and $\mathrm{C}_{2} \mathrm{H}_{2}$ (Chaudhari, 2010).

Tar, oil and polyaromatic hydrocarbons (PAH) generated from tar cracking cannot survive high temperatures. McLean, et al. (1981) first proposed that tar is a precursor of soot in coal flames. Tar is transformed into a soot aerosol that grows and coalesces into sooty chain agglomerates similar to soot formed in gaseous hydrocarbon flames. At moderate temperatures, PAH-like tars will survive but at temperatures above $900-1000^{\circ} \mathrm{C}$, PAH re-polymerizes with non-condensable unsaturated hydrocarbons to form soot (Niksa, 2008). A global mechanism for soot formation that was proposed by Chen et al. (1992) is shown below:

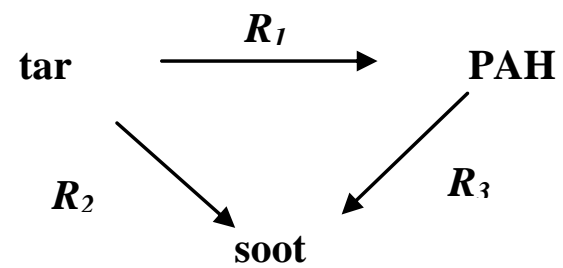

All reaction pathways shown above are irreversible. Initially, $R_{2}$ is the major pathway for soot formation, and nitrogen-containing compounds are incorporated in soot. Thereafter, substantial soot mass is added via $R_{3}$. Direct tar addition to soot in later stages is possible only if tars eliminate their nitrogen before getting added to the soot. Secondary pyrolysis occurs in the gas phase which can be affected by reactive gases, especially $\mathrm{H}_{2}$, steam, and $\mathrm{O}_{2} \cdot \mathrm{H}_{2}$ shifts tar 
conversion from PAH and soot into BTX and non-condensable gaseous hydrocarbons while steam and $\mathrm{O}_{2}$ accelerate the rate of secondary pyrolysis.

Ruiz et al. (2007) studied the influence of temperature on the properties of soot formed from $\mathrm{C}_{2} \mathrm{H}_{2}$ pyrolysis. No soot was observed at low temperatures $\left(<1000^{\circ} \mathrm{C}\right)$. However, with increasing temperature an increase of acetylene $\left(\mathrm{C}_{2} \mathrm{H}_{2}\right)$ conversion into soot and $\mathrm{H}_{2}$ was observed (Fletcher et al. 1997).

Richter and Howard (2000) demonstrated the following six steps involved in soot formation:

a) Formation of a molecular precursor of soot: polyaromatic hydrocarbons (PAH) are the main precursor for soot formation. Their molecular weight varies between 500 to 1000 amu. Smaller C2- C3 carbon compounds combine to form benzene like structural molecules which further recombine to yield PAH.

b) Nucleation or inception of particles from heavy PAH molecules: The heavy PAH molecules cracks and give rise to a path for nascent soot particles with a molecular mass of approximately $2000 \mathrm{amu}$ and an effective diameter of about $1.5 \mathrm{~nm}$.

c) Mass growth of particles by addition of gas phase molecules: After the formation of the nascent soot particles, their mass is increased via the addition of gas phase species such as acetylene $\left(\mathrm{C}_{2} \mathrm{H}_{2}\right)$ and $\mathrm{PAH}$, including $\mathrm{PAH}$ radicals.

d) Coagulation via reactive particle-particle collisions: Growing soot particles collide and reunite with other particles resulting in an increase in particles size and decrease in particle number without changing the total mass of soot present

e) Carbonization of particulate material: At longer residence times and under pyrolytic conditions in the post-flame zone, the polyaromatic material undergoes functional group elimination, cyclization, ring condensation and ring fusion attended by dehydrogenation and growth and alignment of polyaromatic layers. This process converts the initially amorphous soot material into a progressively more graphitic carbon material, with some decrease in particle mass but no change in particle number. 
f) Oxidation: Oxidation of PAH and soot competes simultaneously with the formation reactions and results in the formation of $\mathrm{CO}$ and $\mathrm{CO}_{2}$ by reducing the mass of $\mathrm{PAH}$ and soot.

Wang (2011) presented a detailed study of soot formation from aromatics formed in tar cracking, which includes the following steps:

a) Aromatics formation: Aromatics, mainly $\mathrm{PAH}$, are the precursor to soot formation and can be formed via a hydrogen-abstraction-carbon-addition (HACA) mechanism and other additional recombination mechanisms.

b) Nucleation: Soot nucleation can occur via three pathways; the growth of two dimensional PAHs in to curved, fullerene like structures; physical coalescence of moderate sized PAHs into stacked clusters; and the reaction of PAHs into crosslinked three-dimensional structures.

c) Mass/size growth, chemical composition and morphology: Soot molecules formed in step (b), then agglomerate to form big soot particles by keeping the same chemical composition and mass.

Figure 2.7 shows the proposed pathway for soot formation from tar by Brown and Fletcher (1998). The initial step is the formation of the first aromatic species from the aliphatic hydrocarbons during tar cracking, followed by the addition of other aromatic and alkyl species to give higher species, i.e., PAHs, which results in the generation of the smallest soot particles with diameters of the order of $1 \mathrm{~nm}$ and a mass of around 500-2000 amu (Chen et al. 2011).

Coal $\stackrel{\text { Devolatilization }}{\longrightarrow}$ Char + Light Gases + Tar

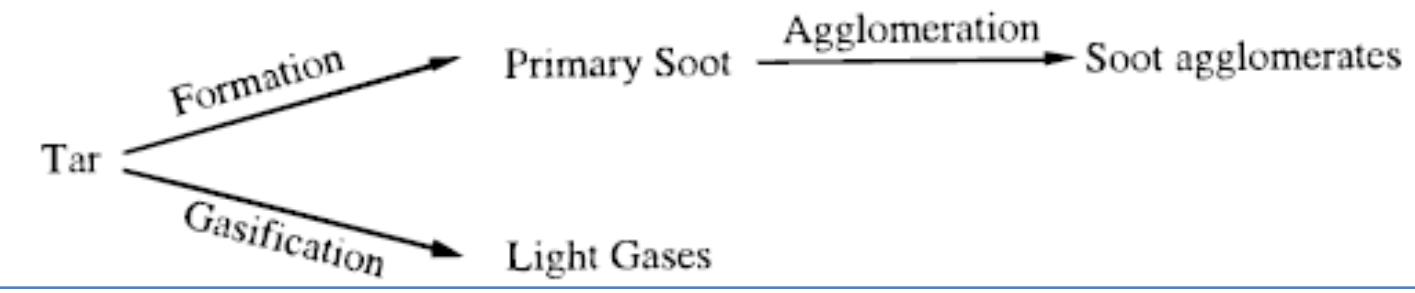

Figure 2.7: Coal devolatilization and soot formation pathways (Brown and Fletcher, 1998). 
Rigby and co-workers (2001) found that soot formed in gaseous hydrocarbon flames goes from lower molecular weight to higher molecular weight substances, which is contrary to the soot formation mechanism in coal pyrolysis that is initiated with very high molecular weight tar without breaking down to acetylene.

Zhang (2001) observed that both temperature and residence time have a significant impact on the secondary reactions of tar. Coal-derived soot exhibited a loss of aliphatic side chains and oxygen functional groups prior to significant growth in average aromatic ring size. The polymerization reactions accelerate at temperatures above $1400 \mathrm{~K}$, which leads to larger and more interconnected cluster.

\subsubsection{Soot Formation in Biomass Pyrolysis}

Soot formation is also observed in biomass gasification and combustion at high temperatures. Soot produced at higher temperature is another serious issue, especially for biomass. Tar produced in the initial stage of biomass pyrolysis is an extremely complex mixture of organic compounds. This tar undergoes sets of secondary tar reactions (STR) which consist of cracking, partial oxidation, re-polymerization, and condensation. These STR products can be classified into three types based on the range of formation temperature (Morf et al., 2002) as shown below:

- Primary products $\left(400-700^{\circ} \mathrm{C}\right)$ : oxygentated compounds like acids, ketones

- Secondary products $\left(700-850^{\circ} \mathrm{C}\right)$ : phenols, monoaromatic compounds and methyl derivatives

- Tertiary products $\left(850^{\circ} \mathrm{C}\right.$ and above): polyaromatic compounds and soot Morf and co-workers (2002) modeled soot formation as three consecutive reactions.

\section{gravimetric tar $\rightarrow$ intermediate $\rightarrow$ naphthalene $\rightarrow$ soot}

Kozinki and Saade (1998) found that soot particles occurred in two forms during biomass combustion experiments: (1) as individual particles usually joined in simple, short chains; and, (2) as branched clusters of these chains (aggregates). Figure 2.8 shows a pictorial view of the formation of soot agglomerates, where A, B, C, and D represent soot particles that are initially 
formed. Numbers 1,2,3,4, and 5 indicate the stages of the soot structure development as a result of particle growth, coagulation and chain agglomeration during biomass combustion. Figure 2.9 shows the possible pathways of polynuclear aromatic compounds (PAC) and soot formation.

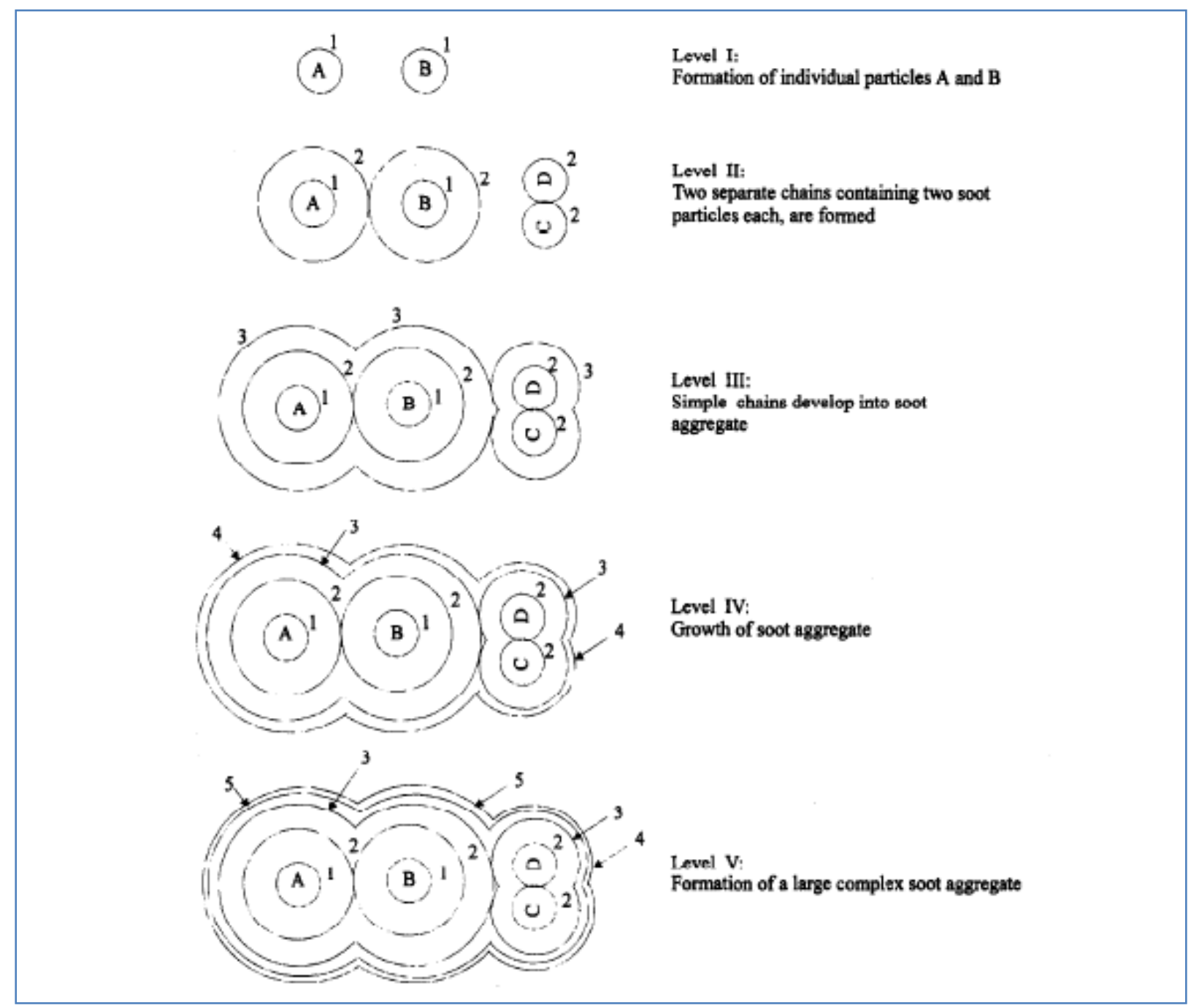

Figure 2.8: Illustration of the development of a soot aggregate structure (Kozinki and Saade 1998). 


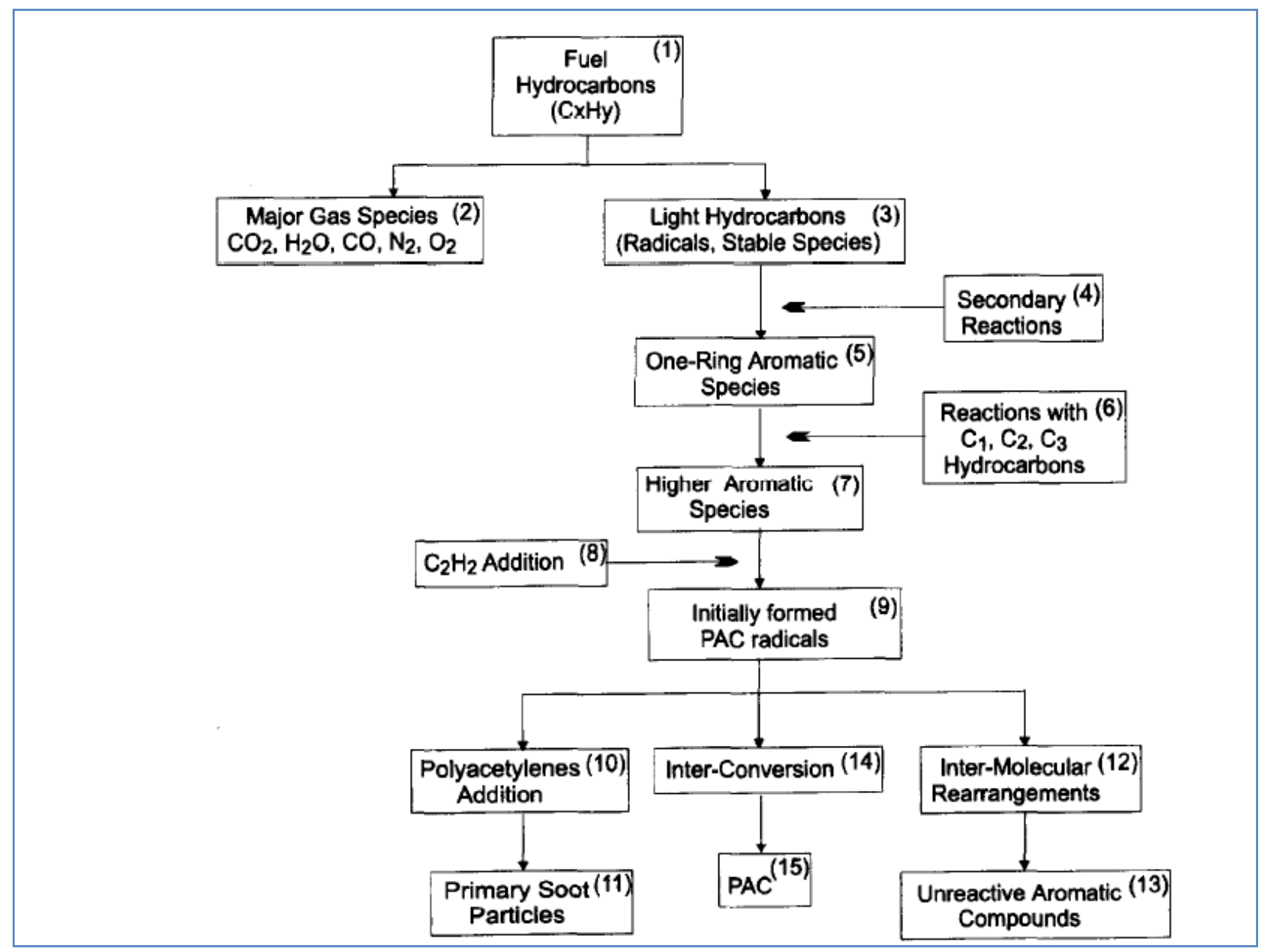

Figure 2.9: Schematic Illustration of PAC and soot formation during biomass combustion (Kozinki and Saade, 1998).

Figure 2.10 shows the main reaction pathways for soot formation from PAH during biomass volatile combustion reported by Wijayanta et al. (2012). 


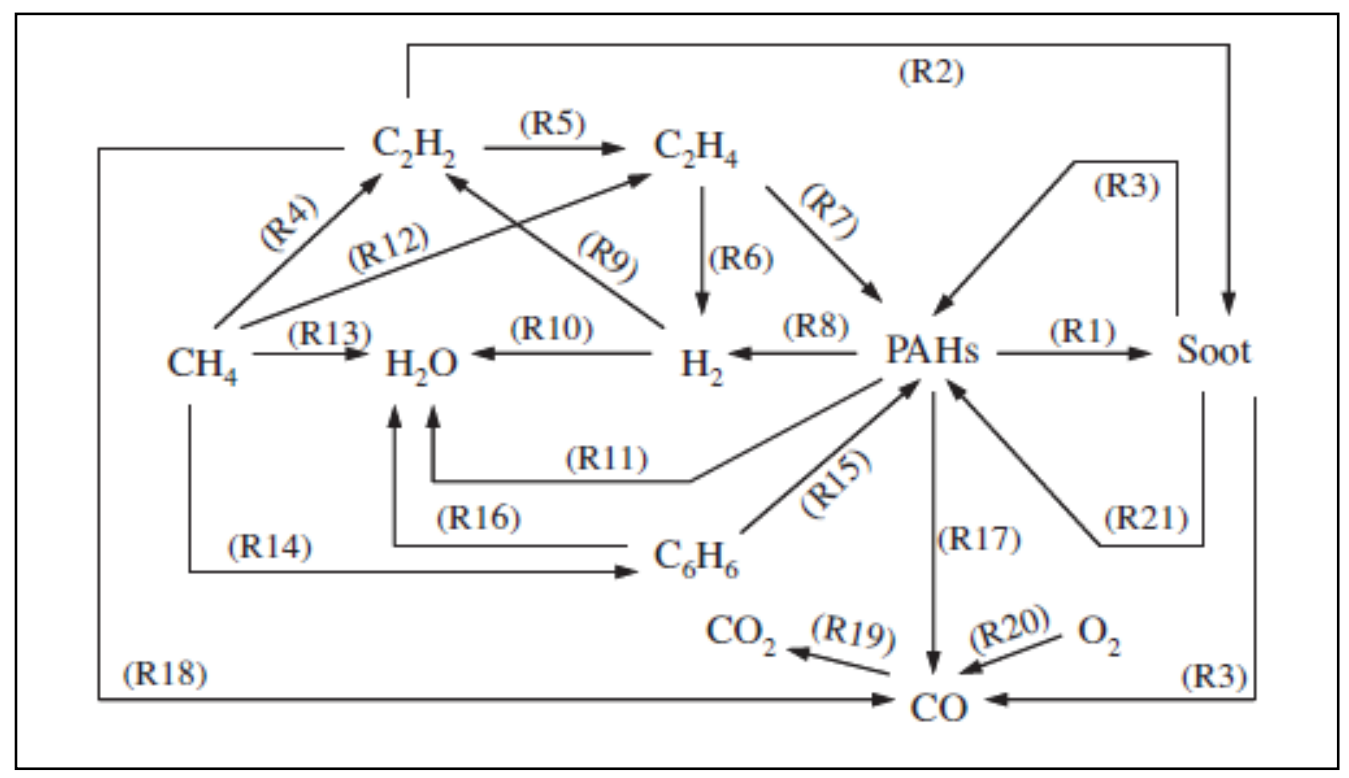

Figure 2.10: Important reaction pathways for soot formation in biomass volatile combustion

(Wijayanta et al. 2012).

Based on the literature review performed to this point, a simple mechanism for the formation of biomass derived soot was not found.

\subsubsection{Effect of Temperature on Soot Production}

According to Rigby et al. (2001), temperature has a large effect on soot yield. Soot yields from coal decrease with increasing temperature above $1000^{\circ} \mathrm{C}$. This decrease in soot yield with increasing temperature is likely due to reactions of radical species from the flame with the soot precursors. In addition, tar molecules are stable at high temperatures and $\mathrm{OH}$ as well as $\mathrm{O}$ radicals react with tar molecules and intermediate PAH species thus reducing soot yields. However, the carbon content in the coal-derived soot increases with reactor temperature. The increase in carbon content is because of the addition of light hydrocarbon species from secondary coal pyrolysis (such as acetylene, $\mathrm{C}_{2} \mathrm{H}_{2}$ ), since these species are generally richer in hydrogen than the local soot particles. 
Reactivity behavior of soot particles is also found to be a function of temperature (Riuz et al., 2007). Soot particles formed at lower temperatures $\left(1000-1100^{\circ} \mathrm{C}\right)$ have higher reactivity with $\mathrm{O}_{2}$ as well as NO. Soot agglomeration is also affected by temperature where the agglomeration rate is observed to be slower at lower temperatures (Fletcher and Ma, 1996).

Wijayanta et al. (2012) observed that production of PAHs increases with increasing temperature $\left(800^{\circ} \mathrm{C}\right.$ to $\left.1200^{\circ} \mathrm{C}\right)$ and decreases at higher temperatures $\left(1405^{\circ} \mathrm{C}\right.$ and $\left.1600^{\circ} \mathrm{C}\right)$. If the temperature is too low $\left(<623^{\circ} \mathrm{C}\right)$, no secondary reactions will take place (Serio, 1987) and the soot yield will be zero

\subsubsection{Effect of Residence Time on Soot Production}

According to Ma (1996), the increase in soot yield with residence time is likely due to the addition of light gases, such as acetylene, from secondary coal pyrolysis. The carbon content in the coal-derived soot was observed to decrease with increasing particle residence time (at a given reactor temperature). Carbon content remains constant with residence time for the soot generated from pyrolysis of acetylene and propane (Rigby, 2011). Soot agglomeration rate increases with increasing residence time (Fletcher et al., 1996).

\subsubsection{Effect of Pressure on Soot Production}

There is little literature available describing the effect of pressure on soot formation in coal pyrolysis. Our knowledge of coal pyrolysis tells us that an increase in pressure decreases the devolatilziation rate, which ultimately decreases the tar production and may result in lower soot yield. However, although elevated pressure decreases tar yield, it enhances conversion of tar and other hydrocarbons to soot (Shurtz et al., 2011).

Joo and Gulder (2009) studied the effects of pressure on soot formation and the structure in the methane-air laminar diffusion flames in a high-pressure combustion chamber (10-60 atm). They observed that a higher fuel pyrolysis rate (at high temperature) causes accelerated soot nucleation and growth as the pressure increases. An increase of pressure leads to an increase in 
density and soot precursor concentration, which leads to an increase in soot yield. Elevated pressure decreases tar yield but enhances conversion of tar and other hydrocarbons to soot.

\subsubsection{Effect of Coal/Biomass Type on Soot Production}

Total soot yield is directly related to the tar yield from coal pyrolysis; high-volatile bituminous coals have the highest yield of soot (Fletcher, 1996). Coal tar secondary reactions are coal rank dependent, Figure 2.11 shows coal rank dependency on coal tar cracking (Zeng et al., 2011). Saade et al. (1998) studied the effect of three types of biomass (particle board, hard pinewood, and paper mill residue) combustion on soot and PAC formation. They observed that the overall PAC's formation tendency decreased in the order particle board > hard pine-wood >> paper-mill residue.

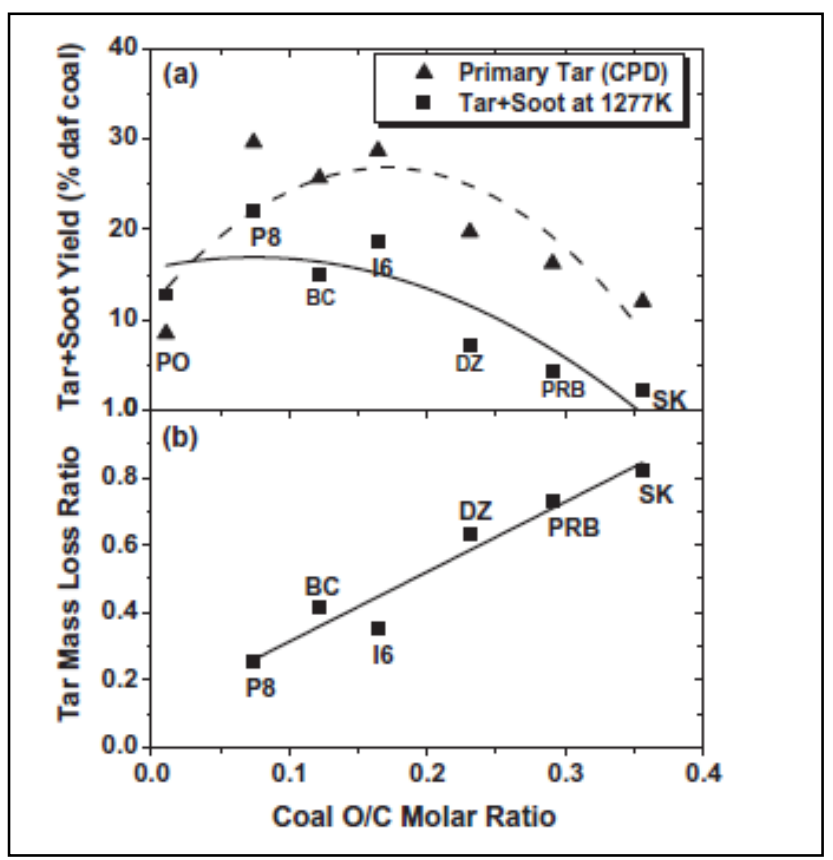

Figure 2.11: Rank dependence of primary and secondary tar yields (Zeng et al., 2011). 
Soot yield is also related to coal rank. Fletcher et al. (1996) reported that soot yield increased in the order Pittsburgh No. 8 coal $>$ the Illinois No. $6>$ Pocahontas No.3 coal > Zap lignite, concluding that a coal with a high tar yield also has a high soot yield.

\subsubsection{Effect of $\mathrm{O} / \mathrm{C}$ Ratio on Soot Production}

The concentration of soot decreases along with the $\mathrm{O} / \mathrm{C}$ ratio in the fly ash. Soot yield can be decreased by increasing oxygen content (Chen et al. 2011).

\subsubsection{Soot Formation Kinetic Models}

Very few coal derived soot models are available in the literature. One well-known soot formation kinetic model was reported by Brown and Fletcher (1998). According to this model soot formation from tar is a single first order reaction kinetics shown below;

$$
\text { rate }_{\text {soot }}=5.02 \times 10^{8} \exp \left(\frac{-198.9}{R T}\right)\left[C_{\text {tar }}\right]
$$

This soot formation equation is also being used in ANSYS-FLUENT CFD code. No other coal derived soot formation kinetics was found during the current literature review.

The kinetic parameters for the reaction mechanism described for biomass gasification by (Richter et al. 2005) are shown in Figure 2.12 and Table 2.2. Here soot is defined as a heavy PAH. Hence reactions R1, R2 and R3 are the major soot formation reactions.

$$
\begin{aligned}
& \mathrm{PAH} / \mathrm{PAH}^{*}+\mathrm{PAH} / \mathrm{PAH}^{*}=\mathrm{PAH} / \mathrm{PAH}^{*}+\mathrm{H} / \mathrm{H}_{2} \\
& \mathrm{PAH}^{*}+\mathrm{C}_{2} \mathrm{H}_{2}=\mathrm{PAH} / \mathrm{PAH}^{*}+\mathrm{H} \\
& \mathrm{PAH} / \mathrm{PAH}^{*}+\mathrm{O} / \mathrm{OH}=\mathrm{PAH} / \mathrm{PAH}^{*}+\mathrm{CO}+\mathrm{H}
\end{aligned}
$$

Figure 2.12: The major reactions taking place in soot formation ( $\mathrm{PAH}^{*}$ : $\mathrm{PAH}$ radical) (Richter et al. 2005). 
Table 2.2: Kinetic parameters for the twenty one-step $\mathrm{PAH} /$ soot reduction formation mechanism in biomass gasification (Richter et al. 2005)

\begin{tabular}{|c|c|c|c|c|}
\hline ID & Reaction & $A_{f}$ & $\alpha$ & E \\
\hline R4 & $\mathrm{C}_{2} \mathrm{H}+\mathrm{CH}_{4}=\mathrm{C}_{2} \mathrm{H}_{2}+\mathrm{CH}_{3}$ & $1.81 \mathrm{E}+12$ & 0 & 497 \\
\hline R5 & $\mathrm{C}_{2} \mathrm{H}_{2}+\mathrm{H}_{2}=\mathrm{C}_{2} \mathrm{H}_{4}$ & $1.20 \mathrm{E}+28$ & -4.98 & 46,410 \\
\hline R6 & $\mathrm{C}_{2} \mathrm{H}_{4}+\mathrm{H}=\mathrm{C}_{2} \mathrm{H}_{3}+\mathrm{H}_{2}$ & $5.07 \mathrm{E}+07$ & 1.93 & 12,951 \\
\hline R7 & $\mathrm{C}_{6} \mathrm{H}_{5}+\mathrm{C}_{2} \mathrm{H}_{4}=\mathrm{C}_{8} \mathrm{H}_{8}+\mathrm{H}$ & $2.51 \mathrm{E}+12$ & 0 & 6200 \\
\hline R8 & $\mathrm{BIN} 4+\mathrm{H}=\mathrm{BIN} 4 \mathrm{~J}+\mathrm{H}_{2}$ & $0.184 \mathrm{E}+09$ & 2.095 & 15842.0 \\
\hline R9 & $\mathrm{H}_{2} \mathrm{CCCCH}+\mathrm{H}_{2}=\mathrm{C}_{2} \mathrm{H}_{2}+\mathrm{C}_{2} \mathrm{H}_{3}$ & $5.01 \mathrm{E}+10$ & 0 & 20,000 \\
\hline R10 & $\mathrm{H}_{2}+\mathrm{OH}=\mathrm{H}_{2} \mathrm{O}+\mathrm{H}$ & $2.14 \mathrm{E}+08$ & 1.51 & 3430 \\
\hline R11 & $\mathrm{BIN} 4+\mathrm{OH}=\mathrm{BIN} 4 \mathrm{~J}+\mathrm{H}_{2} \mathrm{O}$ & $0.120 \mathrm{E}+15$ & 0 & 4571.0 \\
\hline R12 & $\mathrm{CH}+\mathrm{CH}_{4}=\mathrm{C}_{2} \mathrm{H}_{4}+\mathrm{H}$ & $6.00 \mathrm{E}+13$ & 0 & 0 \\
\hline R13 & $\mathrm{CH}_{4}+\mathrm{OH}=\mathrm{CH}_{3}+\mathrm{H}_{2} \mathrm{O}$ & $1.57 \mathrm{E}+07$ & 1.83 & 2780 \\
\hline R14 & $\mathrm{C}_{6} \mathrm{H}_{5}+\mathrm{CH}_{4}=\mathrm{C}_{6} \mathrm{H}_{6}+\mathrm{CH}_{3}$ & $6.00 \mathrm{E}+12$ & 0 & 12,320 \\
\hline R15 & $\mathrm{C}_{6} \mathrm{H}_{6}+\mathrm{C}_{2} \mathrm{H}_{3}=\mathrm{C}_{8} \mathrm{H}_{8}+\mathrm{H}$ & $7.94 \mathrm{E}+11$ & 0 & 6400 \\
\hline R16 & $\mathrm{C}_{6} \mathrm{H}_{6}+\mathrm{OH}=\mathrm{C}_{6} \mathrm{H}_{5}+\mathrm{H}_{2} \mathrm{O}$ & $2.11 \mathrm{E} 13$ & 0.0 & 4571.0 \\
\hline R17 & $\mathrm{C}_{8} \mathrm{H}_{6}+\mathrm{O}=\mathrm{C}_{6} \mathrm{H}_{5} \mathrm{CH}+\mathrm{CO}$ & $3.60 \mathrm{E}+12$ & 0 & 633 \\
\hline R18 & $\mathrm{C}_{2} \mathrm{H}_{2}+\mathrm{O}=\mathrm{HCH}+\mathrm{CO}$ & $1.40 \mathrm{E} 06$ & 2.09 & 1562.0 \\
\hline R19 & $\mathrm{CO}+\mathrm{OH}=\mathrm{CO}_{2}+\mathrm{H}$ & $6.32 \mathrm{E}+06$ & 1.5 & -497 \\
\hline R20 & $\mathrm{HCCO}+\mathrm{O}_{2}=2 \mathrm{CO}+\mathrm{OH}$ & $1.46 \mathrm{E}+12$ & 0 & 2500 \\
\hline R21 & $\mathrm{PYRENE}+\mathrm{OH}=\mathrm{A} 3 \mathrm{~J} 4+\mathrm{CH}_{2} \mathrm{CO}$ & $1.30 \mathrm{E}+13$ & 0 & 10,600 \\
\hline \multicolumn{5}{|c|}{ 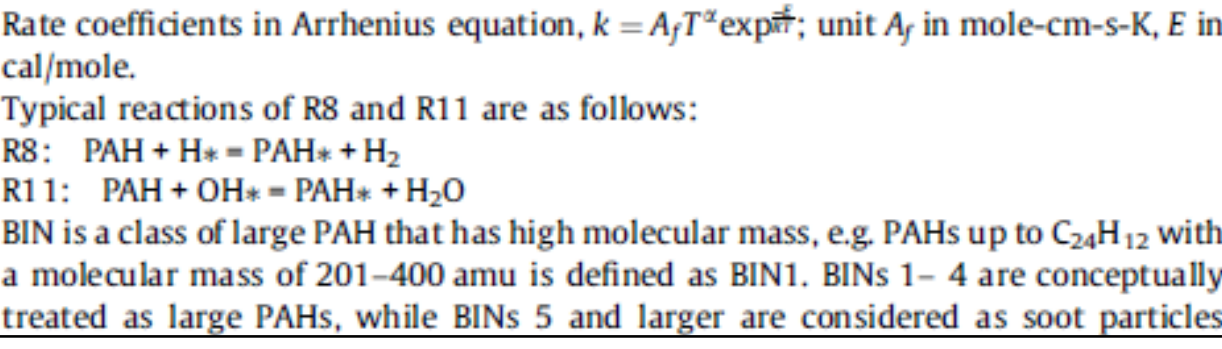 } \\
\hline
\end{tabular}

where rate, $k=A_{f} T^{\alpha} \exp (-E / \mathrm{R} T)$; units of $A=$ mole-cm-s-K and $E=\mathrm{cal} / \mathrm{mol}$

Niksa (2008) describes the coal derived soot formation mechanism used in PC Coal Lab. In secondary pyrolysis, tar and some volatiles crack to $\mathrm{PAH}$ and $\mathrm{C}_{2} \mathrm{H}_{2}$ that further react to give 
soot. But the step describing the soot formation kinetics from $\mathrm{PAH}$ and $\mathrm{C}_{2} \mathrm{H}_{2}$ is missing in the current version of PC Coal Lab. It is suggested that the soot formation from $\mathrm{PAH} / \mathrm{C}_{2} \mathrm{H}_{2}$ observed in the combustion of other fuels, may be used to determine a mechanism for soot formation.

Zhang et al. (2010) modeled soot formation from ethylene/air in a co-flow jet diffusion flame. It was assumed that $\mathrm{C}_{2} \mathrm{H}_{2}$ was the only precursor for soot nucleation and growth. They modeled the process as follows:-

Nucleation:

$$
\mathrm{C}_{2} \mathrm{H}_{2} \rightarrow 2 \mathrm{C}(\mathrm{s})+\mathrm{H}_{2}
$$

Rate: $R_{l}=k_{l}(T)\left[\mathrm{C}_{2} \mathrm{H}_{2}\right] ;\left(\mathrm{kmol} \mathrm{m}^{-3} \mathrm{~s}^{-1}\right)$

Where $k_{l}=1000 \exp (-16,103 / \mathrm{R} T) ; \mathrm{s}^{-1}$

Surface Growth

$$
C_{2} H_{2}+n C(s) \rightarrow(n+2) C(s)+H_{2}
$$

Rate: $R_{2}=k_{2}(T) A_{s}{ }^{0.5}\left[\mathrm{C}_{2} \mathrm{H}_{2}\right] ;\left(\mathrm{kmol} \mathrm{m}^{-3} \mathrm{~s}^{-1}\right)$

Where $A_{s}=$ soot surface area per unit volume and $k_{2}=1750 \exp (-10,064 / \mathrm{RT}) ; \mathrm{s}^{-1}$

Chen and Wang (2009) developed a soot formation model for a reduced diesel-surrogate fuel of n-heptane/toluene. They modeled the reaction scheme with 60 gas species and 145 reactions.

The purpose of the literature review was to determine the suitable range of parameters for an experimental study on the kinetics of soot formation from coal-derived liquids. This experimental work will be carried out as part of an on-going program at Dr. P. Wang's laboratory at DOE's NETL in Pittsburgh. The scope and number of parameters for this study are given in Appendix I 


\subsection{Uncertainty Quantification (UQ)}

UQ is a statistical technique to develop a numerical or mathematical model predicting the uncertainty in the output based on variations in input parameters. Uncertainties are mainly of two types: aleatoric or epistemic. Aleatoric or statistical uncertainties differ each time the same experiment is run. Epistemic or systematic uncertainties are due to things that cannot be measured accurately or are due to the lack of knowledge regarding the behavior of a system that could, in theory, be resolved through the introduction of additional information.

Many assumptions are made by the user when simulating a physical problem as it is very difficult to model all the complex phenomena taking place. These assumptions could make a significant difference between the model predictions and reality. This is referred to as predictive uncertainty, and the degree of this uncertainty is often a function of the ability of the model to capture the phenomena in the physical scenario of interest (Reiley et al. 2011).

Hence, it becomes necessary to understand the change in model predictions based on the variations in the user defined parameters employed in the set-up of the problem. Therefore, it is important that a good understanding of the sensitivity of the output to the input parameters is obtained before performing a UQ analysis. Many simulation practitioners can obtain a deeper understanding from their analyses by using the statistical theory on design of experiments (DOE) developed specifically for exploring computer models (Kliejnen et al., 2005). DOE can be helpful in the analysis of design cost by: speeding up the design process, reducing late engineering design changes, or reducing product material composition. DOE can also serve as a powerful tool to achieve manufacturing cost savings by minimizing process variation and reducing rework (Box et al., 1978). Accurate designs can also filter out noise and discover significant process factors.

An input or parameter in a simulation model is defined as a factor in the DOE. Also this

factor is further categorized as qualitative or quantitative; binary or non-binary; discrete or continuous; controllable or uncontrollable (Sanchez and Wan 2009). Each factor can have two or more factor levels (e.g., high and low values of an input parameter). A metamodel (or response surface, auxiliary model, emulator, etc.) is a model or approximation of this implicit input/output 
(I/O) function that characterizes the relationship between inputs and outputs in much simpler terms than the full simulation or experiment. The number of input parameters/factors and complexity of the model determines the DOE technique to be used. Figure 2.13 shows the pictorial mapping of techniques used for DOE based on the number of factors, the assumptions, and the complexity (Kliejen et al. 2005). However, it is always a trial and error method.

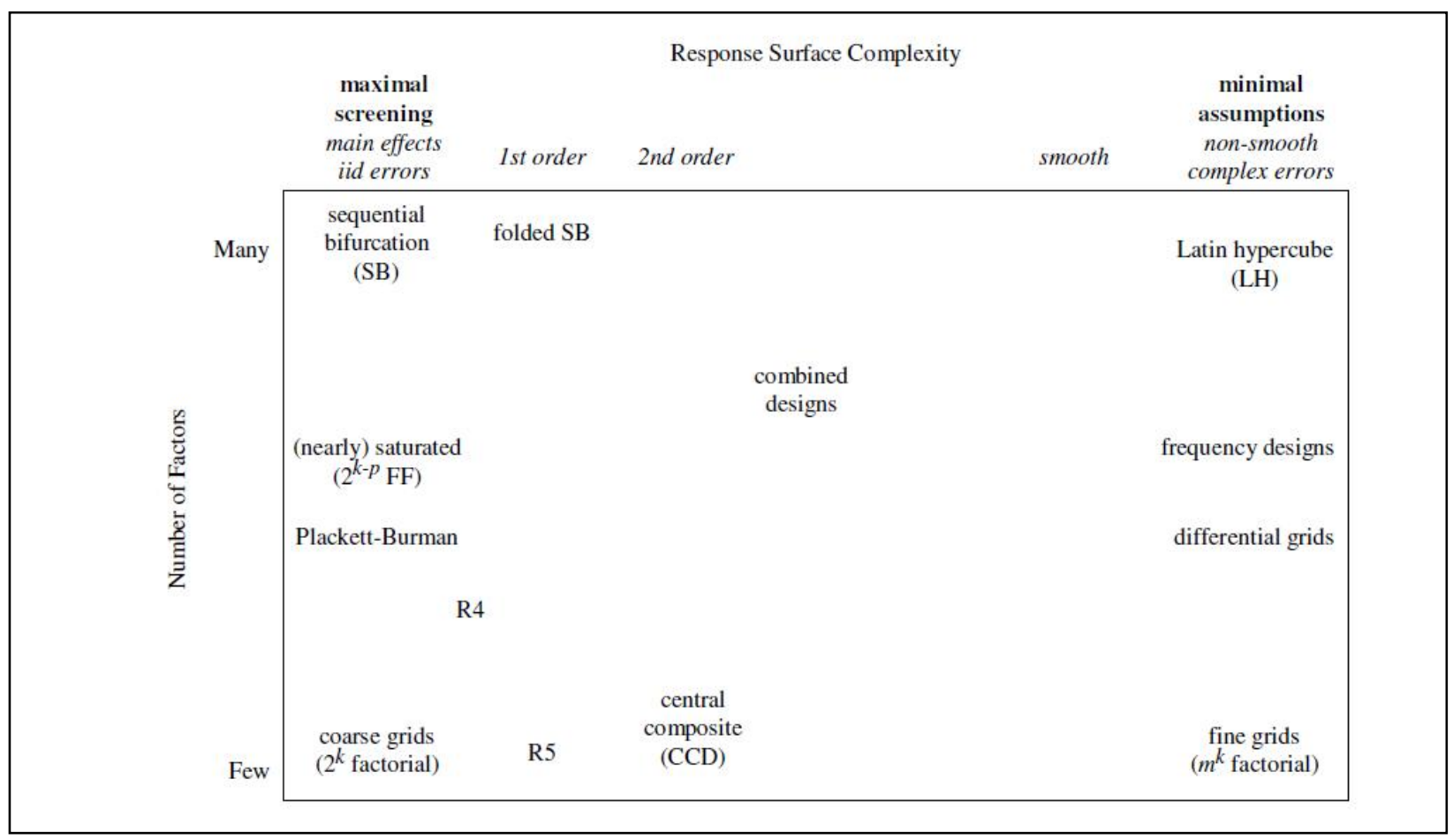

Figure 2.13: Recommended designs according to the number of factors and system complexity assumptions (Kliejen et al. 2005).

In this (Kliejen's) formulation, a design is a matrix with columns and rows; where every column corresponds to a factor; and the entries within the column are settings for this factor. Each row represents a particular combination of factor levels, and is called a design point. These levels have different notations/codes, e.g., if data are quantitative then the low and high levels are often coded as -1 and +1 , respectively.

Many designs are available in the literature (Montgomery, 1984). Figure 2.14 provides some guidelines regarding the DOE-based sample sizing, factors, and their levels (Sanchez 2008). 
The uncertainty quantification (UQ) for coal gasification processes is a unique feature provided by C3M. With the UQ tool, a user can predict and visualize the uncertainties/variations in product yields and reaction rates given the variations in operating conditions and fuel properties. This was achieved through a Monte-Carlo-type simulation consisting of multiple runs on the kinetic packages available in $\mathrm{C} 3 \mathrm{M}$ followed by the subsequent analysis of the output. This was very cheap and cost effective in terms of time and computer capability. This UQ work is ongoing and will be extended to the CFD packages in the future.

For the UQ analyses the software packages PSUADE, DAKOTA and SAS JMP along with Matlab were used. 


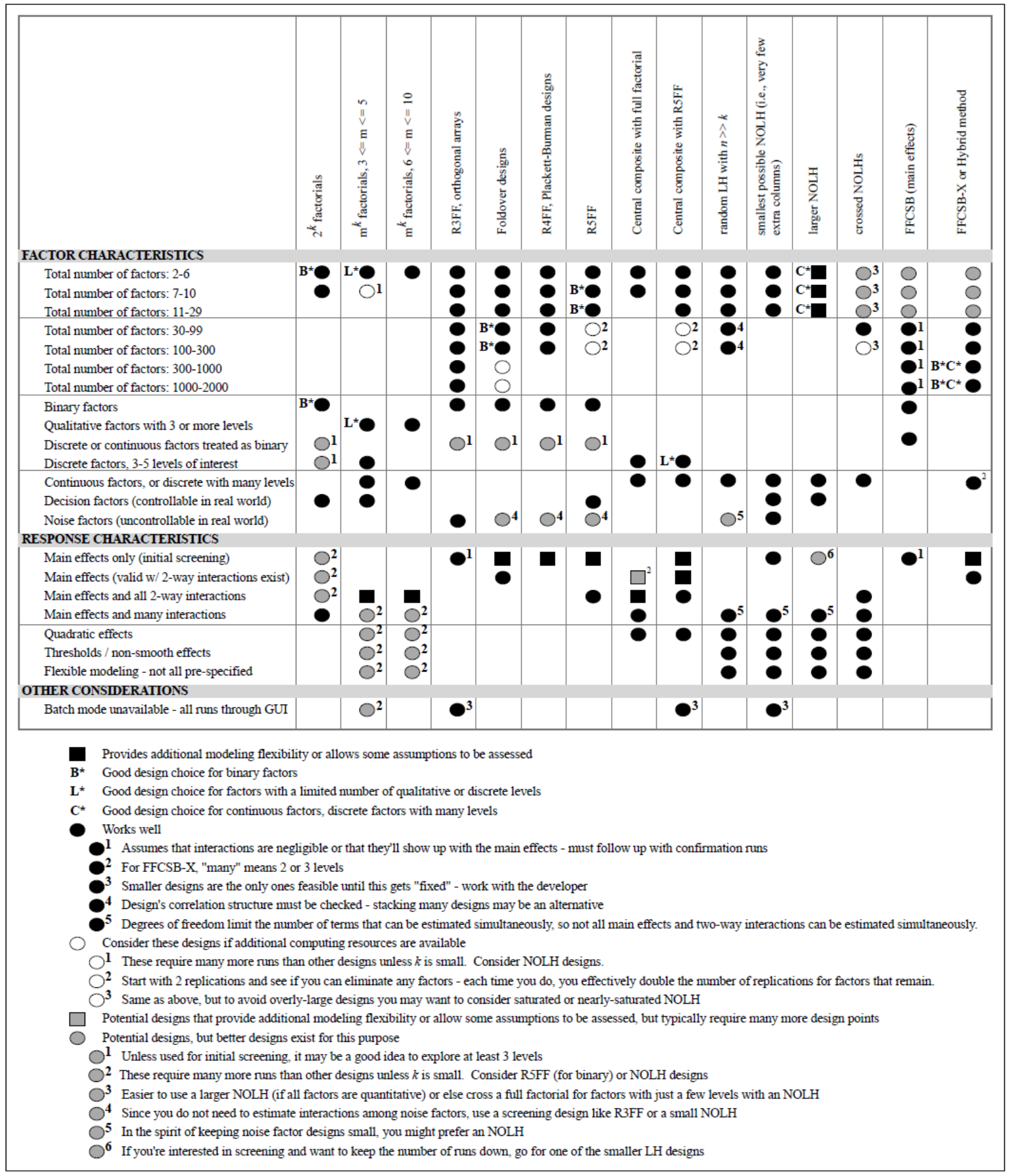

Figure 2.14: Design comparison chart (Sanchez 2008). 


\section{Chapter 3 Reactive Flow Modeling with C3M}

\subsection{Transport Flow Gasifier}

C3M provides a seamless integration between PC Coal Lab, CPD, FG-DVC, and experimental data and leading multiphase CFD solvers MFIX, ANSYS-FLUENT, and BARRACUDA.

To verify the connectivity, simulations of a simple 2-D transport flow gasifier have been performed using open source MFIX. The code used was a multi-phase approach in terms of Eulerian-Eulerian interaction, where each phase was treated as an interpenetrating continuum. MFIX solved the governing equations, including the mass, momentum, energy, and species-mass balances for each phase, gas $(m=g)$ or solids $(m=s)$ that fully account for the spatial and temporal variations in gas and solids volume fractions, velocities, and temperatures with any associated phase changes and chemical reactions, as shown in equation 3.1 to 3.5.(Syamlal et al., 1993)

$$
\begin{gathered}
\frac{\partial}{\partial \mathrm{t}}\left(\varepsilon_{m} \rho_{m}\right)+\nabla \cdot\left(\varepsilon_{m} \rho_{m} \overrightarrow{\mathrm{v}}_{m}\right)=\sum_{l=1}^{N_{m}} R_{m l} \\
\frac{\partial}{\partial \mathrm{t}}\left(\varepsilon_{m} \rho_{m} \overrightarrow{\mathrm{v}}_{m}\right)+\nabla \cdot\left(\varepsilon_{m} \rho_{m} \overrightarrow{\mathrm{v}}_{m} \overrightarrow{\mathrm{v}}_{m}\right)=\nabla \cdot \overline{\bar{S}}_{m}+\varepsilon_{m} \rho_{m} \overrightarrow{\mathrm{g}}+\sum_{n} \vec{I}_{m n} \\
\frac{3}{2} \varepsilon_{m} \rho_{m}\left(\frac{\partial \Theta_{m}}{\partial \mathrm{t}}+\overrightarrow{\mathrm{v}}_{m} \cdot \nabla \Theta_{m}\right)=\nabla \cdot \vec{q}_{\Theta_{m}}+\overline{\bar{S}}_{m}: \nabla \overrightarrow{\mathrm{v}}_{m}-\varepsilon_{m} \rho_{m} J_{m}+\prod_{\Theta_{m}} \quad(\mathrm{~m} \neq \mathrm{g}) \\
\varepsilon_{m} \rho_{m} C_{p m}\left(\frac{\partial T_{m}}{\partial \mathrm{t}}+\overrightarrow{\mathrm{v}}_{m} \cdot \nabla T_{m}\right)=-\nabla \cdot \vec{q}_{m}+\sum_{n} \gamma_{m n}\left(T_{n}-T_{m}\right)-\Delta H_{r m} \\
\frac{\partial}{\partial \mathrm{t}}\left(\varepsilon_{m} \rho_{m} X{ }_{m l}\right)+\nabla \cdot\left(\varepsilon_{m} \rho_{m} X_{m l} \overrightarrow{\mathrm{v}}_{m}\right)=R_{m l}
\end{gathered}
$$

where $m$ and $n$ represent phases, $l$ represents a species in a phase, and $C_{p m}$ represents heat capacity at constant pressure; $\Delta H_{r m}$ is the heat of reaction; $\vec{I}_{m n}$ is the momentum exchange between phases $m$ and $n ; J_{m}$ is the collisional dissipation of granular energy; $\vec{g}$ is the gravitational acceleration; $\vec{q}_{m}$ is heat flux; $\vec{q}_{\Theta_{m}}$ is granular heat flux; $R_{m l}$ is the chemical reaction rate of the $l^{\text {th }}$ species of the $m^{\text {th }}$ phase; $\overline{\bar{S}}_{m}$ is the stress tensor; $T_{m}$ is temperature; $\vec{v}_{m}$ is the 
velocity vector; $X_{m l}$ is the mass fraction of the $l^{\text {th }}$ species in the $m^{\text {th }}$ phase; $\gamma_{m n}$ is the coefficient of heat transfer between phases $m$ and $n ; \varepsilon_{m}$ is the volume fraction; $\Pi_{\Theta_{m}}$ is the dissipation of granular energy due to interaction with gas; $\rho_{m}$ is density; and $\Theta_{m}$ is granular temperature.

These equations were solved simultaneously based on numerical techniques and basic models provided online in the documentation for MFIX (Syamlal et al., 1998).

Table 3.1 gives the detail of first trial run. Figure 3.1 illustrates the geometry of the gasifier used in the simulations.

Table 3.1: Details of the 2-D transport flow gasifier simulation

\begin{tabular}{|c|c|}
\hline Dimension of the gasifier & $\mathbf{1 0} \mathbf{~ c m} \times \mathbf{4 0 0} \mathbf{~ c m}$ \\
\hline Coal type & Powder River Basin (PRB) \\
\hline Fixed carbon (\%) & 40.2 \\
\hline Volatile Matter (\%) & 32.9 \\
\hline Moisture (\%) & 22.3 \\
\hline Ash (\%) & 4.6 \\
\hline Carbon (\%) & 75.2 \\
\hline Hydrogen (\%) & 4.6 \\
\hline Oxygen (\%) & 20.2 \\
\hline Temperature & $1227^{\circ} \mathrm{C}$ \\
\hline Pressure & $2.0 \mathrm{MPa}$ \\
\hline Simulation time & $20 \mathrm{~s}$ \\
\hline
\end{tabular}

For this transport gasifier system, coal is continuously fed from the side inlet (located 30 $\mathrm{cm}$ from bottom) and air is supplied from the bottom, where all the products leave the reactor from side pressure outlet (located at $392 \mathrm{~cm}$ ). Also, recycled char and ash are circulated back (located at $14 \mathrm{~cm}$ from bottom) into the system. Purpose of this recirculation is to maintain the reactor temperature and convert all the remaining char. 


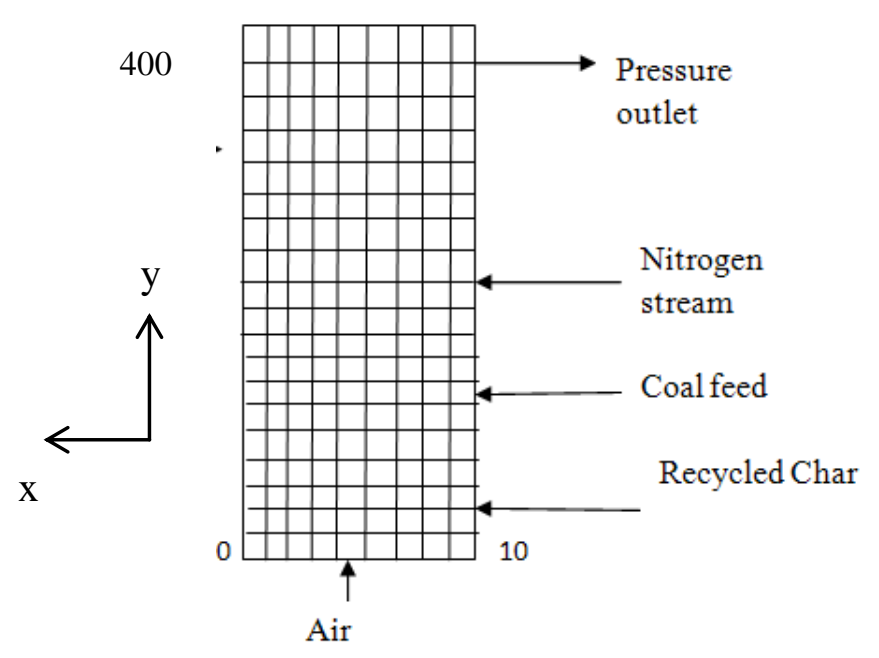

Figure 3.1: 2-D Transport Flow Gasifier

Reaction kinetics obtained from C3M which have been substituted in mfix.dat (input file for running MFIX) are shown in Table 3.2. This simulation was run as a test to check the devolatilizaiton and tar cracking kinetics behavior in the system. All other gasification and combustion reactions were turned off.

Table 3.2: Reaction kinetics obtained from C3M.

\begin{tabular}{|c|c|}
\hline Kinetic Process & Kinetic Package \\
\hline Moisture release & MGAS \\
\hline Devolatilization & CPD \\
\hline Soot formation from tar cracking & CPD \\
\hline
\end{tabular}




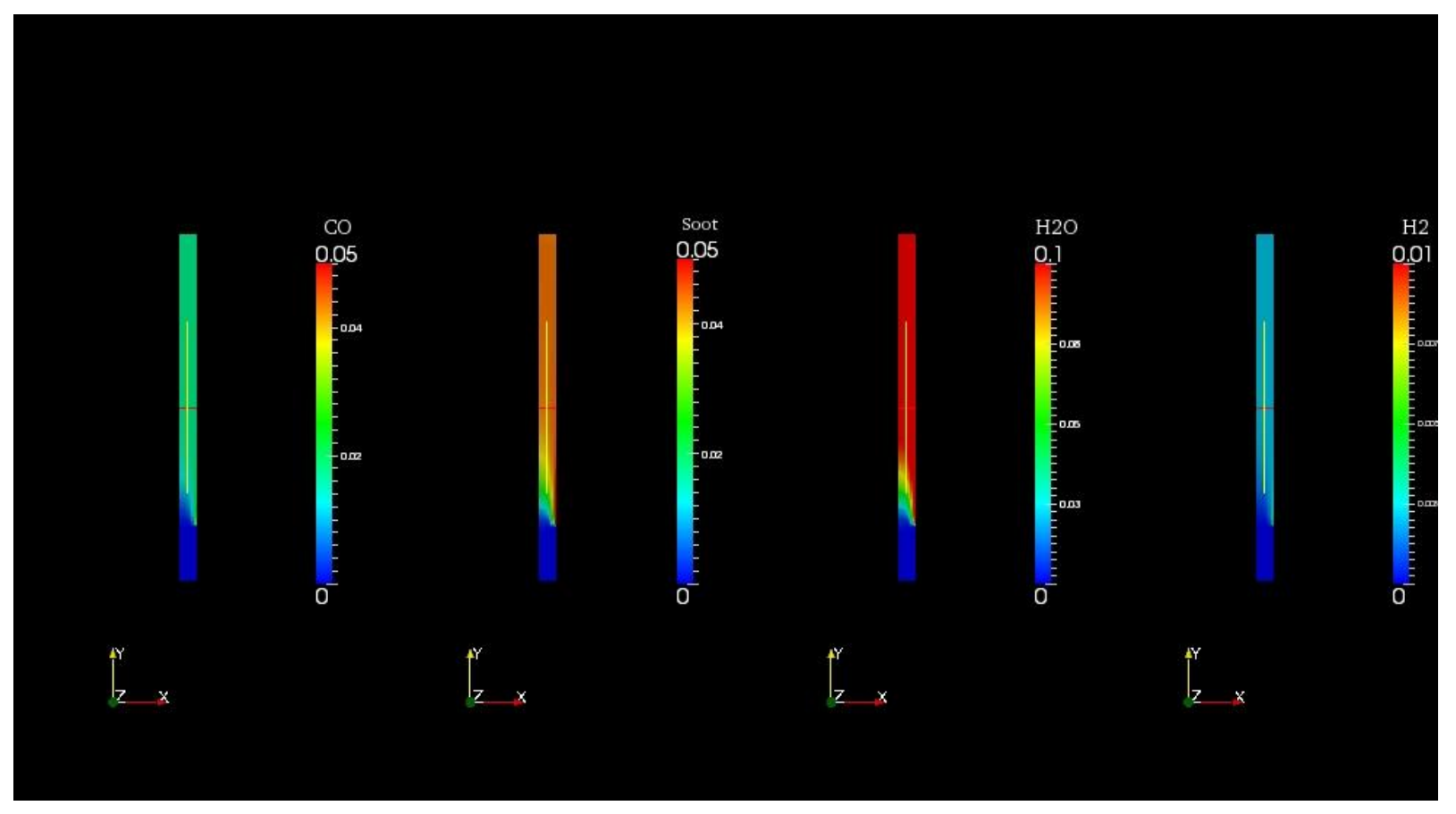

Figure 3.2: Mass fraction of gas species $\left(\mathrm{CO}\right.$, soot, $\mathrm{H}_{2} \mathrm{O}$ and $\left.\mathrm{H}_{2}\right)$ along the reactor length.

Figure 3.2 shows the mass fraction of gas species along the reactor length at $4.4 \mathrm{sec}$. The steady state is achieved after approximately $3 \mathrm{~s}$ only. It can be observed that $\mathrm{H}_{2} \mathrm{O}$ is generated from devolatilization and moisture release near the coal inlet. Soot is formed above the coal inlet during tar cracking reaction, giving the expected trend for tar cracking reaction kinetics introduced in the system. $\mathrm{H}_{2}$ and $\mathrm{CO}$ leaving the reactor are products of the devolatilization reaction. In all, the simulation is showing the expected trends based on reaction chemistry when C3M kinetics are used.

Similar 2-D transport gasifier simulations (with height of $200 \mathrm{~cm}$ ) were run with devolatilization (with soot formation) only and devolatilization with the soot oxidation reaction activated. All other heterogeneous and homogenous gasification, combustion reactions were not activated for these cases. This was a test run to check the soot formation and soot oxidation kinetics behavior of PCCL. Table 3.3 gives details of the simulation and kinetic rate expression used. 
Table 3.3: Details of the 2-D transport flow gasifier simulation

\begin{tabular}{|c|c|}
\hline Dimension of the gasifier & $\mathbf{1 0} \mathbf{c m} \times \mathbf{2 0 0} \mathbf{~ c m}$ \\
\hline Coal type & Powder River Basin (PRB) \\
\hline Fixed carbon (\%) & 32.9 \\
\hline Volatile Matter (\%) & 22.3 \\
\hline Moisture (\%) & 4.6 \\
\hline Ash (\%) & 75.2 \\
\hline Carbon (\%) & 4.6 \\
\hline Hydrogen (\%) & 20.2 \\
\hline Oxygen (\%) & 1227.0 \\
\hline Temperature ( $\left.{ }^{\circ} \mathrm{C}\right)$ & 2.0 \\
\hline Pressure (MPa) & 20.0 \\
\hline Simulation time (s) & PCCL \\
\hline Devlatilization (with soot formation) & PCCL \\
\hline Soot oxidation & \\
\hline
\end{tabular}

Figure 3.3 and Figure 3.4 show the comparison of soot and oxygen yields along the reactor length, after $3 \mathrm{sec}$ in the simulation. From Figure 3.3, it can be seen that when there is no soot oxidation, soot is formed near coal inlet during devolatilization and leaves the reactor without reacting. On other hand, when soot oxidation kinetics are turned on the soot oxidizes rapidly. Figure 3.4 also shows the expected trend for oxygen consumption when the soot oxidation reaction is turned on.

Outputs in both cases are not compared to any experimental data as the purpose of these simulations was to show how the fully functional CFD models performed using C3M kinetics and to observe the appropriate trends for the respective gas and solid species. 


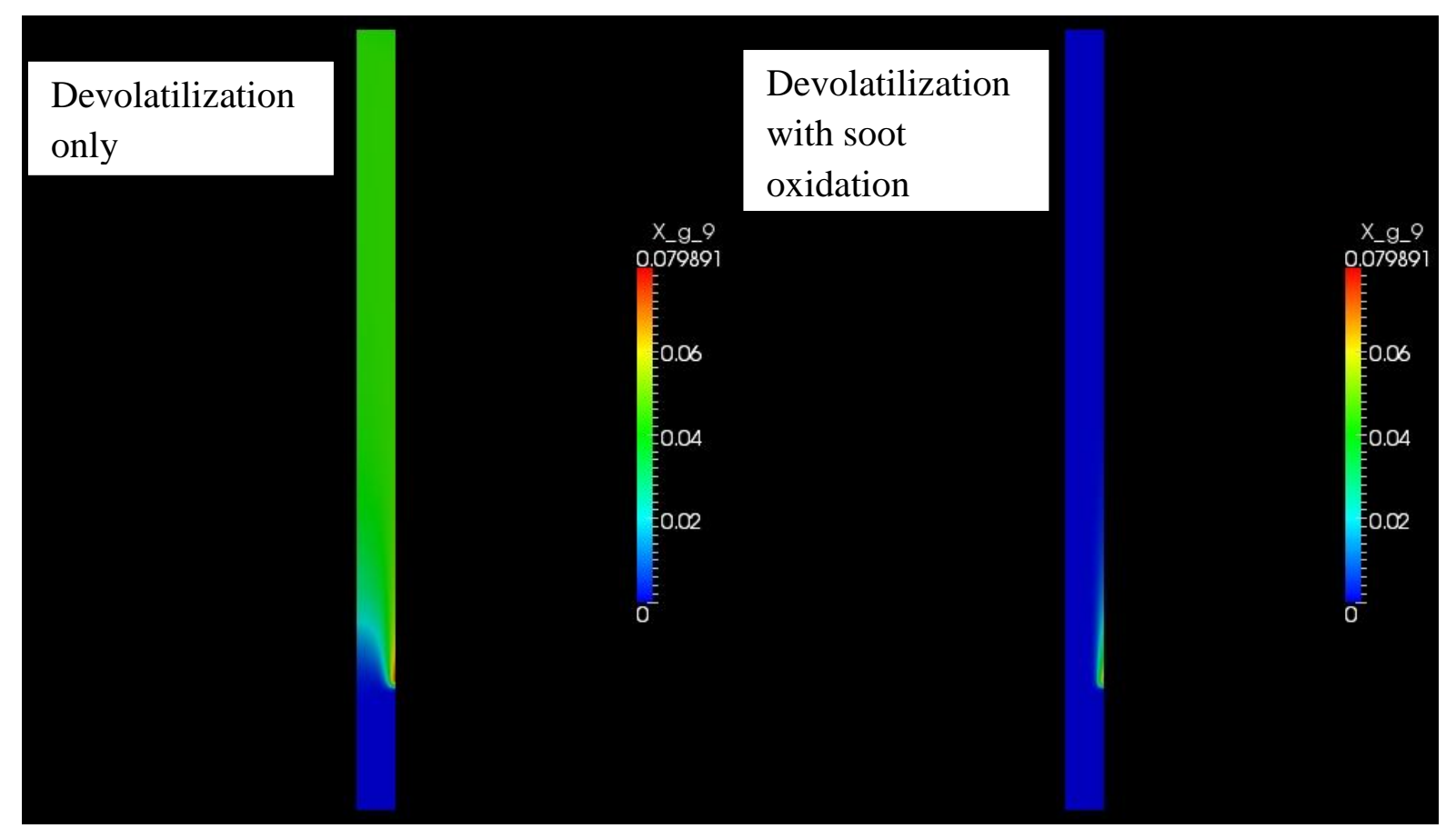

Figure 3.3: Mass fraction of soot along the reactor length.

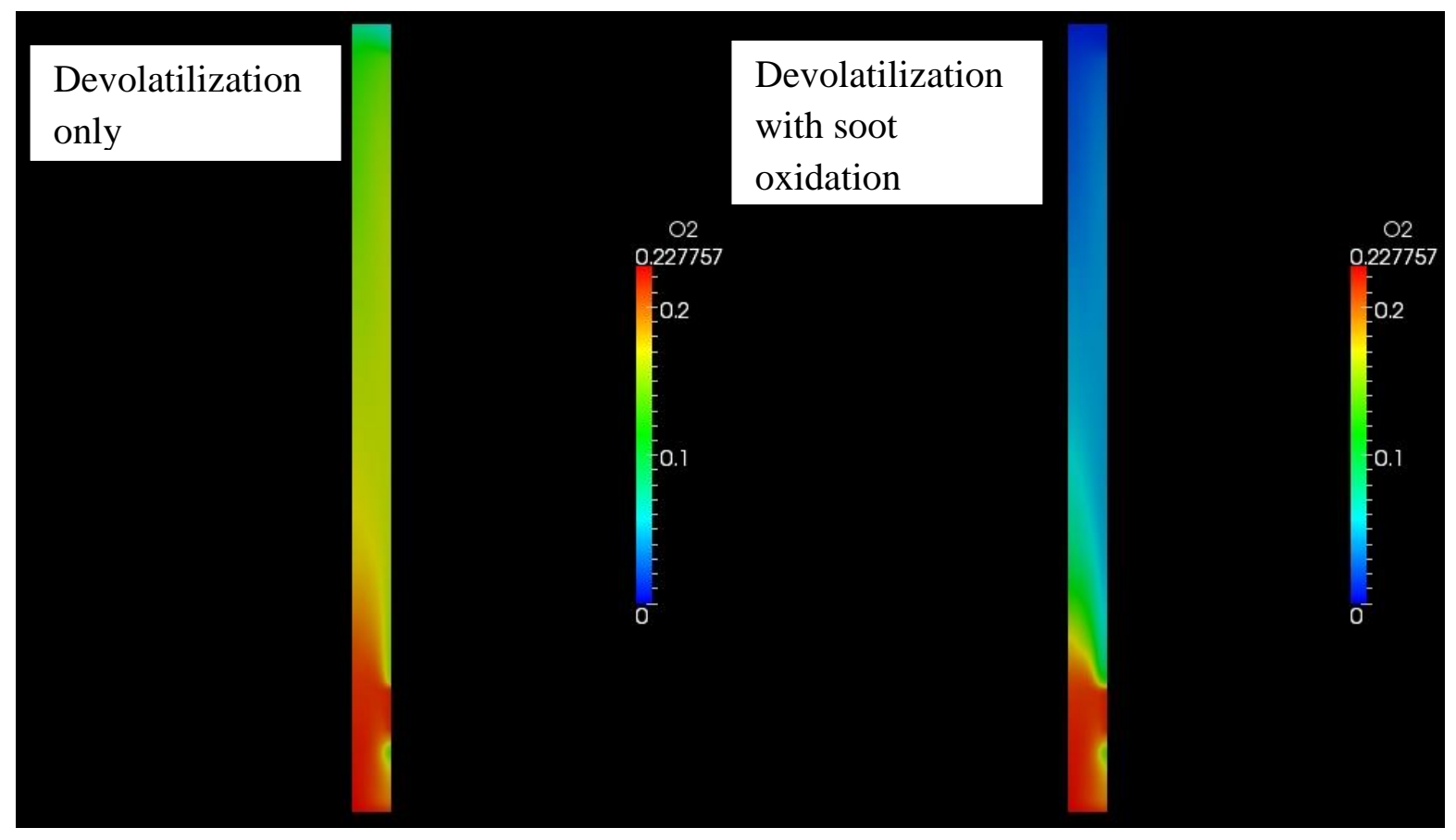

Figure 3.4: Mass fraction of $\mathrm{O}_{2}$ along the reactor length. 


\subsection{Entrained Flow Gasifier}

C3M does not have the capability to transfer appropriate reaction kinetics to ASPEN Plus (or any other process simulation) software, but as mentioned previously, it can be used as a data bank for coal gasification kinetics. The accuracy of coal gasification kinetics derived from C3M was tested using a 1-D steady-state entrained-flow gasifier model developed by Kasule et al. (2012) in Aspen Dynamics. The model simulates a downward, entrained-flow, slurry-fed, oxygen-blown (GEE-Texaco type) gasifier. Figure 3.5 shows the schematic of the gasifier modeled in this study.

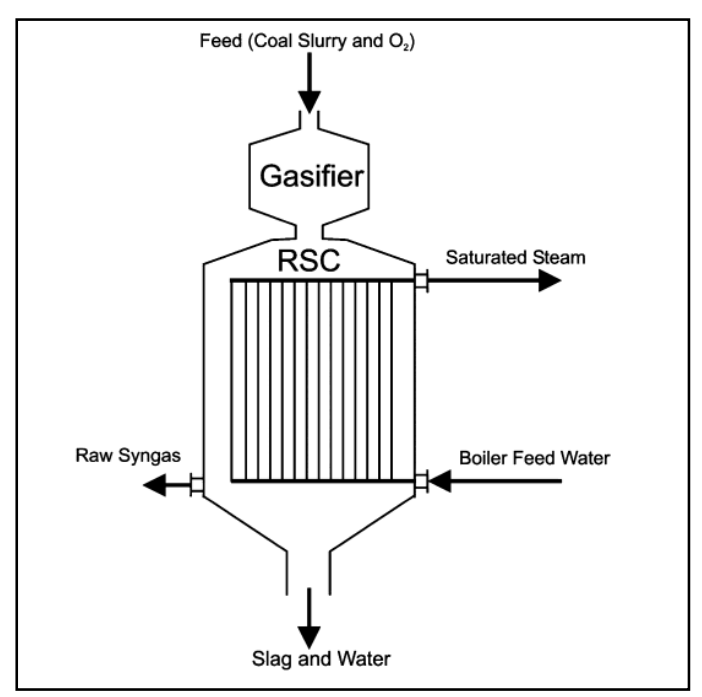

Figure 3.5: Schematic of the GEE-Texaco gasifier with RSC (Kasule et al.,2012)

A detailed description of the model, with the assumptions and the numerical techniques used, has been described previously in Kasule et al. (2012) and Kasule (2012). The model considers the following coal gasification reactions: moisture release, devolatilization, tar cracking, char combustion, char gasification (with $\mathrm{H}_{2} \mathrm{O}, \mathrm{CO}_{2}$, and $\mathrm{H}_{2}$ ) along with the water gas shift reaction. 


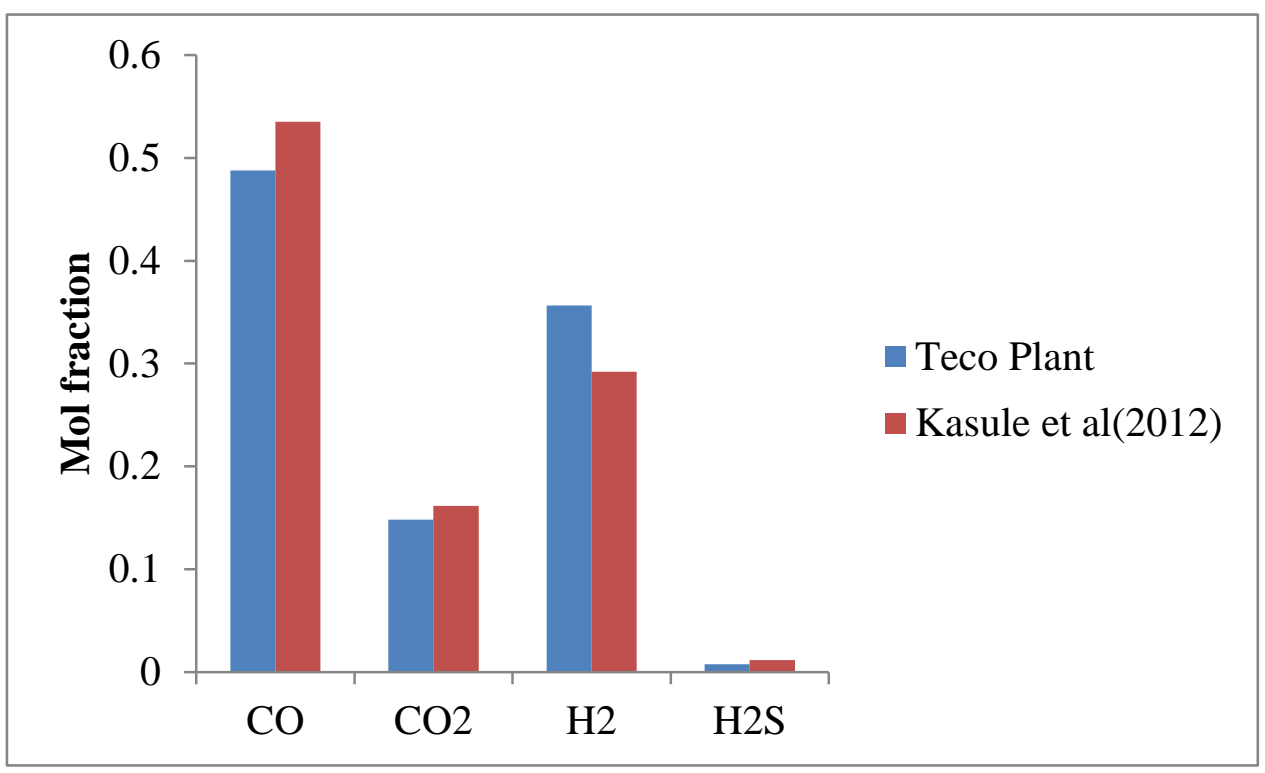

Figure 3.6: Exit gas composition of TECO gasifier $\mathrm{CH} 4$ free and dry basis (Kasule et al., 2012)

The reaction kinetics for all these reactions were derived from MGAS kinetics (Syamlal and Bissett, 1992). Using these kinetics, the original model not only over predicts $\mathrm{CO}, \mathrm{CO}_{2}$ but also under predicts the $\mathrm{H}_{2}$ at the exit of the gasifier when compared to the reported data, as shown in Figure 3.6. The aim of this study was to improve the model predictions using the coal gasification kinetics from C3M. Table 3.4 gives the properties of Illinois No. 6 coal used in the simulation. The gasifier was operated at a coal: oxygen: steam ratio of 1: $0.82: 0.41$ and at an inlet pressure of $2.45 \mathrm{MPa}$. 
Table 3.4 : Proximate and Ultimate Analysis of Illinois \# 6 coal

\begin{tabular}{|c|c|}
\hline Component & \% composition as received \\
\hline Volatile Matter & 34.99 \\
\hline Fixed Carbon & 44.19 \\
\hline Moisture & 11.12 \\
\hline Ash & 9.70 \\
\hline Carbon & 63.75 \\
\hline Hydrogen & 4.50 \\
\hline Oxygen & 6.88 \\
\hline Nitrogen & 1.25 \\
\hline Sulfur & 2.51 \\
\hline
\end{tabular}

Products of devoltilization reaction directly affect the homogeneous and heterogeneous reactions in the gasifier (Naik et al.1996; Chaudhari, 2010; Li et al., 2012). Also MGAS gasification kinetics needed modifications to match the experimental data in the past ( $\mathrm{Li}$ et al,, 2012). Hence in evaluating the effects of different kinetics on the steady state model of Kasule et al. (2012), two approaches were used. In the first approach, only devolatilization kinetics from PCCL were substituted in the model, where in the second approach along with devolatilization, char $\mathrm{CO}_{2}$ and $\mathrm{H}_{2} \mathrm{O}$ gasification kinetics obtained from PCCL were modified in the original ACM model. The different approaches were used to test the best kinetics blend possible in improving model predictions. This also helps in analyzing sensitivity of the devolatilization and gasification kinetics towards model predictions.

Approach I: Substitution of Devolatilization kinetics from PCCL

In this test, only devoaltilization reaction kinetics were modified using the kinetics from PCCL, all other reaction kinetics were kept unchanged in the model. Two cases were tested with this approach. In the first case, $\mathrm{H}_{2} \mathrm{~S}$ formation was lumped into tar. In the second case, $\mathrm{H}_{2} \mathrm{~S}$ was considered as a devolatilization product. PCCL was run via C3M for Illinois No. 6 coal for a 
reactor temperature of $1527^{\circ} \mathrm{C}$ and a heating rate of $1000^{\circ} \mathrm{C} / \mathrm{s}$ at $2.45 \mathrm{MPa}$ pressure. Single first order reaction (SFOR) kinetics were used to model the devolatilization in the original model. Hence, Arrhenius constant (A), activation energy (E) and mass fractions of gas species along with tar molecular weight were extracted from the PCCL runs. All hydrocarbons higher than $\mathrm{CH}_{4}$ were lumped into $\mathrm{CH}_{4}$ (Chaudhari, 2010). These parameters were substituted into the model. Table 3.5 shows the parameters substituted in the model for both the cases.

Table 3.5: Devolatilization reaction kinetics parameters

\begin{tabular}{|c|c|c|}
\hline Parameter & Case I (without $\left.\mathbf{H}_{2} \mathbf{S}\right)$ & Case II (with $\left.\mathbf{H}_{2} \mathbf{S}\right)$ \\
\hline A (1/s) & 216 & 216 \\
\hline E (cal/mol) & 7,430 & 7,430 \\
\hline Tar M.W. & 214.4 & 214.4 \\
\hline Mass Fraction_CO & 0.0469 & 0.0469 \\
\hline Mass Fraction_CO ${ }_{2}$ & 0.0446 & 0.0446 \\
\hline Mass Fraction_CH & 0.2031 \\
\hline Mass Fraction_H ${ }_{2}$ & 0.2031 & 0.0415 \\
\hline Mass Fraction_H ${ }_{2} \mathrm{O}$ & 0.0415 & 0.1228 \\
\hline Mass Fraction_Tar & 0.1228 & 0.4777 \\
\hline Mass Fraction_H $2 \mathrm{~S}$ & 0.5411 & 0.0634 \\
\hline
\end{tabular}




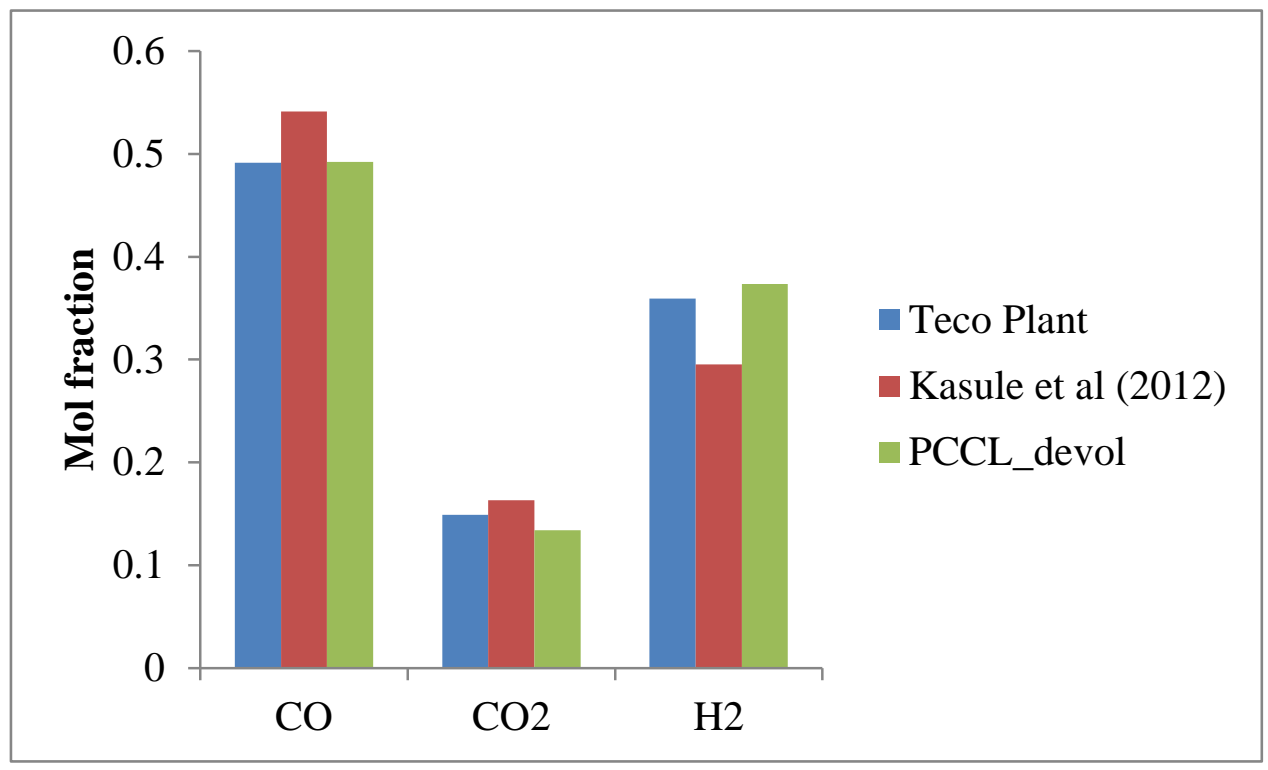

Figure 3.7: Exit gas composition with modified devoltilization, $\mathrm{CH}_{4}$ free, $\mathrm{H}_{2} \mathrm{~S}$ free, and dry basis

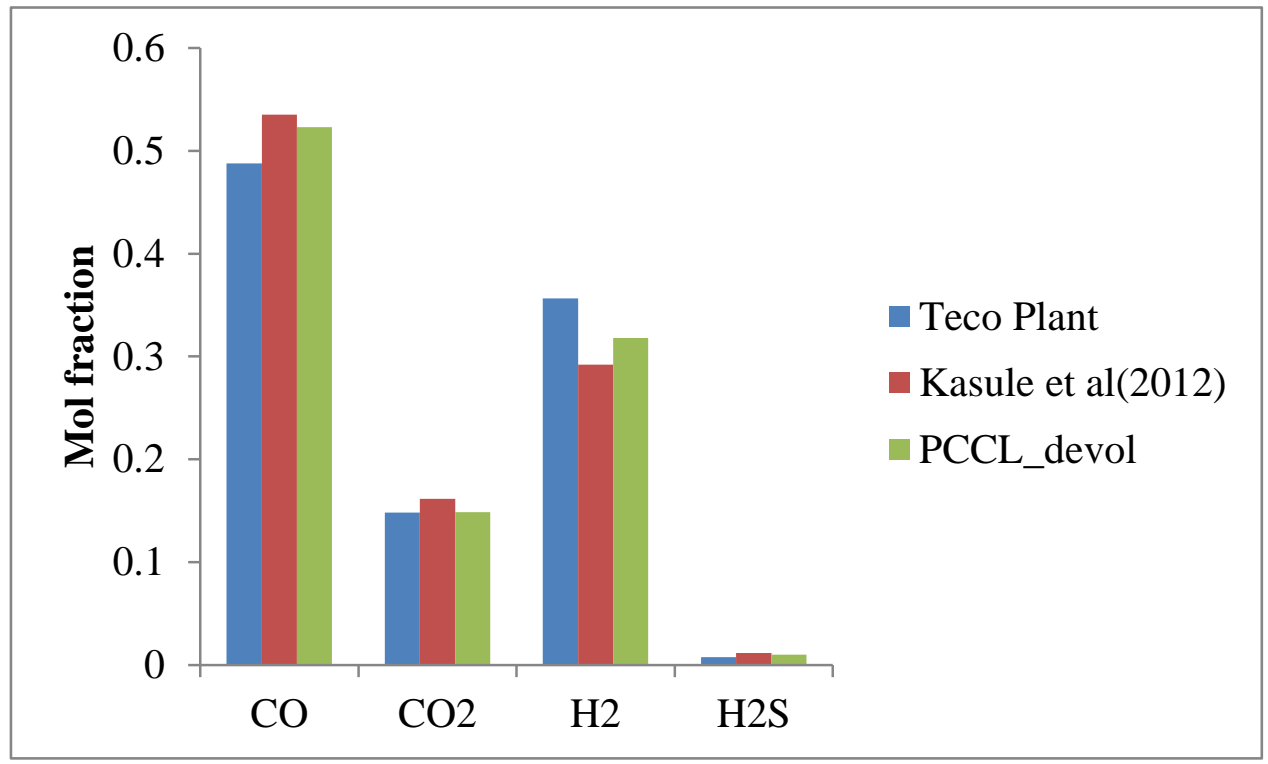

Figure 3.8: Exit gas composition with modified devoltilization, $\mathrm{CH}_{4}$ free, and dry basis

Figure 3.7 shows the exit gas composition of the gasifier on a $\mathrm{CH}_{4}$-free, $\mathrm{H}_{2} \mathrm{~S}$-free, and dry basis. It can be seen that the predictions of the original model has been significantly improved 
when PCCL devolatilizaiton kinetics were used. Also, when $\mathrm{H}_{2} \mathrm{~S}$ formation is considered in the devolatilization step, the model with PCCL devolatilizaiton kinetics captures the $\mathrm{H}_{2} \mathrm{~S}$ and $\mathrm{CO}_{2}$ predictions closely, while predictions of $\mathrm{CO}$ and $\mathrm{H}_{2}$ are improved by an appreciable amount compared to the original model. This can be seen in Figure 3.8.

When $\mathrm{H}_{2} \mathrm{~S}$ formation is not considered in devolatilization the errors in predictions from the model of Kasule et al. (2012) were reduced from $9.6 \%$ to $0.6 \%$ for $\mathrm{CO}, 9.0$ to $1.7 \%$ for $\mathrm{CO}_{2}$ and $18 \%$ to $3 \%$ for $\mathrm{H}_{2}$; with conversion of $95.44 \%$. When $\mathrm{H}_{2} \mathrm{~S}$ formation is considered the error for $\mathrm{CO}$ was $7 \%, \mathrm{CO}_{2}$ was $0.3 \%$ and for $\mathrm{H}_{2}$ it was $10 \%$ with conversion of $90.75 \%$. Hence when $\mathrm{H}_{2} \mathrm{~S}$ formation was not considered syngas predicitons showed better improvement.

\section{Approach II: Substitution of devolatilization along with char $\left(\mathrm{CO}_{2}\right.$ and $\left.\mathrm{H}_{2} \mathrm{O}\right)$ gasification reaction kinetics using PCCL}

In this approach, devolatilization (w/o $\mathrm{H}_{2} \mathrm{~S}$ formation), char, $\mathrm{CO}_{2}$, and $\mathrm{H}_{2} \mathrm{O}$ gasification kinetics obtained from PCCL were substituted into the model and the exit gas compositions were compared. The char- $\mathrm{H}_{2}$ gasification is several orders of magnitude slower than both the steam and $\mathrm{CO}_{2}$ char gasification rates (Syamlal and Bissett, 1992); hence, it was unchanged in the model. PCCL reports the simple $n^{\text {th }}$ order reaction (SNOR) kinetics for gasification, so the gasification reaction kinetics were modified in the model to be of the SNOR form.

The SNOR kinetics from PCCL has following form for char $\mathrm{CO}_{2}$ and $\mathrm{H}_{2} \mathrm{O}$ gasification:

$$
\begin{aligned}
R_{\mathrm{CO}_{2}} & =v \cdot \frac{A_{\mathrm{CO}_{2}} \exp \left(-E_{\mathrm{CO}_{2}} / R T\right) P_{\mathrm{CO}_{2}}^{n}}{1+K_{\mathrm{CO}} P_{\mathrm{CO}}} \\
R_{\mathrm{H}_{2} \mathrm{O}} & =v \cdot \frac{A_{\mathrm{H}_{2} \mathrm{O}} \exp \left(-E_{\mathrm{H}_{2} \mathrm{O}} / R T\right) P_{\mathrm{H}_{2} \mathrm{O}}^{n}}{1+K_{\mathrm{H}_{2}} P_{\mathrm{H}_{2}}}
\end{aligned}
$$

where $A_{\mathrm{CO} 2}, E_{\mathrm{CO} 2}, A_{\mathrm{H} 2 \mathrm{O}}, E_{\mathrm{H} 2 \mathrm{O}}$, and $n$ are the pre-exponential factor, activation energy and reaction order for gasification by $\mathrm{CO}_{2}$ and $\mathrm{H}_{2} \mathrm{O}$, respectively; $K_{C O}$ and $K_{H 2}$ are the rate constant for $\mathrm{CO}$ and $\mathrm{H}_{2}$ inhibition, which is independent of temperature; and $P_{\mathrm{CO}}, P_{\mathrm{CO}}, P_{\mathrm{H} 2 \mathrm{O}}, P_{\mathrm{H} 2}$ are the instantaneous $\mathrm{CO}_{2}, \mathrm{CO}, \mathrm{H}_{2} \mathrm{O}$ and $\mathrm{H}_{2}$ partial pressures (in atm) on the particle surface. $\vartheta$ is an annealing factor which represents the joint impact of the main inhibitory mechanisms that 
decelerate the char gasification rate with conversion, including annealing, random pore evolution, and char density changes.

PCCL was run at a temperature of $1527^{\circ} \mathrm{C}$ and a pressure of $2.45 \mathrm{MPa}$ for $100 \% \mathrm{CO}_{2}$ and $100 \% \mathrm{H}_{2} \mathrm{O}$ as gasification agents, respectively. The reaction parameters for gasification reactions substituted in the model are tabulated in Table 3.6, while for devolatilization the same parameters were used as reported in Table 3.5 above.

Table 3.6: Gasification reaction parameters from PCCL

\begin{tabular}{|c|c|c|}
\hline Parameter & $\mathbf{C O}_{\mathbf{2}}$ gasification & $\mathbf{H}_{\mathbf{2}} \mathbf{O}$ gasification \\
\hline$A(1 / \mathrm{atm} . \mathrm{s})$ & 754 & 3,670 \\
\hline$E(\mathrm{cal} / \mathrm{mol})$ & 37,200 & 36,100 \\
\hline$n$ & 0.02 & 0.21 \\
\hline Annealing Factor & 3.15 & 5.95 \\
\hline
\end{tabular}

The converged solution for the model when $\mathrm{H}_{2} \mathrm{~S}$ in not considered in devolatilization is reported in Figure 3.9, while Figure 3.10 reports exit composition when $\mathrm{H}_{2} \mathrm{~S}$ is considered in devolatilization. It was found that when $\mathrm{H}_{2} \mathrm{~S}$ formation is not considered the error in the model for $\mathrm{CO}$ was $1.9 \%$, for $\mathrm{CO}_{2}$ was $1.1 \%$ and for $\mathrm{H}_{2}$ it was $3.2 \%$ with carbon conversion of $96.84 \%$, but when $\mathrm{H}_{2} \mathrm{~S}$ formation was considered the error for $\mathrm{CO}$ was $8.2 \%$, for $\mathrm{CO} 2$ was $7.1 \%$ and $\mathrm{H}_{2}$ it was $14 \%$, with carbon conversion of $91.80 \%$.

Comparing the errors in predictions, Approach I is recommended over Approach II, because it seems that exit gas composition is more sensitive towards devolatilization reaction kinetics and product yields compared to gasification kinetics in entrained flow gasifier conditions tested. Also PCCL devolatilization kinetics with combination MGAS gasification and combustion kinetics give better predictions for this 1-D steady state model. 


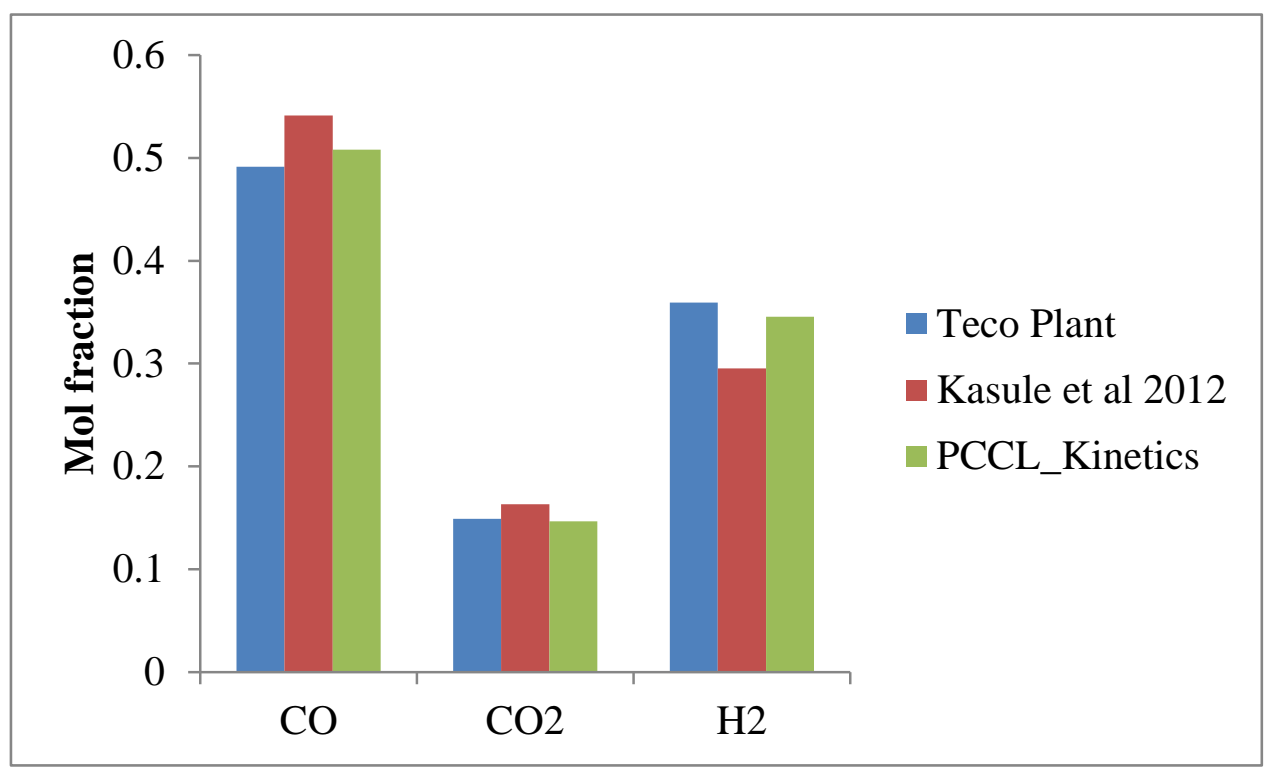

Figure 3.9: Exit gas composition with modified devoltilization and $\mathrm{CO}_{2} / \mathrm{H}_{2} \mathrm{O}$ char gasification kinetics, $\mathrm{CH}_{4}$ free, $\mathrm{H}_{2} \mathrm{~S}$ free and dry basis

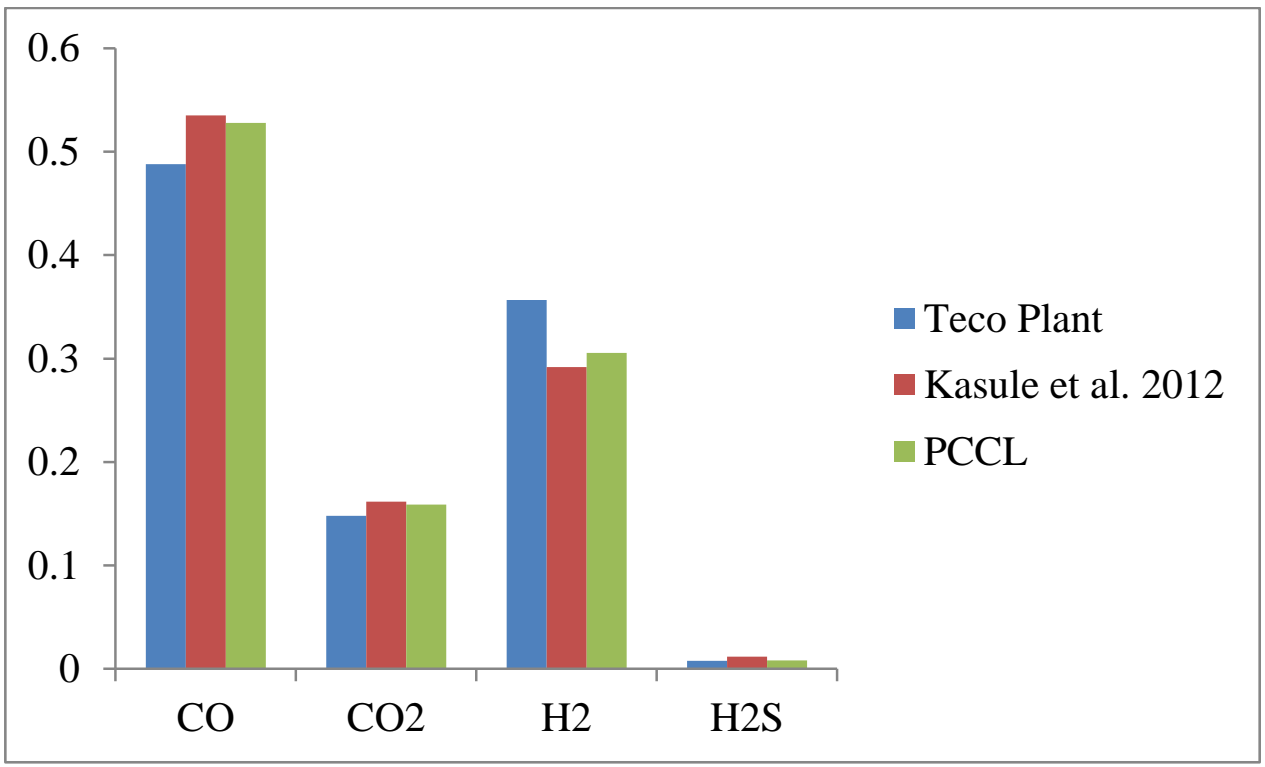

Figure 3.10: Exit gas composition with modified devoltilization and $\mathrm{CO}_{2} / \mathrm{H}_{2} \mathrm{O}$ char gasification kinetics, $\mathrm{CH}_{4}$ free, and dry basis

From these results, it can be concluded that $\mathrm{C} 3 \mathrm{M}$ provides improved kinetic information to simulate coal gasifier systems for the given operating conditions shown here. 


\section{Chapter 4 : Uncertainty Quantification (UQ) Analysis}

Non-intrusive parametric input uncertainty propagation is one of the uncertainty quantification techniques employed in numerical or mathematical models to predict the effect of the uncertainty on output due to variations in input parameters. The current study focused on capturing the input parameter uncertainties affecting the chemical reactions taking place during coal gasification. The UQ for coal gasification processes can be used to predict the uncertainties/variations in product yields and reaction rates given the variations in operating conditions and fuel properties

Among all of the reactions in coal conversion, coal devolatilization can account for up to $70 \%$ of the loss in weight of the coal (Serio et al., 1987). This process depends on the organic properties of the coal. The quantity of volatiles released during pyrolysis impacts the char's heterogenous and gas phase homogeneous reaction chemistry. Various studies (Chaudhari, 2010; Khan, 1984; Manton et al., 2004; Fermosa et al., 2011) have reported that operating conditions such as temperature, pressure, heating rate, particle diameter, residence time, and coal rank can affect the coal devolatilization reaction kinetics. Hence, it is crucial to obtain kinetics and product yields for devolatilization by considering the effects of these parameters. Experimental investigations have been done in the past, as described in Section 2.2, to address these effects.

In a given gasifier reactor system, different temperature zones will exist in the gasifier. In addition, it may be difficult to measure the exact temperature of particles inside the reactor. Therefore, a coal particle may experience a range of heating rates in an actual gasifier and it is hard to predict the exact heating rate for the coal particle. Even though the variation in these key conditions in the reactor will cause quite different reaction rates to occur, there have been few studies carried out to model these uncertainties in coal-based systems. The commercial kinetic package, PCCL, can predict the effect of heating rate, temperature and pressure on coal devolatilization (Niksa, 2008). Hence it was chosen as the source to generate the coal devolatilization kinetics data over the range of uncertainties prescribed by the operating conditions. Section 4.1 describes the UQ approach to capture the uncertainties of heating rate, pressure and temperature on coal devolatilization in terms of variations in product yield. 
The main task after analyzing the uncertainties propagation is to build a model that can predict the variations in output yields based on variations introduced in the inputs. In current CFD simulation codes it is quite difficult to back calculate the heating rate for the particle. Although the pressure in the reactor remains fairly constant, the temperature may vary widely over the length of the gasifier. Therefore, efforts were made to try to capture uncertainties in temperature on coal gasification kinetics. In this study the effect of temperature on devolatilization reaction rate parameters was studied. Based on the kinetic information generated from PCCL for a prescribed temperature range, a kinetic sub-model was developed for coal devolatilization reaction that captured the effect of temperature on coal devolatilization behavior. Section 4.2 gives the approach and methodology used to develop this sub-model. Subsequently, a 1-D entrained flow gasifier model (discussed in section 3.2) was tested using this sub-model by comparing the model results with experimental data.

In addition to the operating conditions within a gasifier, the properties of the feed coal may vary widely, which will depend strongly on the origin of the coal (Liu et al., 2003). Coal properties are determined empirically by coal quality tests, such as, proximate analysis (volatile matter, fixed carbon, moisture, and ash), ultimate analysis (mainly \% Carbon, Hydrogen, Oxygen, Nitrogen, Sulfur) and calorific value (Diez et al. 2005). In most of the cases, the blending of coals affects coal quality, leading to a decrease in combustion efficiency and unexpected slag formation behavior (Perata et al., 2001). The review article by Collot (2006) reports that coal composition and rank can significantly affect the syngas composition at the exit of the gasifier systems. This makes the composition of coal a key parameter to be considered in coal gasifier uncertainty modeling. Variations in coal composition in terms of proximate or ultimate analyses can directly affect the coal reaction chemistry, leading to changes in exit gas composition over a wide range. Hence it is necessary to capture this effect.

In previous coal gasifier CFD or process modeling, the coal composition fed to the system always remains constant for a particular run. This makes it very difficult to introduce any surrogate model to predict uncertainties initiated due to coal composition variation. One approach adopted to address this issue was to run multiple CFD runs with different coal feeds of same coal type and analyze the exit gas composition after steady state. The output data will serve as a baseline to correlate the range in uncertainties to coal composition variations. Section 
4.3, reports the coal feed variation captured using CFD runs in a transport flow gasifier for four coal types namely Pittsburgh No.8, Illinois No.6, PRB and Lignite coal.

Continuing with this analysis, the effect of coal blending for the same coal type was tested in both a transport and an entrained flow gasifier. Section 4.4 gives an overview of the sensitivity of product gas composition to coal blending of Pittsburgh No.8 coal and Illinois No. 6 coals in transport flow and entrained gasifier, respectively.

\subsection{Effect of Operating Conditions on Devolatilization Kinetics}

One objective of using UQ in this work is to predict the uncertainties/variations in product yields $\left(\mathrm{CO}, \mathrm{CO}_{2}, \mathrm{H}_{2} \mathrm{O}, \mathrm{H}_{2}\right.$, tar, $\left.\mathrm{CH}_{4}, \mathrm{VM}\right)$ and devolatilization reaction rates reported by PCCL with prescribed variability in the operating conditions (pressure, temperature and heating rate) for PRB coal.

\subsubsection{Sampling Method}

The first step required in the UQ analysis is to establish a run matrix, which is done using a Design of Experiments (DOE) or a Monte-Carlo-simulation-based approach. The objective of the simulation, for this case, is to assess the effect of three factors; namely pressure, temperature, and heating rate - on the devolatilization product yields predicted by PCCL.

When utilizing the DOE approach, the important task is to select a factorial method by which sampling will be done for this run matrix. The objective is to ensure that most of the possibilities, in terms of sample points in a given range of the variable, are covered. The mean and standard deviation selected for the three factors based on typical transport gasifier operating conditions are given in Table 4.1. For the factorial method, the high- and low-level limits of the parameters are; heating rate $\left(2000-4000{ }^{\circ} \mathrm{C} / \mathrm{s}\right)$, temperature $\left(700-900^{\circ} \mathrm{C}\right)$, and pressure $(1500$ $2500 \mathrm{kPa}$ ). For simplicity, it is assumed that all these factors have normal distributions. 
Table 4.1: Factors values for the UQ analysis used in the current work

\begin{tabular}{|c|c|c|}
\hline Factor/variable & Mean & Std Dev \\
\hline Temperature $\left({ }^{\circ} \mathrm{C}\right)$ & 800 & 100 \\
\hline Heating rate $\left({ }^{\circ} \mathrm{C} / \mathrm{s}\right)$ & 3000 & 1,000 \\
\hline Pressure $(\mathrm{kPa})$ & 2,000 & 500 \\
\hline
\end{tabular}

When a central composite design is selected with two center points, a matrix of 16 run points is obtained, as shown in Figure 4.1. It can be seen that although the data set covers the major range, the major area is not covered completely.

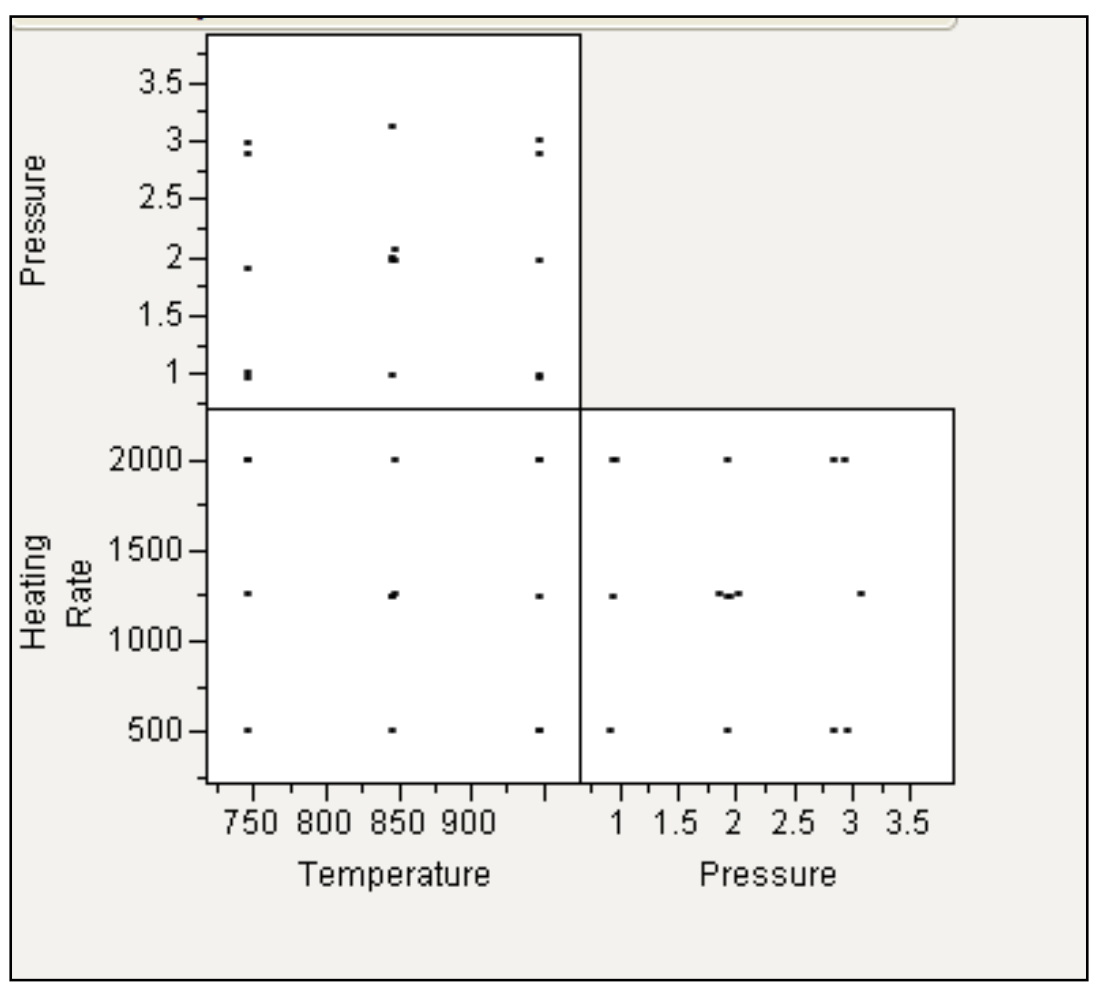

Figure 4.1: Scatter plot matrix using CCD 
When a full factorial design with two center points is selected, a run matrix consisting of 10 sample points is generated. Figure 4.2 shows the sampling points in a scatterplot. Here again, the majority of the area, in desired range, is not covered.

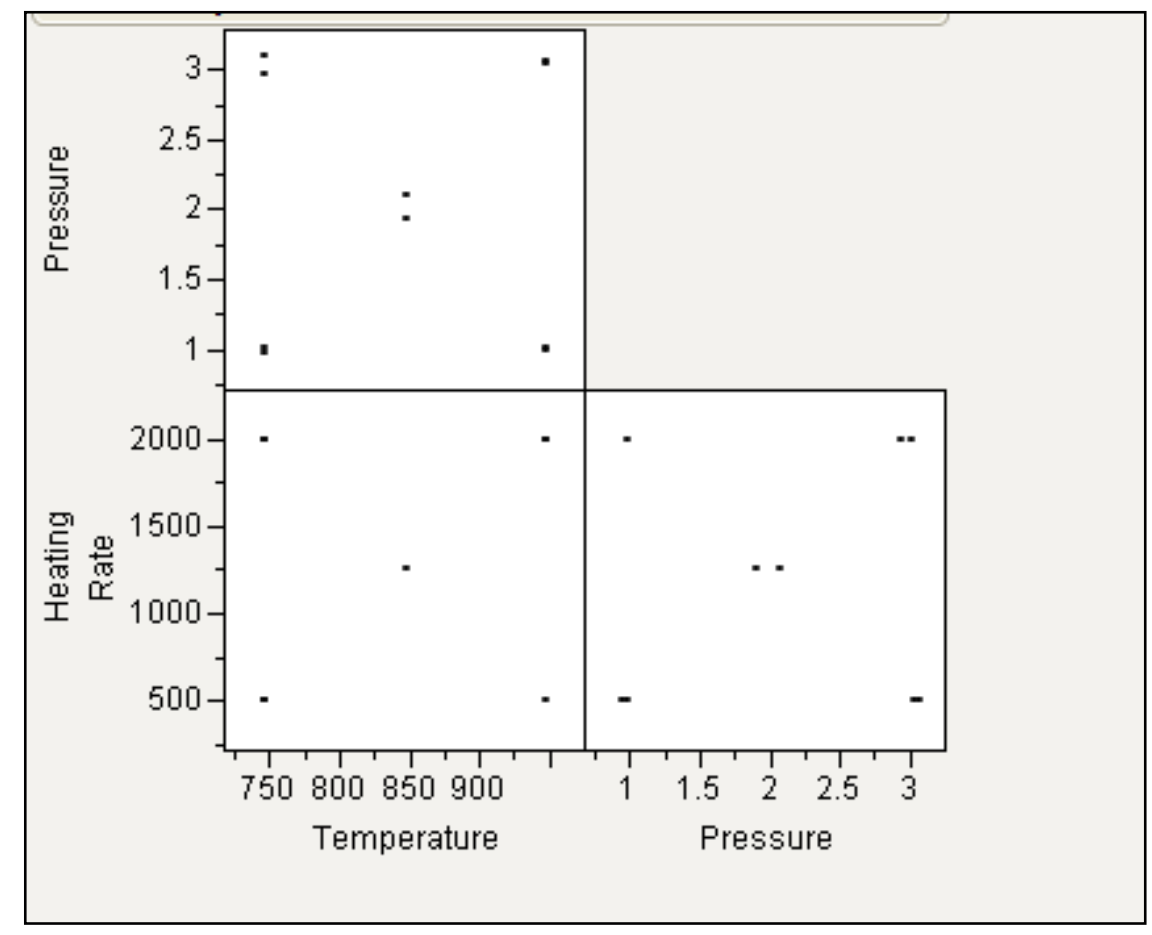

Figure 4.2: Scatter plot matrix using $2 \times 2 \times 2$ Full Factorial Design

In order to cover the large area for the desired range of variables, it is necessary to select the space filling Latin hypercube sampling method. With three factors and high- and low-levels for each, a run matrix of 500 runs is required to see the space filling effect, which is illustrated in Figure 4.3. Similarly, a Monte-Carlo-simulation-based random sampling approach was used for the parameters reported in Table 4.1. The parameters were assumed to have normal distributions. 10,000 sample points were generated using the sampling method in PSUADE. Figure 4.4 shows the scatterplot matrix for the 10,000 samples. It can be seen that Latin hypercube and MC can covers the majority of sample points in a specified range. As the computational cost of $\mathrm{C} 3 \mathrm{M}$ was insignificant, direct Monte Carlo simulation was employed so that multiple sample data points can be generated for propagating the uncertainties.

When performing CFD simulations, it is not feasible to perform many runs for each sample because of the cost and time. Ideally, Monte-Carlo-simulation-based random sampling 
approaches are preferred for investigating input uncertainty propagation or for performing other UQ analysis. However, for CFD applications where the computation load is large, it is not suitable. Instead, surrogate models characterizing the system behavior for the selected response variables need to be constructed separately. In order to build an adequate surrogate model, a certain number of sampling simulations must be performed. Additionally, the quality of the surrogate model needs to be assessed to quantify the additional uncertainty introduced by employing the surrogate model instead of the actual application code. In this study, the computational cost of the $\mathrm{C} 3 \mathrm{M}$ runs were quite cheap, so both direct Monte-Carlo-simulationbased and surrogate-model-based approaches were employed.

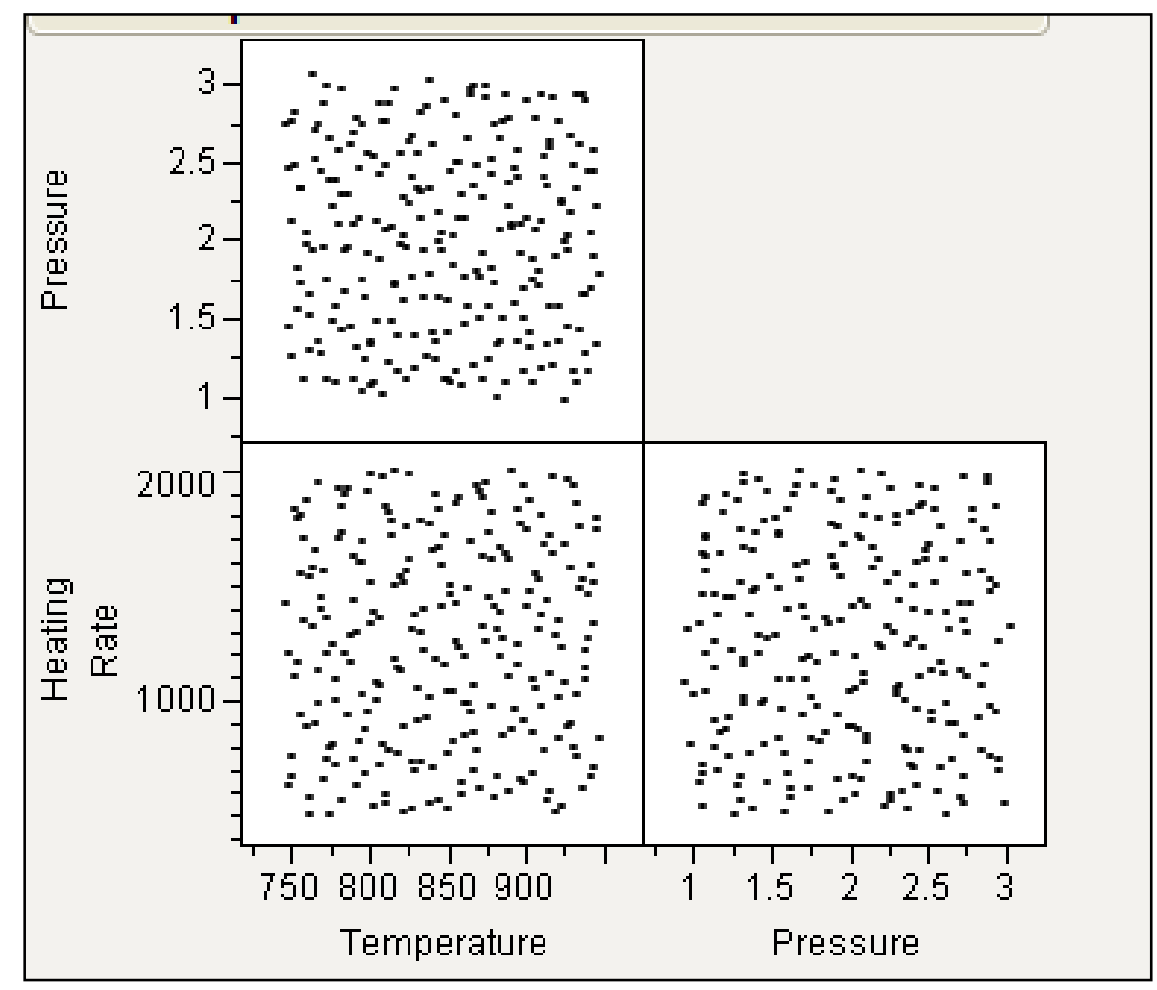

Figure 4.3: Scatter plot matrix using Latin Hypercube method for 250 runs 


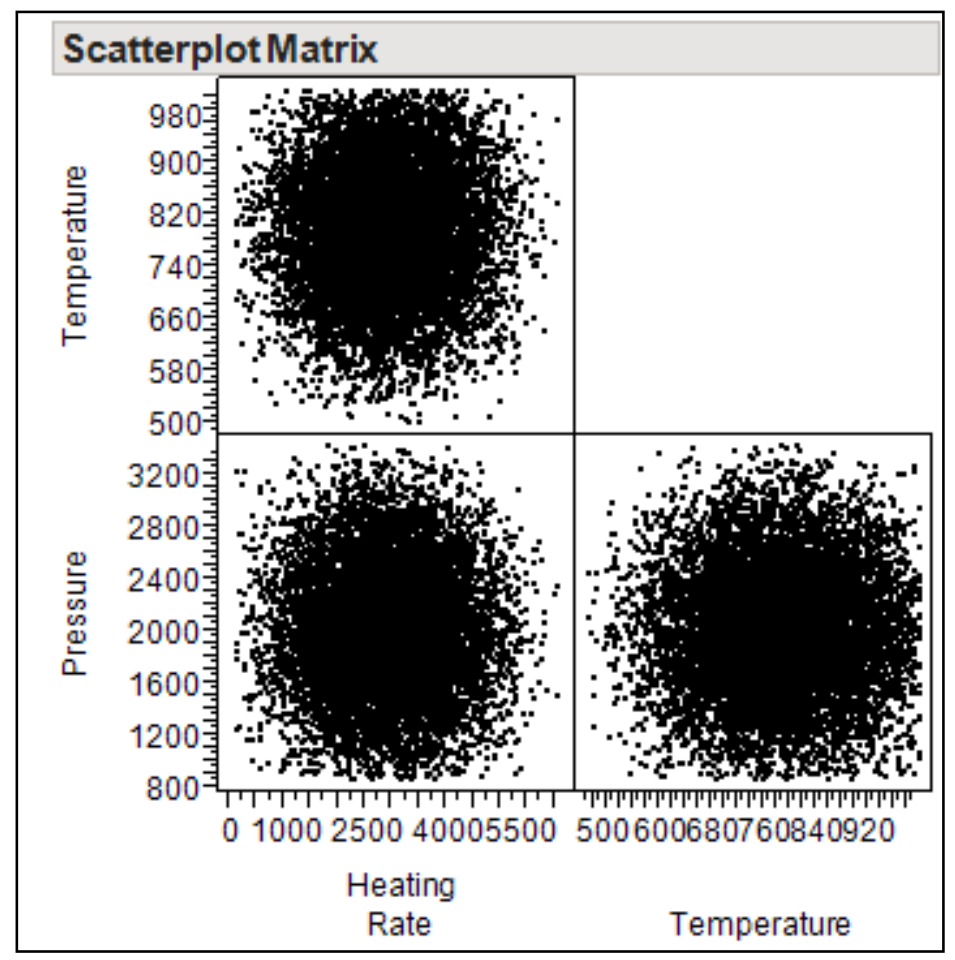

Figure 4.4: Scatter plot matrix of Monte Carlo simulation sampling for 10,000 samples

\subsubsection{Propagation of input uncertainties with Direct Monte Carlo Simulation}

For the scope of this study, the first three input parameters shown in Table 4.1 were considered to be uncertain parameters to be used in the UQ analysis. For demonstration purposes, all uncertainties were considered as aleatory. PCCL devolatilization product yields, in terms of mass fractions, were considered as response variables. Table 4.2 shows the seven response variables considered in this study. Here mass fractions of $\mathrm{C}_{2} \mathrm{H}_{4}, \mathrm{C}_{2} \mathrm{H}_{6}$ and $\mathrm{C}_{3} \mathrm{H}_{6}$ gas species were not considered, though they were reported by PCCL.

While sampling the run matrix, no run condition is repeated because the output reported by PCCL does not change if it is repeated multiple times for the same operating condition. Using C3M, PC Coal Lab (PCCL) was run for PRB coal using the matrix for 10,000 sample run points and output data were collected in terms of devolatilizaiton product yields. 
Table 4.2: Response variables from PCCL

\begin{tabular}{|c|l|}
\hline & \multicolumn{1}{|c|}{ Response Variable } \\
\hline $\mathbf{1}$ & $\mathrm{CO}$ species mass fraction \\
\hline $\mathbf{2}$ & $\mathrm{CO}_{2}$ species mass fraction \\
\hline $\mathbf{3}$ & Tar species mass fraction \\
\hline $\mathbf{4}$ & $\mathrm{H}_{2}$ species mass fraction \\
\hline $\mathbf{5}$ & $\mathrm{H}_{2} \mathrm{O}$ species mass fraction \\
\hline $\mathbf{6}$ & $\mathrm{CH}_{4}$ species mass fraction \\
\hline $\mathbf{7}$ & $\mathrm{H}_{2} \mathrm{~S}$ species mass fraction \\
\hline
\end{tabular}

A normal distribution has been assumed for the input parameters of heating rate, temperature, and pressure but it is important to verify the distribution of output products. Figure 4.5 shows the normal distributions of heating rate, temperature and pressure for 10,000 sample points. The solid line represents the fitted distribution provided by the statistical analysis software for the data obtained from 10,000 sample run Monte Carlo simulation.

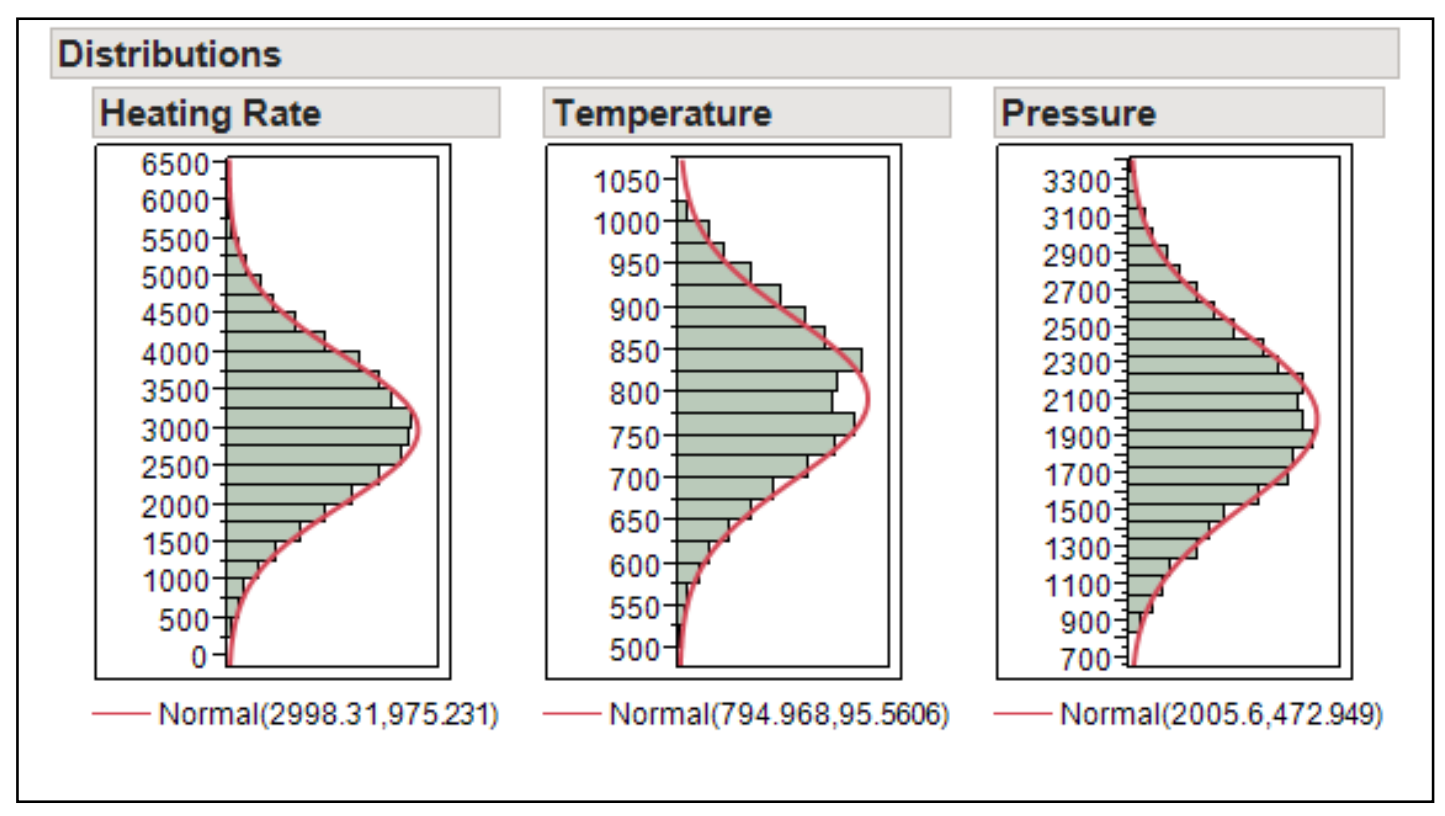

Figure 4.5 : Distribution of 10,000 samples of heating rate, temperature and pressure. 
Figures 4.6 to 4.12 show the histograms of the response variables, i.e., $\mathrm{CO}, \mathrm{CO}_{2}$, Tar, $\mathrm{H}_{2}$, $\mathrm{H}_{2} \mathrm{O}, \mathrm{CH}_{4}$, and $\mathrm{H}_{2} \mathrm{~S}$ species. The Monte Carlo simulations show that with the prescribed variability in input parameters (heating rate, temperature and pressure), the mean $\mathrm{CO}$ species mass fraction will be 0.1112 and there will be some variability with standard deviation of 0.0115 . On the other hand, for the same prescribed uncertainty in input parameters, less variability is observed in $\mathrm{CO}_{2}$, tar, and $\mathrm{H}_{2} \mathrm{O}$ species mass fraction as can be observed from the narrower distributions shown in Figure 4.7, 4.8 and 4.10, respectively. However, $\mathrm{H}_{2}$ species mass fraction shows substantially larger variation with a skew towards the right as shown in Figure 4.9.

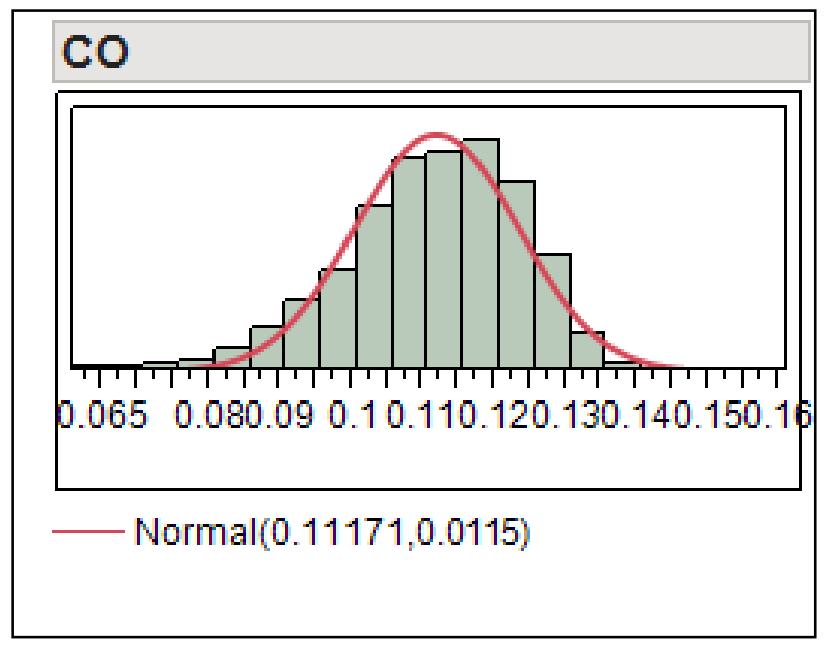

Figure 4.6: Histogram of $\mathrm{CO}$ mass fraction

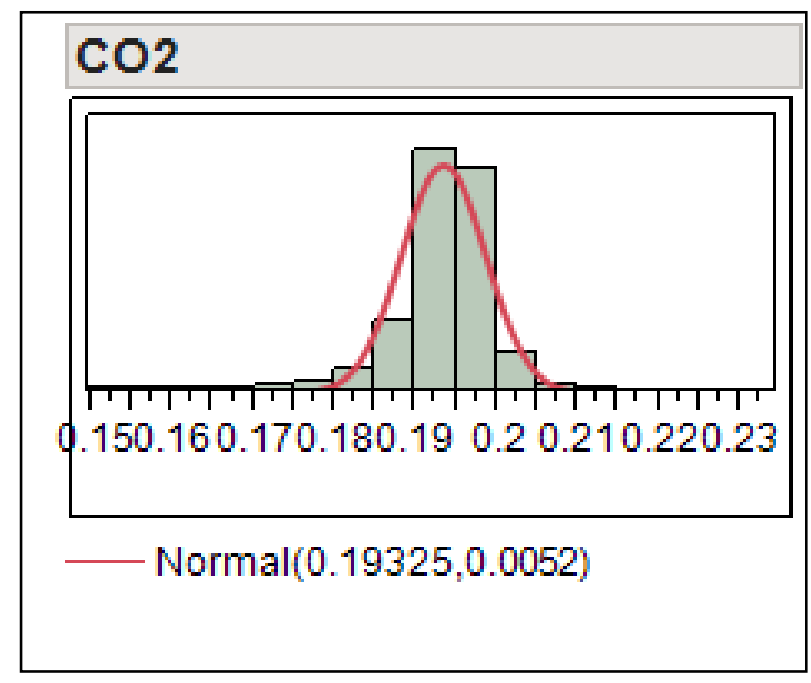

Figure 4.7: Histogram of $\mathrm{CO}_{2}$ mass fraction 


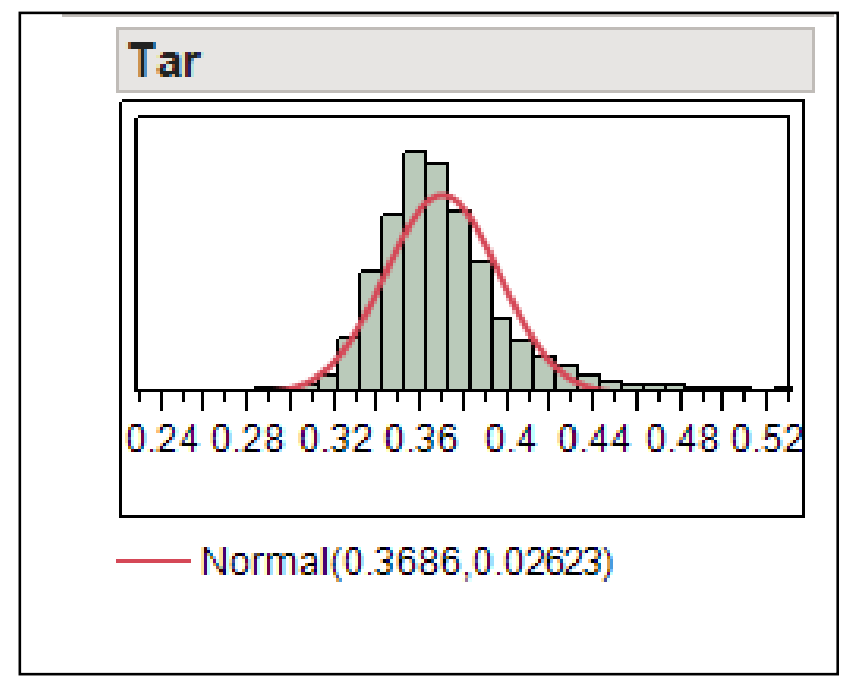

Figure 4.8: Histogram of tar mass fraction

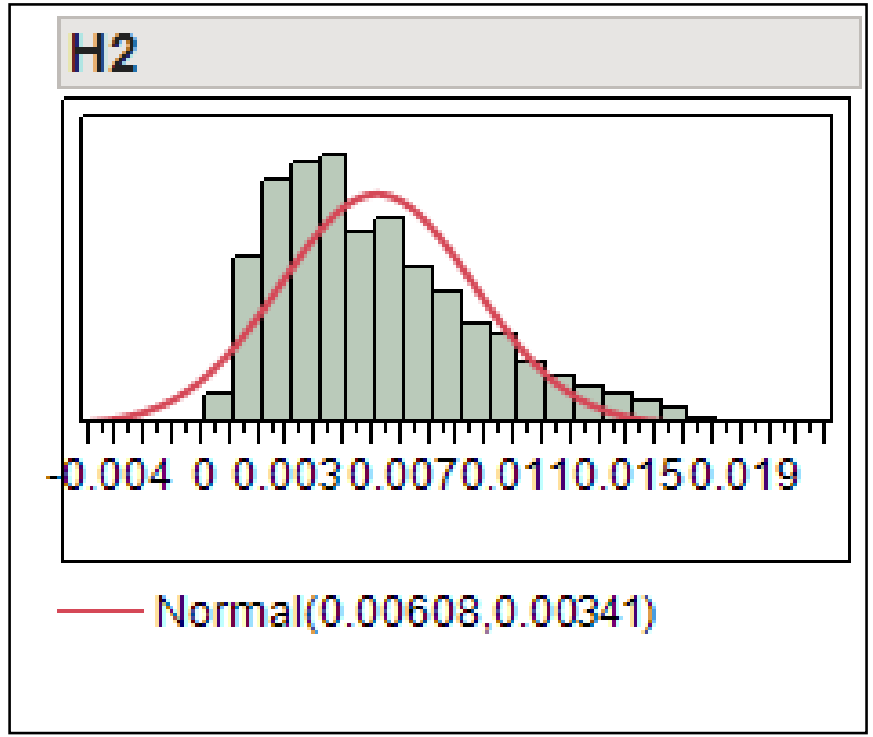

Figure 4.9: Histogram of $\mathrm{H}_{2}$ mass fraction 


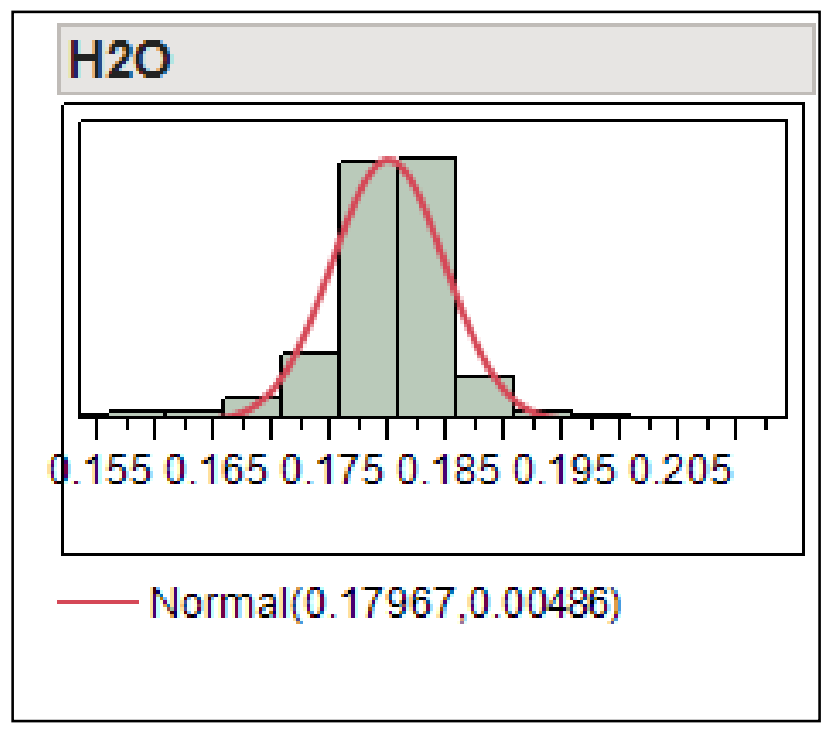

Figure 4.10: Histogram of $\mathrm{H}_{2} \mathrm{O}$ mass fraction

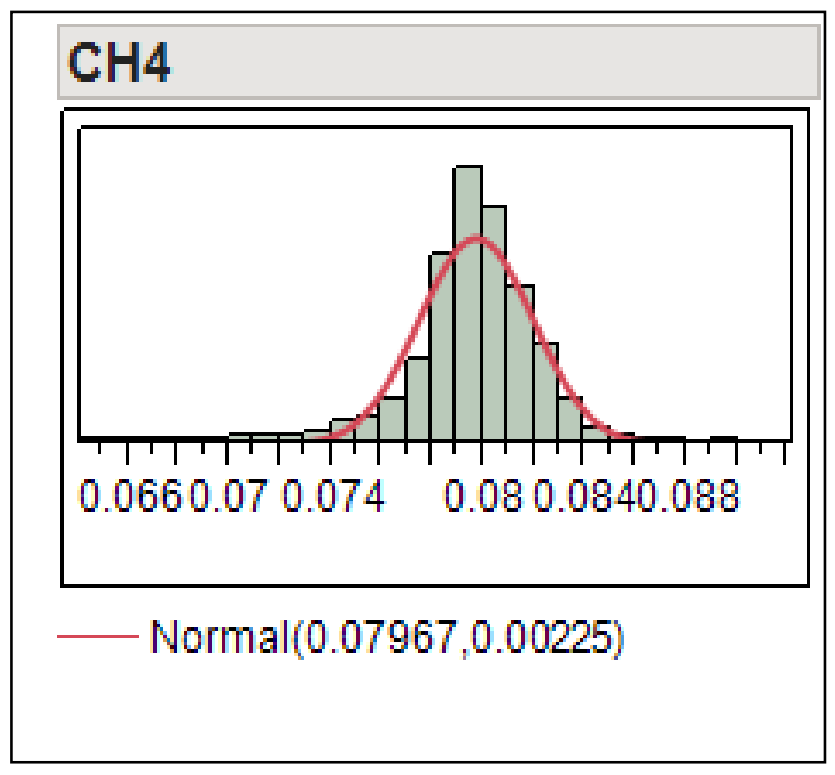

Figure 4.11: Histogram of $\mathrm{CH}_{4}$ mass fraction 


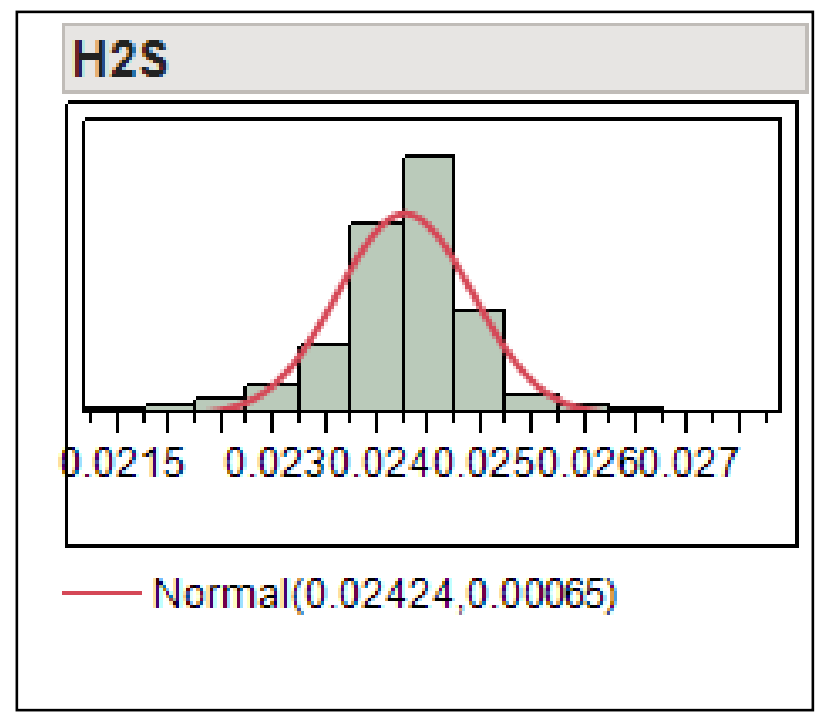

Figure 4.12: Histogram of $\mathrm{H}_{2} \mathrm{~S}$ mass fraction

The cumulative density function (CDF) plots for each of the histograms are given in Figures 4.13 to 4.19 . CDF plots can provide more practical information as they assess the probability of a certain event occurring given the prescribed input uncertainties. For example, from Figure 4.13, one can read the probability of CO species mass fraction being less than or equal to 0.13 is $90 \%$. Alternatively, the probability of $\mathrm{CO}$ species mass fraction being less than 0.13 and greater than 0.12 is about $60 \%$

Another interpretation on how to use the information gained from uncertainty propagation may be gained by considering another response variable, i.e., $\mathrm{CO}_{2}$ species mass fraction $\mathrm{CDF}$ as seen in Figure 4.14. The probability for $\mathrm{CO}_{2}$ species mass fraction being less than or equal to 0.20 is $80 \%$. If a design engineer is constrained due to some regulations with coal kinetics requiring the $\mathrm{CO}_{2}$ species to be $\leq 0.20$ then $80 \%$ of the time it could be achieved based on the current model predictions and with the prescribed input uncertainties. However, if the allowable limit is to achieve a mean value of the histogram, i.e., 0.1933 then the probability reduces to slightly less than $60 \%$. To increase this probability, the uncertainty in the input parameters needs to be reduced. This will require adequate assessment of which input parameter has the most significant influence on the $\mathrm{CO}_{2}$ species mass fraction. Sensitivity analysis will determine the most significant input parameter. One can then reduce the uncertainties in that parameter (by modifying the conditions in the reactor to narrow the range over which the parameter varies) to achieve the desired result. 


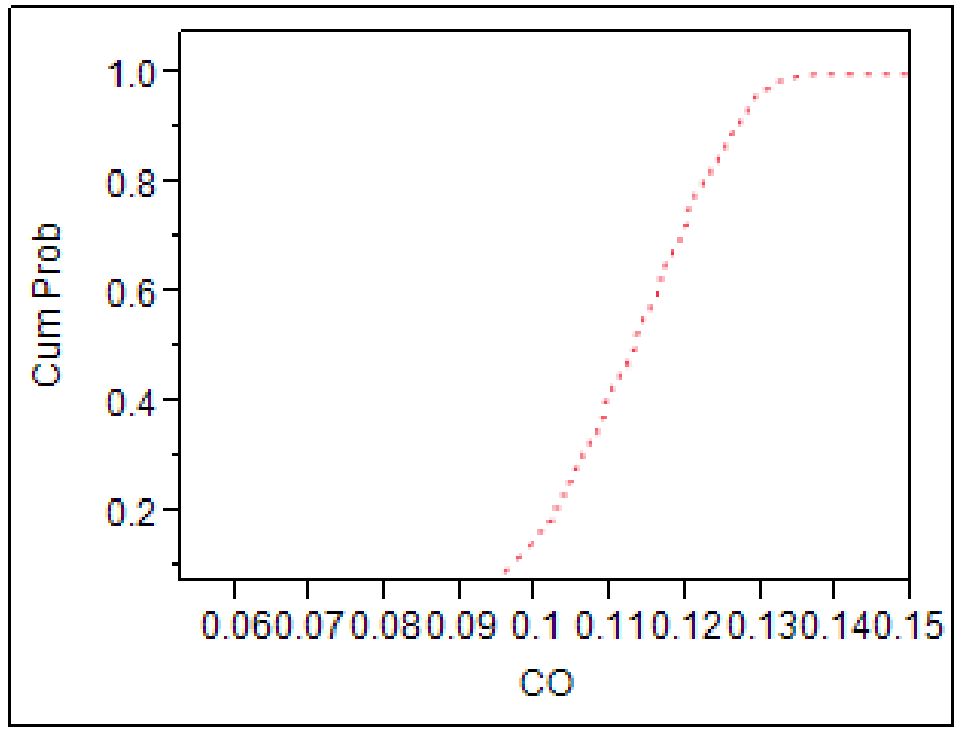

Figure 4.13: $\mathrm{CDF}$ of $\mathrm{CO}$ mass fraction

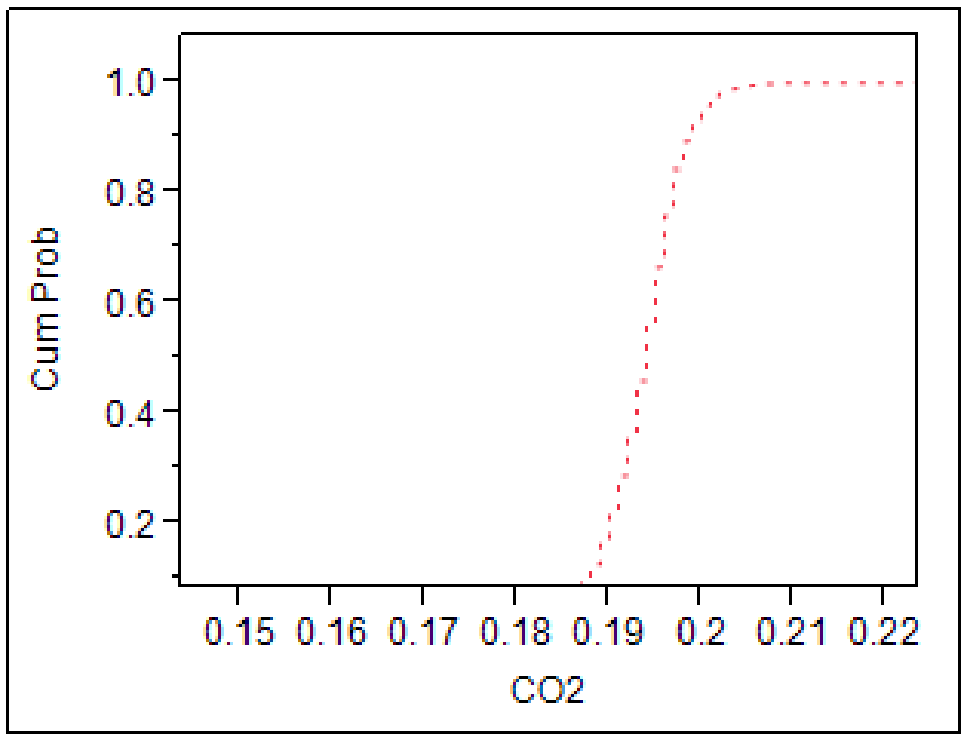

Figure 4.14: $\mathrm{CDF}$ of $\mathrm{CO}_{2}$ mass fraction 


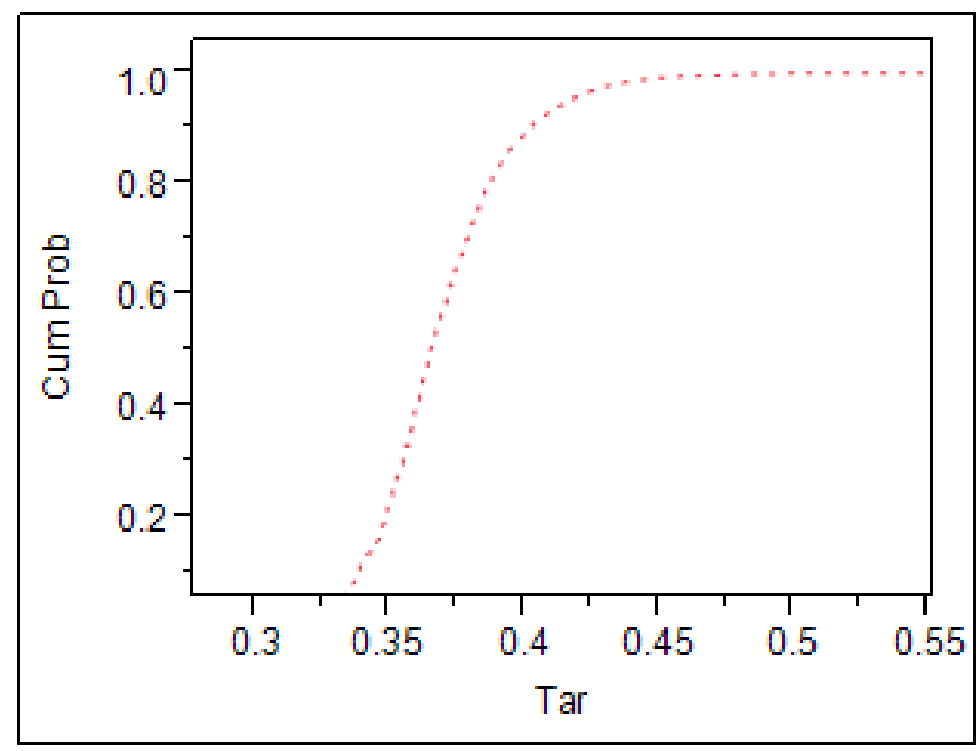

Figure 4.15: CDF of tar mass fraction

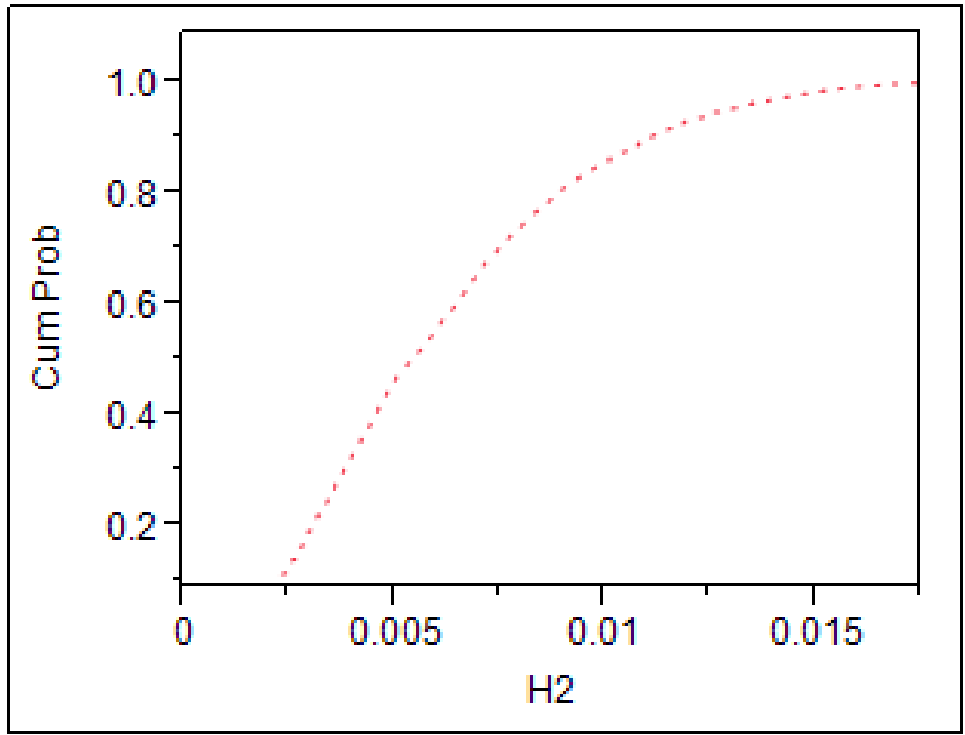

Figure 4.16: $\mathrm{CDF}$ of $\mathrm{H}_{2}$ mass fraction 


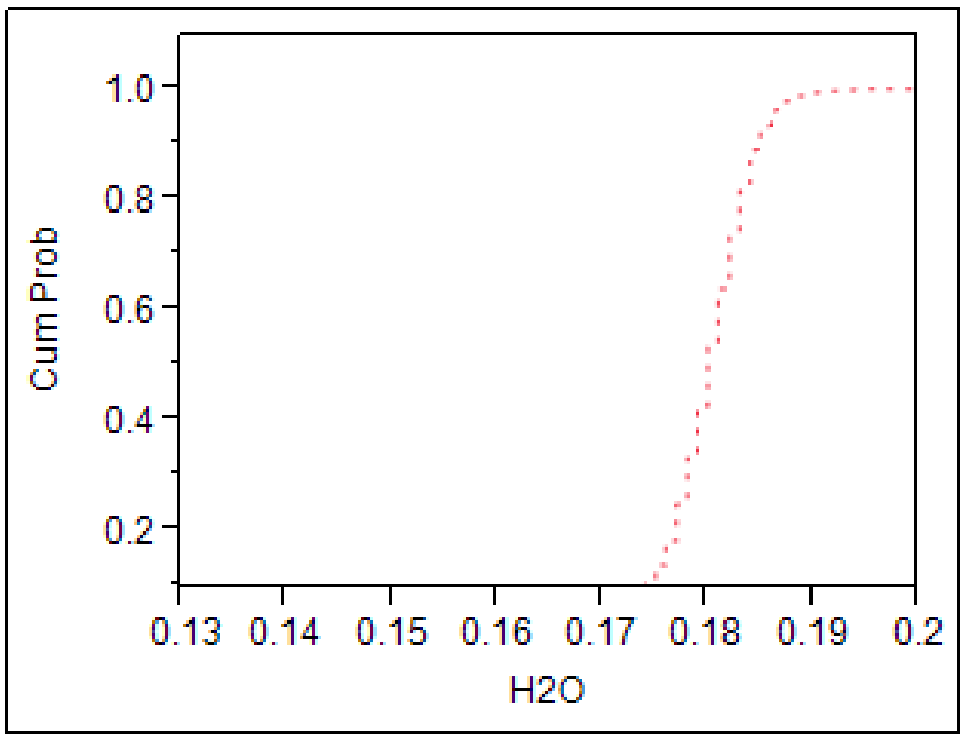

Figure 4.17: $\mathrm{CDF}$ of $\mathrm{H}_{2} \mathrm{O}$ mass fraction

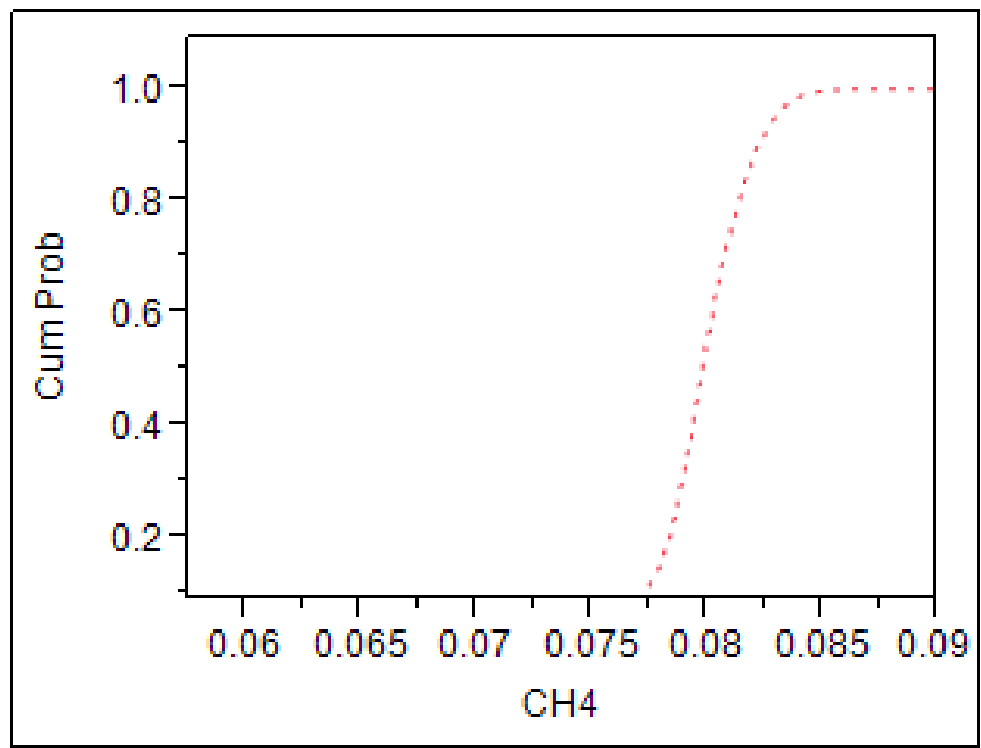

Figure 4.18: $\mathrm{CDF}$ of $\mathrm{CH}_{4}$ mass fraction 


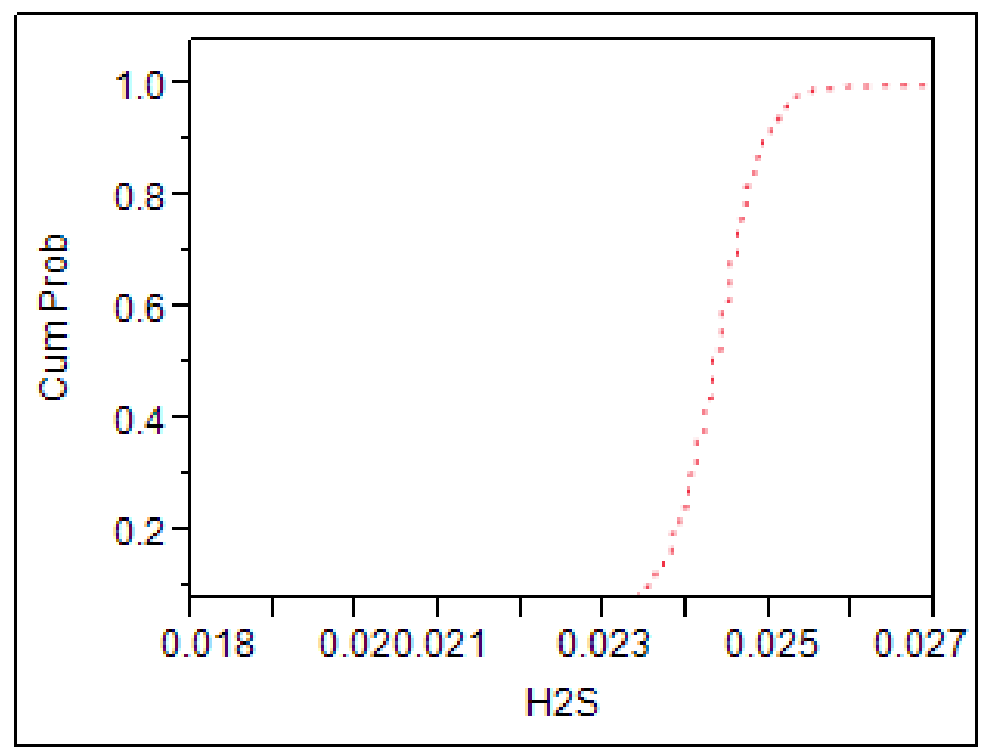

Figure 4.19: $\mathrm{CDF}$ of $\mathrm{H}_{2} \mathrm{~S}$ mass fraction

Comparing the histogram and CDF plots shown in Figures 4.6 to 4.19, one can develop several practical insights. For example, the tar and $\mathrm{H}_{2} \mathrm{O}$ species mass fractions appear to be the least sensitive to uncertainty based upon the variability observed in the three input parameters. On the other hand, the $\mathrm{H}_{2}$ species mass fraction appears to be the most sensitive (as seen from Figures 4.9 and 4.16 due to the skew of the right tail). These types of insights can play a crucial role in achieving robust design where the process is tolerant, or less sensitive, to fluctuations in inputs.

Table 4.3 shows the range of variation observed during this run for devolatilization products. 
Table 4.3: Ranges of input and output parameters for PRB coal

\begin{tabular}{|c|c|c|}
\hline Quantity & Mean & Std Deviation \\
\hline Input Parameters & 3000 & 1000 \\
\hline Heating Rate $\left({ }^{\circ} \mathrm{C} / \mathrm{s}\right)$ & 800 & 500 \\
\hline Temperature $\left({ }^{\circ} \mathrm{C}\right)$ & 2000 & \\
\hline Pressure $(\mathrm{kPa})$ & & 0.0115 \\
\hline Output Parameters & 0.1112 & 0.0052 \\
\hline $\mathrm{CO}$ mass fraction & 0.1933 & 0.0262 \\
\hline $\mathrm{CO}_{2}$ mass fraction & 0.3686 & 0.0034 \\
\hline Tar mass fraction & 0.0061 & 0.0049 \\
\hline $\mathrm{H}_{2}$ mass fraction & 0.1797 & 0.0025 \\
\hline $\mathrm{H}_{2} \mathrm{O}$ mass fraction & 0.0797 & 0.0006 \\
\hline $\mathrm{CH}_{4}$ mass fraction & 0.0242 & \\
\hline $\mathrm{H}_{2} \mathrm{~S}$ mass fraction & & \\
\hline
\end{tabular}

\subsubsection{Correlation Matrix for Response Variables}

It is important to see if there is any correlation between the product yields of devolatilization based on input variations. The investigation of correlation between response variables is another useful analysis that can be performed as part of the UQ process in order to gain better insight into the uncertainty in predicted results. Given the prescribed input uncertainties, a correlation matrix shows how each species is correlated with each other. In other words, the correlation is a measure of the strength of linear association between two numeric variables. Table 4.4 shows the correlation matrix computed for the quantities of interest based on the 10,000 sample Monte Carlo simulation results. When the absolute values of the correlation matrix are close to 1 , this shows a strong correlation between variables, e.g., $\mathrm{H}_{2}$ and $\mathrm{CO}, \mathrm{H}_{2} \mathrm{O}$ and $\mathrm{CO}_{2}, \mathrm{CH}_{4}$ and $\mathrm{H}_{2} \mathrm{O}$. Values closer to zero indicate no correlation whereas values in between reflect weak correlations. Negative values indicate inverse correlation, e.g., CO and tar are weakly and inversely correlated, i.e., when $\mathrm{CO}$ increases then tar decreases and vice versa. 
Table 4.4: Correlation matrix for response variables

\begin{tabular}{|lrrrrrrr|}
\hline \multicolumn{6}{l}{ Correlations } & \multicolumn{7}{l|}{} \\
$\mathrm{CO}$ & $\mathrm{CO}$ & $\mathrm{CO} 2$ & $\mathrm{Tar}$ & $\mathrm{H} 2$ & $\mathrm{H} 2 \mathrm{O}$ & $\mathrm{CH} 4$ & $\mathrm{H} 2 \mathrm{~S}$ \\
$\mathrm{CO} 2$ & 0.7389 & 0.7389 & -0.9486 & 0.9242 & 0.7384 & 0.7033 & 0.7399 \\
$\mathrm{Tar}$ & -0.9486 & -0.9090 & -0.9090 & 0.4836 & 0.9796 & 0.9467 & 0.9867 \\
$\mathrm{H} 2$ & 0.9242 & 0.4836 & -0.7912 & 1.0000 & 0.4844 & 0.4627 & 0.4833 \\
$\mathrm{H} 2 \mathrm{O}$ & 0.7384 & 0.9796 & -0.9089 & 0.4844 & 1.0000 & 0.9525 & 0.9826 \\
$\mathrm{CH} 4$ & 0.7033 & 0.9467 & -0.8782 & 0.4627 & 0.9525 & 1.0000 & 0.9453 \\
$\mathrm{H} 2 \mathrm{~S}$ & 0.7399 & 0.9867 & -0.9083 & 0.4833 & 0.9826 & 0.9453 & 1.0000 \\
& & & & & & & \\
& & & & & & & \\
\hline
\end{tabular}

Table 4.4 shows that there is a positive correlation between the devolatilization yield of $\mathrm{CO}$ and $\mathrm{H}_{2}$, along with $\mathrm{CO}_{2}$ and $\mathrm{H}_{2} \mathrm{O}$, which supports the findings reported by Weiland et al. (2011) and Serio et al. (1987) for PRB coal and Pittsburgh No.8, respectively. Figure 4.20 shows that the yields of $\mathrm{CO}$ and $\mathrm{H}_{2}$ from devolatilization of PRB coal increase with an increase in temperature. Figure 4.21 shows the devolatilization yields of $\mathrm{CO}_{2}$ and $\mathrm{H}_{2} \mathrm{O}$ reported at various temperatures. Figure 4.21 also shows a positive correlation between the devolatilization yield of $\mathrm{CO}_{2}$ and $\mathrm{H}_{2} \mathrm{O}$ and temperature as suggested by a positive strong correlation from Table 4.4, i.e., 0.9796. The correlations demonstrate the findings of yield of devolatilization reported by various researchers (Freihaut and Seery, 1985; Zhong et al., 2012; Nelson et al., 1988; Niksa, 2008), that gives confidence about the validity of these correlations in specified input uncertainties.

The scatterplot shown in Figure 4.22 is simply the visual representation of the correlation matrix provided in Table 4.4, which is obtained by plotting data from the Monte Carlo simulations. In this figure, narrow or tilted ellipses (represented by dotted lines) show strong correlations; while more circular ellipses show weak correlations. 


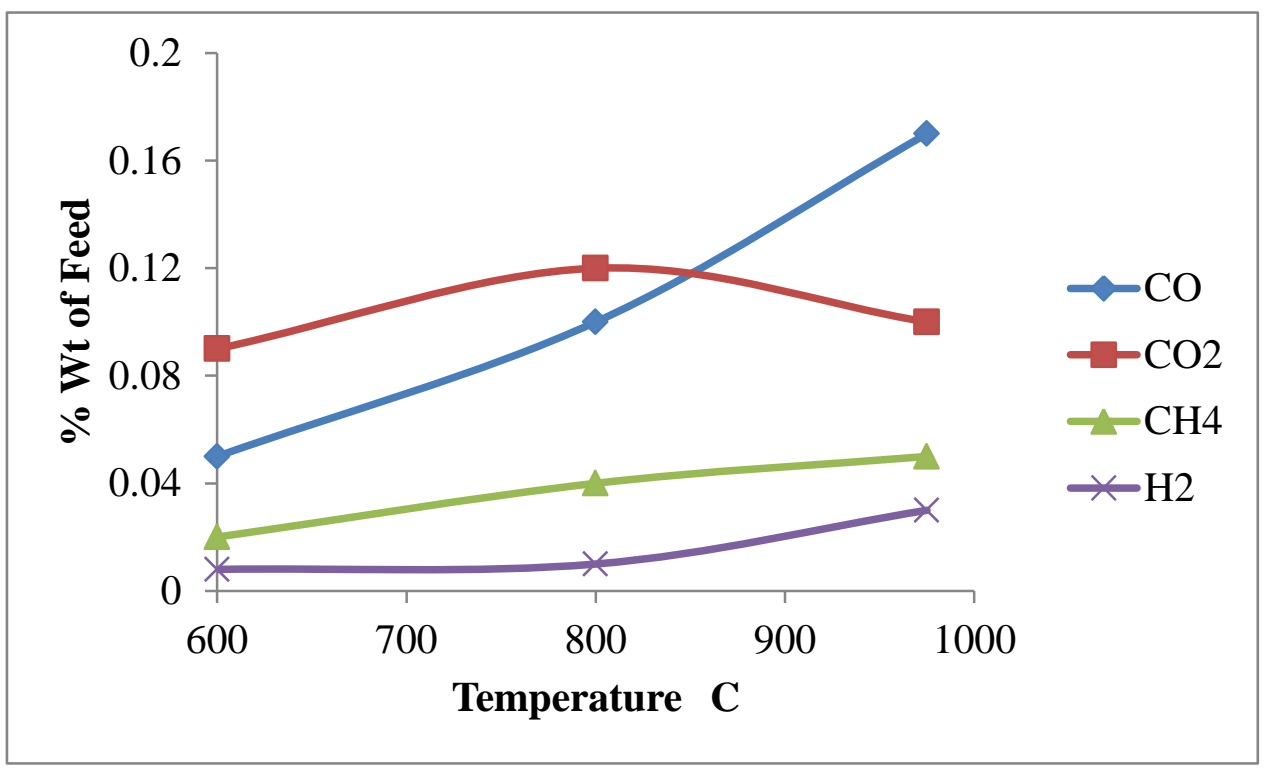

Figure 4.20: Devolatilization gaseous product yield obtained for PRB coal at 600, 800 and $975^{\circ} \mathrm{C}$ (Weiland et al., 2011)

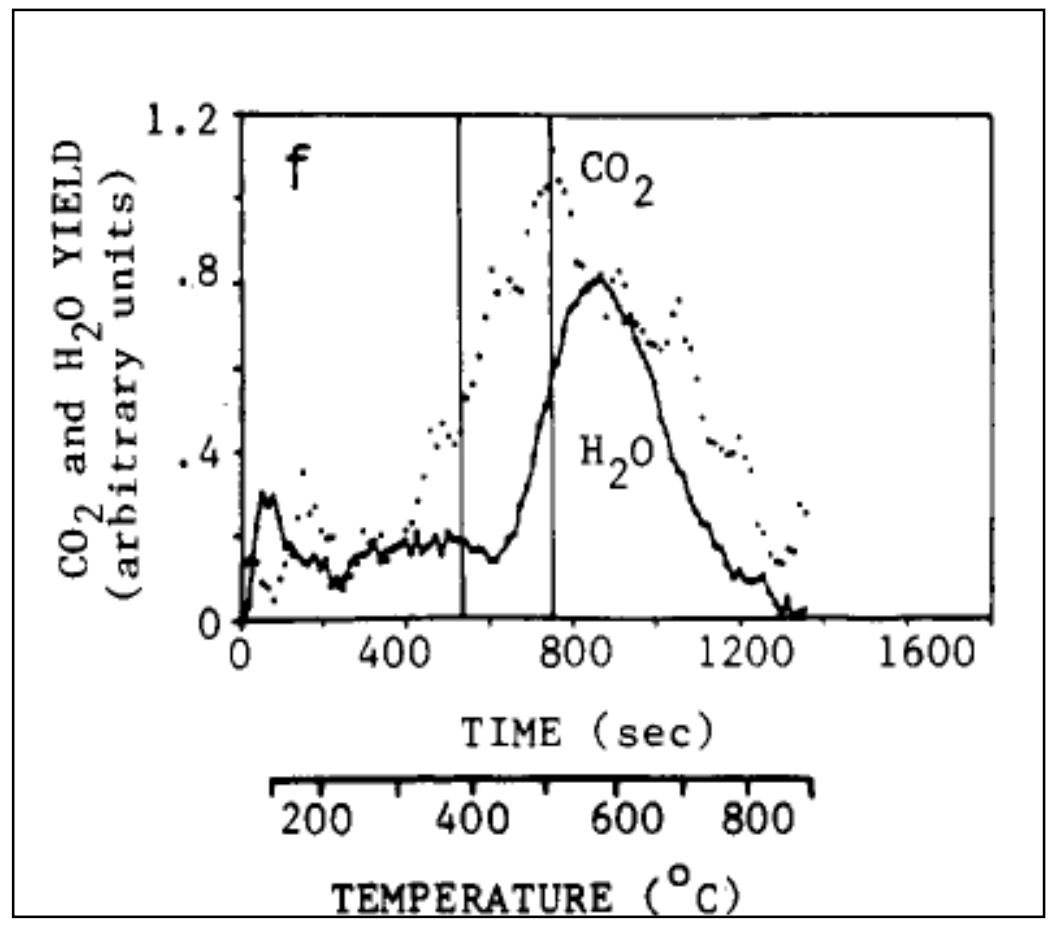

Figure 4.21: Devolatilizaiton yield of $\mathrm{CO}_{2}$ and $\mathrm{H}_{2} \mathrm{O}$ for Pittsburgh No.8 (Serio et al., 1987). 


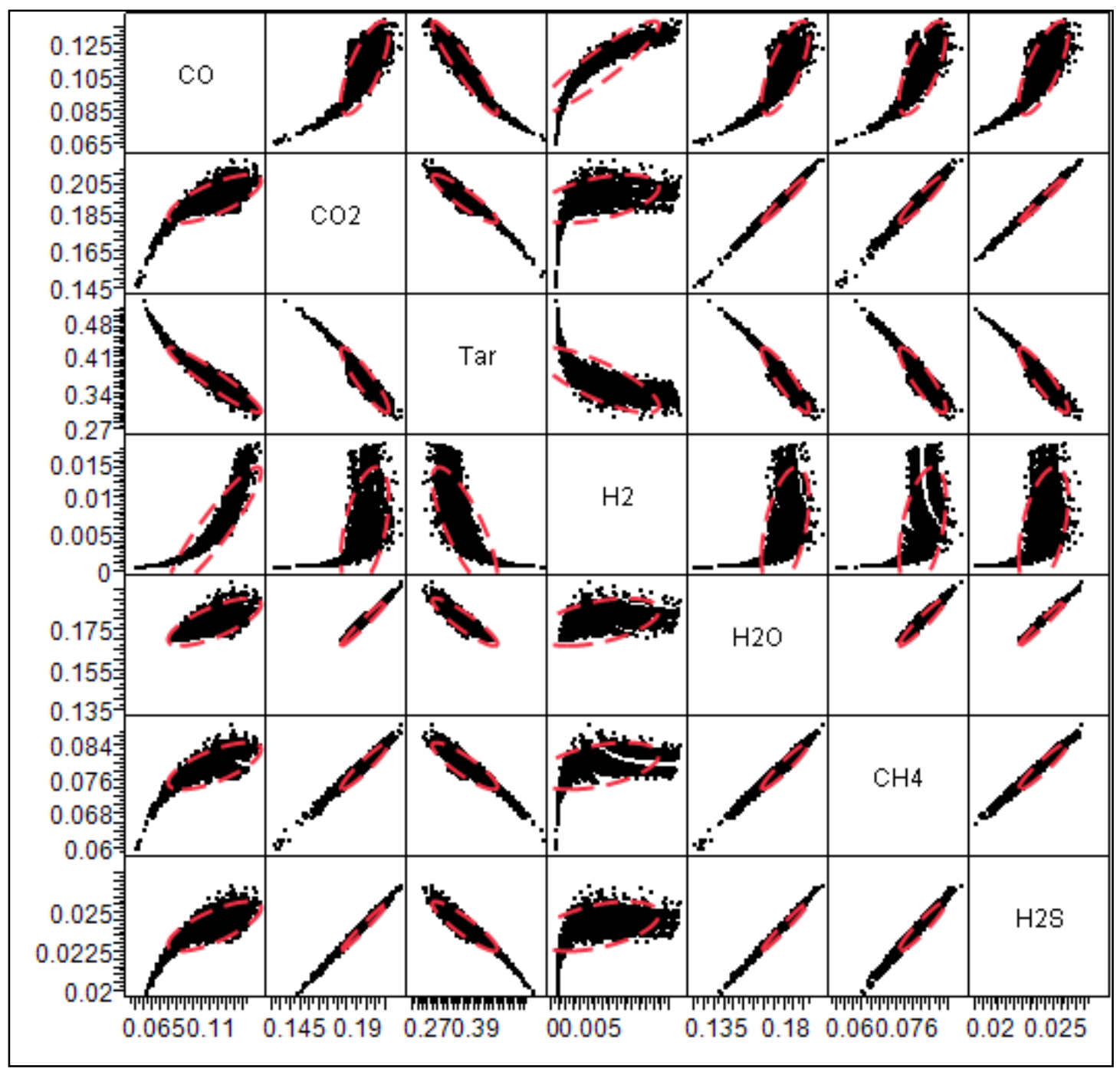

Figure 4.22: Multivariate plot of response variables.

The major task remaining is to build a model that can predict the variations in output yields based on variations introduced in the inputs. To make an accurate model, it is important to determine the sensitivity of input parameters on the output. Using software packages like JMP and PSUADE, the effects of all the input parameters on the outputs are determined. A model with the best regression value for the effects of interest should be chosen. 
For demonstration purpose a model predicting yield of tar based on uncertainties in input parameters was derived. Here using logarithmic transformation on input parameters (temperature, pressure and heating rate) a linear model was obtained capturing 95\% variations in tar yield. Figure 4.23 shows the linear fit prediction for tar yield using the model.

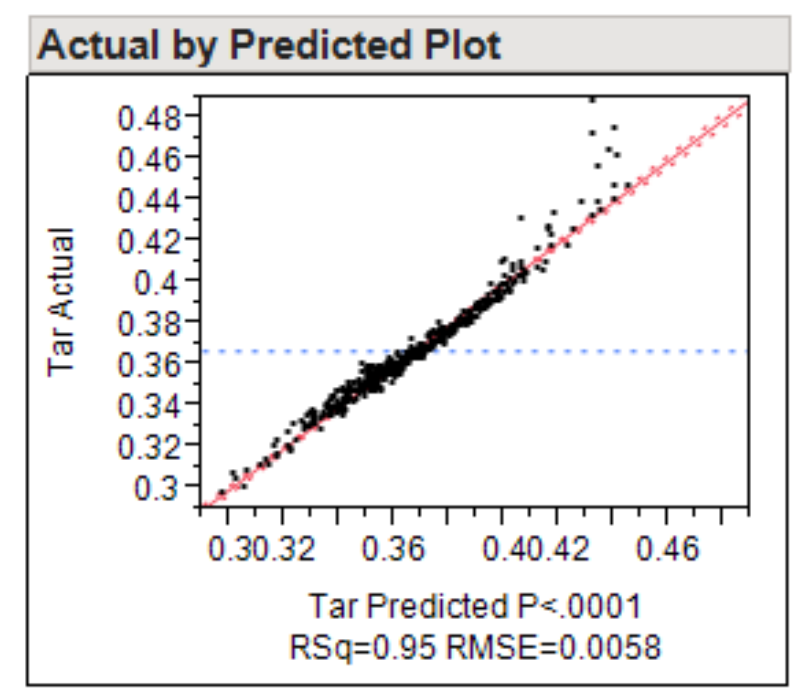

Figure 4.23: Plot showing linear fit predictions for tar yield in given input uncertainties.

The model has following form,

$$
\operatorname{tar}=1.7605-0.4476 \log _{10}(\text { Temp })+0.0396 \log _{10}(\mathrm{HR})-0.0707 \log _{10}(\text { Press })
$$

This kind of analysis will help in predicting variations in tar yield based on prescribed variations in pressure, temperature and heating rate without running $\mathrm{C} 3 \mathrm{M}$ in future. But one should note that for this analysis, the model predictions can only be used for the range of uncertainties chosen for pressure, temperature and heating rate while sampling.

It is a tedious job to incorporate these models into CFD codes as it may lead to mass imbalances in neighboring computational cells. Hence, simplified models or other approaches should be taken into consideration to address these uncertainties. The next section gives a methodology of using a sub-model approach to test the effect of temperature variations on coal devolatilization kinetics in a gasifier system. 


\subsection{Implementing a Sub-Model for Coal Devolatilization Kinetics}

The reaction rates of primary pyrolysis/devolatilization, along with total volatile yield, increase with an increase in temperature (Tamhankar et al., 1984; Serio et al. 1987). The reaction rates reported by PCCL are instantaneous rates at the input temperature (Niksa, 2008). When a coal particle enters the reactor, it starts heating up and attains various temperature levels. Hence, the devolatilization rate obtained for one particular operating temperature may not exactly capture the behavior of the particle while going through pyrolysis at different temperatures.

For demonstration purposes, three temperatures were chosen, $600^{\circ} \mathrm{C}, 1300^{\circ} \mathrm{C}$ and $1500^{\circ} \mathrm{C}$. The PCCL software, using a drop tube method, was run for Illinois No.6 coal at 2.45 MPa pressure. The analysis of coal was shown in Table 3.4. The Arrhenius constant $(A)$ and Activation energy $(E)$ for SFOR devolatilization kinetics were collected for these runs. Table 4.5 reports the kinetic parameters obtained. The devolatilization reaction rate was derived over the range of $500-1550^{\circ} \mathrm{C}$ to test the response of these three reaction rates. Figure 4.24 shows the response of the reaction rates over the temperature range.

These results show that the reaction rates calculated based on the parameters derived at $600^{\circ} \mathrm{C}$ predict higher devolatilization rates compared to the reaction rates calculated using parameters derived at 1300 and $1500^{\circ} \mathrm{C}$ when temperature of the particle is above $800^{\circ} \mathrm{C}$. This shows that the instantaneous reaction rate parameters will not predict similar pyrolysis rates over the different temperature range in the reactor.

Table 4.5: Kinetic Parameters from PCCL

\begin{tabular}{|c|l|c|}
\hline Temperature $\left({ }^{\circ} \mathbf{C}\right)$ & $\boldsymbol{A}(\mathbf{1} / \mathbf{s})$ & $\boldsymbol{E}(\mathbf{c a l} / \mathbf{m o l})$ \\
\hline 600 & $3.14 \times 10^{6}$ & 20,240 \\
\hline 1300 & $4.55 \times 10^{4}$ & 11,800 \\
\hline 1500 & $1.11 \times 10^{5}$ & 13,170 \\
\hline
\end{tabular}




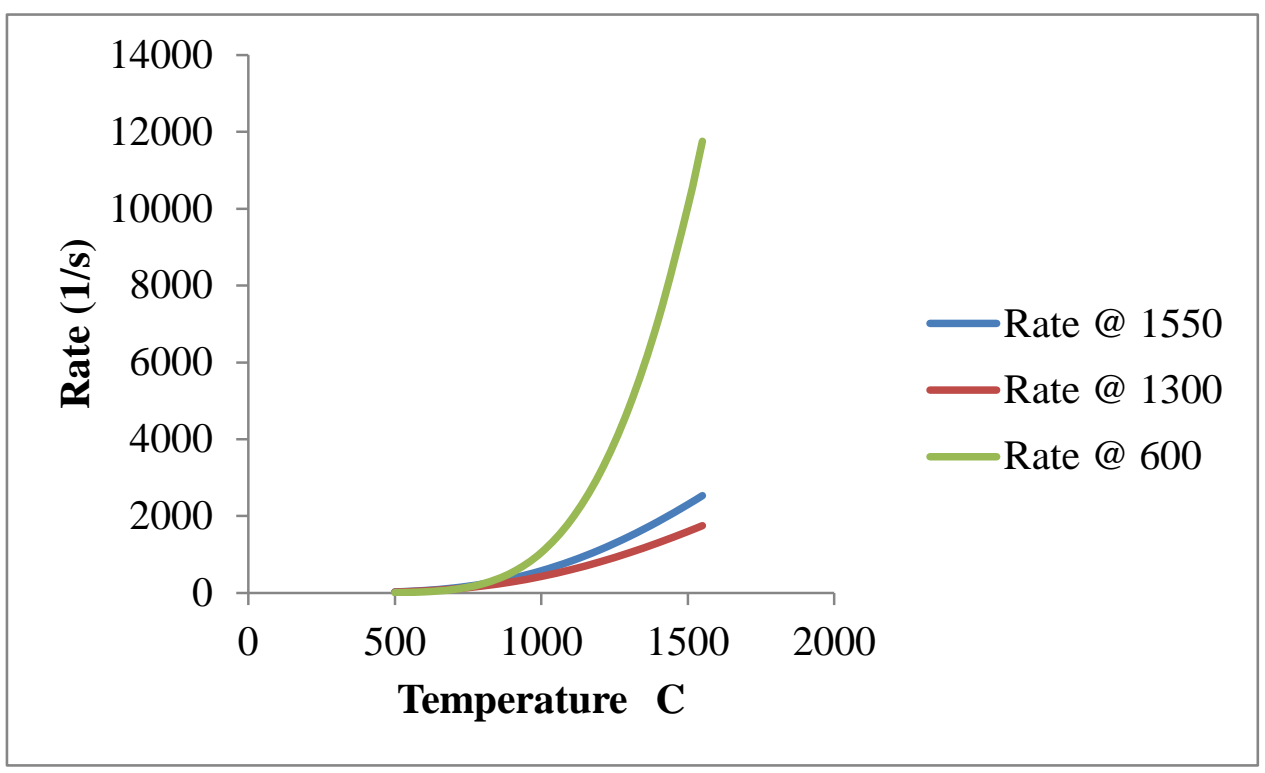

Figure 4.24 : Devolatilization reaction rate response over different temperature ranges

To resolve this issue, a sub-model was derived to capture the effect of temperature on the devolatilization reaction rate. For this study, the entrained flow gasifier developed by Kasule et al. (2012) was chosen because experimental data was available to compare the predictions of this model. It was assumed that the coal particle will attain temperatures from 500 to $1550^{\circ} \mathrm{C}$ while traveling through the reactor.

PCCL with the drop tube method was run for Illinois No.6 coal for a temperature range of $500-1550^{\circ} \mathrm{C}$. Table 4.6 shows the kinetic parameters $A(1 / \mathrm{s})$ and $E$ (cal $\left./ \mathrm{mol}\right)$ derived from the runs. 
Table 4.6: Devolatilization reaction rate parameters

\begin{tabular}{|c|l|c|}
\hline Temperature $\left({ }^{\circ} \mathrm{C}\right)$ & $A(1 / \mathrm{s})$ & $E(\mathrm{cal} / \mathrm{mol})$ \\
\hline 500 & $1.08 \times 10^{6}$ & 16,960 \\
\hline 600 & $3.14 \times 10^{6}$ & 20,240 \\
\hline 700 & $9.18 \times 10^{4}$ & 14,650 \\
\hline 800 & $8.95 \times 10^{3}$ & 10,330 \\
\hline 900 & $5.28 \times 10^{3}$ & 8,990 \\
\hline 1000 & $7.25 \times 10^{3}$ & 9,130 \\
\hline 1100 & $1.38 \times 10^{4}$ & 10,020 \\
\hline 1200 & $2.91 \times 10^{4}$ & 11,170 \\
\hline 1300 & $4.55 \times 10^{4}$ & 11,800 \\
\hline 1400 & $5.22 \times 10^{4}$ & 11,870 \\
\hline 1500 & $1.11 \times 10^{5}$ & 13,170 \\
\hline 1550 & $7.81 \times 10^{4}$ & 12,420 \\
\hline
\end{tabular}

Correlations between the temperature and Arrhenius constant and activation energy were determined. As an initial guess, an exponential fit for $A$ vs. temperature $(T)$ and a linear fit for $E$ vs. temperature $(T)$ were obtained. Figures 4.25 and 4.26 show these fits. 


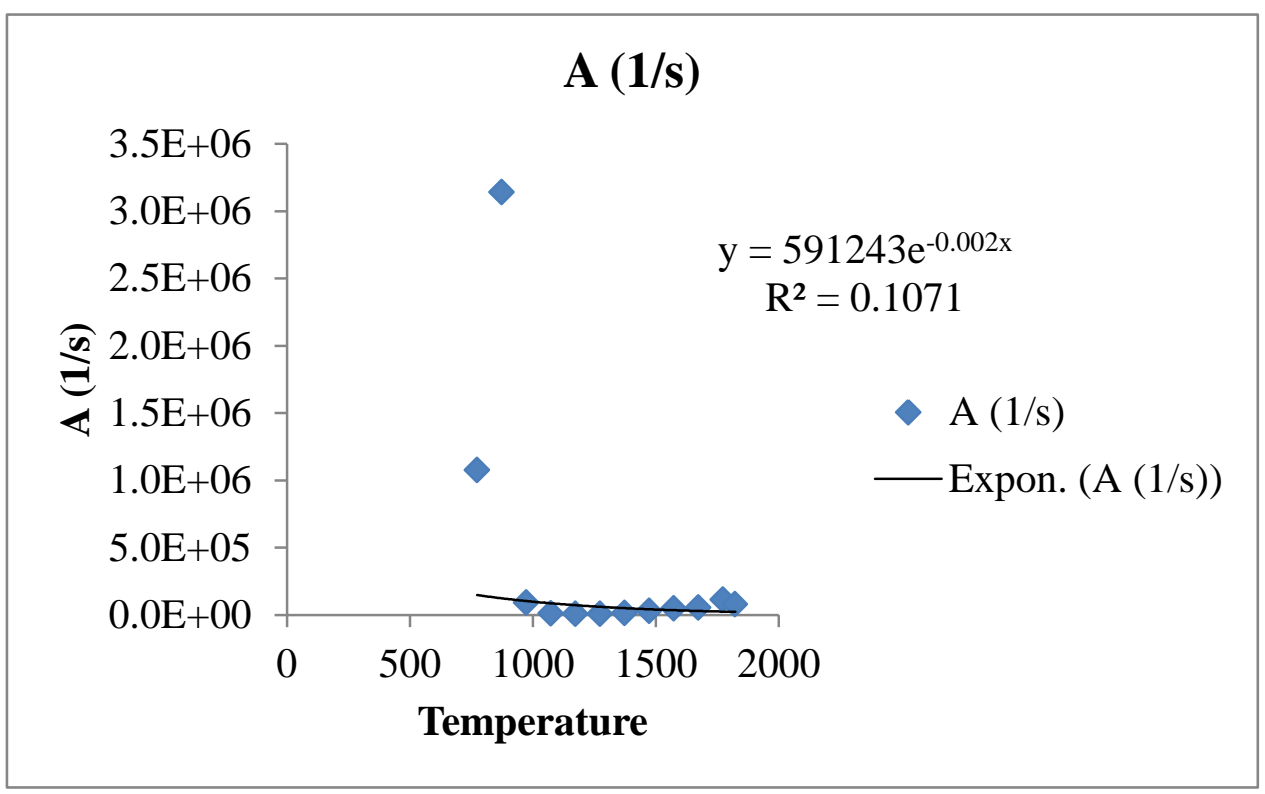

Figure 4.25: Effect of temperature on Arrhenius constant

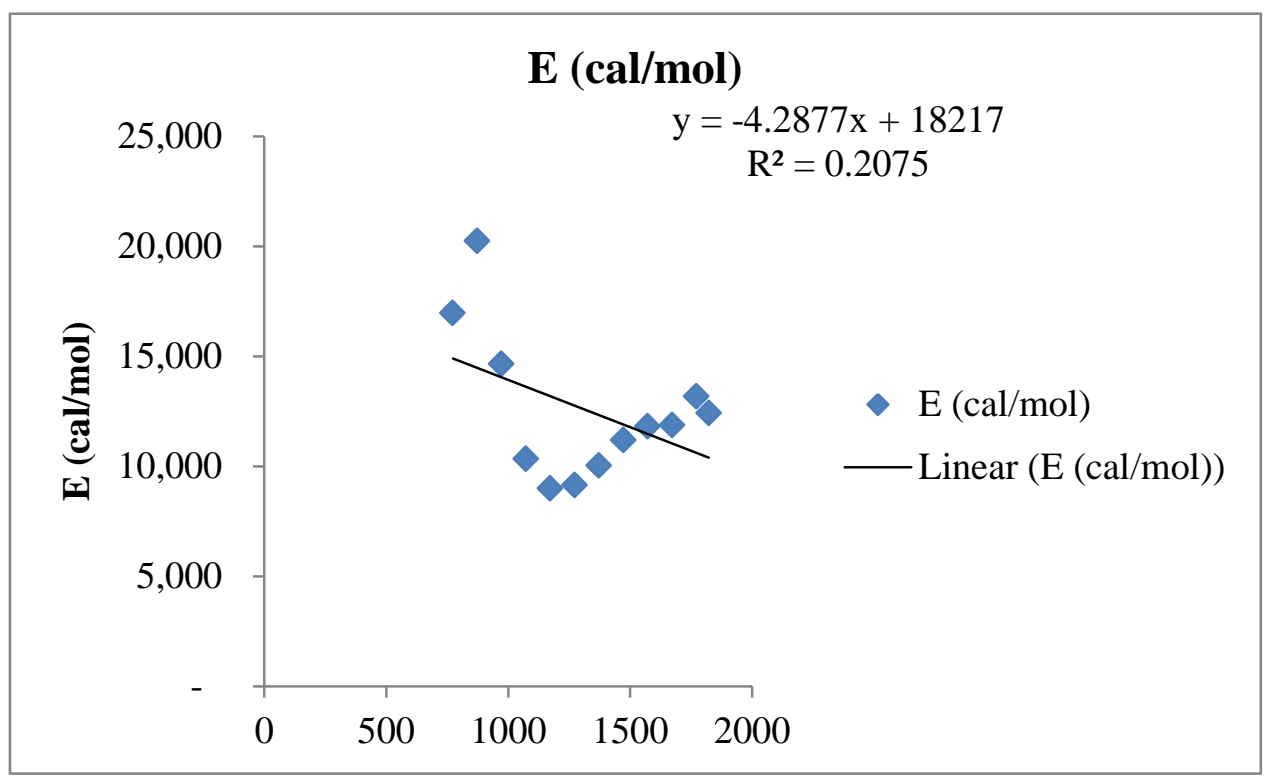

Figure 4.26: Effect of temperature on activation energy

Therefore, $A$ can be written as,

$$
A=X_{1} \exp \left(-X_{2} T\right)
$$


And $E$ can be written as,

$$
E=X_{3}+X_{4} T
$$

Where $X_{1}$ and $X_{2}$ are parameters from exponential fit; $X_{3}$ and $X_{4}$ are parameters from linear fit. The single first order reaction (SFOR) rate can be written as,

$$
\text { rate }=A \exp \left(\frac{-E}{R T}\right)
$$

So after substitution equation (4.1) and (4.2) into (4.3),

$$
\text { rate }=X_{1} \exp \left(\frac{-\left(X_{2} R T^{2}+X_{3} T+X_{4}\right)}{R T}\right)
$$

The devolatilization rates are then predicted using Equation (4.4) and varying the values of $X_{1}, X_{2}, X_{3}$ and $X_{4}$. The error between the predicted and PCCL devoltilization reaction rate was minimized using the GRG solver by manipulating the values of $X_{1}, X_{2}, X_{3}$ and $X_{4}$. Figure 4.27 shows the best-fit between the predicted and PCCL devolatilization rates, with an $R^{2}$ value of 0.9831 . 


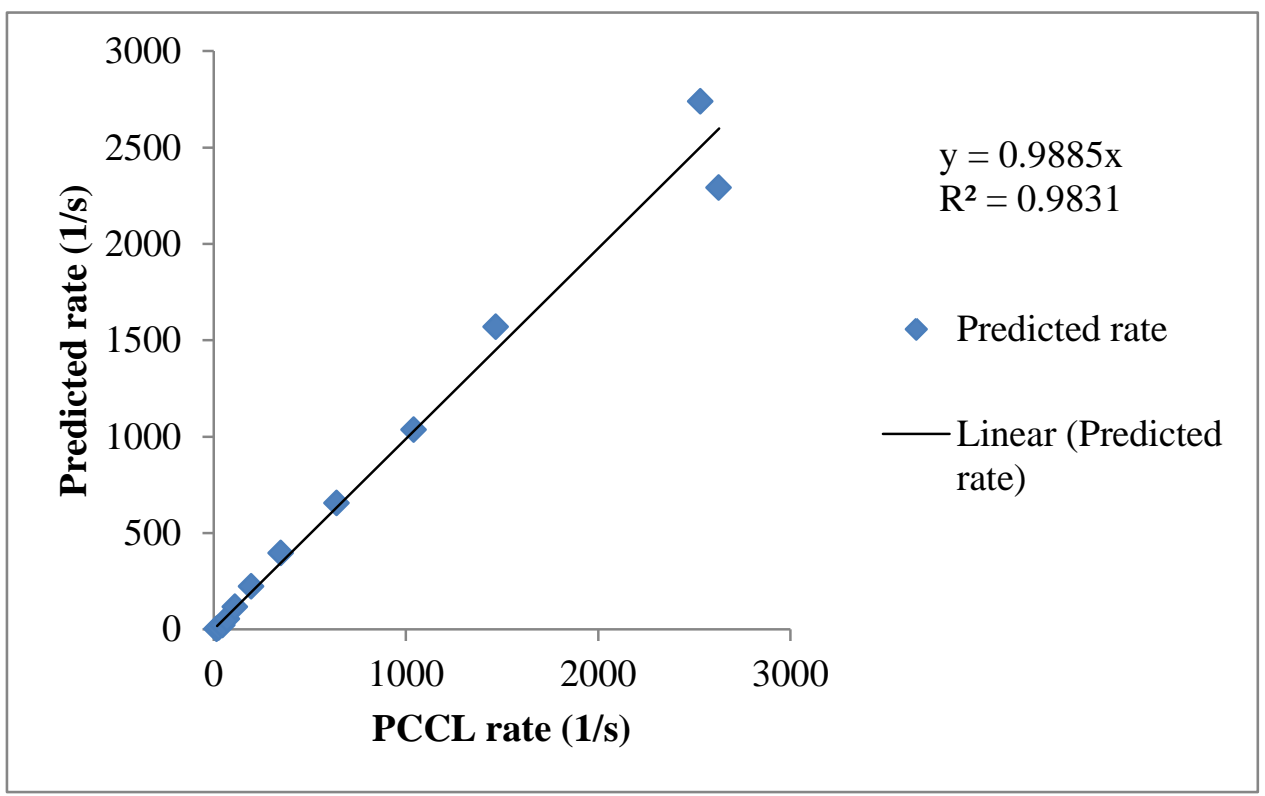

Figure 4.27: Comparison of predicted devolatilization rate with respect to PCCL devolatilization rate

Using this procedure, the effect of temperature on devolatilization rate was captured. To test this approach, the new derived devolatilization equation, shown in Equation (4.5), was substituted in the 1-D model. All other reaction rates were kept unchanged.

$$
\text { rate }=5.52 \times 10^{5} \exp \left(\frac{-\left(0.001 R T^{2}+4.91 T+16632.53\right)}{R T}\right)
$$

Figure 4.28 shows the exit gas syngas composition when the new modified devolatilization rate equation was used. It can be seen that using this approach, there is a slight improvement in model predictions of $\mathrm{CO}$ and $\mathrm{CO}_{2}$.

The slight improvement in model predictions could be attributed to the small sample size chosen while developing the sub-model. Multiple points in the chosen temperature variation range could have generated a better sub-model leading to capturing better uncertainty propagation in the system. Also a sub-model predicting devolatilization product yields was not developed. Introduction of sub-models for devlatilization reaction kinetics as well as product yields can lead to improvement in predictions with UQ analysis. 


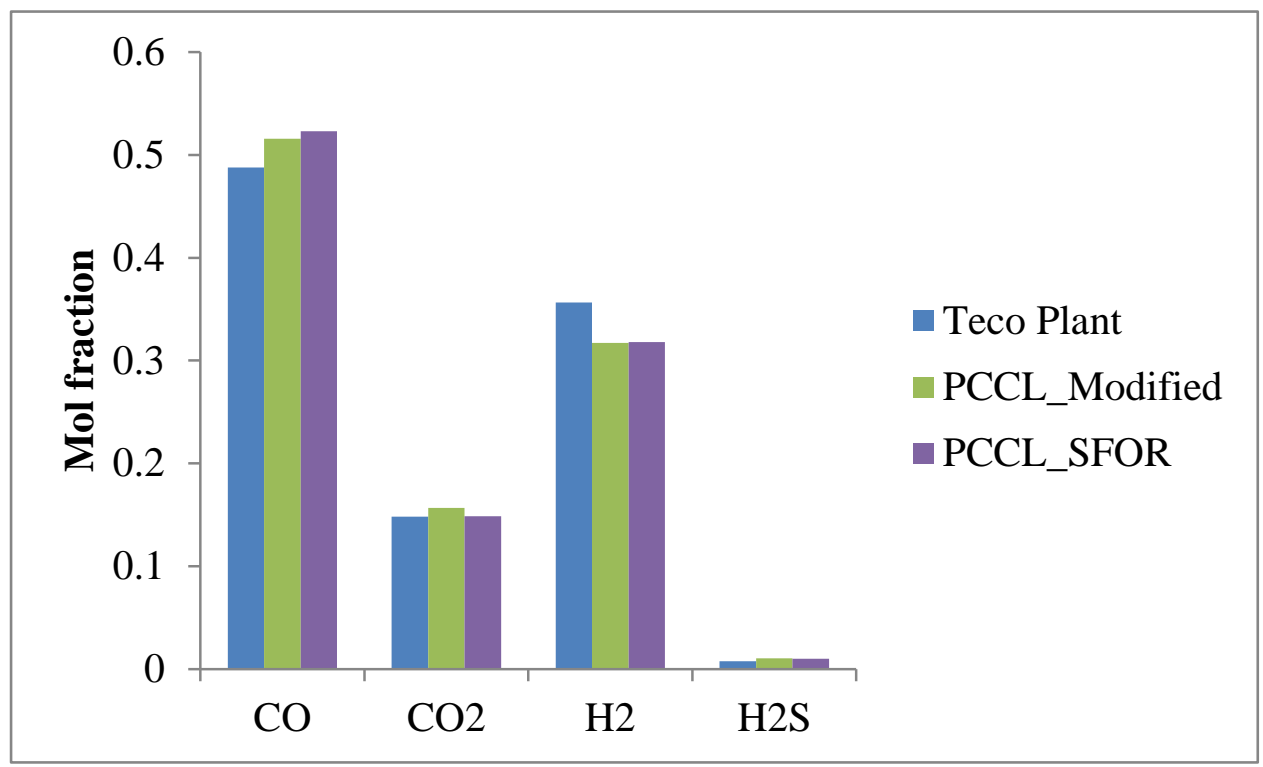

Figure 4.28: Exit synthesis gas composition $\mathrm{CH} 4$ free and dry basis with modified PCCL devolatilization rate.

This demonstration paves a path for UQ analysis of temperature variation on coal gasification reaction rate kinetics. Multiple sampling and new surrogate model development can improve this analysis further.

\subsection{Uncertainties Related to Coal Feed Variation}

The aim of this study was to observe the effects of coal feed variations on exit gas composition and to quantify them. For this study, Pittsburgh No.8, Illinois No.6, Powder River Basin (PRB) and North Dakota Lignite coals were evaluated. At least five samples of each coal were gathered from the literature. Table 4.7, 4.8, 4.9 and 4.10 show the analyses of coal gathered in terms of proximate and ultimate analyses on an as-received basis for Pittsburgh No.8, Illinois No. 6, PRB and Lignite coals. 
Table 4.7: Analyses of Pittsburgh No. 8

\begin{tabular}{|c|c|c|c|c|c|c|c|c|c|}
\hline Pittsburgh No.8 & & & & & & & & & \\
\hline Reference & VM & FC & Moisture & Ash & $\mathbf{C}$ & $\mathbf{H}$ & $\mathbf{O}$ & $\mathbf{N}$ & $\mathbf{S}$ \\
\hline Robinson et al. (2002) & 38.89 & 51.98 & 1.52 & 7.61 & 76.94 & 5.12 & 4.61 & 1.39 & 2.79 \\
\hline \multirow{3}{*}{ Baxter et al. (1996) } & 35.27 & 55.62 & 1.55 & 7.56 & 75.24 & 5.06 & 7.89 & 1.51 & 1.19 \\
\hline & 41.10 & 50.03 & 2.02 & 6.86 & 75.51 & 5.01 & 7.20 & 1.56 & 1.89 \\
\hline & 40.61 & 50.04 & 1.94 & 7.41 & 74.98 & 5.07 & 7.21 & 1.56 & 1.82 \\
\hline Slezak et al(2010) & 33.52 & 57.69 & 1.00 & 7.79 & 78.65 & 5.62 & 4.00 & 1.43 & 1.49 \\
\hline Chakravarty (1988) & 37.86 & 54.30 & 0.57 & 7.27 & 77.18 & 5.03 & 6.52 & 1.44 & 1.98 \\
\hline Shurtz et al. (2012) & 38.33 & 53.97 & 1.21 & 6.49 & 75.86 & 5.00 & 7.92 & 1.46 & 2.06 \\
\hline Gasior et al.(1967) & 35.60 & 54.40 & 2.00 & 8.00 & 75.87 & 5.04 & 6.30 & 1.53 & 1.26 \\
\hline Johnson et al.(1970) & 36.80 & 54.80 & 1.40 & 7.00 & 75.91 & 5.20 & 7.14 & 1.57 & 1.77 \\
\hline Rigby et al (2001) & 36.41 & 57.69 & 1.87 & 4.03 & 79.70 & 5.08 & 6.83 & 1.61 & 0.88 \\
\hline
\end{tabular}

Table 4.8: Analyses of Illinois No.6 Coal

\begin{tabular}{|c|c|c|c|c|c|r|r|r|r|}
\hline Illinois 6 & & & & & & \\
\hline Reference & VM & FC & Moisture & Ash & C & H & O & N & S \\
\hline Dennis et al.(2010) & 35.3 & 49 & 7.1 & 8.6 & 64.16 & 3.93 & 12.30 & 1.55 & 2.38 \\
\hline Helbel et al.(1996) & 35 & 43.4 & 11.7 & 9.9 & 62.00 & 4.00 & 8.40 & 1.10 & 2.90 \\
\hline Yoshida et al.(1990) & 32.3 & 44.5 & 5.8 & 17.4 & 61.67 & 4.76 & 7.14 & 1.23 & 2.00 \\
\hline Lee et al.(1991) & 35 & 52 & 3.2 & 9.8 & 67.16 & 4.52 & 10.70 & 1.31 & 3.31 \\
\hline Baxter et al. (1996) & 35.5 & 47.2 & 3.2 & 14.1 & 63.55 & 3.62 & 9.49 & 1.06 & 4.93 \\
\hline Mohomaad (2009) & 36.9 & 40.9 & 8 & 14.2 & 60.45 & 3.89 & 8.17 & 1.09 & 4.20 \\
\hline Weiland et al.(2012) & 40.6 & 44.9 & 3.6 & 11.0 & 61.60 & 4.61 & 13.38 & 1.16 & 4.70 \\
\hline Rigby et al.(2001) & 34.5 & 44.5 & 6.9 & 14.1 & 60.54 & 3.89 & 7.91 & 1.16 & 5.47 \\
\hline Robinson et al.(2008) & 37 & 39.3 & 13 & 10.7 & 59.82 & 4.12 & 7.55 & 1.07 & 3.74 \\
\hline Sheth et al.(2004) & 35.4 & 39.7 & 13.2 & 11.6 & 57.33 & 3.98 & 8.08 & 0.99 & 4.80 \\
\hline
\end{tabular}


Table 4.9: Analysis of PRB coal

\begin{tabular}{|c|c|c|c|c|c|r|r|r|r|}
\hline PRB & & & & & & \\
\hline Reference & VM & FC & Moisture & Ash & C & H & O & N & S \\
\hline Guffey and Bland(2004) & 31.5 & 35.7 & 29.8 & 3 & 50.28 & 4.23 & 11.93 & 0.55 & 0.21 \\
\hline Weiland et al.(2012) & 32.49 & 40.05 & 20.43 & 7.03 & 53.49 & 3.37 & 14.16 & 1.22 & 0.30 \\
\hline Popa et al.(2013) & 34.29 & 38.98 & 20.87 & 5.86 & 53.67 & 2.46 & 15.83 & 0.89 & 0.42 \\
\hline Prabu and Jayanti(2012) & 31.9 & 32.53 & 29.2 & 6.37 & 47.42 & 3.53 & 11.95 & 0.91 & 0.62 \\
\hline Chen et al.(2011) & 36.8 & 41.7 & 15.0 & 6.5 & 59.01 & 4.04 & 14.77 & 0.68 & - \\
\hline Wang et al.(2012) & 40.2 & 43.2 & 8.5 & 8.1 & 64.50 & 4.40 & 12.60 & 0.60 & 1.30 \\
\hline NETL Document & 35.7 & 43.44 & 15.24 & 5.61 & 59.28 & 3.73 & 15.15 & 0.76 & 0.26 \\
\hline
\end{tabular}

Table 4.10: Analysis of Lignite coal

\begin{tabular}{|c|c|c|c|c|c|c|c|r|l|}
\hline Lignite & & & & & & & & \\
\hline Reference & VM & FC & Moisture & Ash & C & H & O & N & S \\
\hline NETL document & 37.1 & 31.0 & 17.1 & 14.8 & 45.98 & 3.51 & 17.10 & 0.94 & 0.56 \\
\hline Robinson et al.(2008) & 24.9 & 27.8 & 36.9 & 10.4 & 37.42 & 2.27 & 12.23 & 0.58 & 0.21 \\
\hline Tang et al.(1996) & 44.83 & 45.69 & 3.9 & 5.58 & 58.68 & 3.81 & 26.83 & 0.97 & 0.24 \\
\hline Tamhankar et al. (1984) & 31.3 & 31.7 & 26.9 & 10.1 & 44.39 & 2.99 & 13.48 & 0.77 & 1.35 \\
\hline Shadle et al. (2001) & 38.9 & 36.4 & 20.0 & 4.7 & 55.23 & 4.15 & 14.90 & 0.67 & 0.35 \\
\hline Yang et al.( 2007) & 37.3 & 45.7 & 6.8 & 10.3 & 52.52 & 4.25 & 25.56 & 0.25 & 0.36 \\
\hline
\end{tabular}

Table 4.11 reports the variation observed in a particular coal when different samples of the same type are considered, e.g., mean volatile matter contents for Pittsburgh No.8, Illinois No.6, PRB and Lignite coals are 37.44, 35.75, 34.70, and 35.72, respectively, per $100 \mathrm{gm}$ of coal. Based on the samples considered, the standard deviations observed are 2.39 and 2.13 for Pittsburgh No. 8 and Illinois No.6 coals, respectively, and 3.13 for the remaining two coal types. The ultimate aim is to quantify the uncertainty in exit gas compositions with respect to coal feed. 
Table 4.11: Variations in coal analysis

\begin{tabular}{|l|c|r|r|r|r|r|r|r|r|r|}
\hline & & \multicolumn{1}{|c|}{ VM } & \multicolumn{1}{c|}{ FC } & Moisture & \multicolumn{1}{c|}{ Ash } & \multicolumn{1}{c|}{ C } & \multicolumn{1}{c|}{ H } & O & N & S \\
\hline Pitt \# 8 & Mean & 37.44 & 54.05 & 1.51 & 7.00 & 76.58 & 5.12 & 6.56 & 1.50 & 1.71 \\
\hline & Std Dev & 2.39 & 2.71 & 0.48 & 1.14 & 1.55 & 0.18 & 1.30 & 0.07 & 0.54 \\
\hline & & & & & & & & & & \\
\hline ILL \# 6 & Mean & 35.75 & 44.54 & 7.57 & 12.14 & 61.83 & 4.13 & 9.31 & 1.17 & 3.84 \\
\hline & Std Dev & 2.13 & 4.05 & 3.89 & 2.71 & 2.68 & 0.37 & 2.13 & 0.16 & 1.17 \\
\hline & & & & & & & & & & \\
\hline PRB & Mean & 34.70 & 39.37 & 19.86 & 6.07 & 55.38 & 3.68 & 13.77 & 0.80 & 0.44 \\
\hline & Std Dev & 3.13 & 4.03 & 7.76 & 1.58 & 5.88 & 0.65 & 1.60 & 0.23 & 0.42 \\
\hline & & & & & & & & & & \\
\hline Lignite & Mean & 35.72 & 36.38 & 18.60 & 9.31 & 49.04 & 3.50 & 18.35 & 0.70 & 0.51 \\
\hline & Std Dev & 3.13 & 4.03 & 7.76 & 1.58 & 5.88 & 0.65 & 1.60 & 0.23 & 0.42 \\
\hline
\end{tabular}

\subsubsection{Coal Feed Variation in Transport Flow Gasifier}

As stated previously, the aim of this study was to capture the variations in exit gas composition from a transport flow gasifier caused by the variations in coal feed. For this geometry, which is similar to a KBR transport gasifier, a model was created in MFIX. Based on data available in the open literature (Ariyapadi et al., 2008) and case number KBR TC20-69 reported by Li et al. (2012), the geometry was set up to be proportional to the original reactor configuration, a 2-D geometry of $10 \mathrm{~cm} \times 1200 \mathrm{~cm}$ was used. The recycle char flow rate, which is not reported in the open literature, was manipulated to obtain similar exit trends as reported by $\mathrm{Li}$ et al. (2012). Using this 2-D transport gasifier geometry a series of runs was performed to enable a UQ analysis for input coal variation. Table 4.12 gives the operating conditions of the gasifier. 
Table 4.12: Operating conditions of the gasifier

\begin{tabular}{|c|c|}
\hline Parameter & Value \\
\hline Temperature & $955^{\circ} \mathrm{C}$ \\
\hline Pressure & $1.2 \mathrm{MPa}$ \\
\hline Coal feed rate & $4 \mathrm{~g} / \mathrm{s}$ \\
\hline Air flow rate & $23.57 \mathrm{~g} / \mathrm{s}$ \\
\hline Recycled char flow rate & $100 \mathrm{~g} / \mathrm{s}$ \\
\hline Diameter of coal particle & $100 \mu \mathrm{m}$ \\
\hline
\end{tabular}

\section{Simulation set up:}

The computational domain for the 2-D gasifier, shown previously in Figure 3.1, was discretized using Cartesian coordinates, which correspond to the following dimensions: $10 \mathrm{~cm}$ $\times 1200 \mathrm{~cm} \times 1 \mathrm{~cm}$. Proper boundary conditions in terms of coal and air feed inlet, pressure outlet and temperature along with gas species composition were specified based on the operating conditions. Relevant information, such as PRB coal proximate and ultimate analysis, operating pressure, and temperature, were provided to $\mathrm{C} 3 \mathrm{M}$ for running PCCL and MGAS packages to extract appropriate chemical kinetics. In the current study, kinetic expressions for moisture release, devolatilization, tar cracking, steam gasification, $\mathrm{CO}_{2}$ gasification, hydrogasification, char combustion, hydrogen combustion, carbon monoxide combustion, and methane combustion are based on the MGAS model. To evaluate the effect of coal devolatilization, different product yields and kinetic expressions derived from PCCL were incorporated into the gasifier simulation through C3M.

\section{Grid Independence Study:}

The first step in the current analysis was to determine the grid independence of the geometry used. This was performed by using four resolutions of $10 \times 1200,20 \times 2400,40 \times 4800$ and $60 \times 7200$, respectively. The computation was conducted on a high-performance computing (HPC) system with 192 Xeon quad-core CPU running at $2.83 \mathrm{GHz}$. Transient simulations of 20 
seconds of real time were conducted for each case on 128 cores. The time taken for each grid resolution is reported in Table 4.12 .

Table 4.13: Simulation time

\begin{tabular}{|c|c|}
\hline Resolution & Total Time (hr) \\
\hline $10 \times 1200$ & 28.00 \\
\hline $20 \times 2400$ & 43.42 \\
\hline $40 \times 4800$ & 56.53 \\
\hline $60 \times 7200$ & 98.61 \\
\hline
\end{tabular}

The gas composition along the reactor length was compared in all cases in order to evaluate if grid independence, in terms of hydrodynamics and reactivity, was obtained. Figures 4.29 to 4.31 show the yields of $\mathrm{CO}, \mathrm{CO}_{2}$ and $\mathrm{H}_{2}$ along the reactor length for all four cases. It can be seen that the trends from grid resolution of $40 \times 4800$ and $60 \times 7200$ are very similar. Hence the grid resolution of $40 \times 4800$ is chosen to perform further UQ analysis as its computation cost is lower. 


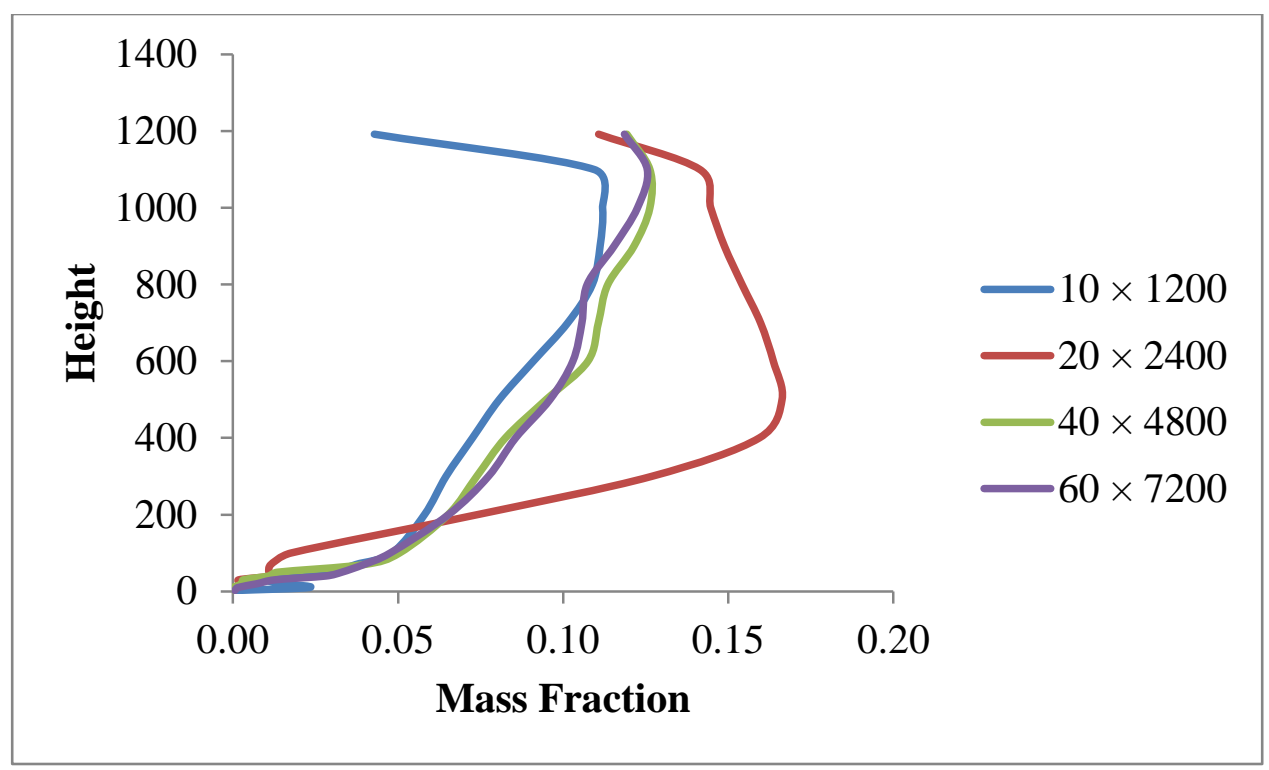

Figure 4. 29: Mass fraction of $\mathrm{CO}$ along the reactor height for grid resolutions of $10 \times 1200,20$ $\times 2400,40 \times 4800$ and $60 \times 7200$ for PRB coal.

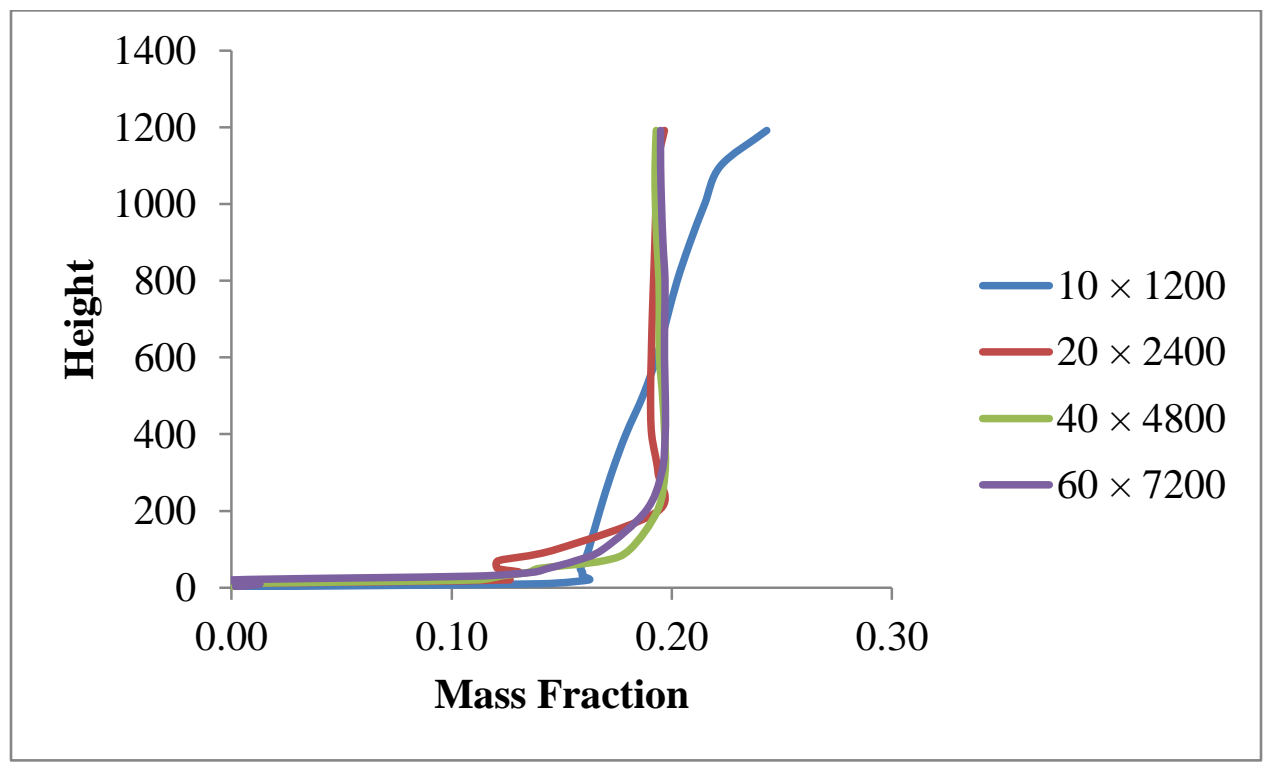

Figure 4.30: Mass fraction of $\mathrm{CO}_{2}$ along the reactor height for grid resolutions of $10 \times 1200,20$ $\times 2400,40 \times 4800$ and $60 \times 7200$ PRB coal. 


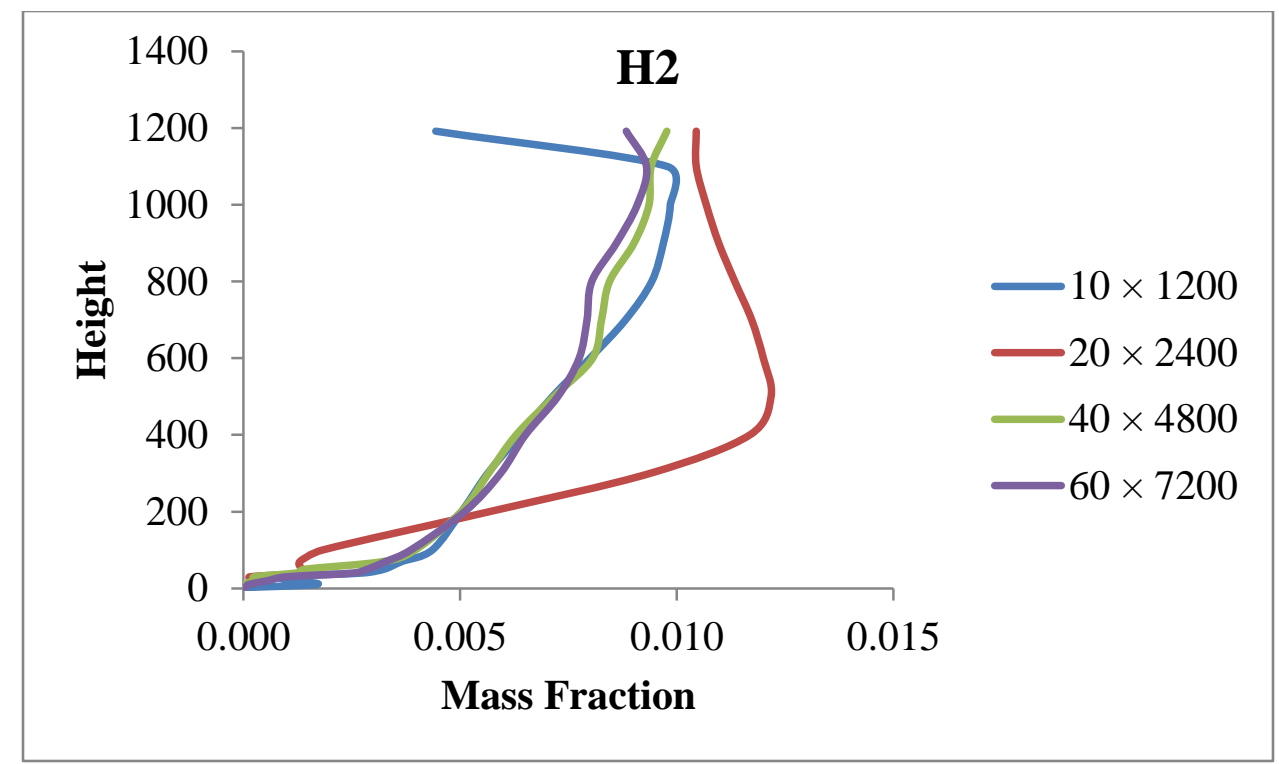

Figure 4.31: Mass fraction of $\mathrm{H}_{2}$ along the reactor height for grid resolutions of $10 \times 1200,20$ $\times 2400,40 \times 4800$ and $60 \times 7200$ PRB coal.

In total, 10 runs each for Pittsburgh No.8 and Illinois No.6 coals were performed; 7 runs for PRB coals and 6 runs for Lignite coals were also performed. Exit gas flow was monitored to determine if the simulation reached a steady state. The molar exit gas composition reported here were time-averaged over the last 15 to 20 seconds of the simulation.

Figures 4.32 and 4.33 show the compositions of $\mathrm{CO}$ and $\mathrm{H}_{2}$ along the reactor length for 10 coal samples of Pittsburgh No.8. It can be seen that variations in the coal feeds lead to some variations in gas species composition along the reactor length. These variations can lead to different temperature zones in the reactor, which affect other reactions that are occurring simultaneously. The trend reported in these figures might be the result of the back mixing of gas flow . It should be noted that plots are not the real cross-sectional average of mass fraction of species; they are the average of mass fraction along all cells divided by the number of cells. Similar trends were observed when Illinois No.6, PRB and Lignite coal samples were simulated.

Averaged exit gas compositions of all gas species were obtained in order to study the effect of coal feed. 


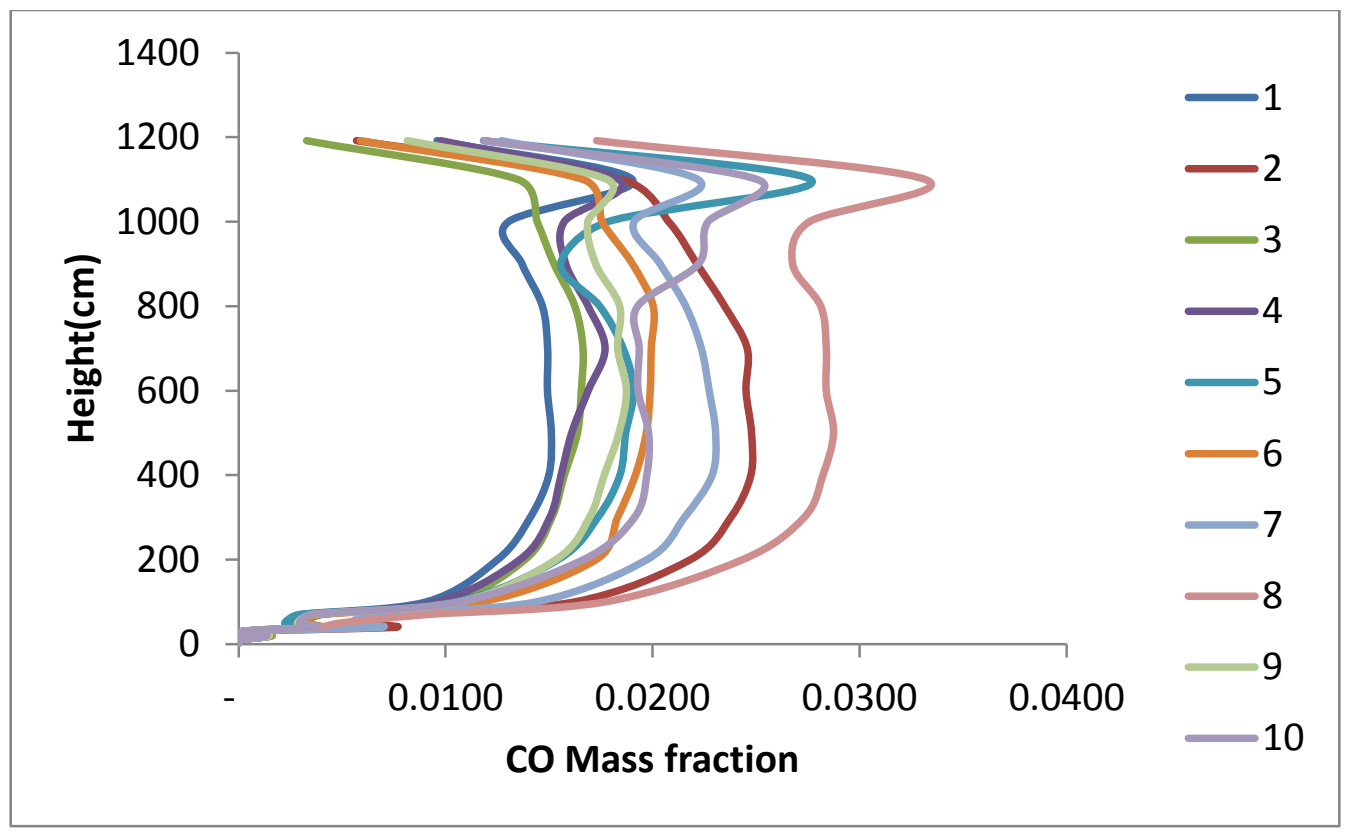

Figure 4.32: Mass fraction of $\mathrm{CO}$ along the reactor height for 10 coal samples of Pittsburgh No.8

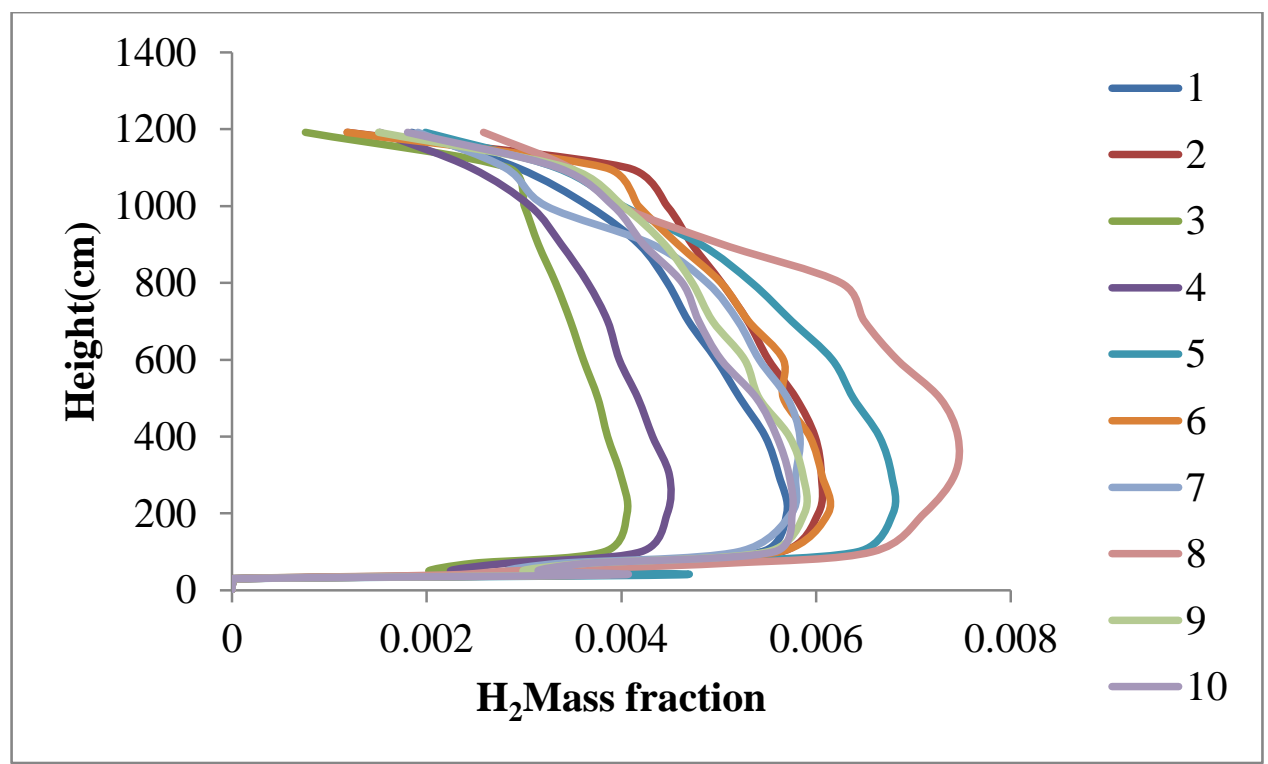

Figure 4.33: Mass fraction of $\mathrm{H}_{2}$ along the reactor height for 10 coal samples of Pittsburgh No.8

Figures 4.34 to 4.37 show the distributions of exit molar gas composition for $\mathrm{CO}, \mathrm{CO}_{2}$, $\mathrm{H}_{2}$, and $\mathrm{CH}_{4}$ for Pittsburgh No.8, Illinois No.6, PRB and Lignite coals, respectively. In all the cases tested, distributions are close to normal for $\mathrm{CO}$ and $\mathrm{CO}_{2}$, while $\mathrm{H}_{2}$ and $\mathrm{CH}_{4}$ show skewed distributions. 


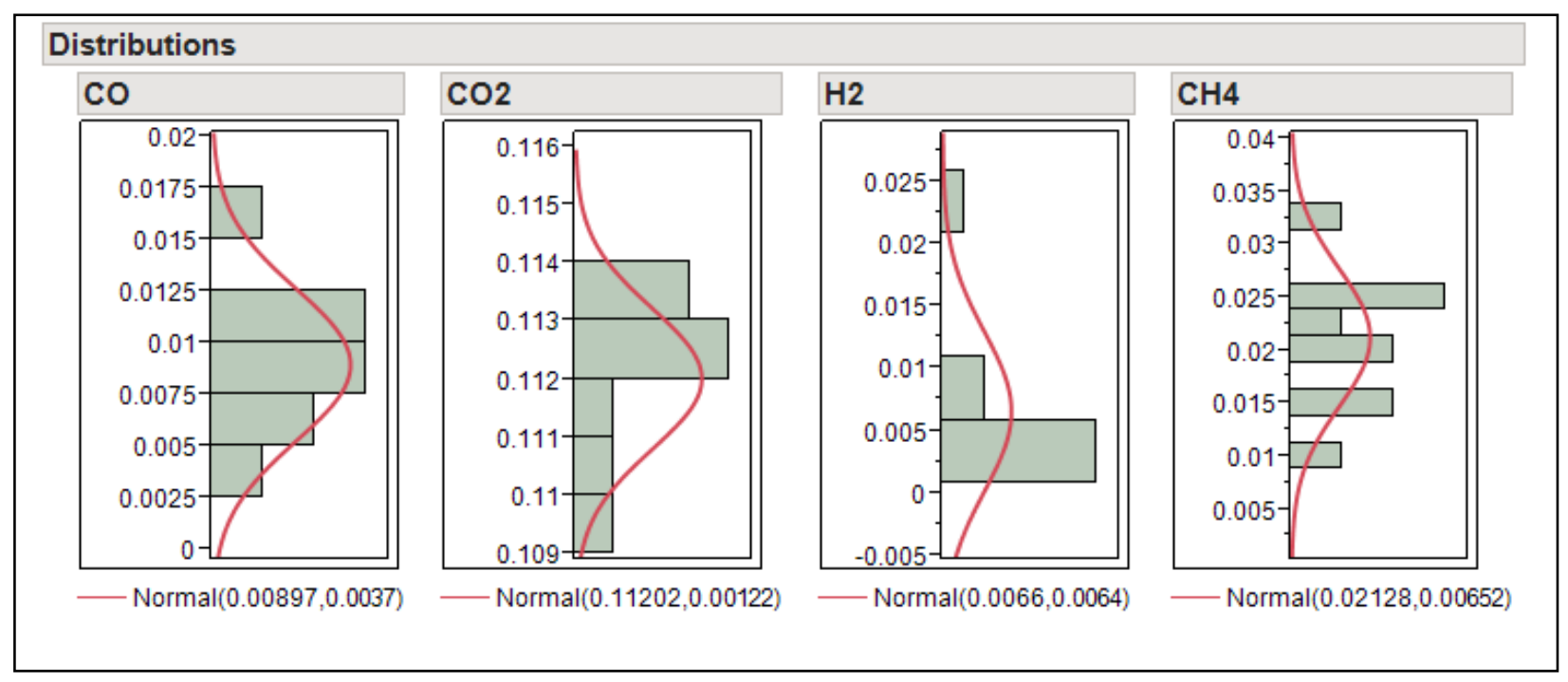

Figure 4.34: Exit molar gas composition of $\mathrm{CO}, \mathrm{CO}_{2}, \mathrm{H}_{2}, \mathrm{CH}_{4}$ for 10 samples of Pittsburgh No.8

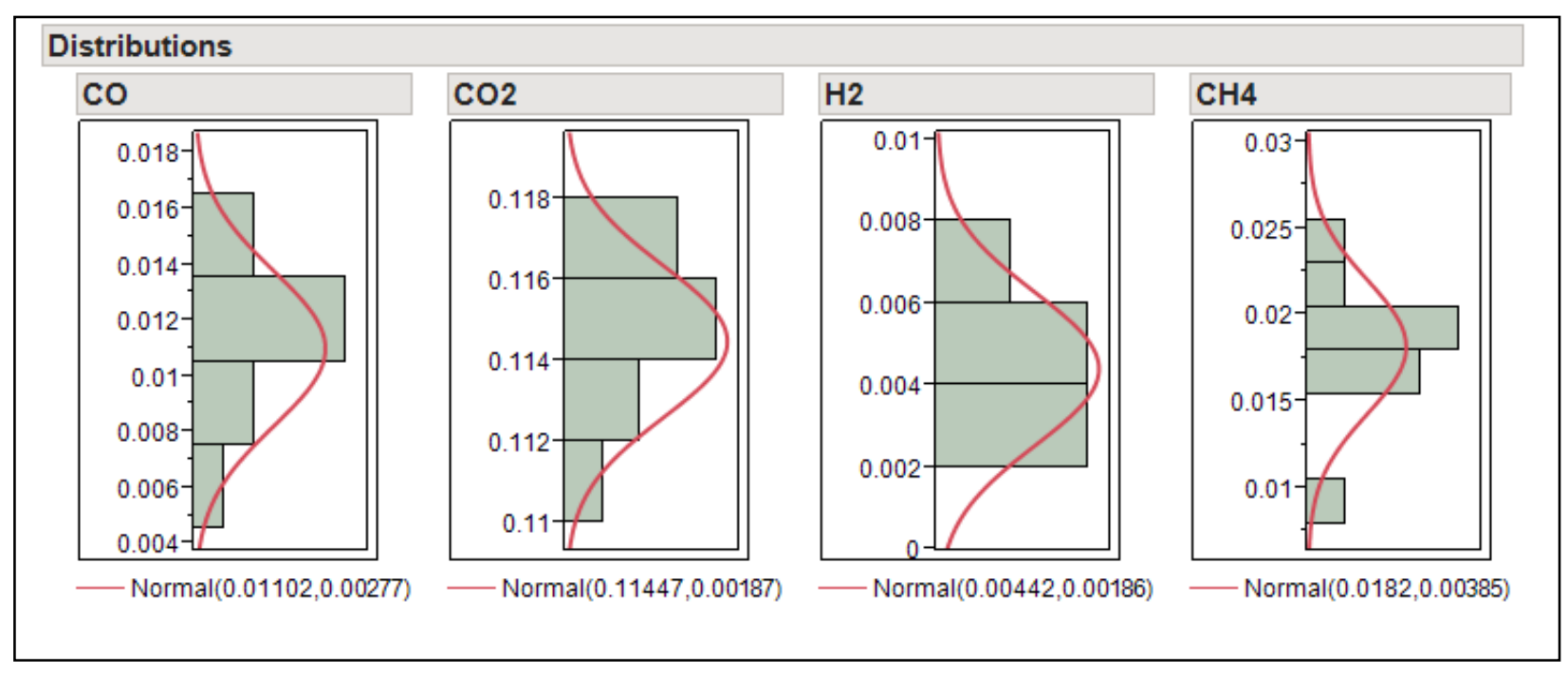

Figure 4.35: Exit molar gas composition of $\mathrm{CO}, \mathrm{CO}_{2}, \mathrm{H}_{2}, \mathrm{CH}_{4}$ for 10 samples of Illinois No.6 


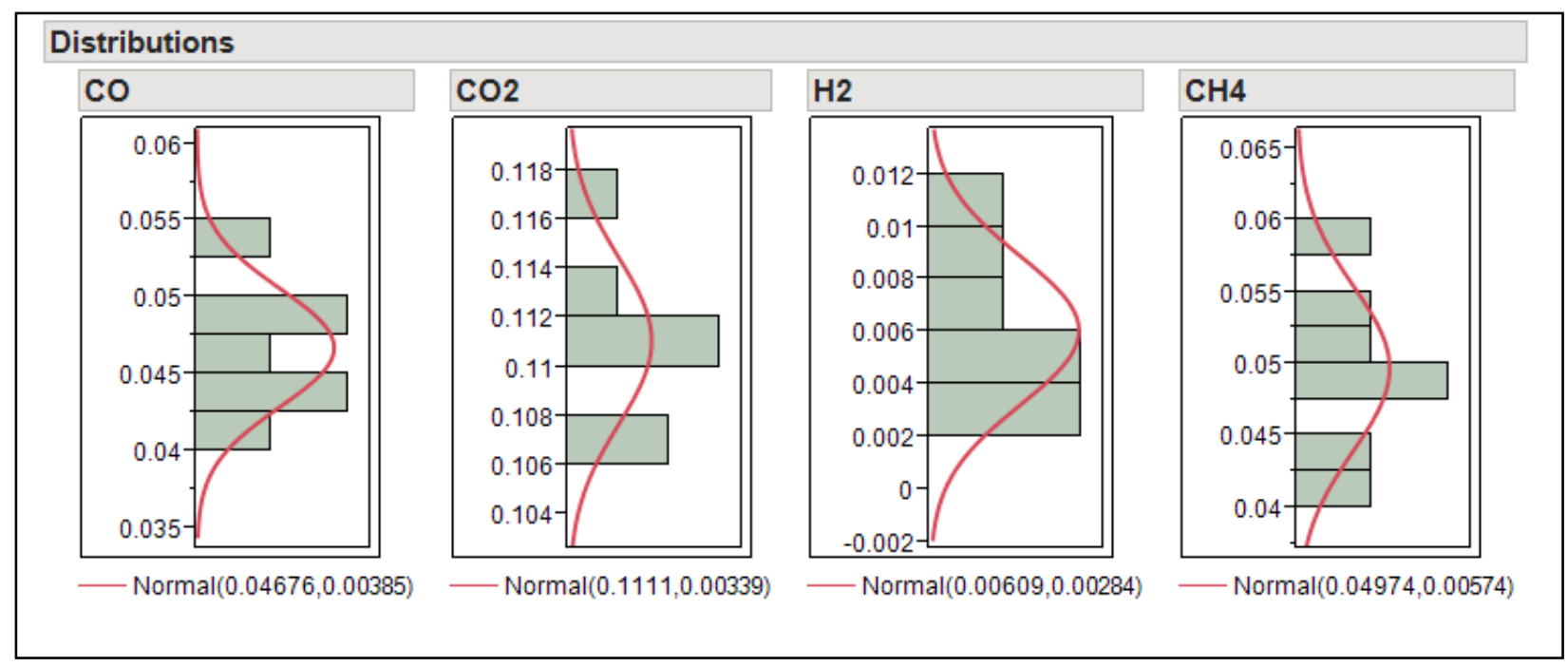

Figure 4.36: Exit molar gas composition of $\mathrm{CO}, \mathrm{CO}_{2}, \mathrm{H}_{2}, \mathrm{CH}_{4}$ for 7 samples of PRB Coal

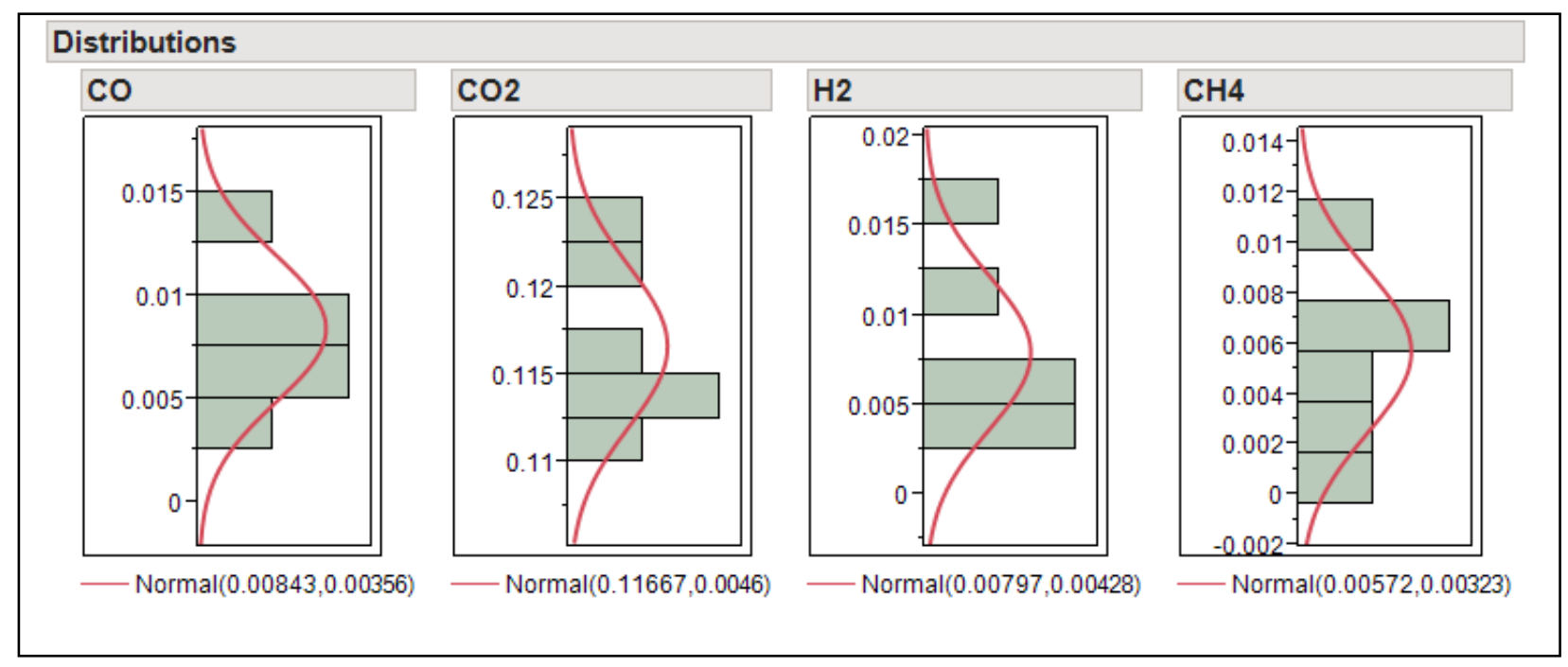

Figure 4.37: Exit molar gas composition of $\mathrm{CO}, \mathrm{CO}_{2}, \mathrm{H}_{2}, \mathrm{CH}_{4}$ for 6 samples of Lignite Coal

In the case of Pittsburgh No.8, $\mathrm{CO}$ and $\mathrm{CH}_{4}$ show normal distributions, but $\mathrm{CO}_{2}$ and $\mathrm{H}_{2}$ are skewed to the right. For Illinois No.6 coal samples, $\mathrm{CO}, \mathrm{CO}_{2}, \mathrm{CH}_{4}$ and $\mathrm{H}_{2}$ show nearly perfect normal distributions. $\mathrm{H}_{2}$ distribution for PRB coal samples are skewed to the left. For Lignite coal, $\mathrm{CH}_{4}$ has distribution skewed to the right. 
Table 4.14 summarizes the mean, standard deviation, and high-low range for exit gas composition in terms of \% C content for all 4 coals.

Table 4.14: Exit gas composition variation

\begin{tabular}{|c|c|c|c|c|c|c|}
\hline & & $\% \mathrm{C}$ & $\mathrm{CO}$ & $\mathrm{CO}_{2}$ & $\mathbf{H}_{2}$ & $\mathrm{CH}_{4}$ \\
\hline \multirow[t]{4}{*}{ Pit \# 8} & Mean & 76.58 & 0.0090 & 0.1120 & 0.0066 & 0.0213 \\
\hline & Std Dev & 1.55 & 0.0037 & 0.0012 & 0.0064 & 0.0065 \\
\hline & High & 78.13 & 0.0127 & 0.1132 & 0.0130 & 0.0278 \\
\hline & Low & 75.04 & 0.0053 & 0.1108 & 0.0002 & 0.0148 \\
\hline \multirow[t]{4}{*}{ ILL \# 6} & Mean & 70.90 & 0.0110 & 0.1145 & 0.0044 & 0.0182 \\
\hline & Std Dev & 8.22 & 0.0028 & 0.0019 & 0.0019 & 0.0038 \\
\hline & High & 79.12 & 0.0138 & 0.1163 & 0.0063 & 0.0220 \\
\hline & Low & 62.68 & 0.0082 & 0.1126 & 0.0026 & 0.0144 \\
\hline \multirow[t]{4}{*}{ PRB } & Mean & 76.88 & 0.0468 & 0.1111 & 0.0061 & 0.0497 \\
\hline & Std Dev & 1.72 & 0.0038 & 0.0034 & 0.0028 & 0.0058 \\
\hline & High & 78.60 & 0.0506 & 0.1145 & 0.0089 & 0.0555 \\
\hline & Low & 75.16 & 0.0429 & 0.1077 & 0.0032 & 0.0440 \\
\hline \multirow[t]{4}{*}{ Lignite } & Mean & 66.73 & 0.0084 & 0.1167 & 0.0080 & 0.0057 \\
\hline & Std Dev & 6.42 & 0.0035 & 0.0046 & 0.0043 & 0.0032 \\
\hline & High & 73.14 & 0.0120 & 0.1212 & 0.0123 & 0.0089 \\
\hline & Low & 60.31 & 0.0049 & 0.1121 & 0.0037 & 0.0024 \\
\hline
\end{tabular}

For the given transport gasifier operating condition, when the Pittsburgh No.8 coal fed to the system has a carbon content ranging from $75.04 \%$ to $78.13 \%$, then the exit $\mathrm{CO}$ and $\mathrm{H}_{2}$ 
molar composition will vary between 0.0053 to 0.0127 and 0.0002 to 0.013 , respectively. The compositions of $\mathrm{CO}_{2}$ show little variation.

Similarly for Illinois No. 6 coal, when the carbon content varies from $62.68 \%$ to 79.12 $\%$, the exit $\mathrm{CO}$ and $\mathrm{H}_{2}$ mole fraction will vary between 0.0082 to 0.0138 and 0.0026 to 0.0063 , respectively, and the $\mathrm{CO}_{2}$ composition will remain relatively unaffected. Figure 4.38 shows the variation of $\mathrm{CO}, \mathrm{CO}_{2}, \mathrm{CH}_{4}$ and $\mathrm{H}_{2}$ mol fractions with error bar predictions for Illinois No.6 coal.

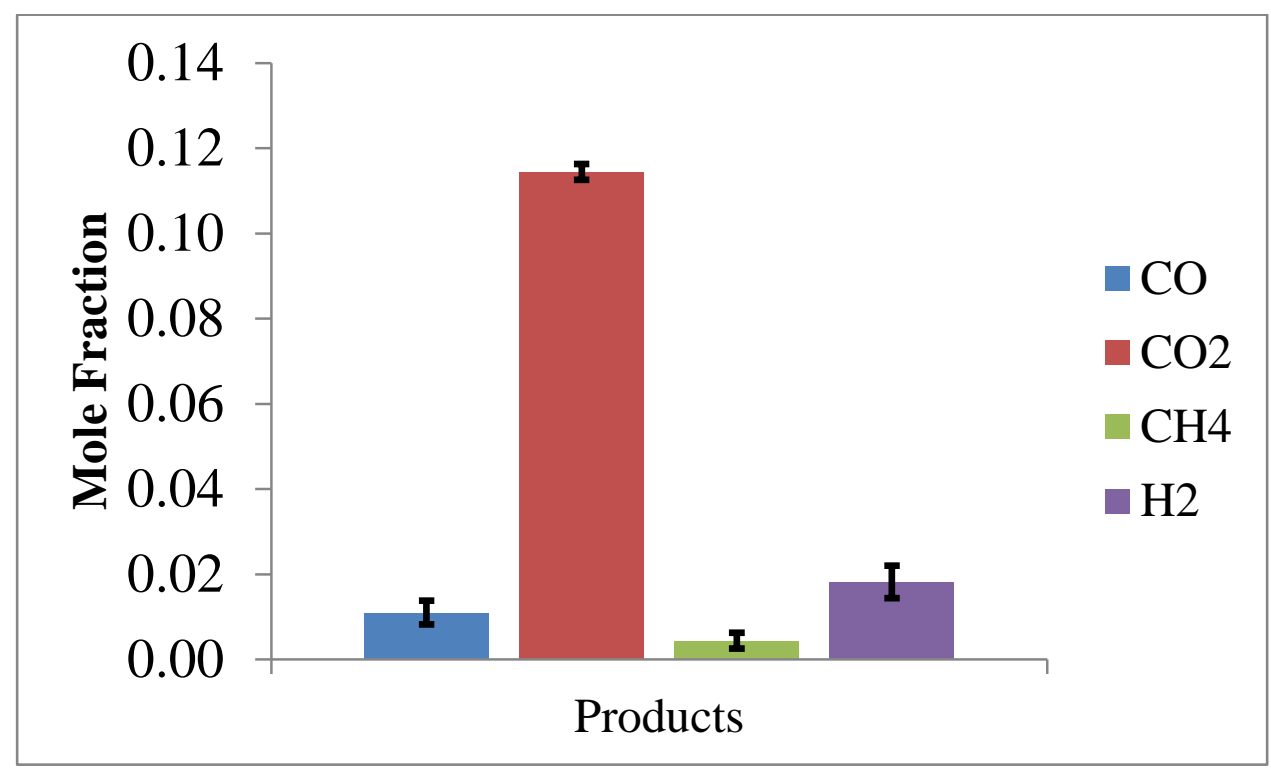

Figure 4.38: Graph showing variation in $\mathrm{CO} \mathrm{CO}_{2}, \mathrm{CH}_{4}$ and $\mathrm{H}_{2}$ mol fractions at exit for Illinois No.6 coal in transport flow gasifier.

These kinds of analyses are helpful in predicting the range of uncertainties in exit syngas composition based on possible coal feed variation in operational coal gasifier plant. 


\subsection{Coal Blending Sensitivity Study}

In most cases, the blending of coals affects coal quality leading to a decrease in combustion efficiency and unexpected slag formation behavior (Perata et al., 2001). For this reason, the sensitivity of coal blending on exit syngas composition was studied for transport and entrained flow gasifiers.

\subsubsection{Coal blending in a Transport Flow Gasifier}

For this case study, 3 blends of Pittsburgh No.8 and Illinois No.6 were created from the 10 coal samples reported in Table 4.7 and Table 4.8. These new coal samples are shown in Table 4.15 .

Table 4.15: Coal Blends used for the Transport Flow Gasifier Study

\begin{tabular}{|c|c|c|c|c|c|c|}
\hline $\begin{array}{c}\text { Analyses } \\
(\boldsymbol{\%})\end{array}$ & Pit8_1 & Pi8_2 & Pit8_3 & ILL_1 & ILL_2 & ILL_3 \\
\hline VM & 40.10 & 37.83 & 33.52 & 37.71 & 34.49 & 35.00 \\
\hline FC & 50.79 & 53.05 & 57.69 & 42.57 & 44.00 & 52.00 \\
\hline Moisture & 01.89 & 01.62 & 01.00 & 07.89 & 06.75 & 03.20 \\
\hline Ash & 07.23 & 07.50 & 07.79 & 11.83 & 14.76 & 09.80 \\
\hline $\mathbf{C}$ & 75.41 & 75.92 & 78.65 & 75.89 & 77.83 & 77.20 \\
\hline $\mathbf{H}$ & 05.05 & 05.08 & 05.62 & 05.43 & 05.53 & 05.20 \\
\hline $\mathbf{O}$ & 07.01 & 06.44 & 04.00 & 12.15 & 10.28 & 12.30 \\
\hline $\mathbf{N}$ & 01.54 & 01.47 & 01.43 & 01.41 & 01.50 & 01.50 \\
\hline $\mathbf{S}$ & 01.88 & 01.96 & 01.49 & 05.11 & 04.85 & 03.80 \\
\hline
\end{tabular}

The transport gasifier set up described in Section 4.2 was used and simulations were run for a total of 90 seconds. Once steady state conditions were achieved, the new blend of coal was introduced. The transient results show the effect of introducing the new coal feed on the exit gas composition. 
For Pittsburgh No.8, the simulation was started with blend Pit8_1, and after 26 sec blend Pit8_2 was introduced, and finally after $60 \mathrm{sec}$ the last blend was fed to the system. In a similar manner for Illinois No.6, the simulation was started with blend ILL_1, after 27 sec blend ILL_2 was introduced, and after $51 \mathrm{sec}$ the last blend was fed to the system. For each change in feed, devolatilization kinetics and product yield in terms of mass fractions were changed in the input file for MFIX (mfix.dat).

For the analysis, transient exit gas compositions of $\mathrm{CO}, \mathrm{CO}_{2}$ and $\mathrm{H}_{2}$ were obtained via post processing. Figures 4.39 to 4.41 show the transient exit gas compositions of $\mathrm{CO}, \mathrm{CO}_{2}$ and $\mathrm{H}_{2}$ for Pittsburgh No. 8, respectively. The dotted lines mark the point of entry of a new coal blend. There is not much fluctuation in exit gas composition of $\mathrm{CO}, \mathrm{CO}_{2}$, and $\mathrm{H}_{2}$ for these coal blends.

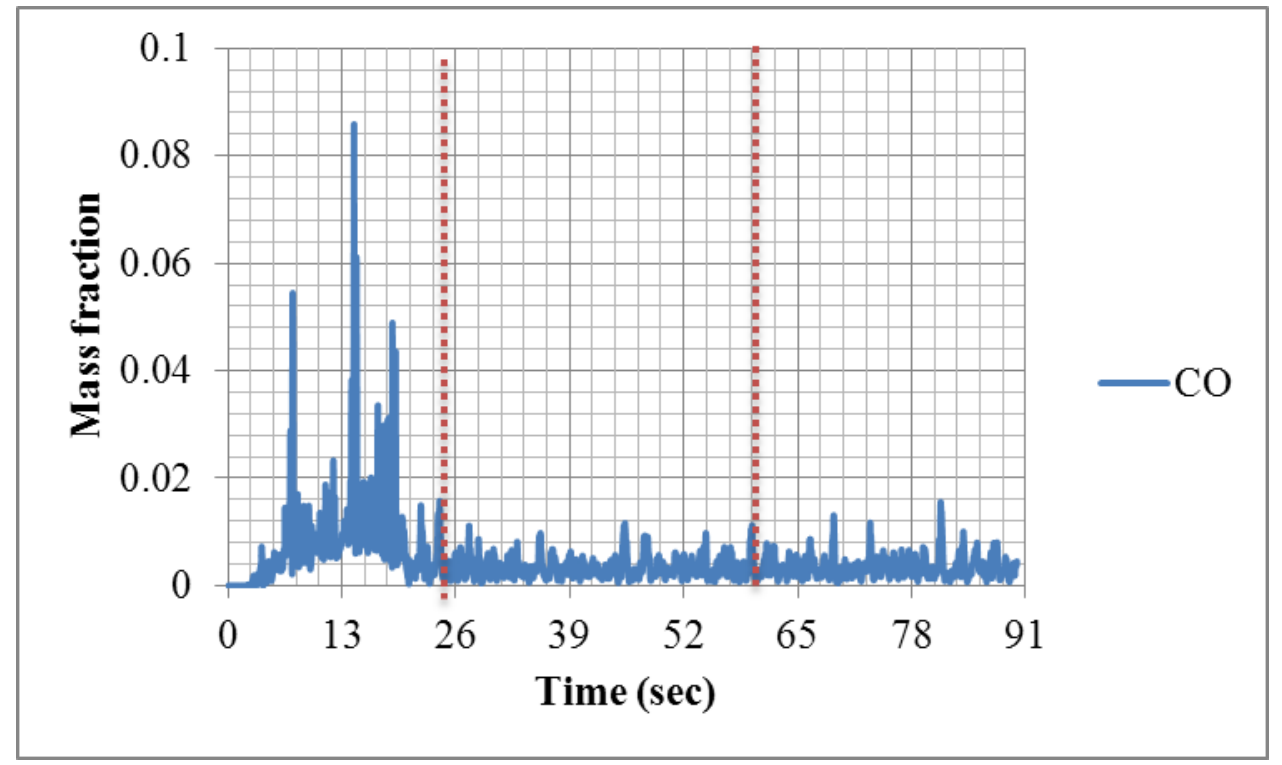

Figure 4.39: Transient exit gas composition of CO for Pittsburgh No.8 coal blending 


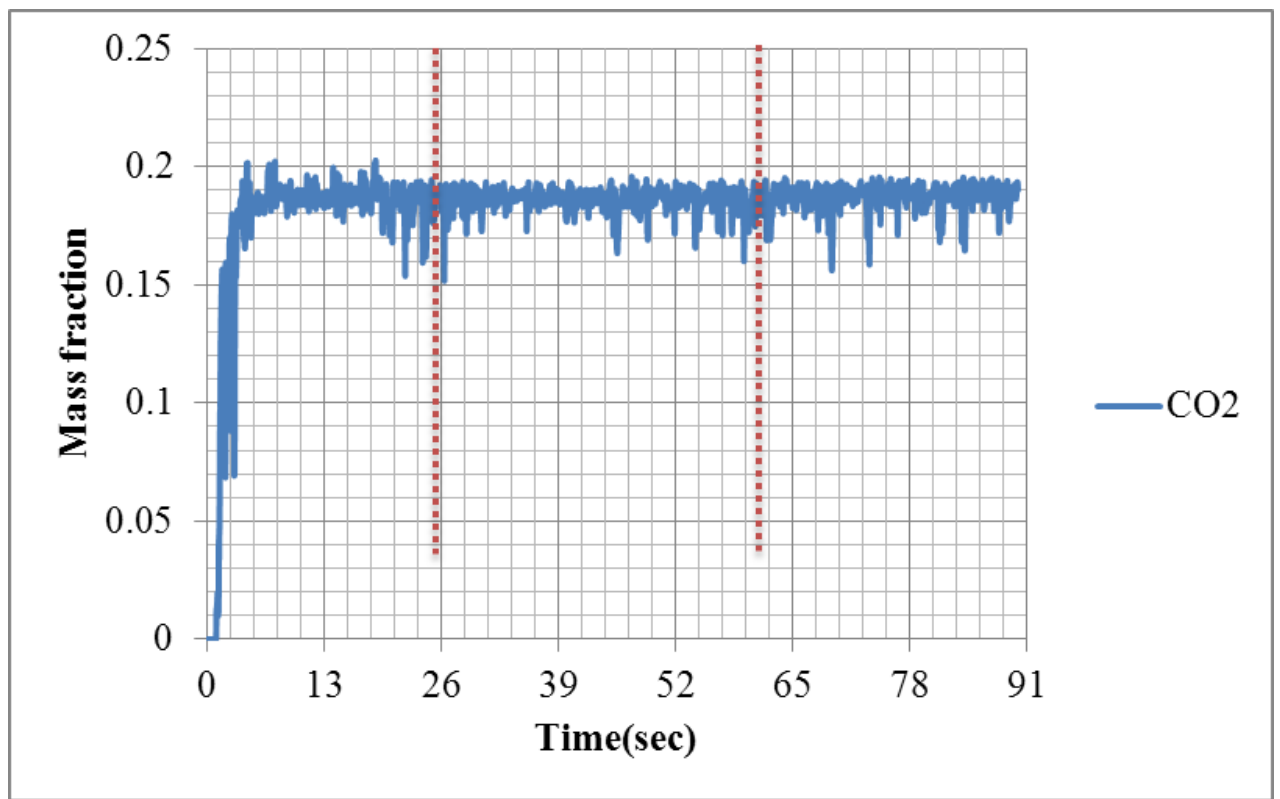

Figure 4.40: Transient exit gas composition of $\mathrm{CO}_{2}$ for Pittsburgh No.8 coal blending

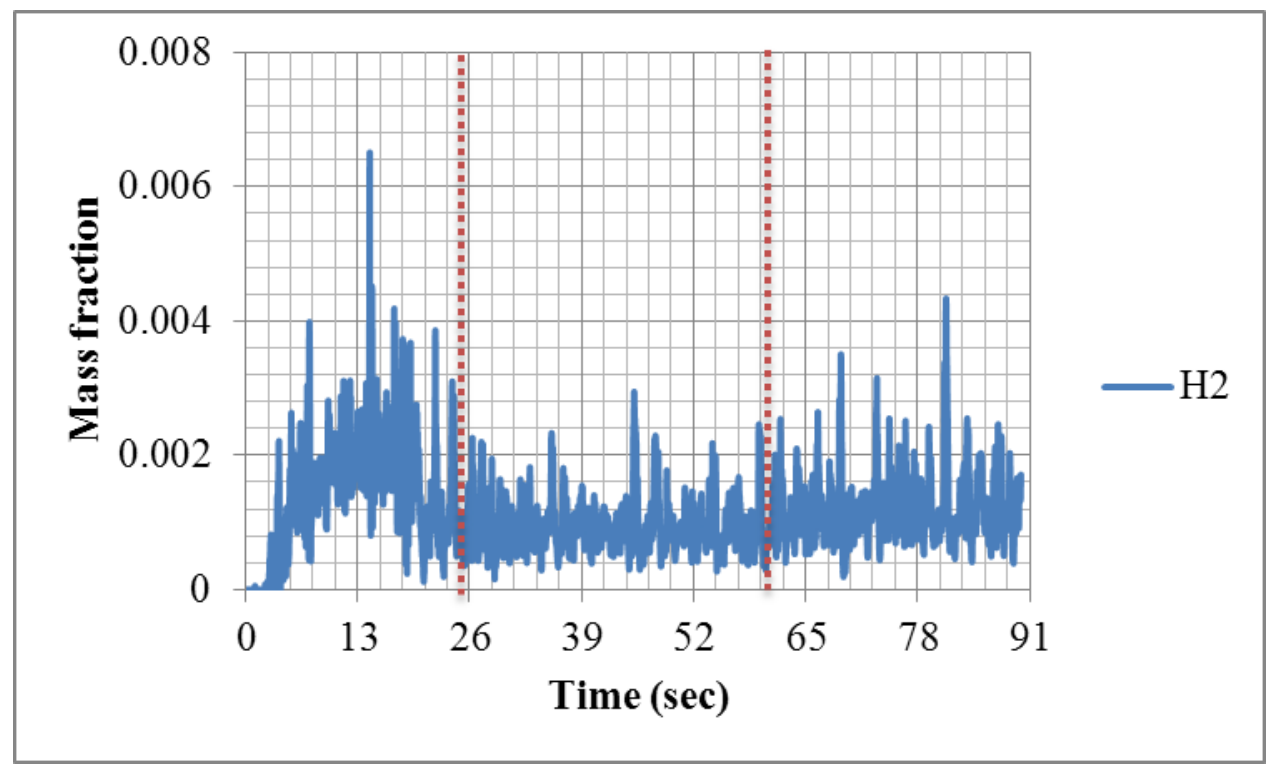

Figure 4.41: Transient exit gas composition of $\mathrm{H}_{2}$ for Pittsburgh No.8 coal blending 


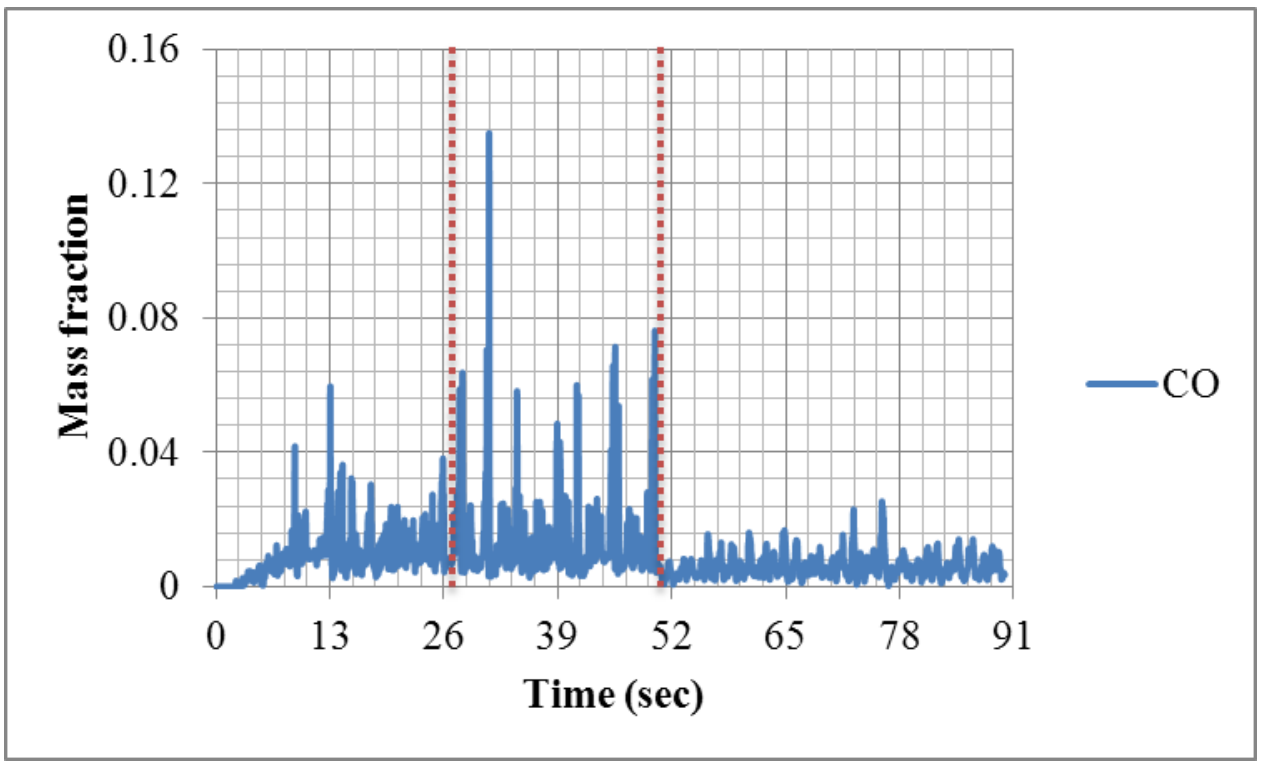

Figure 4.42: Transient exit gas composition of $\mathrm{CO}$ for Illinois No.6 coal blending

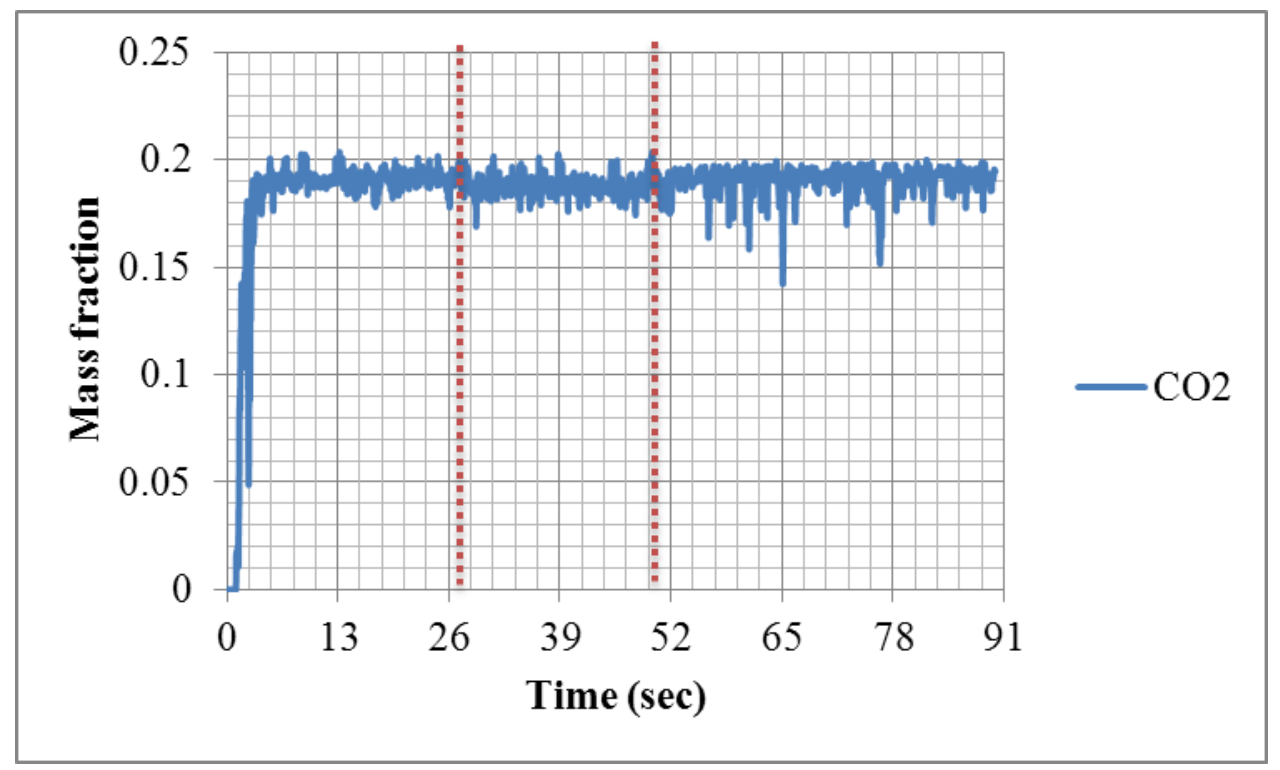

Figure 4.43 : Transient exit gas composition of $\mathrm{CO}_{2}$ for Illinois No.6 coal blending 


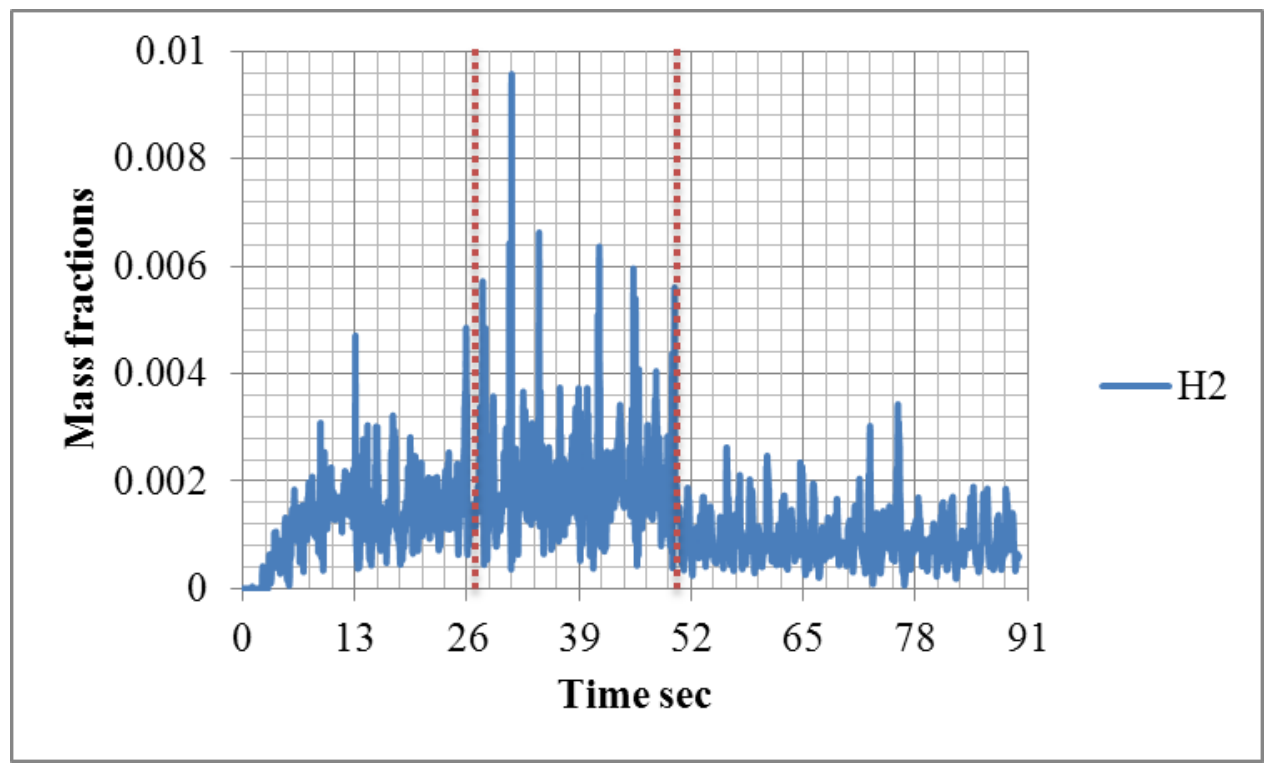

Figure 4.44 : Transient exit gas composition of $\mathrm{H}_{2}$ for Illinois No.6 coal blending

Transient exit gas compositions of $\mathrm{CO}, \mathrm{CO}_{2}$, and $\mathrm{H}_{2}$ for Illinois No.6 are also shown in Figures 4.42 to 4.44 , respectively. The dotted lines mark the point of entry for new blend. CO and $\mathrm{H}_{2}$ show little variation in the transient composition. Table 4.16 reports the time averaged exit gas composition for all the cases for the last 5 seconds of the steady state.

Table 4.16: Time averaged exit composition

\begin{tabular}{|l|c|c|c|}
\hline Pitt 8 & CO & $\mathbf{C O}_{2}$ & $\mathbf{H}_{2}$ \\
\hline $\mathbf{2 1 - 2 6} \mathbf{~ s}$ & 0.0043 & 0.1850 & 0.0011 \\
\hline $\mathbf{5 5 - 6 0} \mathbf{~ s}$ & 0.0035 & 0.1861 & 0.0010 \\
\hline $\mathbf{8 5 - 9 0} \mathbf{~ s}$ & 0.0035 & 0.1890 & 0.0012 \\
\hline IlL 6 & & & \\
\hline $\mathbf{2 2 - 2 7} \mathbf{~ s}$ & 0.0114 & 0.1917 & 0.0016 \\
\hline $\mathbf{4 6 - 5 1} \mathbf{~ s}$ & 0.0114 & 0.1882 & 0.0019 \\
\hline $\mathbf{8 5 - 9 0} \mathbf{~ s}$ & 0.0059 & 0.1918 & 0.0009 \\
\hline
\end{tabular}


The exit compositions do not fluctuate drastically in either case after the entry of the new blend, this may be attributed to the slow char gasification rates at the chosen temperature and pressure.

\subsubsection{Effect of Coal Blending in Entrained Flow Gasifier}

The effect of coal blending on exit syngas composition from an entrained flow gasifier was tested using a 1-D steady state model developed by Kasule et al. (2012) in Aspen Dynamics. Here three coal samples of Illinois No.6 were tested. Table 4.17 reports the analysis of coal samples used.

Table 4.17 : Coal Analyses of Illinois No.6 as received

\begin{tabular}{|c|c|c|c|}
\hline Component & Sample I & Sample II & Sample III \\
\hline Volatile Matter & 35.0 & 35.0 & 37.0 \\
\hline Fixed Carbon & 44.2 & 43.4 & 39.3 \\
\hline Moisture & 11.1 & 11.7 & 13.0 \\
\hline Ash & 9.7 & 9.9 & 10.7 \\
\hline Carbon & 63.8 & 62.0 & 59.8 \\
\hline Hydrogen & 4.5 & 4.0 & 4.1 \\
\hline Oxygen & 6.9 & 8.4 & 7.6 \\
\hline Nitrogen & 1.3 & 1.1 & 1.3 \\
\hline Sulfur & 2.5 & 3.7 & 3.3 \\
\hline
\end{tabular}

PCCL was run via $\mathrm{C} 3 \mathrm{M}$ to obtain the devolatilization and $100 \% \mathrm{CO}_{2} / \mathrm{H}_{2} \mathrm{O}$ char gasification reaction kinetics and product yields for these 3 samples. Only the devolatilization, char $\mathrm{CO}_{2} / \mathrm{H}_{2} \mathrm{O}$ gasification reaction kinetics and coal composition were changed in the model, all other reactions were unchanged. 
The exit syngas compositions for all three samples were compared against the reported experimental plant data (Kasule et al., 2012) to determine the effect of coal blending. Figure 4.45 shows the comparison of exit syn-gas composition for all 3 samples with the experimental plant data from TECO (Tampa Electric Company). It can be seen that the variations in $\mathrm{CO}$ and $\mathrm{CO}_{2}$ are much higher compared to those for $\mathrm{H}_{2}$.

Based on the Illinois no.6 samples tested, variations from $59.8 \%$ to $63.75 \%$ in fixed carbon lead to variations in mole fractions of $\mathrm{CO}$ from 0.4954 to 0.5232 and for $\mathrm{CO}_{2}$ from 0.1486 to 0.1644 .

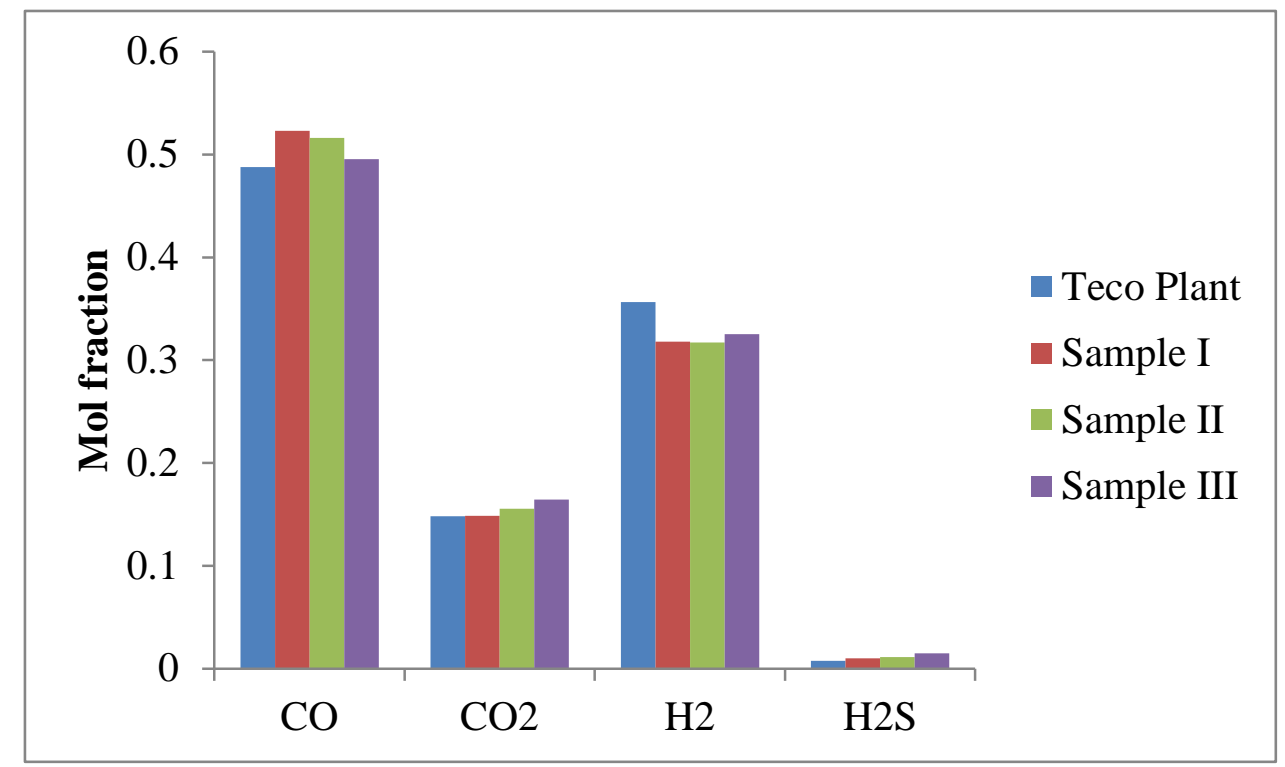

Figure 4.45 : Exit syngas composition, $\mathrm{CH} 4$ free and dry basis.

From Figure 4.45 it can be concluded that, coal blending can significantly affect the exit syngas composition for entrained flow gasifier. These studies help to quantify the range in uncertainties in syngas composition based on variations in coal feed. 


\section{Chapter 5 : Summary}

A graphical user interface entitled Carbonaceous Chemistry for Computational Modeling $(\mathrm{C} 3 \mathrm{M})$ that can access a variety of kinetic processes and reaction mechanisms typically found in coal gasification has been developed. It creates an interface between CFD software such as Multiphase Flow with Interphase Exchanges (MFIX) developed at NETL, ANSYS-FLUENT by ANSYS Inc., and BARRACUDA by CPFD Software with mathematical kinetic models such as PC Coal Lab (PCCL), Chemical Percolation Model for Coal Devolatilization (CPD), Solomon's Functional-Group, Depolymerization, Vaporization, Cross-linking (FGDVC) model, or experimental data generated at NETL.

Algorithms were written to create this interface in extracting the kinetic information from all models. In this study, char oxidation, char $\mathrm{CO}_{2} / \mathrm{H}_{2} \mathrm{O} / \mathrm{H}_{2}$ gasification, soot, and $\mathrm{CO}_{2} / \mathrm{H}_{2} \mathrm{O}$ / $\mathrm{H}_{2}$ gasification from PCCL, devolatilization and soot formation kinetics from CPD along with higher hydrocarbon combustion and toluene steam reforming reaction kinetics were implemented in C3M. The validity and compatibility of C3M kinetics were tested by implementing them in a (2-D) transport gasifier and in an industrial (1-D) GE Texaco gasifier model.

For the transport gasifier model, the trends of gas species matched very closely with studies shown in the past. For the 1-D entrained flow gasifier model predictions were improved somewhat, when devolatilizaiton, char $\mathrm{CO}_{2}$ and steam gasification reaction rates generated from PCCL via C3M were implemented in the model. This supported the claim of accuracy of coal gasification kinetics from $\mathrm{C} 3 \mathrm{M}$.

The coal/biomass derived soot literature review reported the lack of detailed soot formation kinetics at high pressure (1-20 atm) and high temperature $\left(1000-1600{ }^{\circ} \mathrm{C}\right)$ operating conditions. In addition, soot gasification and oxidation kinetics at these operating conditions have not been studied in the past. Hence experimental study to determine the soot formation, oxidation, and gasification reaction kinetics have been suggested.

Uncertainty quantification in chemically reacting multiphase flows plays a critical role in robust design and optimization of fossil fuel based energy production systems such as coal gasifiers. The current study addresses the uncertainties affecting the coal gasification kinetics. As part of this study, the effect of uncertainty in three key input parameters (heating rate, 
temperature and pressure) on coal devolatilization kinetics was investigated through nonintrusive parametric uncertainty propagation. Due to the low cost of the computational model, a direct Monte Carlo simulation with 10,000 samples was performed. The response variables were species mass fraction of devolatilization products such as $\mathrm{CO}, \mathrm{CO}_{2}, \mathrm{H}_{2}, \operatorname{tar}, \mathrm{H}_{2} \mathrm{O}, \mathrm{H}_{2} \mathrm{~S}$, and $\mathrm{CH}_{4}$.

The preliminary results demonstrated that tar and $\mathrm{CO}_{2}$ species appeared to be the least sensitive to the prescribed uncertainties in input parameters, whereas $\mathrm{H}_{2}$ appears to be the most sensitive. The correlation among the response variables was also investigated by computing the correlation matrix. The correlations demonstrate the findings of yield of devolatilization. The positive correlation trends between $\mathrm{CO}$ and $\mathrm{H}_{2}, \mathrm{CO}_{2}$ and $\mathrm{H}_{2} \mathrm{O}$ along with $\mathrm{CH}_{4}$ and $\mathrm{CO}_{2}$ supported findings in the literature. Negative correlation of $\mathrm{CO}$ and tar also supported findings of the past experiments.

For the first time, the response of exit gas composition to coal feed variations was quantified and tested in a (2-D) transport gasifier model. Coal samples of Pittsburgh No.8, Illinois No.6, Lignite and Powder River Basin (PRB) were obtained from the open literature. In all coal samples $\mathrm{CO}, \mathrm{CO}_{2}$ and $\mathrm{CH}_{4}$ show normal distributions, but the $\mathrm{H}_{2}$ distribution was skewed to the right. This study helped in predicting the bound in uncertainties of exit syngas composition based on coal feed variations for industrial scale gasifiers. Findings from this UQ study are in good agreement with the observations reported by various experiments in the literature.

The sensitivity of coal blending on exit gas composition was tested in transport and entrained flow gasifier conditions. It was found that in transport gasifier conditions blending did not affect the exit gas composition significantly. This could be the result of slow gasification rate at the tested operating condition. Blending showed appreciable variations in exit syngas for entrained flow gasifier conditions at high temperatures.

Finally, a sub-model approach was used to incorporate the effect of temperature on coal devolatilization kinetics. The new modified rate kinetics predicted the devolatilization rate in close agreement with observed data. Implementation of this sub-model in a 1-D entrained flow gasifier showed improvement in model prediction. This demonstration paves a path for UQ analysis of temperature variation on coal gasification reaction rate kinetics. Multiple sampling and new sub-model developments can improve this analysis further. 


\section{Chapter 6 : Future Work}

Future work in this research area should focus strongly on the development of new efficient gasifier models with fuel flexibility for coal/biomass/petcoke. The C3M kinetic data base can be modified for soot formation reaction, coal and biomass gasification, high pressure, high temperature water gas shift reaction, chemical looping and $\mathrm{CO}_{2}$ adsorbent reactions. $\mathrm{C} 3 \mathrm{M}$ validity should be verified using a fluidized bed reactor set up. The C3M connectivity to ASPEN should be developed for modeling purpose.

Uncertainty Quantification (UQ) analysis for CFD codes should continue to be developed. New surrogate models should be developed to test the effect of heating rate, temperature, pressure, char reactivity, particle diameter and coal composition on char gasification kinetics. 


\section{Chapter 7 : References}

1. Anthony, D. and Howard J., "Coal Devolatilization and Hydrogasification," AIChE J., 22, 1976, p. 625-656.

2. Aren, P. and Heek K., "Comparative Investigation of Coal Pyrolysis under Inert Gas and $\mathrm{H}_{2}$ at Low and High Heating Rates and Pressures up to 10 MPa," Fuel, 60, 1981, p.779787.

3. Ariyapadi S., Shires P., Bhargava M., Ebbern D., “KBR's Transport Gasifier (TRIG $\square$ ) - an Advanced Gasification Technology for SNG Production from Low-Rank Coals," Twentyfifth Annual International Pittsburgh Coal Conference September 29 - October 02, 2008, Pittsburgh, PA .

4. Bautista, J., Russel W. and Saville D., "Time-Resolved Pyrolysis Product Distribution of Softening Coals," Industrial and Engineering Chemistry. Fundamentals., 25, 1986, p. 536544 .

5. Baxter L., Mitchell R., Fletcher T., Hurt R., "Nitrogen release during coal combustion," Energy \& Fuels, 10,1996, p. 188-196.

6. Brown A., "Modeling soot in coal pulverized flame," a thesis submitted to Mechanical Engineering Department, Brigham Young University, 1997.

7. Brown Alexander and Fletcher Thomas, "Modeling soot derived from pulverized coal," Energy and Fuels, 12, 1998, p. 745-757.

8. Cao Y., Casenas B., Pan W., "Investigation of chemical looping combustion by solid fuels. 2. redox reaction kinetics and product characterization with coal, biomass, and solid waste as solid fuels and cuo as an oxygen carrier," Energy and Fuels, 20, 2006, p. 1845-1854.

9. Chaudhari K., "Development of Advanced Coal Devolatilization and Secondary Pyrolysis Kinetics Models for CFD (and process simulation) Codes," thesis document submitted to Department of Chemical Engineering West Virginia University, 2010.

10. Chaudhari K., Turton R., Guenther C., Shahnam M., Li T., VanEssendelft D., Nicoletti P., Gel A., "Recent developments in Carbonaceous Chemistry for Computational Modeling (C3M) with Uncertainty Quantifications (UQ)," 2012 International Pittsburgh Coal Conference, October 15-18, 2012, Pittsburgh. 
11. Chen G, Zhang Y, Zhu J, Cao Y, Pan W., "Coal and biomass partial gasification and soot properties in an atmospheric fluidized bed," Energy and Fuels , 25, 2011, p.1964-1969.

12. Chen L., Zeng C., Guo X., Mao Y., Zhang Y., Zhang X., Li W., Long Y., Zhu H., Eiteneer B., Zamansky V., "Gas evolution kinetics of two coal samples during rapid coal pyrolysis," Fuel Processing Technology, 91, 2010, p. 848-852.

13. Chen, J., "Effect of Secondary Reactions on Product Distribution and Nitrogen Evolution From Rapid Coal Pyrolysis,” Ph.D. dissertation, Stanford University, 1991.

14. Chkravarty T., Windig W., Hill G., Meuzelaar H., "Time-Resolved Pyrolysis Mass Spectrometry of Coal, a New Tool for Mechanistic and Kinetic Studied ," Energy \& Fuels, 2(4), 1988, p. 400-405.

15. Collot A., " Matching gasification technologies to coal properties," International Journal of Coal Geology 65, 2006, p. 191-212.

16. Dennis J., Muller C., Scott S., “ In situ gasification and CO2 separation using chemical looping with a Cu-based oxygen carrier: Performance with bituminous coals," Fuel ,89 , 2010,p. 2353-2364.

17. Diez LI, Cortes C, Campo A. "Modelling of pulverized coal boilers: review and validation of on-line simulation techniques." Applied Thermal Engineering 25, 2005, p.1516-33.

18. Fletcher T and Brown A., "Modeling soot derived from pulverized coal," Energy and Fuels, 12, 1998, p. 745-757.

19. Fletcher T, Ma J, Rigby J, Brown A , Webb B., " Soot in coal combustion system," Progress in Energy and Combustion Science, 23, 1997, p. 283-301.

20. Fletcher, T. H. and Hardesty D. H., "Compilation of Sandia Coal Devolatilization Data: Milestone Report,” Sandia Report No. SAND92-8209, available NTIS, 1992.

21. Fletcher. T and Shurtz R., " Pressurised coal pyrolysis and gasification at high initial heating rate," NETL Multiphase Flow Science Workshop, 2010.

22. Freihaut J. and Seery D., "Effects of pyrolysis conditions on coal devolatilization," Proceedings of the International Conference on Coal Science, IEA, 1985, p. 957.

23. Gasior S., Forney A., Field J., "Decaking of Coal in Free Fall," Publication Date: June 1, 1967 | doi: 10.1021/ba-1967-0069.ch001. 
24. Gel A, Garg R, Tong C, Shahnam M, Guenther C.," Applying Uncertainty Quantification to Multiphase Flow Computational Fluid Dynamics. Powder Technology," 2013, Available online 4 February 2013, ISSN 0032-5910, doi:10.1016/j.powtec.2013.01.045.)

25. Gel A., Pannala S, Sankaran R, Guenther C, Syamlal M, and O’Brien T, "Accelerating Clean Coal Gasifier Designs with Hybrid MPI/OpenMP High Performance Computing," Proceedings of the 21st International Conference on Parallel Computational Fluid Dynamics, Moffett Field, CA, May 18-22, 2009, p. 224-228.

26. Gibbins J. and Kandiyoti R, "The effect of variations in time-temperature history on product distribution from the pyrolysisof coal in a wire-mesh reactor," Fuel, 68, 1989 p.895-903.

27. Gomez A, Littman M, Glassman I, "Comparative study of soot formation on the centerline of axisymmetric laminar diffusion flames: fuels and temperature effects," Combustion and Flames, 70, 1987, p.225-241.

28. Griffin, T. P., Howard J. and Peters W., "Pressure and Temperature Effects in Bituminous Coal Pyrolysis: Experimental Observations and a Transient Lumped parameter Model," Fuel, 73, 1994, p.591-601.

29. Guenther C., Syamlal M., Longanbach J., and Smith P., "CFD modeling of a transport gasifier Part II," Proceedings of the $20^{\text {th }}$ Annual Pittsburgh Coal Conference, Pittsburgh, PA, September 15-19, 2003.

30. Guenther C., Shahnam M., Syamlal M, Longanbach J, Cicero D., and Smith P., "CFD modeling of a transport gasifier," Proceedings of the $19^{\text {th }}$ Annual Pittsburgh Coal Conference, Pittsburgh, PA, September 23-27, 2002.

31. Guffey F., and Bland A., "Thermal pretreatment of low-ranked coal for control of mercury emissions," Fuel Processing Technology, 85, 2004, p. 521- 531.

32. Guo Z., Zhang L., Wang P., Liu H., Jia J., Fu S., et al., "Study of kinetics of coal pyrolysis at different heating rates to produce hydrogen," Fuel Processing Technology, 2012, http://dx.doi.org/10.1016/j.fuproc.2012.08.021.

33. Haryanto and Hong, "Modeling and simulation of an oxy-fuel combustion boiler system with flue gas recirculation"Computers and Chemical Engineering, 35 , 2011, p.25-40. 
34. Hayashi J., Takahashi H., Doi S., Kumagal H., Chiba T., Yoshida Y. and Tsutsumi A., "Reactions in Brown Coal Pyrolysis Responsible for Heating Rate Effect on Tar Yield," Energy \& Fuels, 14, 2000, p. 400-408.

35. Haynes, B. S. and G. P. Prado, "Soot and PAH Formation in Coal Combustion," Pulverized Coal Combustion: Pollutant Formation and Control, EPA/600/8-90/049, PB90-229253, 1980 .

36. Helbel J., Mojtahedi W., Lyyranen J., Jokineimi J., Kauppinein E., “ Trace element participating during coal gasification," Fuel, 75(8), 1996, p. 931-939.

37. Howard J. B., Richter H., "Formation of polycyclic aromatic hydrocarbons and their growth to Soot a review of chemical reaction pathways", Progress in Energy and Combustion Science, 26, 2000, p. 565-608.

38. Hurt R. and Lang T., "Char Combustion Reactivities for a Suite of Diverse Solid Fuels and Char-Forming Organic Model Compounds," Proceeding of the Combustion Institute., 29, 2002, p.423-431.

39. Ismail A. F., "The effect of process conditions on coal pyrolysis and char reactivity," thesis submitted to department of chemical engineering, Rice University, 1993.

40. Joo H, Gulder O, "Soot formation and temperature field structure in co-flow laminar methane-air diffusion flames at pressures from 10 to 60 atm," Proceedings of the Combustion Institute, 32, 2009, p.769-775.

41. Joshi R., "Destruction and Removal Efficiency of Toluene in a Steam Reforming atmosphere," thesis submitted to Department of Chemical Engineering at West Virginia University, 1998.

42. Kasule J., Turton R. Bhattacharya D., Ziteny S., “ Mathematical modeling of a single stage downward firing entrained flow gasifier," Industrial and Energy Chemistry Research, 51, 2012, p. 6429- 6440.

43. Khan, M. and Jenkins R., "Thermoplastic Properties of Coal at Elevated Pressures :1. Evaluation of a High-pressure Microdilatometer," Fuel, 63, 1984, p.109.

44. Kleijnen J., Sanchez S., Lucas T.,Cioppa T., “A User's Guide to the Brave New World of Designing Simulation Experiments," INFORMS Journal on Computing, 17(3), Summer 2005, pp. 263-289. 
45. Kozinski J. and Saade R., "Effect of biomass burning on the formation of soot particles and heavy hydrocarbons. An experimental study," Fuel, 77 (4), 1998, p.225-237.

46. Kronholm D and Howard J.," Analysis of soot surface growth pathways using published plug-flow reactor data with new particle size distribution measurements and published premixed flame data," Proceedings of the Combustion Institute, 28, 2000, p. 2555-2561.

47. Lautenberger C, John L. de Ris, Nicholas A. Dembsey, Jonathan R. Barnett, Howard R. Baum, "A simplified model for soot formation and oxidation in CFD simulation of nonpremixed hydrocarbon flames," Fire Safety Journal, 40, 2005, p.141-176.

48. Lee C., Scaroni A., and Jenkins R., "Effect of pressure on the devolatilization and swelling behavior of a softening coal during rapid heating," Fuel,70, 1991 p. 957-965.

49. Li T., Chaudhari K., Turton R., Nicoletti P., Guenther C., Shahnam M., VanEssendelft D., Gel A., " Effect of coal devolatilization kinetics in CFD simulation of a transport gasifier," IGSA Vancouver October 15-19, 2012

50. Liu G, Yang P, Peng Z, Wang G, Zhang W., "Comparative study of the quality of some coals from the Zibo coal field," Energy B, 2003, p.969-78.

51. Liu S, Wang C, Zhang S, Liang J, Chen F, Zhao F, "Formation and distribution of polycyclic aromatic hydrocarbons (PAHs) derived from coal seam combustion: A case study of the Ulanqab lignite from Inner Mongolia, northern China," International Journal of Coal Geology, 90-91, 2012, p.126-134.

52. Ma J., "Soot formation during coal pyrolysis," a thesis submitted to Department of Chemical Engineering, Brigham Young University, 1996.

53. Ma J., Fletcher T, Webb B., "Conversion of coal tar to soot during coal pyrolysis in a postflame environment," Twenty-Sixth Symposium (International) on Combustion, The Combustion Institute, 1996, pp. 3161-3167.

54. Manton, N., Cor J., Mul G., Eckstrom D., Malhotra R. and Niksa S., "Impact of Pressure Variations on Coal Devolatilization Products. 2. Detailed Product Distributions from 1.0 MPa," Energy \& Fuels, 18, 2004, p.520-530.

55. Matsuoka K., Ma , Akiho H., Zhang, Tomita A., Fletcher T., Niksa S., "High-Pressure Coal Pyrolysis in a Drop Tube Furnace” Energy \& Fuels, 17, 2003, p. 984-990. 
56. McLean, W. J., D. R. Hardesty and J. H. Pohl, "Direct Observations of Devolatilizing Pulverized Coal Particles in a Combustion Environment," Eighteenth Symposium (International) on Combustion, 1981, p.1239.

57. Mohammad S., Chen J., Fitzgerald J., Robinson R., Gasem K., "Adsorption of Pure Carbon Dioxide on Wet Argonne Coals at 328.2 K and Pressures up to $13.8 \mathrm{MPa}$, Energy \& Fuels, 23,2009, p. 1107-1117.

58. Morf P., Hasler P., Nussbaumer T., "Mechanism and kinetics of homogeneous secondary reactions of tar from continuous pyrolysis of wood chips," Fuel, 81, 2002, p. 843-853.

59. Muhammad F. Irfan, Muhammad R. Usman, K. Kusakabe, "Coal gasification in $\mathrm{CO}_{2}$ atmosphere and its kinetics since 1948: A brief review," Energy, 36(1), January 2011, p.12-40.

60. Naik Chitralkumar and Niksa Stephen, $5^{\text {th }}$ US combustion meeting, paper no.G23, March 25-28, 2006.

61. Nelson P., Smith I., Tyler R. and Mackies J., "Pyrolysis of Coal at High Temperature," Energy \& Fuels, 2, 1988, p.391-400.

62. Nenniger, R. D., Aerosol Produced from Coal Pyrolysis, D.Sc. dissertation, MIT (1986).

63. Niksa S., Liu Giu, Hurt R. H., "Coal conversion submodels for designs applications at elevated pressures.Part I.devolatilization and char oxidation," Progress in Energy and Combustion Science, 29, 2003, p. 425-477.

64. Niksa S., PCCL version 4.1 User Guide and Tutorial, 2008.

65. Oh, M., Peters W. and Howard J., "An Experimental and Modeling Study of Softening Coal Pyrolysis," AIChE J., 35, 1989 p.775.

66. Peralta D, Paterson NP, Dugwell DR, Kandiyoti R. Coal blend performance during pulverized fuel combustion: estimation of relative reactivities by a bomb calorimeter test. Fuel 80, 2001, p.1623-34.

67. Pollack Martin, "Integration of a detailed Pyrolysis Submodel for use in CFD Simulations of Coal Gasification and Combustion," thesis document submitted to Department of Mechanical, Process and Energy Engineering Chair of Numerical Thermo-Fluid Dynamics,2012.

68. Popa T., Fan M., Argyle M., Slimane R., Bell D., Towler B., " Catalytic gasification of powder river basin," Fuel, 103, 2013, p. 161-173. 
69. Prabu V.,Jayanti S., " Underground coal gasification based solid oxy fuel cell systems," Applied Energy, 94, 2012, p. 406-414.

70. Qin K., Lin W., Jensen P., Jensen A., "High-temperature entrained flow gasification of biomass," Fuel, 93, 2012, p.589-600.

71. Rigby J, Ma J., Webb, T. H. Fletcher, “Transformations of Coal-Derived Soot at Elevated Temperature," Energy and Fuels, 15, 2001, p. 52-59.

72. Riley M. and Grandhi R.,"Quantification of model-form and predictive uncertainty for multi-physics simulation," Computers and Structures, 89, 2011, p. 1206-1213.

73. Roberts, D. G., D. J. Harris and T. F. Wall, "On the Effects of High Pressure and Heating Rate during Coal Pyrolysis on Char Gasification Reactivity," Energy \& Fuels, 17, 2003, p. 887-895.

74. Robinson P., Luyben W., "Simple Dynamic Gasifier Model That Runs in Aspen Dynamics," Industrial and Energy Chemistry Research., 47, 2008,p. 7784-7792.

75. Roy, C. J.; Oberkampf, W. L.,“ A comprehensive framework for verification, validation, and uncertainty quantification in scientific computing," Computational Methods in Applied Mathematics 200(25-28), 2011, p.2131-2144.

76. Ruiz M., R. Guzm'an de Villoria, A. Millera, M.U. Alzueta, R. Bilbao, "Influence of the temperature on the properties of the soot formed from $\mathrm{C}_{2} \mathrm{H}_{2}$ pyrolysis," Chemical Engineering Journal ,127, 2007, p. 1-9

77. Saltelli A., "Sensitivity analysis in practice: a guide to assessing scientific models", John Wiley \& Sons, Inc, 2004.

78. Saltelli, A.; Ratto, M.; Andres, T.; Campolongo, F.; Cariboni, J.; Gatelli, D.; Saisana, M.; Tarantola, S. Global Sensitivity Analysis: The Primer: Wiley-Interscience; 2008

79. Sanchez, S. M., S. J. Mason, R. R. Hill, L. Moench, O. Rose, "Better than a petaflop: The power of efficient experimental design," In Proceedings of the 2008 WinterSimulation Conference, 2008a, p.73-84.

80. Serio M, Solomon P, Yu Z., Bassilakis R., "Kinetics of Volatile Product Evolution in Coal Pyrolysis Experiment and Theory," Energy \& Fuels, 1, 1987, p.138-152.

81. Sheth A., Sastry C., Yeboah Y., Xu Y., Agarwal P., "Catalytic gasification of coal using eutectic salts: reaction kinetics for hydrogasification using binary and ternary eutectic catalysts," Fuel ,83 ,2004, p. 557-572. 
82. Shurtz Randy C., Kolbein K. Kolste, and Thomas H. Fletcher, "Coal Swelling Model for High Heating Rate Pyrolysis Applications,” Energy and Fuels, 25, 2011, p.2163-2173.

83. Shurtz, R. C. and Fletcher T., "A Coal Swelling Model for Pressurized High Particle Heating Rate Pyrolysis Applications," Energy \& Fuels, 26, 2012, p.3612-3627.

84. Slezak A., Kulhman J., Shadle L., Spenil J., Shi S., "CFD simulation of entrained-flow coal gasification: Coal particle density/size fraction effects," Powder Technology 203, 2010 p 98-108.

85. Solomon, P.R, Hamblen, D.G., Carangelo, R.M., Serio, M.A., and Deshpande, G.V. "A Genaral Model of Coal Devolatilization," Energy and Fuels, 2, 1988, pp. 405-422.

86. Solomon, P.R. "The Evolution of Pollutants During the Rapid Devolatilization of Coal," Rep. R76-952588-2, United Technologies Research Center, East Hartford, 1977.

87. Solomon, P.R. and Hamblen, D.G., in Chemistry of Coal Conversion, (R.H. Schlosberg, Editor), Plenum Press, NY, Chapter 5, p. 1211985.

88. Solomon, P.R., Serio, M.A., and Suuberg, E.M. "Coal pyrolysis: experiments, kinetic rates and mechanisms," Progress in Energy and Combustion Science, 18, 1992, p.133-220.

89. Stanmore B., Brilhac, Gilot P., "The oxidation of soot: a review of experiments, mechanisms and models," Carbon, 39, 2001, p. 2247-2268.

90. Sun, C., Xiong Y., Liu Q. and Zhang M., "Thermogravimetric Study of the Pyrolysis of Two Chinese Coals Under Pressure," Fuel, 76, 1997, p.639-644.

91. Syamlal M., and Bissett, L.A., "METC Gasifier Advanced Simulation (MGAS) Model," Technical Note, NTIS report No. DOE/METC-92/4108 (DE92001111), 1992.

92. Syamlal M., Guenther C, Gel A, Pannala S, "High performance Computing: Clean Coal Gasifier Designs Using Hybrid Parallelization,” Fluidization XIII, Gyeong-ju, Korea, May 16-20, 2009.

93. Syamlal, M. MFIX documentation: Numerical techniques. Department of Energy, National Energy Technology Laboratory, Morgantown 1998.

94. Syamlal, M.; Rogers, W.; O'Brien, T.J. MFIX documentation: Theory guide. U.S. Department of Energy, Morgantown Energy Technology Center, Morgantown, 1993.

95. Tamhankar S., Sears T., Wen Y., "Coal pyrolysis at high pressure and temperature,” Fuel, 63(9), 1984, p. 1230-1235. 
96. Tang Y., Jenden P., Nigrini A., Teerman S., “ Modeling early methane generation in coal,”, Energy and Fuels, 10, 1996 , p.659-671.

97. Tong C, Gel A. Applying Uncertainty Quantification to Multiphase Flow CFDs. in NETL Multiphase Flow Science Workshop. 2011: Pittsburgh, PA.

98. Van Heek K H., “ Advanced Coal conversion by Pyrolysis and Hydrogenation”, Third Flame Research Course, IFRF, sept 1990, Netherlands.

99. Veranth J, Fletcher T., Pershing D, Sarofim A, "Measurement of soot and char in pulverized coal fly ash," Fuel, 79 , 2000, p.1067-1075

100. Wang H.,"Formation of nascent soot and other condensed-phase materials in flames," Proceedings of the Combustion Institute, 33, 2011, p.41-67.

101. Wang P., Hedges S., Casleton K., Guenther C., "Thermal behavior of coal and biomass pyrolysis in inert and oxidizing gaseous environment," International Journal of Clean Coal and Energy, 1(3) 2012, pp. 35-42. doi: 10.4236/ijcce.2012.13004.

102. Weiland N., Means N., Morreale B., "Product distributions from isothermal co-pyrolysis of coal and biomass," Fuel, 94, 2012, p. 563-570.

103. Weiland N., Means N., Soncini R., "Co- Pyrolysis of coal and biomass in transport gasifier conditions," NETL Multiphase Flow Workshop, April 2011.

104. Wen, C.Y., Chen, H., and Onozaki, M., "User's Manual for Computer Simulation and Design of the Moving Bed Coal Gasifier,” DOE/MC/16474-1390(1982), NTIS/DE83009533.

105. Westbrooke and Dryer, "Simplified mechanisms for the oxidations of hydrocarbon fuels in flames," Combustion Science Technology, 27, 1981, p.31-43.

106. Wijayanta A, Md. Saiful Alam, Koichi Nakaso, Jun Fukai, Masakata Shimizu, "Optimized combustion of biomass volatiles by varying $\mathrm{O} 2$ and $\mathrm{CO} 2$ levels: A numerical simulation using a highly detailed soot formation reaction mechanism," Bioresource Technology, 110 , 2012, p. 645-651.

107. Wijayanta A, Md. Saiful Alam, Koichi Nakaso, Jun Fukai , "Numerical investigation on combustion of coal volatiles under various $\mathrm{O}_{2} / \mathrm{CO}_{2}$ mixtures using a detailed mechanism with soot formation," Fuel, 93, 2012, p. 670-676. 
108. Wiktorsson L. and Wanzl W., "Kinetic parameters for coal pyrolysis at low and high heating rates-a comparison of data from different laboratory equipment," Fuel, 79, 2000, p. 701-716.

109. Wojtowicz. M, “The fg-dvc coal pyrolysis model user's guide," Version 8.2.2, 2005.

110. Wornat, M. J., A. F. Sarofim and J. P. Longwell, "Changes in the Degree of Substitution of Polycyclic Aromatic Compounds from Pyrolysis of a High-Volatile Bituminous Coal," Energy and Fuels, 1, 1987, p.437.

111. Yan S, Jiang, Y, Marsh N, Eddings G, Sarofim A, Pugmire R., "Study of the evolution of soot from various fuels," Energy and Fuels, 19,2005, p. 1804-1811.

112. Yang J., Cai N., Li Z., " Reduction in iron oxide as a n oxygen carrier by coal pyrolysis and steam char gasification intermediate products," Energy and Fuels, 21, 2007, p. 3360-3368.

113. Yoshida H. and Kataoka, "Feedstock effects in coal flash pyrolysis," Industrial Engineering Chemical. Resource, 29, 1990, p. 2154-2159.

114. Yun Y. and Lee G., "Effects of Pressure in Coal Pyrolysis Observed by High Pressure TGA,” Korean Z Chemical Engineering., 16(6), 1999, p.798-803.

115. Yu L, Lu J, Zhang X, Zhang S, “ Numerical simulaiton of the bubbling fluidized bed coal gasification by kinetic theory of granular flow," Fuel, 86, 2007, p.722-734.

116. Zeng D , Shengteng Hu, Alan N. Sayre, Hamid Sarv, "On the rank-dependence of coal tar secondary reactions," Proceedings of the Combustion Institute, 33, 2011, p. 1707-1714.

117. Zeng D. and Fletcher T.,"Effects of Pressure on Coal Pyrolysis and Char Morphology," Energy \& Fuels, 19, 2005, p.1828-1838.

118. Zhang H., "Nitrogen evolution and soot formation during secondary coal pyrolysis," a thesis submitted to Department of Chemical Engineering, Brigham Young University, 2001.

119. Zhang Yindi, Zhou Huaichun, Xie Minglian, Fang Qingyan and Wei Yan, "Modeling of Soot Formation in Gas Burner Using Reduced Chemical Kinetics Coupled with CFD Code," Chinese Journal of Chemical Engineering, 18(6), 2010 ,p. 967-978.

120. Zhong M., Zhang Z., Zhou Q., Yue J., Gao S., Xu G., “Continuous high-temperature fluidized bed pyrolysis of coal in complex atmospheres: Product distribution and pyrolysis gas," Journal of Analytical and Applied Pyrolysis, 97 2012,p. 123-129. 
121. Zhong Z, Ooi JY, Rotter JM. "Predicting the handlability of a coal blend from measurements on the source coals," Fuel, 84 ,2005, p.2267-74.

122. Zitney S. and Guenther C., "Gasification CFD Modeling for Advanced Power Plant Simulations," DOE/ NETL -IR-2005-211. 


\section{Appendix I: Soot Formation Experimental Matrix}

Based on the literature review on soot formation, an experimental matrix was proposed. Tables I.1- I.3 show the sample runs, coal types, and operating conditions for the experiments to be performed. Dr. Ping Wang will carry out these experiments at NETL site Pittsburgh,Pa.

In this experimental procedure, soot formation in inert (helium), steam, and oxygen environment will be studied. Firstly coal/biomass will be pyrolysed and tar will be collected, then the tar will be cracked in high temperature tubular furnace and product of this reaction will be monitored using mass spectroscopy (MS). The experimental data collected in terms of weight loss will be used to fit an appropriate kinetic model to derive soot formation kinetics. Also chemical composition of tar will be characterized to determine the structural changes in tar during secondary cracking.

Table I.1. HS TGA-MS system

\section{Temperature and fuels}

Non-isothermal method from $100{ }^{\circ} \mathrm{C}$ to $1600^{\circ} \mathrm{C}$ in $\mathrm{He}$ [ref]

\begin{tabular}{|l|l|l|l|}
\hline \multicolumn{1}{|c|}{ Fuels } & \multicolumn{3}{c|}{ Heating rates $\left({ }^{\circ} \mathrm{C} / \mathrm{s}\right)$} \\
\cline { 2 - 4 } & 5 & 50 & 95 \\
\hline PRB coal & & & \\
\hline Illinois No 6 & & & \\
\hline Pittsburgh No.8 & & & \\
\hline Wood & & & \\
\hline Blends & & & \\
\hline
\end{tabular}


Table I.2: Isothermal method at heating rate $95^{\circ} \mathrm{C} / \mathrm{s}$ in $\mathrm{He}$

\begin{tabular}{|l|l|l|l|l|l|}
\hline \multicolumn{1}{|c|}{ Fuels } & \multicolumn{3}{|c|}{ Temperature $\left({ }^{\circ} \mathrm{C}\right)$} & 1400 & 1550 \\
\cline { 2 - 6 } & $\begin{array}{l}\mathrm{T}_{\text {max. }} \text { from } \\
\text { non- } \\
\text { isothermal } \\
\text { study }\end{array}$ & 1000 & 1200 & & \\
\hline PRB coal & & & & & \\
\hline Illinois No.6 & & & & & \\
\hline Pittsburgh No.8 & & & & & \\
\hline Wood & & & & & \\
\hline Blends & & & & & \\
\hline
\end{tabular}

\section{Gas environment in $\mathrm{H}_{2} \mathrm{O}$ and $\mathrm{O}_{2}$}

Isothermal method

Heating rate $95^{\circ} \mathrm{C} / \mathrm{s}$

Fuels

Maximum temperature of soot formation based on isothermal study 
Table I.3: HS TGA-tube furnace-MS system

\section{Temperature and fuels}

Isothermal method at heating rate $95^{\circ} \mathrm{C} / \mathrm{s}$

\begin{tabular}{|c|c|c|c|c|}
\hline \multirow[t]{2}{*}{ Fuels } & \multicolumn{4}{|c|}{ Primary pyrolysis temperature in $\mathrm{HS}-\mathrm{TGA}\left({ }^{\circ} \mathrm{C}\right)$} \\
\hline & 400 & 500 & 600 & $T_{\max }$ \\
\hline \multicolumn{5}{|l|}{ PRB coal } \\
\hline \multicolumn{5}{|l|}{ Illinois No.6 } \\
\hline \multicolumn{5}{|l|}{ Pittsburgh No.8 } \\
\hline \multicolumn{5}{|l|}{ Wood } \\
\hline \multicolumn{5}{|l|}{ Blends } \\
\hline \multirow[t]{2}{*}{ Fuels } & \multicolumn{4}{|c|}{ Primary pyrolysis temperature in tube reactor $\left({ }^{\circ} \mathrm{C}\right)$} \\
\hline & 1000 & 1200 & 1400 & 1550 \\
\hline \multicolumn{5}{|l|}{ PRB coal } \\
\hline \multicolumn{5}{|l|}{ Illinois No.6 } \\
\hline \multicolumn{5}{|l|}{ Pittsburgh No.8 } \\
\hline \multicolumn{5}{|l|}{ Wood } \\
\hline Blends & & & & \\
\hline
\end{tabular}

\section{Gas environment in $\mathrm{H}_{2} \mathrm{O}$ and $\mathrm{O}_{2}$}

Isothermal method

Heating rate $95^{\circ} \mathrm{C} / \mathrm{s}$

Fuels

\section{Characteristic process and products}

Feed gas: flow rate by mass flow meter

Temperature in HS TGA and tube furnace: thermocouple

Fuels: proximate, ultimate analysis, ash analysis

Char, and soot: ultimate analysis, SEM, reactivity in $\mathrm{O}_{2}$ and $\mathrm{H}_{2} \mathrm{O}$, ash analysis

Tar: ultimate analysis, chemical composition by GC-MS

Gas: chemical composition by MS 


\section{Appendix II: Co-pyrolysis kinetics for low heating rates}

The objectives of this study were to investigate thermal behavior of coal and biomass blends in inert gas environment at low heating rates and to develop a simplified kinetic model using model fitting techniques based on TGA experimental data.

The proximate and ultimate analysis of the coal and wood samples are listed in Table III.1.

Table II. 1: Proximate and Ultimate analysis of Powder River Basin (PRB) Sub-bituminous Coal and Wood

\begin{tabular}{|c|c|c|c|c|c|c|}
\hline & \multicolumn{6}{|c|}{ Proximate analy sis ( $\%$ dry basis) } \\
\hline & \multicolumn{2}{|c|}{ Volatile matter } & \multicolumn{2}{|c|}{ Fixed carbon } & \multicolumn{2}{|c|}{ Ash } \\
\hline PRB coal & \multicolumn{2}{|c|}{46.2} & \multicolumn{2}{|c|}{47.2} & \multicolumn{2}{|c|}{6.6} \\
\hline \multirow[t]{3}{*}{ Wood } & & & & & & .6 \\
\hline & \multicolumn{6}{|c|}{ Ultimate analy sis (\% dry basis) } \\
\hline & $\mathrm{C}$ & $\mathrm{H}$ & $\mathrm{N}$ & $\mathrm{S}$ & ash & $\mathrm{O}$ (diff) \\
\hline PRB coal & 66.21 & 4.2 & 1.21 & 0.48 & 6.6 & 21.3 \\
\hline Wood & 48.84 & 5.78 & 0.38 & 0.15 & 0.6 & 44.21 \\
\hline
\end{tabular}

Thermal behavior and co-pyrolysis kinetics of the coal, wood, and blends having 10 and $20 \mathrm{wt} \%$ of wood were studied using a thermogravimetric analyzer (TGA) (Perkin Elmer Pyris 1) by Dr.Wang at NETL site Pittsburgh, PA. The samples $(\sim 10 \mathrm{mg})$ were first heated up to $100^{\circ} \mathrm{C}$ and held for 20min to dry them. A non-isothermal method with low heating rates of 10, 20, and $50^{\circ} \mathrm{C} / \mathrm{min}$, respectively, was selected. The samples were heated up to $1000^{\circ} \mathrm{C}$ and held for $5-20$ min in dry $\mathrm{N}_{2}$ with a total flow rate of approximately $125 \mathrm{ml} / \mathrm{min}$. The experiments were performed in triplicate (quadruplicate or more for coal and wood blends) to assess their reproducibility. 


\section{Kinetic Data Fitting:}

Figure II.1 shows weight loss of $20 \%$ wood in blend at heating rates of 10, 20 and $50^{\circ} \mathrm{C} / \mathrm{min}$ during co-pyrolysis. As heating rates increase, weight loss rates increase but $T_{\max }$ and weight fraction remaining are not significantly different. This absence of clear trends is likely due to the high heterogeneity of wood and coal, and the relatively small differences between heating rates.

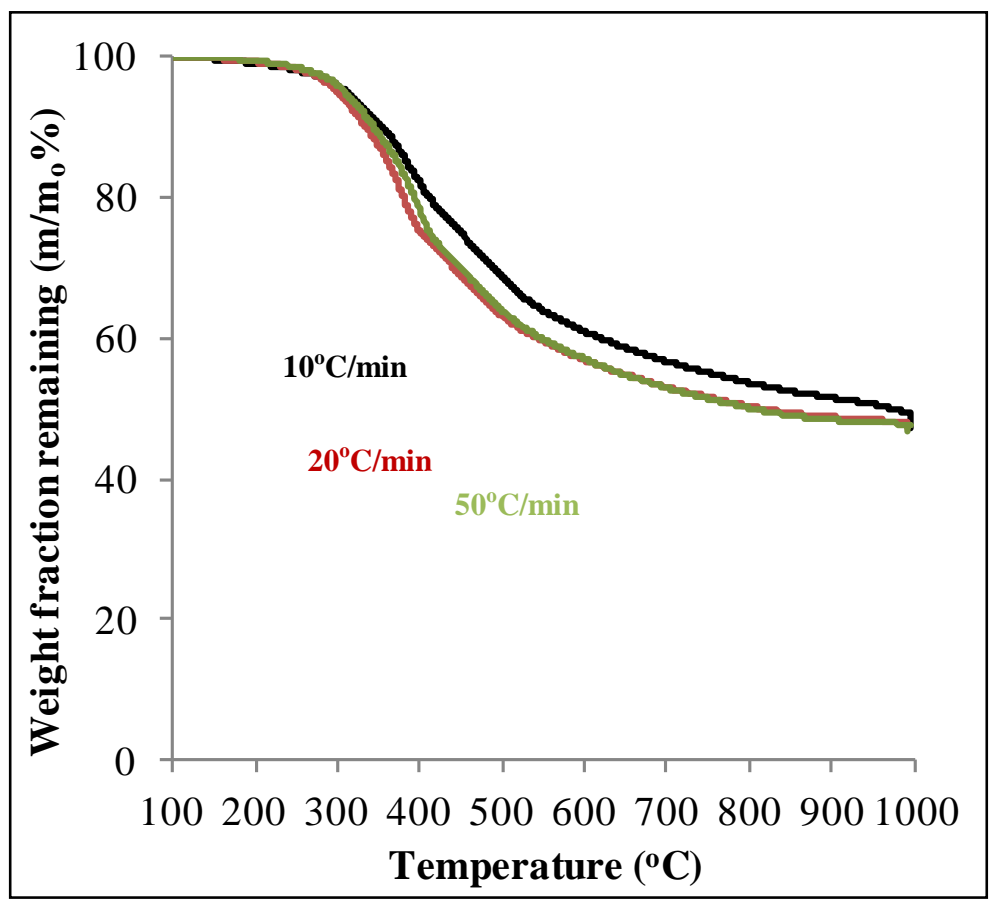

Figure II.1: Weight loss of $20 \%$ wood in blend vs. temperature at heating rates of 10, 20 and $50^{\circ} \mathrm{C} / \mathrm{min}$ during co-pyrolysis. 


\section{Modeling fitting and Kinetic Parameters of coal, wood and their blends pyrolysis.}

Single first order reaction (SFOR) kinetic model and competitive two step reaction (CTSR) model that two single first order reactions (SFOR) take place simultaneously are selected to fit the experimental data. The two kinetic models can be described as following equations of SFOR (II.1) and CTSR (II.2).

$$
\frac{d V(t)}{d t}=A \exp \left(\frac{-E}{R T}\right)\left(V^{\infty}-V(t)\right)
$$

where $V(t)$ is the instantaneous volatiles yield; $V^{\infty}$ is the ultimate volatiles yield (obtained from experiment weight loss data); $A$ is a pseudo-frequency factor, and $E$ is an apparent activation energy; $R$ is the universal gas constant and $T$ is the sample temperature in $\mathrm{K}$.

$$
\frac{d V(t)}{d t}=\left\{\alpha A_{1} \exp \left(\frac{-E_{1}}{R T}\right)+(1-\alpha) A_{2} \exp \left(\frac{-E_{2}}{R T}\right)\right\}\left(V^{\infty}-V(t)\right)
$$

where $A_{1}$ and $A_{2}$ are frequency factors for reaction $R_{1}$ and $R_{2}$ respectively; $E_{1}$ and $E_{2}$ are apparent activation energy for reaction $R_{I}$ and $R_{2}$ respectively; and $\alpha$ is the fraction of volatile matter participating into reactions.

SFOR kinetic model was fitted to the experimental data using Generalized Reduced Gradient (GRG) nonlinear solver that minimizes the error between the predicted and experimental weight loss with respect to $A$ and $E$. For CTSR, it was assumed that $E_{l}=E$ from the SFOR, and $E_{2}=E+5000 \mathrm{cal} / \mathrm{mol}$ and $\alpha=0.5$. Then the GRG was used to obtain $A_{1}$ and $A_{2}$. Figure 2 shows the experimental and predicted weight losses by SFOR and CTSR models with respect to temperature for $10 \%$ wood in blend. The kinetic parameters for the blend from CTSR are listed below at 10,20 and $50^{\circ} \mathrm{C} / \mathrm{min}$ heating rates. SFOR model failed to replicate the experimental weight loss exactly in all tests of the coal and wood blends. CSTR model fits well with experiment weight loss data.

\section{Kinetic Parameters for Char and Wood Pyrolysis:}

Table II.2- Table II.5 show kinetic parameters obtained for $10 \%$ and $20 \%$ wood and PRB coal mixture along with $100 \%$ wood and $100 \%$ coal respectively at 10 and $50 \mathrm{~K} / \mathrm{s}$ heating rate. 


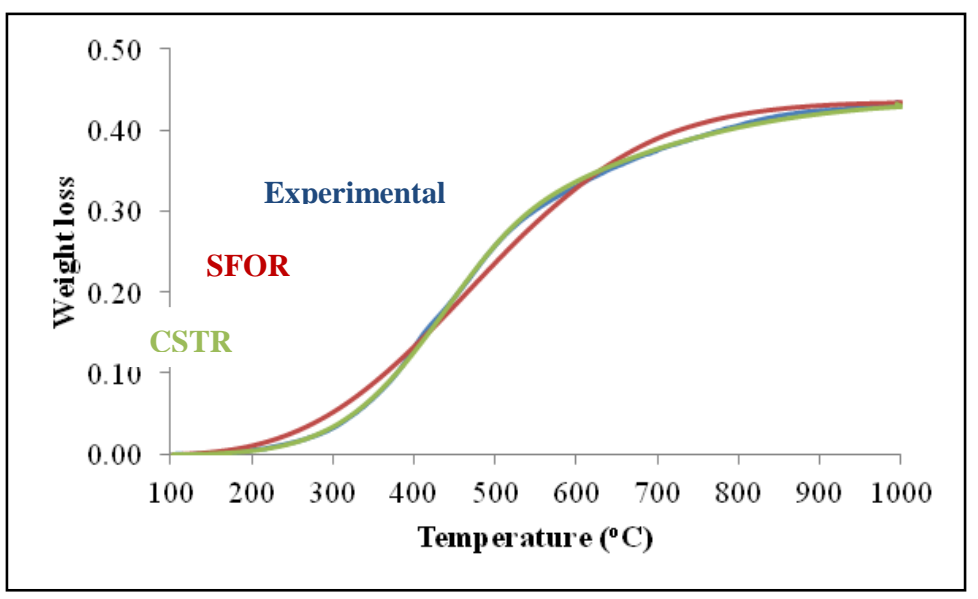

Figure II.2: Weight loss vs temperature of experimental and predicted by single first order reaction (SFOR) and two step reactions (CSTR) models for 10\% wood in blends at the heating rate of $50^{\circ} \mathrm{C} / \mathrm{min}$.

Table II.2: $10 \%$ wood and coal mixture

\begin{tabular}{|c|c|c|c|c|c|c|}
\hline Name & $\begin{array}{c}\text { Weight } \\
(\mathbf{g m})\end{array}$ & $\begin{array}{c}\boldsymbol{A}_{\boldsymbol{1}} \\
(\mathbf{1} / \mathbf{m i n})\end{array}$ & $\begin{array}{c}\boldsymbol{E}_{\boldsymbol{l}} \\
(\mathbf{c a l} / \mathbf{m o l})\end{array}$ & $\begin{array}{c}\boldsymbol{A}_{\mathbf{2}} \\
(\mathbf{1} / \mathbf{m i n})\end{array}$ & $\begin{array}{c}\boldsymbol{E}_{2} \\
(\mathbf{c a l} / \mathbf{m o l})\end{array}$ & $\boldsymbol{\alpha}$ \\
\hline $\mathbf{1 0 ~ K / s}$ & & & & & & \\
\hline Mean & 9.931 & 0.53163 & 4547.98 & 55.29 & 9548.06 & 0.5 \\
\hline Std Dev & 0.27303 & 0.15475 & 407.45 & 17.4999 & 407.317 & 0.0 \\
\hline $\mathbf{5 0 ~ K / s ~}$ & & & & & & \\
\hline Mean & 10.4385 & 0.9075 & $4,232.83$ & 87.04 & $7,982.83$ & 0.5 \\
\hline Std Dev & 0.7681 & 0.4373 & 763.36 & 41.13 & $1,469.89$ & 0.0 \\
\hline
\end{tabular}

Table II.3: $20 \%$ wood and coal mixture

\begin{tabular}{|c|c|c|c|c|c|c|}
\hline Name & $\begin{array}{c}\text { Weight } \\
(\mathbf{g m})\end{array}$ & $\begin{array}{c}\boldsymbol{A}_{\boldsymbol{I}} \\
(\mathbf{1} / \mathbf{m i n})\end{array}$ & $\begin{array}{c}\boldsymbol{E}_{\boldsymbol{1}} \\
(\mathbf{c a l} / \mathbf{m o l})\end{array}$ & $\begin{array}{c}\boldsymbol{A}_{\mathbf{2}} \\
(\mathbf{1} / \mathbf{m i n})\end{array}$ & $\begin{array}{c}\boldsymbol{E}_{\mathbf{2}} \\
(\mathbf{c a l} / \mathbf{m o l})\end{array}$ & $\boldsymbol{\alpha}$ \\
\hline $\mathbf{1 0 ~ K / s}$ & & & & & & \\
\hline Mean & 9.951 & 0.3845 & $3,651.32$ & 50.06 & $8,651.32$ & 0.5 \\
\hline Std Dev & 0.05469 & 0.11672 & 394.05 & 16.6247 & 394.05 & 0.0 \\
\hline $\mathbf{5 0 ~ K / s}$ & & & & & & \\
\hline Mean & 11.054 & 1.3515 & $4,613.73$ & 178.81 & $9,613.73$ & 0.5 \\
\hline Std Dev & 0.4519 & 0.4146 & 480.02 & 47.16 & 480.02 & 0.0 \\
\hline
\end{tabular}


Table III.4 : $100 \%$ wood

\begin{tabular}{|c|c|r|r|r|r|c|}
\hline Name & $\begin{array}{c}\text { Weight } \\
(\mathbf{g m})\end{array}$ & $\begin{array}{c}\boldsymbol{A}_{\boldsymbol{I}} \\
(\mathbf{1} / \mathbf{m i n})\end{array}$ & $\begin{array}{c}\boldsymbol{E}_{\boldsymbol{I}} \\
(\mathbf{c a l} / \mathbf{m o l})\end{array}$ & $\begin{array}{c}\boldsymbol{A}_{\mathbf{2}} \\
(\mathbf{1} / \mathbf{m i n})\end{array}$ & $\begin{array}{c}\boldsymbol{E}_{2} \\
(\mathbf{c a l} / \mathbf{m o l})\end{array}$ & $\boldsymbol{\alpha}$ \\
\hline $\mathbf{1 0 ~ K / s}$ & & & & & & \\
\hline Mean & 10.608 & $4,347.36$ & $13,016.68$ & $66,485.64$ & $18,016.64$ & 0.5 \\
\hline Std Dev & 0.2062 & $1,395.53$ & 456.32 & 22829.60 & 456.31 & 0.0 \\
\hline $\mathbf{5 0} \mathbf{~ K / s}$ & & & & & & \\
\hline Mean & 10.591 & $1,964.82$ & $12,404.79$ & $298,236.25$ & $17,404.79$ & 0.5 \\
\hline Std Dev & 0.4488 & $1,044.23$ & 809.38 & $145,960.89$ & 809.38 & 0.0 \\
\hline
\end{tabular}

Table III.5: $100 \%$ coal

\begin{tabular}{|c|c|c|c|c|c|c|}
\hline Name & $\begin{array}{c}\text { Weight } \\
(\mathbf{g m})\end{array}$ & $\begin{array}{c}\boldsymbol{A}_{\boldsymbol{I}} \\
(\mathbf{1} / \mathbf{m i n})\end{array}$ & $\begin{array}{c}\boldsymbol{E}_{\boldsymbol{1}} \\
(\mathbf{c a l} / \mathbf{m o l})\end{array}$ & $\begin{array}{c}\boldsymbol{A}_{\mathbf{2}} \\
(\mathbf{1} / \mathbf{m i n})\end{array}$ & $\begin{array}{c}\boldsymbol{E}_{2} \\
(\mathbf{c a l} / \mathbf{m o l})\end{array}$ & $\boldsymbol{\alpha}$ \\
\hline $\mathbf{1 0 ~ K / s}$ & & & & & & \\
\hline Mean & 11.246 & 2.597 & $5,380.41$ & 11.78 & $10,380.41$ & 0.5 \\
\hline Std Dev & 0.6045 & 0.1618 & 126.12 & 0.7834 & 126.12 & 0.0 \\
\hline $\mathbf{5 0 ~ K / s ~}$ & & & & & & \\
\hline Mean & 10.501 & 1.3188 & $5,101.49$ & 101.06 & $10,101.49$ & 0.5 \\
\hline Std Dev & 0.6542 & 0.4157 & 418.78 & 31.23 & 418.78 & 0.0 \\
\hline
\end{tabular}

